\title{
Multitasking mesoporous nanomaterials for biorefinery applications
}

by

\section{Kapil Kandel}

\author{
A dissertation submitted to the graduate faculty \\ in partial fulfillment of the requirements for the degree of \\ DOCTOR OF PHILOSOPHY \\ Major: Chemistry \\ Program of Study Committee: \\ Brian G. Trewyn, Co-Major Professor \\ Young-Jin Lee, Co-Major Professor \\ Marek Pruski \\ Ning Fang \\ Kan Wang \\ Wenyu Huang
}

Iowa State University

Ames, Iowa

2013

Copyright (C) Kapil Kandel, 2013. All rights reserved. 
TABLE OF CONTENTS

Page

ACKNOWLEDGEMENTS ......................................................................

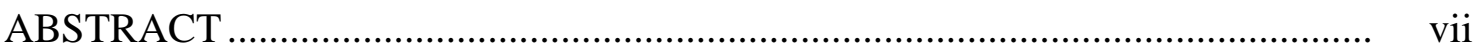

CHAPTER 1. GENERAL INTRODUCTION ................................................ 1

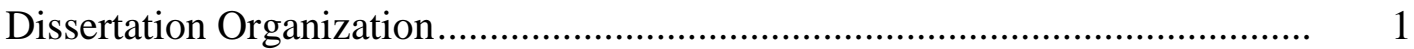

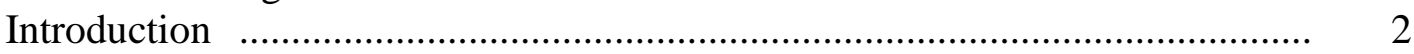

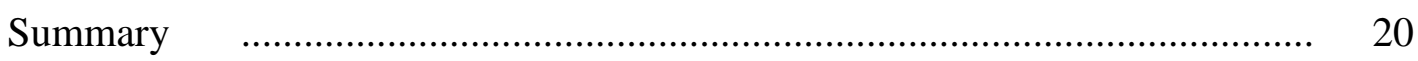

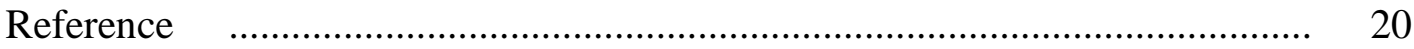

CHAPTER 2. SUBSTRATE INHIBITION IN THE HETEROGENEOUS CATALYZED ALDOL CONDENSATION: A MECHANISTIC STUDY OF SUPPORTED ORGANOCATALYSTS ….................................................... 29

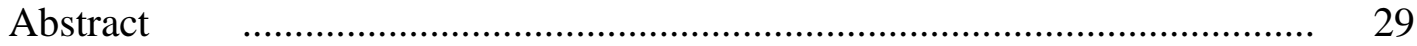

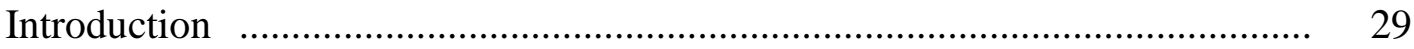

Materials and Methods ........................................................................... 31

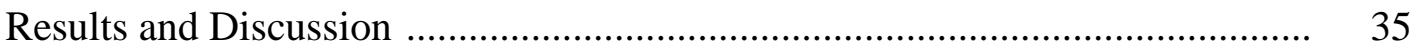

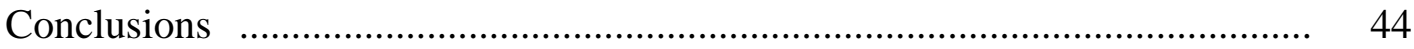

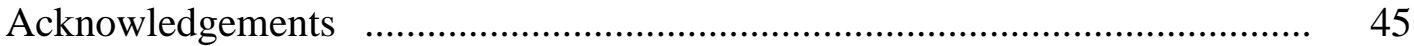

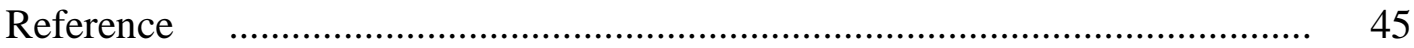

Supporting Information ..................................................................... 50

CHAPTER 3. SOLVENT-INDUCED REVERSAL OF ACTIVITIES BETWEEN TWO CLOSELY RELATED HETEROGENEOUS CATALYSTS IN THE ALDOL

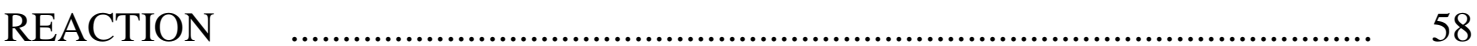

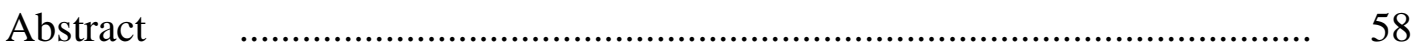

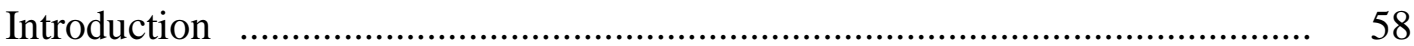

Materials and Methods .............................................................................. 61

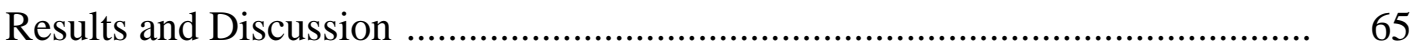

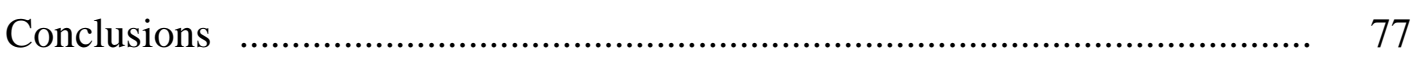

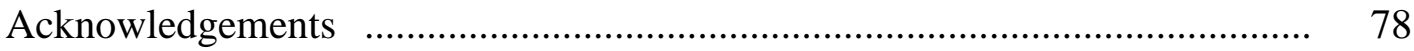

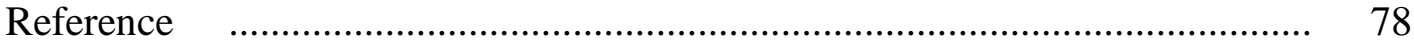

Supporting Information .................................................................. 82 
CHAPTER 4. SUPPORTED HYBRID ENZYME-ORGANOCATALYSTS FOR UPGRADING THE CARBON CONTENT OF ALCOHOLS

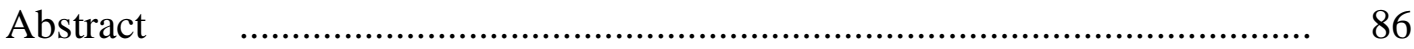

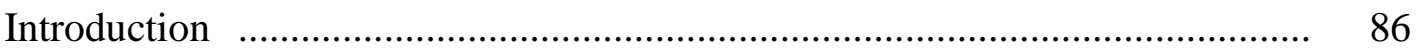

Materials and Methods ......................................................................... 88

Results and Discussion ......................................................................... 91

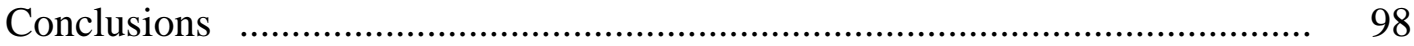

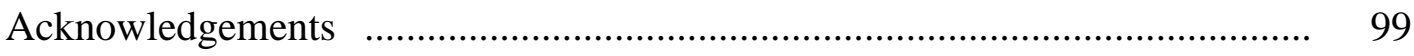

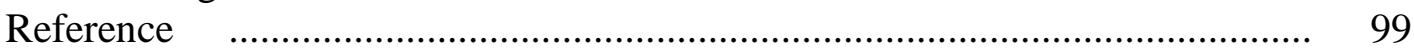

CHAPTER 5. TOWARDS MICROALGAE BIOREFINERY: UTILIZING MAGNETIC MESOPOROUS SILICA NANOTECHNOLOGY FOR HARVESTING, EXTRACTION, AND SELECTIVE SEQUESTRATION OF VALUE-ADDED

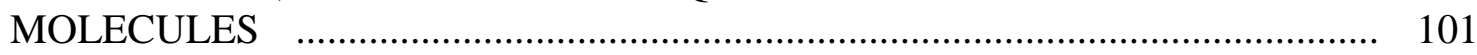

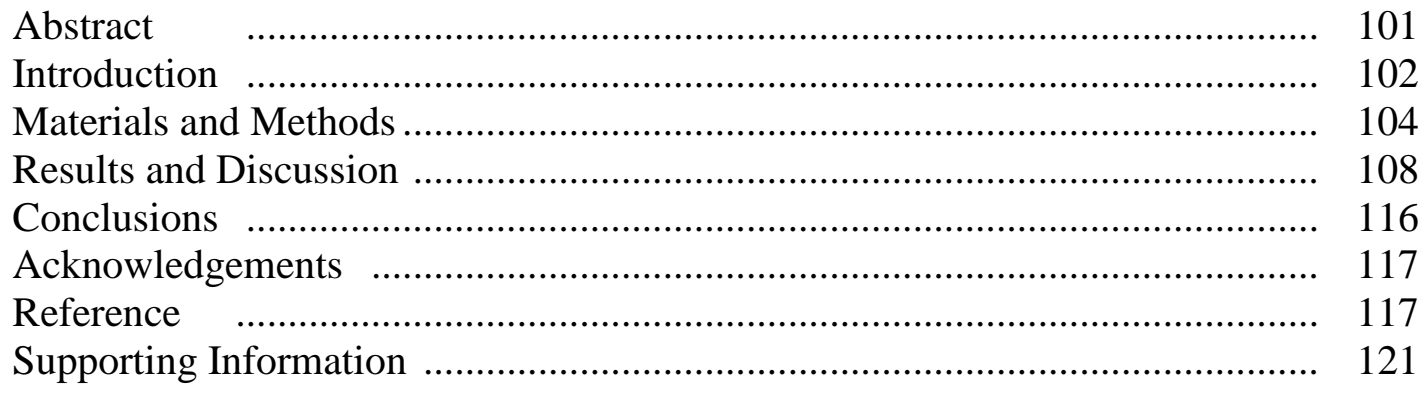

CHAPTER 6. SORBENT-ASSISTED CATALYSIS: AN INTEGRATED APPROACH FOR THE REFINERY OF RENEWABLE FEEDSTOCKS .............................. 127

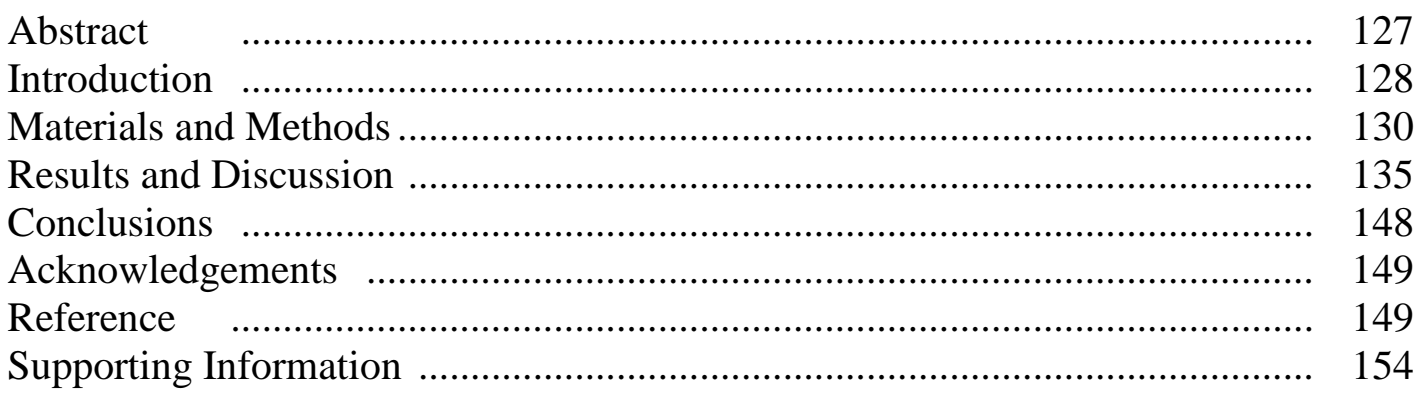

CHAPTER 7. IRON NANOPARTICLES SUPPORTED ON MESOPOROUS SILICA FOR THE HYDRODEOXYGENATION OF MICROALGAE OIL TO GREEN DIESEL

Abstract

Introduction

Materials and Methods 
Results and Discussion ..................................................................... 161

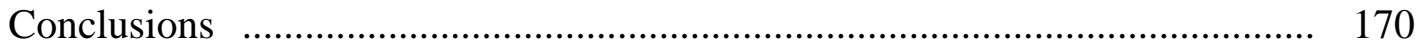

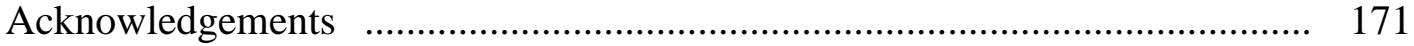

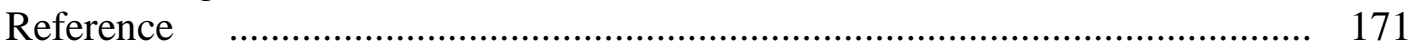

CHAPTER 8. PENTAFLUOROPHENYL FUNCTIONALIZED MESOPOROUS SILICA NANOMATERIALS FOR SELECTIVE ADSORPTION OF $\alpha-$

TOCOPHEROL IN BIOREFINERY ............................................................ 177

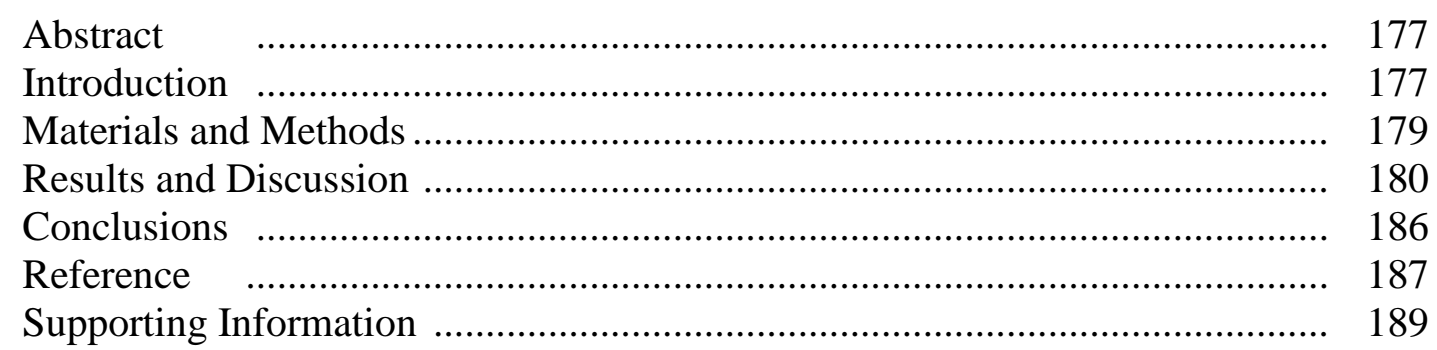

CHAPTER 9. GENERAL CONCLUSIONS …...................................................... 193 


\section{ACKNOWLEDGEMENTS}

I would like to express my sincere gratitude to my mentors, colleagues, friends and families to whom I am truly indebted for their support and guidance during these years.

To Professor Victor Shang-Yi Lin, for giving me an opportunity to work in his research group, for his guidance and encouragement both in class and in laboratory, for inspiring me to think positively and creatively and for teaching me the value of conveying a proper message both in scientific and non-scientific fields.

To Dr. Brian Trewyn, for his support, guidance and encouragement since the earlier days of my graduate career, for giving me the freedom to work on multiple ideas in the laboratory and for all his help outside the laboratory.

To Dr. Igor I. Slowing, for his guidance and counseling from the start of my graduate career, for giving me the freedom in research, for teaching me to make rational analysis, for sharing his time and experience to improve my writing and presentation skills, for all the invaluable scientific discussions and for all his help outside the laboratory.

To my co-major professor and collaborator Dr. Young-Jin Lee and my POS Committee members, Dr. Marek Pruski, Dr. Ning Fang, Dr. Kan Wang, and Dr. Wenyu Huang, for their valuable time and support.

To my group members and collaborators, especially Dr. Justin Valenstein, Forrest Melcher and Stacey Althaus, for their help and invaluable discussions. 
To the U.S Department of Energy, Ames Laboratory and National Alliance for Advanced Biofuels and Bioproducts for the funding of the projects in this dissertation.

To my parents, Chandra Kandel and Sharada Kandel, for all their efforts to help me achieve my goal.

To my sisters, Kanchan and Kabita and their families, for their continuous love and support.

Last, but not the least, to my dearest friend Roshani Malla for her support and encouragement during these years in Ames, Iowa. Thank you for teaching me the small yet the most important things in life that I tend to overlook. 


\begin{abstract}
Mesoporous silica nanoparticles (MSNs) have attracted great interest for last two decades due to their unique and advantageous structural properties, such as high surface area, pore volume, stable mesostructure, tunable pore size and controllable particle morphology. The robust silica framework provides sites for organic modifications, making MSNs ideal platforms for adsorbents and supported organocatalysts. In addition, the pores of MSNs provide cavities/ channels for incorporation of metal and metal oxide nanoparticle catalysts. These supported metal nanoparticle catalysts benefit from confined local environments to enhance their activity and selectivity for various reactions.
\end{abstract}

Biomass is considered as a sustainable feedstock with potential to replace diminishing fossil fuels for the production of biofuels. Among several strategies, one of the promising methods of biofuel production from biomass is to reduce the oxygen content of the feedstock in order to improve the energy density. This can be achieved by creating $\mathrm{C}-\mathrm{C}$ bonds between biomass derived intermediates to increase the molecular weight of the final hydrocarbon molecules. In this context, pore size and organic functionality of MSNs are varied to obtain the ideal catalyst for a C-C bond forming reaction: the aldol condensation. The mechanistic aspects of this reaction in supported heterogeneous catalysts are explored. The modification of supported organocatalyst and the effect of solvent on the reaction are rationalized. The significance of two functional surfaces of MSNs is exploited by enzyme immobilization on the external surface and 
organo catalyst functionalization on the internal surface. Using this bifunctional catalyst, the tandem conversion of small chain alcohols into longer chain hydrocarbon molecules is demonstrated.

The ability to incorporate metal and metal oxide nanoparticles in the pores and subsequent functionalization led to develop organic modified magnetic MSNs (OMMSNs) for applications in microalgae biorefinery. Two different integrated biorefinery systems are highlighted. (i) OM-MSNs are used to harvest microalgae and selectively sequester free fatty acids (FFAs). (ii) OM-MSNs are shown to selectively sequester FFAs and convert them into diesel-range liquid hydrocarbon fuels. A similar MSN supported metal nanoparticle catalyst is demonstrated to transform FFAs into green diesel with even greater activity and selectivity.

The incorporation of a different organic functional group into MSN provides a selective adsorbent for separation and purification of $\alpha$-tocopherol from microalgae oil. The functional group with electron deficient aromatic rings demonstrated high sequestration capacity and selectivity of $\alpha$-tocopherol. 


\section{CHAPTER 1. GENERAL INTRODUCTION}

\section{Dissertation Organization}

This dissertation presents the research on the development of mesoporous silica based nanotechnology for application in separations and catalysis in biorefinery and biofuel production.

The dissertation is organized in 9 chapters. Chapter 1 is a literature review focusing on the development and properties of mesoporous silica nanomaterials (MSN). In the context of biorefinery, pathways for production of biofuels from biomass are discussed. Recent development of MSNs for applications in separations and catalysis are included. Chapters 2 to 8 are journal articles, in which Chapter 2, 3 and 4 have already been published/ accepted. Chapter 5 and 6 have been submitted for publications and Chapter 7 and 8 are manuscripts ready for submission. Chapter 9 is a general conclusion summarizing the significance of the research done in this dissertation.

Aldol condensation is one of the most important $\mathrm{C}-\mathrm{C}$ bond forming reactions in the production of liquid alkanes from carbohydrate-based biomass. Chapter 2 reports the investigations on the mechanistic causes of the poor catalytic activity of primary aminefunctionalized MSNs toward the aldol condensation. The modification of catalyst support and functional groups are illustrated in order to improve the activity. Chapter 3 elucidates the effect of solvents on the activity of same reaction using two closely related amine-functionalized MSN catalysts. Chapter 4 discusses the synthesis of hybrid enzyme organocatalyst on MSN supports for sequential oxidation-aldol reactions in order to upgrade smaller alcohols to higher molecular weight hydrocarbons. 
Chapter 5, 6 and 7 highlights the applications of mesoporous silica based adsorbents and catalysts for biofuel production from microalgae. Two types of integrated biorefinery are demonstrated. Chapter 5 involves integration of microalgae harvesting and selective sequestration of free fatty acids (FFAs) and Chapter 6 includes selective sequestration of FFAs and sequential conversion to liquid hydrocarbon fuels. Chapter 7 presents the development of more economic and efficient catalysts to transform triglycerides and FFAs to diesel range alkanes.

Chapter 8 reports the design and development of mesoporous silica based adsorbent for selective separation and purification of $\alpha$-tocopherol from microalgae oil. The dissertation is finished in Chapter 9 with a general conclusion and an outline of the directions that this research is expected to take in future.

\section{Introduction}

According to International Union of Pure and Applied Chemistry (IUPAC), porous solids are classified in to three main categories depending on their pore size: below $2 \mathrm{~nm}$ are microporous, between $2 \mathrm{~nm}$ to $50 \mathrm{~nm}$ are mesoporous and those above $50 \mathrm{~nm}$ are macroporous materials. ${ }^{1}$

Zeolites are perfect inorganic crystals on the molecular scale and are typically composed of a framework of tetrahedral $\mathrm{TO}_{4}(\mathrm{~T}=\mathrm{Si}, \mathrm{Al}$, etc. $)$ units linked with each other by sharing oxygen atoms. $^{2}$ Due to their high degree of crystallinity, perfectly controllable microporous structure, presence of charge compensation cations in the pores and tailorable hydrophobic/hydrophilic inorganic framework, these materials are used in the industry for drying, ion-exchange, catalysis, adsorption and separation. ${ }^{3-9}$ However, the applications of zeolites are often restricted to small 
molecules because of their sub-nanometer scale pore size. To overcome this limitation, researchers have been focusing for last two decades on the development of mesoporous materials. This chapter will focus on mesoporous materials, particularly on mesoporous silica nanomaterials.

\section{Synthesis of Mesoporous Silica Nanomaterials}

Understanding the significance of supramolecular assembly (micellar aggregates) as templating agents, scientists at Mobil corporation reported in 1992 a series of ordered mesoporous materials (M41S) with pore sizes ranging from $1.5-10 \mathrm{~nm} .{ }^{10-11}$ Depending on the mesostructure, the M41S family includes MCM-41(2D hexagonal phase), MCM-48 (cubic phase) and MCM-50 (lamellar phase) (Figure 1). The formations of these nanomaterials are based on the condensation of silica precursors such as tetramethylorthosilicate or tetraethylorthosilicate in the presence of structure-directing agents (quaternary ammonium cationic surfactants) under basic aqueous conditions.
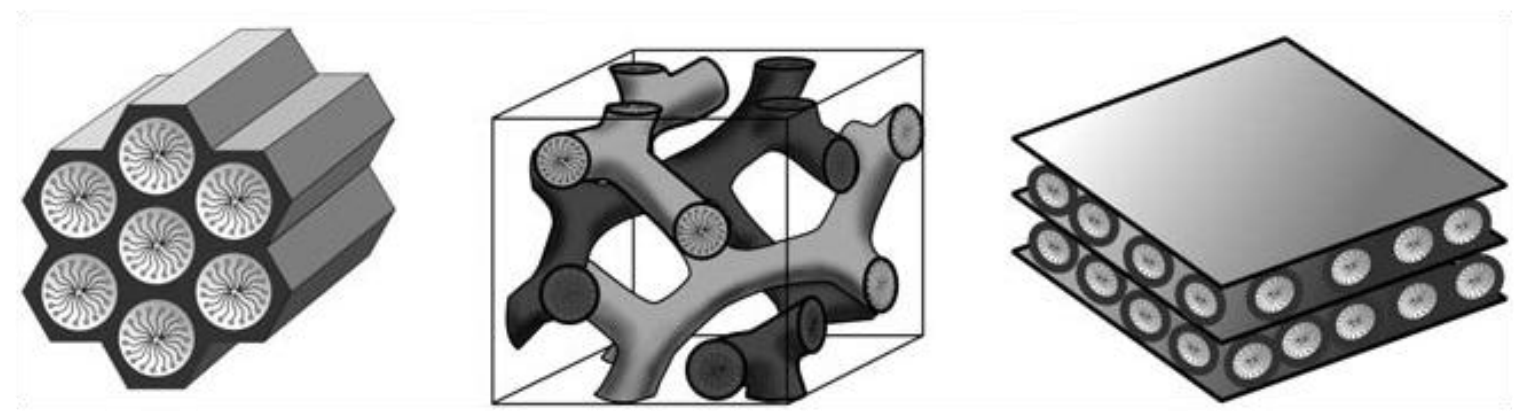

Figure 1. The structures of the materials in the M41S family. ${ }^{12}$

Initially, two possible pathways were proposed to explain the formation of these nanomaterials (Figure 2). ${ }^{11}$ Pathway (a) suggested a liquid crystal templating mechanism (LCT) in which surfactant molecules self-assemble into micellar liquid crystal structures and serve as 
organic templates for the assembly of anionic silicate species to balance the cationic surface of the micelles. In this mechanism, the silicate condensation is not the dominant factor for the formation of the structure. However, the liquid crystal structures are highly sensitive to solution's environment such as ionic strength, counter ion polarizability, charge, surfactant concentration, temperature and additives. One of the most important additives during mesoporous silica synthesis is silicate precursors. The silicate anions are polymeric species that can undergo condensation, while controlling over the liquid crystalline phase. Pathway (b) suggests the cooperative ordering of the surfactant micelles into a specific mesophase as a result of the addition of silicate precursor. ${ }^{11,13}$

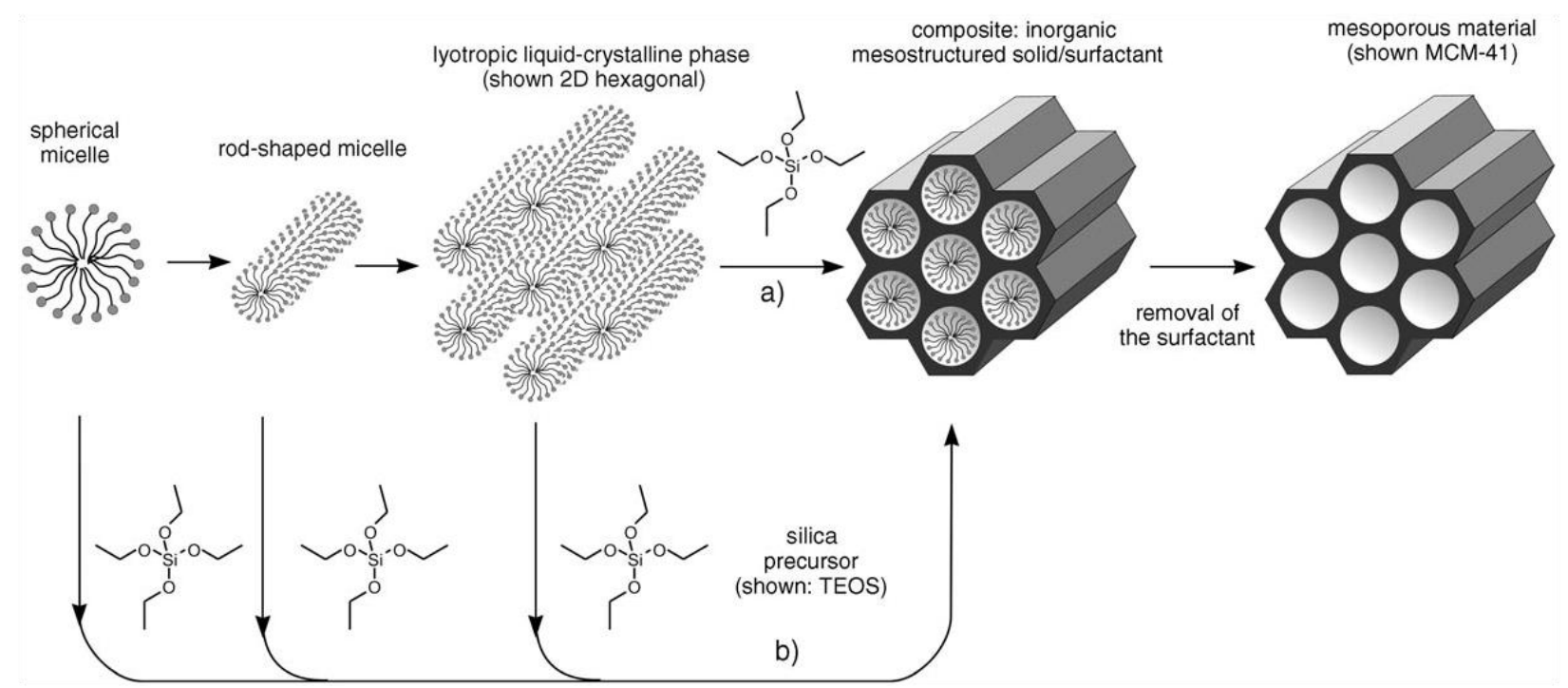

Figure 2. Pathways for mesoporous silica materials formation: a) liquid crystal templating and b) cooperative assembly. ${ }^{12}$

The most accepted, cooperative assembly, mechanism was later elucidated by Stucky and co-workers in 1994. ${ }^{14-15}$ This mechanism is based on the columbic force interaction between silicate anions with the positively charged head groups of cationic micellar surfactant. The silica condensation reduces the negative charge density in the solution, leading to the rearrangement of 
surfactant to maintain the overall charge density to neutral. ${ }^{16}$ This matching of charge density at the silica/surfactant interface is responsible for the assembly process i.e. transition from lamellar to hexagonal phase and was explained by considering the packing property (g) of the surfactant molecules. ${ }^{17-19}$

Packing parameter $(\mathrm{g})=\mathrm{v} / \mathrm{l}_{\mathrm{c}} \mathrm{a}_{\mathrm{o}}$

where, $\mathrm{v}$ is the hydrophobic chain volume, $1_{\mathrm{c}}$ is the chain length of fully extended hydrophobic tail and $a_{0}$ is the effective optimal surface of polar head group. With increase of $g$, the curvature of the micelle decreases and for silica system, the phase transition proceeds along the sequence: cubic $\longrightarrow$ hexagonal $\longrightarrow$ bicontinuous cubic $\longrightarrow$ lamellar. ${ }^{20-21}$

To increase the dimension of pore structure, in 1998 Stucky and co-workers reported the successful synthesis of well-ordered hexagonal mesoporous silica nanomaterial (SBA-15) with tunable large uniform pore size (up to $30 \mathrm{~nm}$ ) using a triblock co-polymer poly(ethylene oxide-

propylene oxide) (PEO-PPO-PEO) as the structure-directing agent. ${ }^{22-23}$ The mesopores of SBA15 are connected by numerous disordered micropores, which arise from the partial occlusion of PEO chains of triblock co-polymer into the silica matrix. ${ }^{24}$ In contrast to MCM-41 material, the wall of SBA-15 is thicker and ranges around 4-6 nm making this material more stable. It is believed that hydrogen bonding at silica/surfactant interface is responsible for the formation of SBA-15 materials (Figure 1). ${ }^{15,19}$

\subsection{Surface Functionalization of Mesoporous Silica Nanomaterials (MSNs)}

The silica framework of MSNs is amorphous and possesses a large number of surface silanol groups. Surface functionalization of these materials with organic groups occurs most commonly by silylation on free silanol groups via covalent bonding. Incorporation of organic 
groups either on the wall of silica or within the channels is one of the important ways of modifying the physical and chemical properties of mesoporous silica nanomaterials. In this respect, the large surface area of MSNs is categorized into two surfaces: internal surface within the mesopores occupying $90 \%$ of the total surface area and external surface area outside the mesopores. This interesting feature of MSNs suggests that it is possible to selectively functionalize either surface with different functional groups. In general, there are two wellestablished methods for surface functionalization of MSNs: (i) co-condensation and (ii) postsynthesis grafting method.

Co-condensation method is a direct synthesis route to prepare organic functionalized MSNs, based on the co-condensation of silica precursor (TMOS or TEOS) and organoalkoxysilane groups ( $\left.\mathrm{R}^{\prime} \mathrm{O}\right)_{3} \mathrm{SiR}$ (Figure 3). ${ }^{25-26}$ In surfactant templated synthesis, the hydrophobic regions of organoalkoxysilane groups orient themselves to intercalate into the hydrophobic part of the surfactant micelles, resulting in the projection of the functionalities into the pores. ${ }^{27}$ It has been shown that the direct co-condensation method of functionalization provides a uniform distribution of organic groups throughout the channels without blocking the pores. ${ }^{12,26-27}$ This method also provides better control over the amount of organic groups in the structure. However, due to the addition of organoalkoxysilane groups, the materials obtained after the synthesis can sometimes result in change of mesoscopic order and morphology. In addition, the choice of the organoalkoxysilane groups is limited by the synthesis condition. Factors such as solubility, hydrolysis and condensation rate of organoalkoxysilane groups need to be considered in order to avoid phase separation issues. 


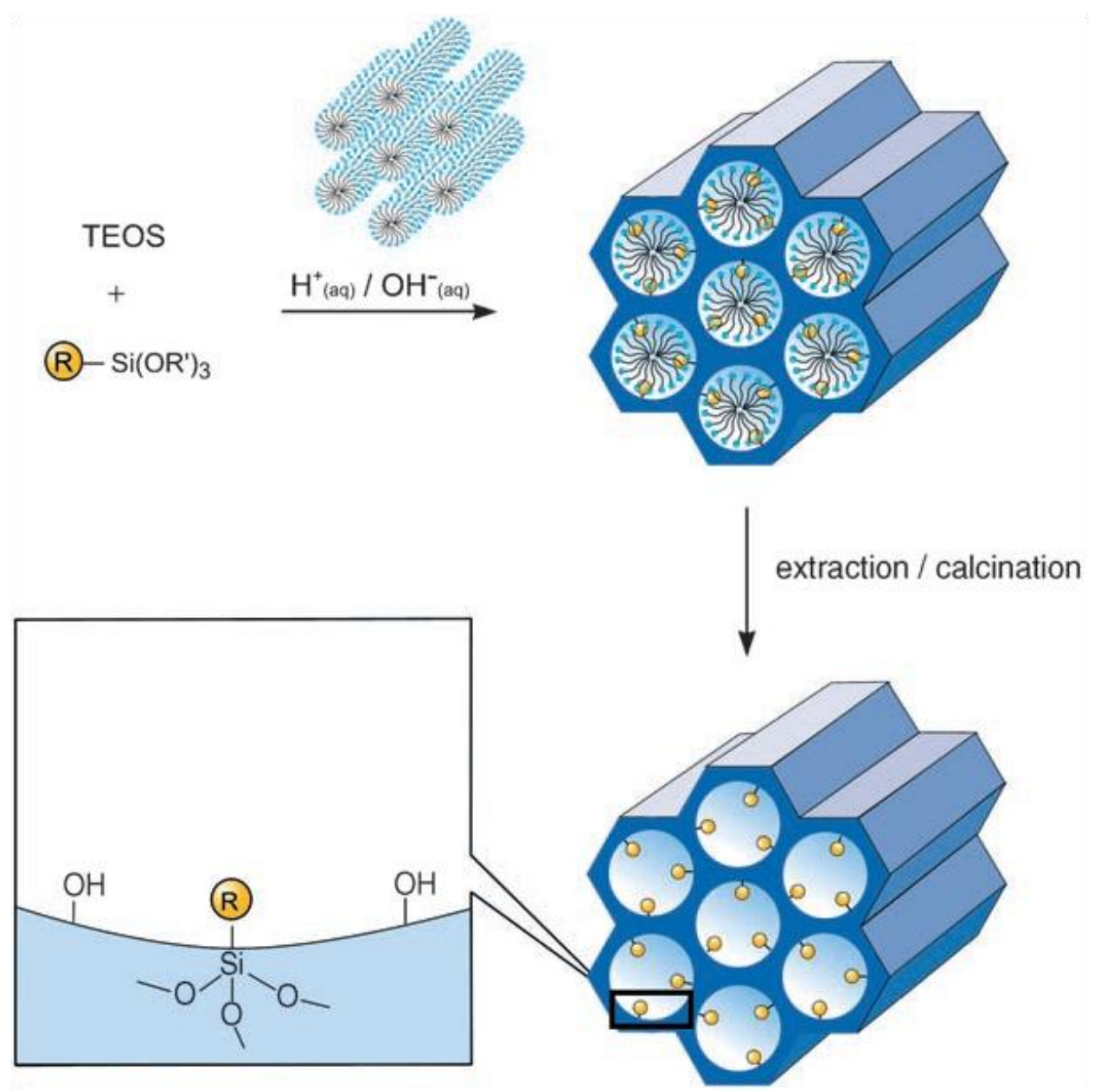

Figure 3. Schematic representation of co-condensation method for organic modification of mesoporous silica nanomaterials. ${ }^{12}$

In grafting method, the reactive organoalkoxysilanes $\left(\mathrm{R}^{\prime} \mathrm{O}\right)_{3} \mathrm{SiR}, \mathrm{ClSiR}_{3}$ or silazanes

$\mathrm{HN}\left(\mathrm{SiR}_{3}\right)_{2}$ are covalently bound on the inorganic walls of MSNs by condensation reactions with silanol or Si-O-Si groups (Figure 4). ${ }^{28}$ The distribution and amount of organic groups introduced depends on the accessibility of surface silanols and the nature of organoalkoxysilanes. ${ }^{29-30}$ The major advantage of grafting method is that the materials retain their mesostructure and are hydrolytically more stable. However, due to the preferential reaction of organoalkoxysilanes at the pore opening in the initial stages of grafting, the diffusion of functional groups into the pores 
is restricted leading to non-homogenous distribution and low grafting efficiency. ${ }^{12}$ Depending on the size of organoalkoxysilane groups, this can lead to reduction of pore sizes and pore blocking.

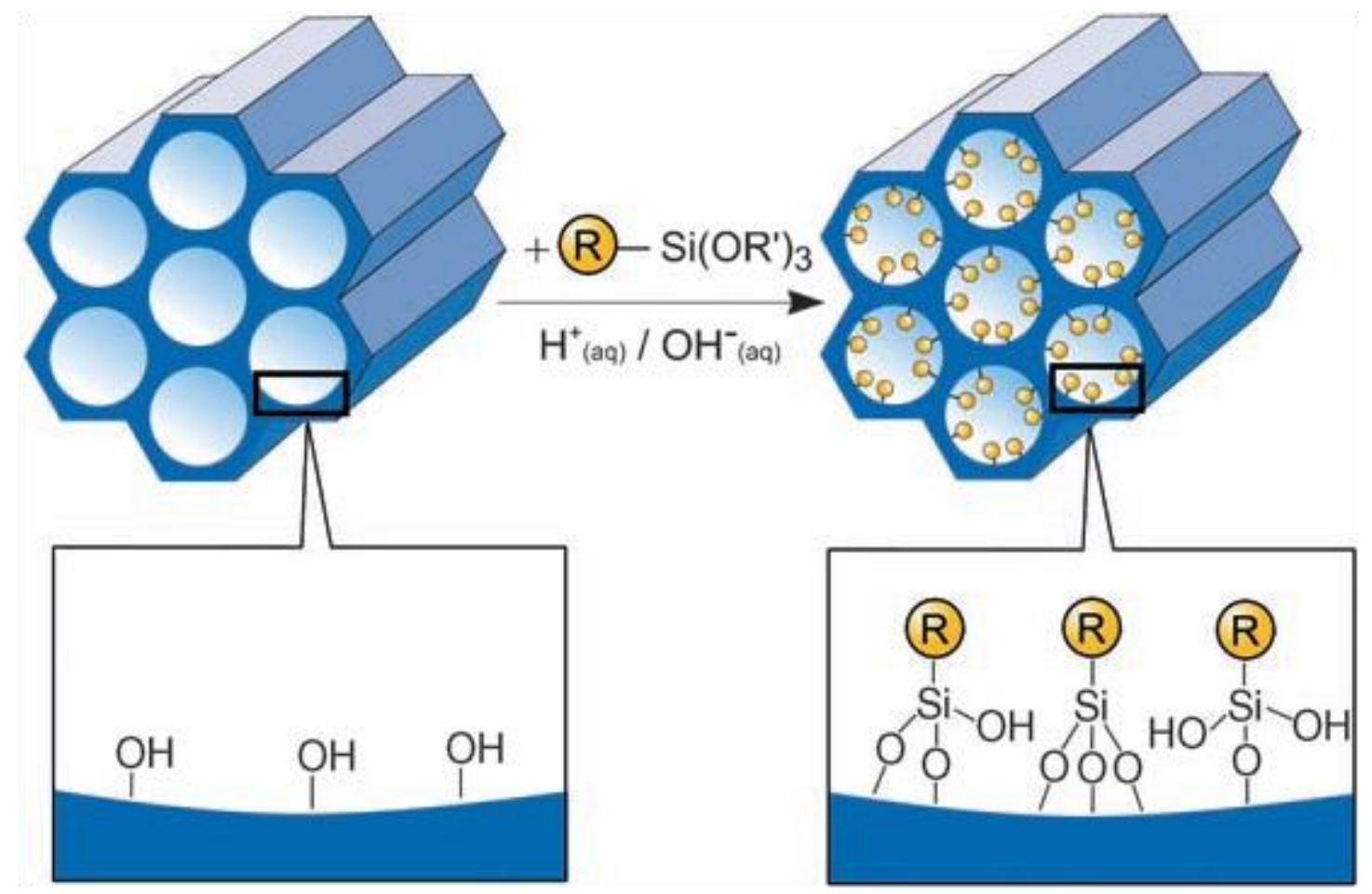

Figure 4. Schematic representation of postsynthesis grafting method for organic modification of mesoporous silica nanomaterials. ${ }^{12}$

\subsection{Pore Size Control}

The capability to tune the pore size of MSNs has a direct advantage in regulating the mass-transport properties of molecules during catalysis and separation. The pore sizes of MSNs mainly depend on the size of surfactant micelles. The increase in pore size of MCM-41 from 1.6 to $4.2 \mathrm{~nm}$ has been demonstrated with increase in the surfactant chain length from $\mathrm{C}_{8}$ to $\mathrm{C}_{22}{ }^{31}$ For SBA type materials, the pore size increases with increase in molecular weight of the hydrophobic blocks of PEO-PPO-PEO triblock copolymers. ${ }^{32}$ 
Additionally, the introduction of swelling agents such as alkanes and 1,3,5-

trimethylbenzene has been shown to expand the pore sizes of MCM-41. ${ }^{33-34}$ The incorporation of hydrophobic organic molecules in the hydrophobic region of surfactant micelles is responsible for the increase in pore sizes. Even though this method is simple, it sometimes lacks reproducibility and results into less organized mesophases. In the case of SBA type material, changing the hydrothermal temperature changes the pore size. At high temperature, the PEO blocks become hydrophobic and retracts from the silicate walls thereby increasing the size of surfactant micelles and hence the pore size. ${ }^{35-36}$ However, this simpler method decreases the pore wall and micropore volume decreases with increase in hydrothermal temperature.

\section{Applications}

In response to diminishing fossil fuels, the development of bio-energy derived from biomass has attracted considerable attention. ${ }^{37}$ The increased interest in biomass is because of its potential as a renewable source of carbon for the production of liquid biofuels on a short time scale. In addition, these biofuels are sulfur-free and therefore environmental friendly. Two major categories of feedstocks derived from biomass are appropriate for the production of renewable biofuels : carbohydrate based feedstocks and lipid based feedstocks. Significant processing and upgrading of these feedstocks is needed to generate biofuels for use in transportation sector. ${ }^{38-39}$ In this part, the application of heterogeneous catalysts and adsorbents are discussed.

\subsection{Carbohydrate-based feedstocks}

Carbohydrate-based feedstocks can be classified into two major categories: cellulosic and sugar derived feedstocks. ${ }^{37}$ Currently three types of processes exist for the production of liquid fuels from these feedstocks (Figure 5). ${ }^{40}$ The first process involves gasification to produce syn- 
gas, followed by further refining to produce alkanes and methanol by Fischer-Tropsch synthesis and methanol synthesis respectively. The second process includes thermochemical liquefaction or pyrolysis for bio-oil production, which are subsequently upgraded to produce liquid alkanes. The third employs acid hydrolysis to produce sugar monomers and then conversion into ethanol and aromatic hydrocarbons via fermentation and dehydration respectively.

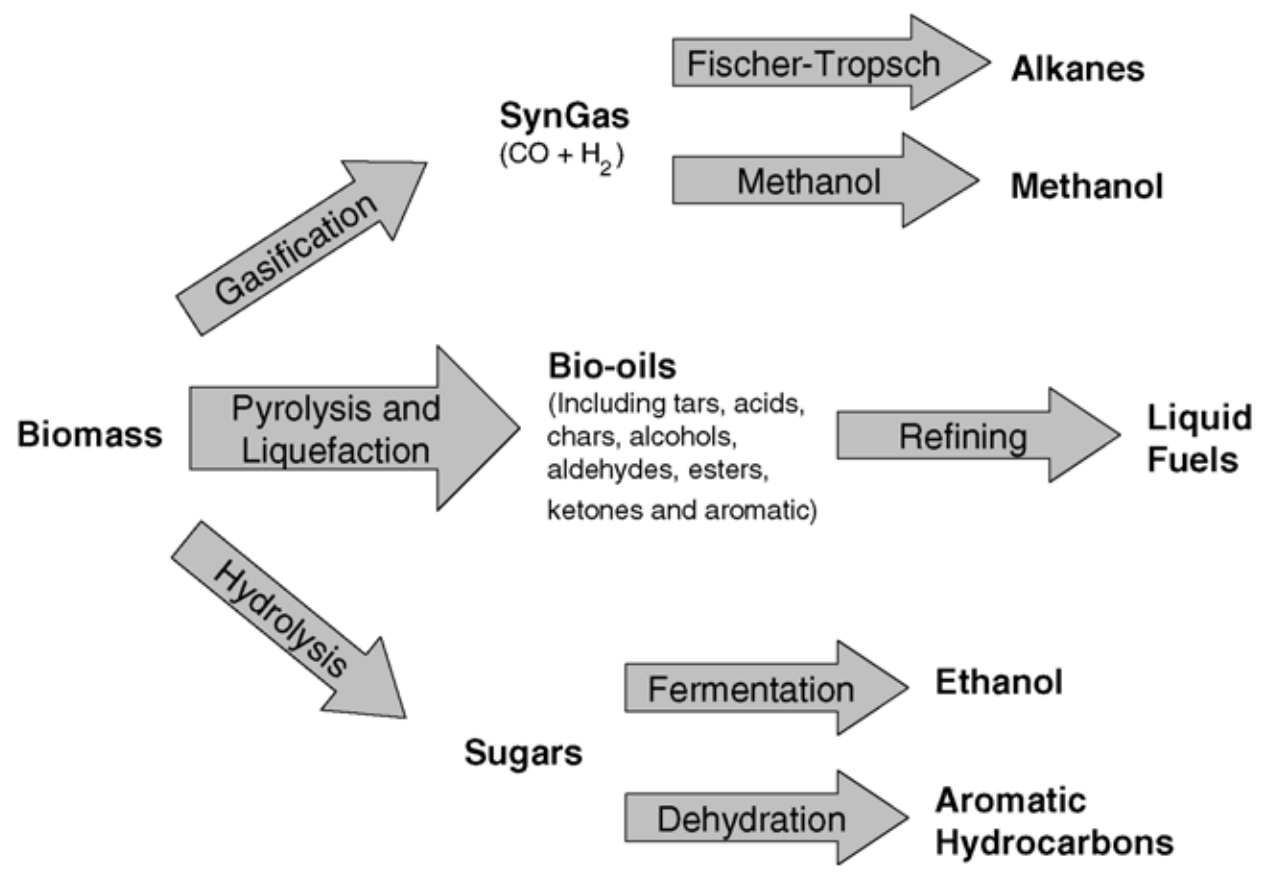

Figure 5. Strategies for production of liquid fuels from carbohydrate-based feedstocks. ${ }^{40}$

Even though the production of bio-ethanol as liquid fuel is the primary technology employed at present time, its catalytic upgrading into larger molecules is being investigated to increase the energy density. ${ }^{41-42}$ Industrially, Guerbert reaction is an important reaction to increase the carbon number of alcohols. ${ }^{43-44}$ It involves three steps: oxidation of alcohol to intermediate aldehydes, aldol condensation of the resulting aldehydes and hydrogenation to produce higher alcohols. Similarly, conversions of aromatic hydrocarbons such as furfural and 5hydroxymethylfurfural (HMF) to heavier alkanes are being studied to produce jet and diesel 
fuels (Figure 6). ${ }^{40}$ For example: Huber and Dumesic have reported processes to produce furfural and HMF from a combined acid hydrolysis of oligomers and dehydration to C5 sugar monomers. ${ }^{45-46}$ The furfural and HMF are then reacted with acetone by a base-catalyzed aldol condensation to generate alkane precursors, which are further converted into straight-chain alkanes by hydrogenation/ dehydration. Researches to develop an efficient catalyst for each step have attracted a considerable attention. While hydrogenation is usually catalyzed by heterogeneous catalyst such as platinum ( $\mathrm{Pt})$ and palladium $(\mathrm{Pd})$ supported on alumina $\left(\mathrm{Al}_{2} \mathrm{O}_{3}\right)$, hydrochloric acid $(\mathrm{HCl})$ and sodium hydroxide $(\mathrm{NaOH})$ are usually used for acid hydrolysis and base catalyzed aldol reaction steps. ${ }^{46}$ In this context, it is important to develop acidic and basic heterogeneous catalysts.

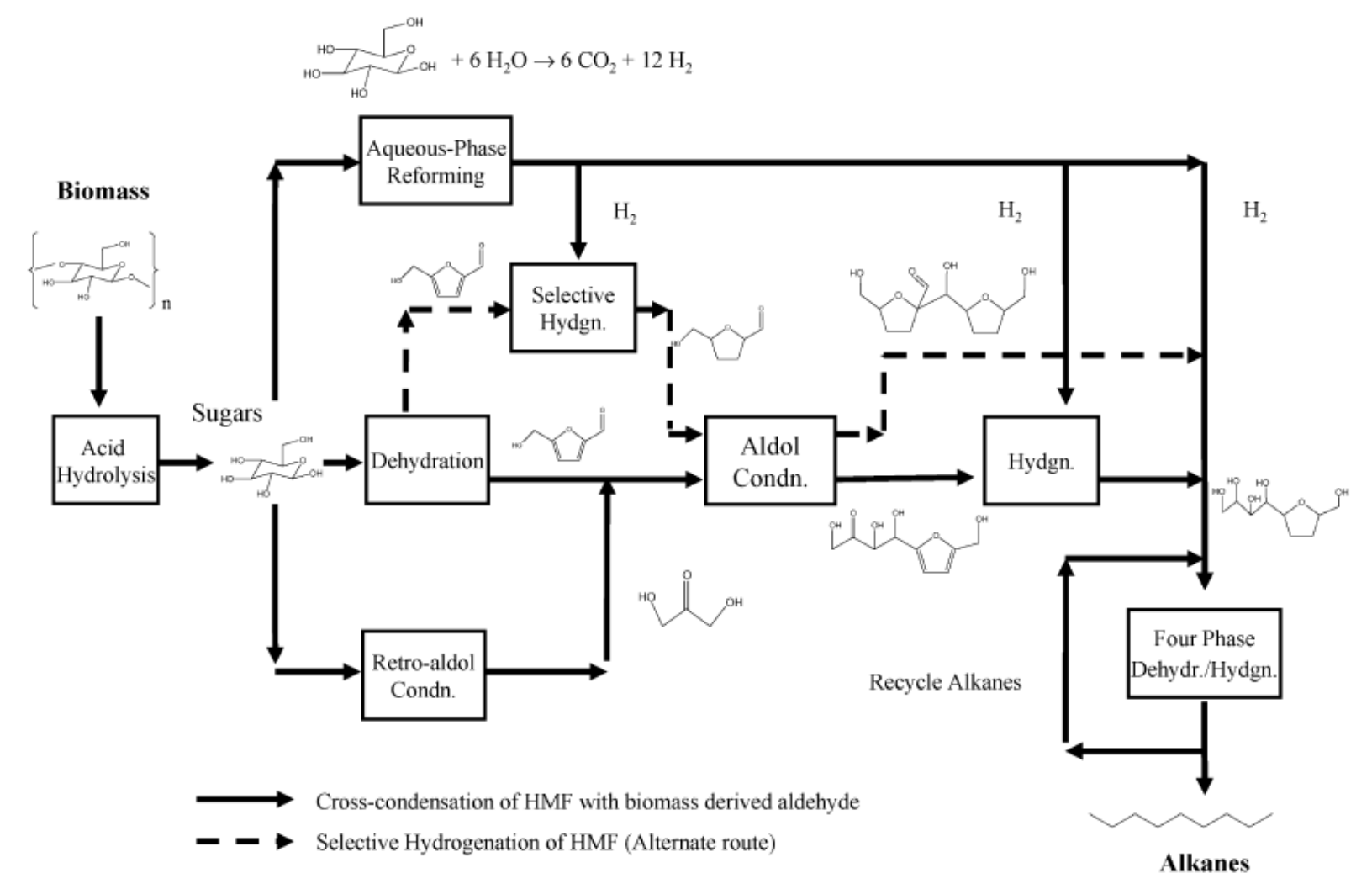

Figure 6. Reaction pathways for production of liquid alkanes from carbohydrate-based feedstocks in biorefinery. ${ }^{47}$ 


\section{Mesoporous silica supported organocatalyst}

For last two decades, mesoporous silica nanomaterials have been considered as a heterogeneous catalyst for wide range of reactions applied in scientific and industrial areas. ${ }^{48-53}$ Even though homogeneous catalysts are known to exhibit higher selectivity and superior kinetics, heterogeneous catalysts are advantageous with respect to easy product separation from reaction mixtures and reuse until loss of activity. ${ }^{54}$ Moreover, the ability to confine the catalyst inside the mesopores provides a greater specificity to a reaction by introducing size and shape selectivity. $^{55}$

MSN-based organocatalyst can be synthesized either by co-condensation or postsynthesis grafting methods. Depending on the type of reactions, mesoporous silica catalysts functionalized with acidic groups, ${ }^{56-58}$ basic groups, ${ }^{59-61}$ ionic liquids ${ }^{62-65}$ and other molecules ${ }^{66-68}$ have been reported. Several groups have applied sulfonic acid derivatized MSNs for alcohol coupling to form ethers, ${ }^{69}$ esterification of fatty acids with methanol to produce fatty acid methyl esters (FAMES/ biodiesel) ${ }^{70}$ and dehydration of fructose to 5 -hydroxymethylfurfural (HMF). ${ }^{71}$ Fukuoka and co-workers showed higher TOF using sulfonic acid functionalized mesoporous silica than Amberlyst-15 for hydrolysis of sucrose and starch to glucose and fructose. ${ }^{72}$ In addition they demonstrated that the catalyst prepared by co-condensation method resulted in higher activity than grafting method mainly due to the presence of higher acidic sites.

Taking advantage of co-condensation method, our group has synthesized two opposing catalysts with 4-ethyl-phenylsulfonic acid (SA) and aminopropyl (AP) groups. The researchers envisioned that these two nanomaterials can serve as acid and base catalysts for a one-pot reaction cascade that requires incompatible catalysts. ${ }^{73}$ Using these catalysts, they demonstrated 
the catalytic conversion of 4-nitrobenzaldehyde dimethylacetal to (E)-1-nitro-4-(2-nitrovinyl)benzene, which involved two separate reactions, i.e. an acid-catalyzed deprotection of 4nitrobenzaldehyde dimethylacetal to yield the 4-nitrobenzaldehyde followed by a base-catalyzed Henry reaction in nitromethane to generate the final product (E)-1-nitro-4-(2-nitrovinyl)benzene. Following this work, our group successfully proved the site-separation of Brønsted acid and base groups on a single mesoporous silica nanomaterial by combining co-condensation to functionalize the internal surface of MSNs and postsynthesis grafting to functionalize the external surface (Figure 7) ${ }^{74}$ The same reaction mentioned above was successfully carried out using the site-separated bifunctional catalysts.

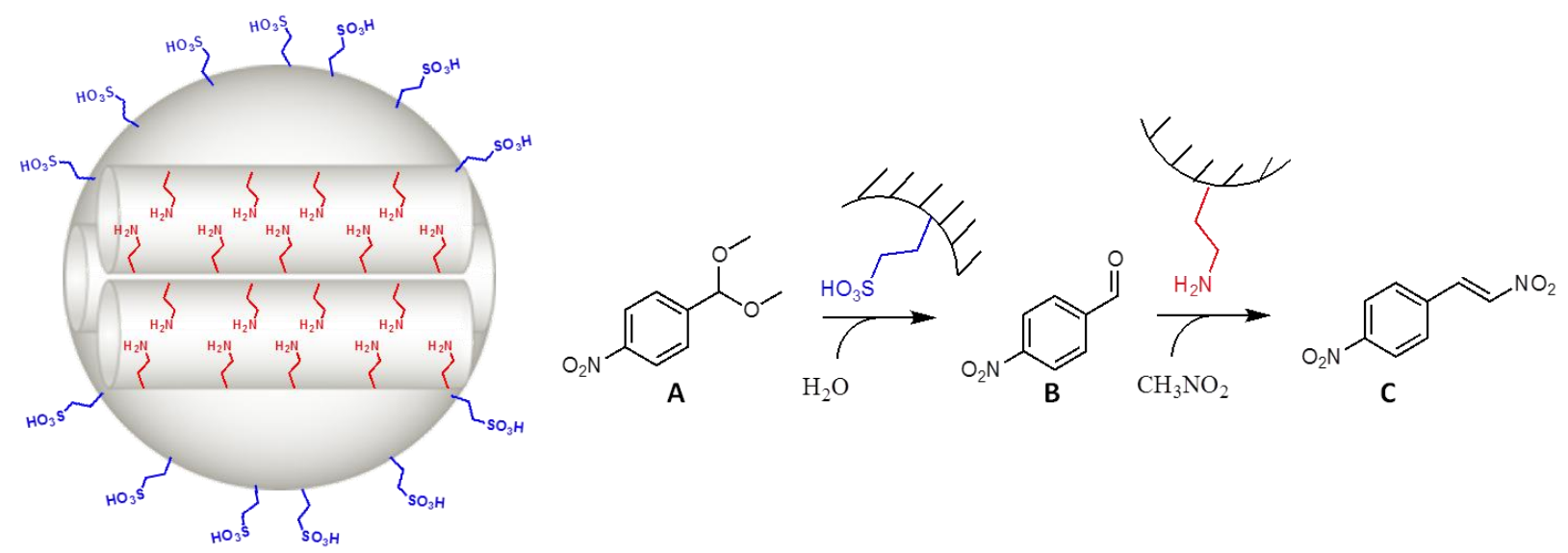

Figure 7. Schematic representation of the reaction catalyzed by a bifunctional mesoporous silica catalyst functionalized with 4-ethyl-phenylsulfonic acid (SA) and aminopropyl (AP) groups.

Incorporation of bifunctional or multifunctional groups on the surface of mesoporous silica nanomaterials has been shown to mimic biological systems and efficiently catalyze reactions with enhanced reactivity and selectivity. Similar to enzymes, the multifunctional catalysts supported on MSNs engage to activate specific substrates cooperatively. Previously, our group developed a bifunctional catalyst with a general acid, uridopropyl (UDP) group, and a 
base, 3-[2-(2-aminoethylamino)ethylamino]propyl (AEP) group and demonstrated the cooperative catalysis for aldol, Henry and cyanosilylation reactions (Figure 8). ${ }^{75}$ The UDP group served to activate the carbonyl group of 4-nitrobenzaldehyde through double hydrogen bonding. The AEP group was responsible for enamine formation with acetone in aldol reaction, deprotonation of nitromethane in Henry reaction and formation of a hypervalent silicate nucleophile with trimethylsilyl cyanide in cyanosilylation. The reaction rates of all three reactions were significantly accelerated by AEP-UDP bifunctional MSN catalysts due to cooperative catalysis.

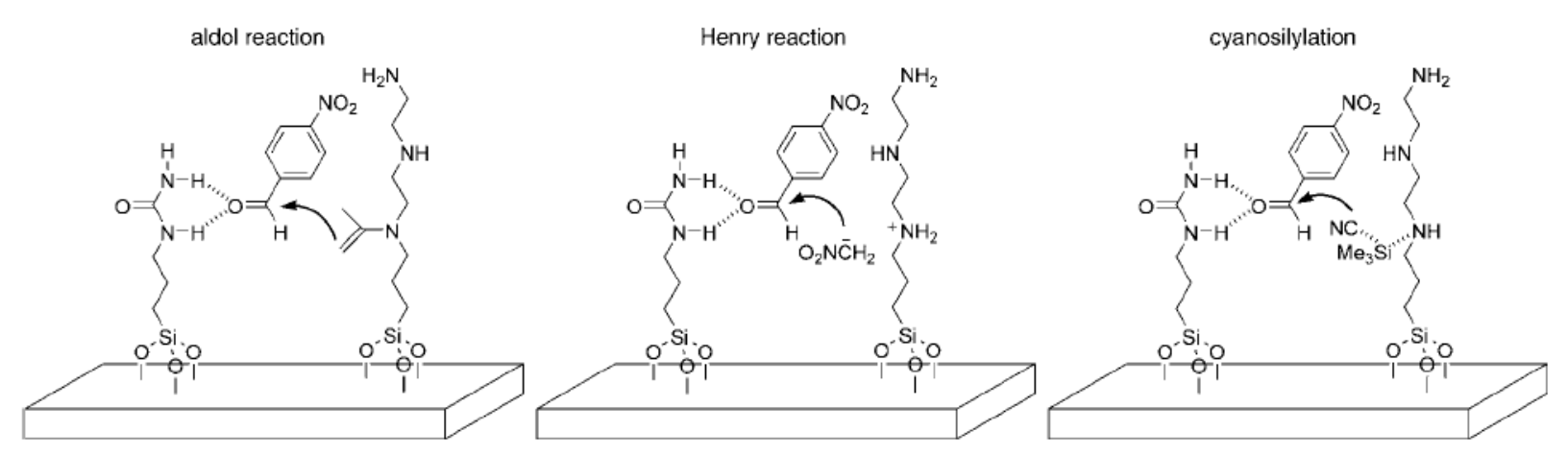

Figure 8. Representation of cooperative catalysis by AEP-UDP bifunctional mesoporous silica catalysts. ${ }^{75}$

The cooperative interactions between weakly acidic surface silanol ( $\mathrm{p} K a=7)$ of MSNs and functionalized amine group have also been demonstrated to promote the activity relative to amine alone for $\mathrm{C}-\mathrm{C}$ bond forming reactions. ${ }^{76-79}$ However, their catalytic efficiency is relatively low compared to bifunctional catalysts containing primary amine bases and sulfonic or carboxylic acid groups. In Chapters 2 and 3, the investigations on the mechanistic causes of the poor catalytic activity of primary amine-functionalized MSNs toward the aldol condensation is reported. This understanding led to modify the structure of amine in order to improve the activity. The cooperative role of silanols and amine groups is also explained in detail. 
Additionally, taking advantage of site-separation in MSNs, a catalyst with two active groups: functionalized amine groups inside the pores and immobilized enzyme outside the pores was synthesized. This bifunctional catalyst was shown to convert short chain alcohols to longer chain molecules in Chapter 4.

\subsection{Lipid-based feedstocks}

Vegetable oils are considered as the major lipid based feedstocks for biofuel production and are mostly composed of triglycerides (TAGs) and free fatty acids (FFAs) ${ }^{80}$ Triglycerides are hydrophobic molecules that are made up of one glycerol unit and three fatty acids. More than 350 crops are known with the potential for biofuel production such as soybean, sunflower, cottonseed, rapeseed, canola, corn and peanut. ${ }^{81}$ However, the sustainability of biofuels production from vegetable oils is heavily criticized due to concerns of competing with food supply, arable land culture and climate change. ${ }^{82}$ In this respect, cultivation of microalgae at sea water or industrial or other waste water provides a possible solution to solve the issue of diminishing fossil fuel supplies and increasing emission of green house gases. ${ }^{83-84}$

Microalgae have the ability to synthesize lipids by photosynthesis. Lipid content in algae can exceed $80 \%$ by weight of dry biomass; twelve times more compared to soybean oil or palm oil which has 5\% lipid concentration. ${ }^{85}$ Microalgae can be grown anywhere utilizing fresh, salt and waste water streams and their growth rate is rapid with, doubling time between $3.5 \mathrm{~h}$ to $24 \mathrm{~h}$. The biofuels produced from microalgae are carbon neutral and sulfur-free. ${ }^{84}$ However, due to small cell size, similar density to water and low biomass concentrations in cultures, microalgae harvesting is extremely capital and energy intensive ${ }^{86-90}$ The major techniques currently employed in microalgae harvesting and recovery include centrifugation, flocculation and 
filtration. ${ }^{89,91}$ Nevertheless, the processing of large volumes of culture with these techniques is time consuming and expensive.

Furthermore, even though triglycerides present in microalgae can be directly used in diesel engines, their high viscosity and low volatility can cause engine problems such as coking deposits and thickening of lubricating oils. ${ }^{81,92}$ Therefore, it is important to upgrade triglycerides if they are to be used in conventional diesel engines. Two major upgrading processes are discussed below: (i) transesterification of triglycerides to produce bio-diesel and (ii) hydrogenation to produce diesel range alkanes.

\subsubsection{Transesterification}

Transesterification chemistry is the most popular commercial method for biodiesel production. It generally involves the reaction between a triglycerides and methanol to produce fatty acids methyl esters (FAMEs) or biodiesel (Figure 9). While this reaction can be catalyzed with acids or bases, the homogeneous alkaline catalysts such as sodium or potassium hydroxide is preferred due to faster reaction kinetics. ${ }^{93}$ Recently there has been growing interest in developing heterogeneous catalysts to produce biodiesel because of easy product separation and reuse of the catalyst. ${ }^{94-95}$ 


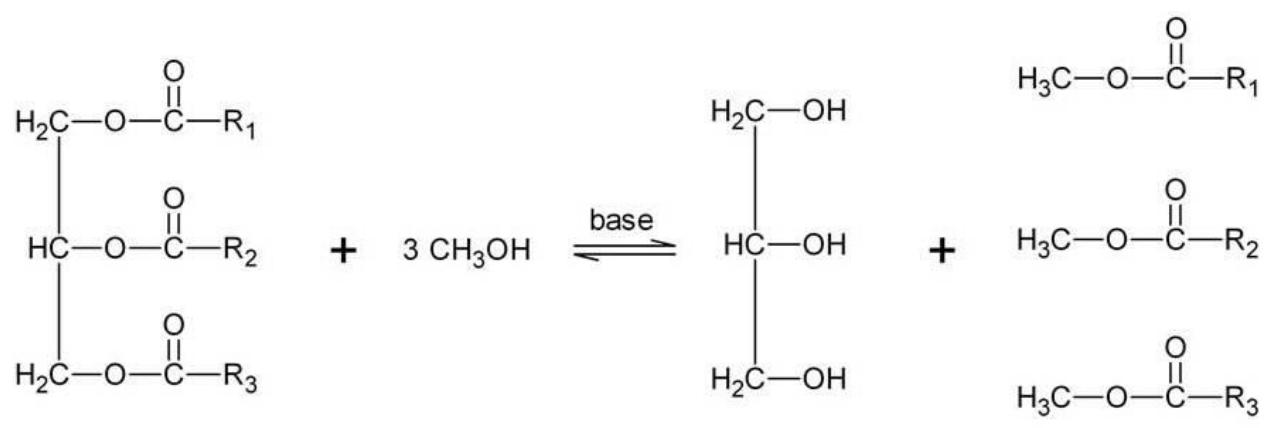

Triglyceride Methanol Glycerol Methyl Esters

Figure 9. Schematic representation of transesterification of triglycerides for biodiesel production.

\subsubsection{Hydroprocessing}

Biodiesel produced from transesterification has some disadvantages from the viewpoint of fuel specifications. Due to the presence of oxygen atoms, biodiesel has limitations such as poor storage ability, marginal cold flow properties and engine compatibility issues. Additionally, the calorific value of biodiesel is approximately $33 \mathrm{MJ} / \mathrm{L}$, which is $9 \%$ lower than that of petroleum based diesel. ${ }^{81,92}$ Hydroprocessing is an alternative way to upgrade triglycerides to liquid hydrocarbon fuels and usually involves hydrocracking and hydrotreating (Figure 10).

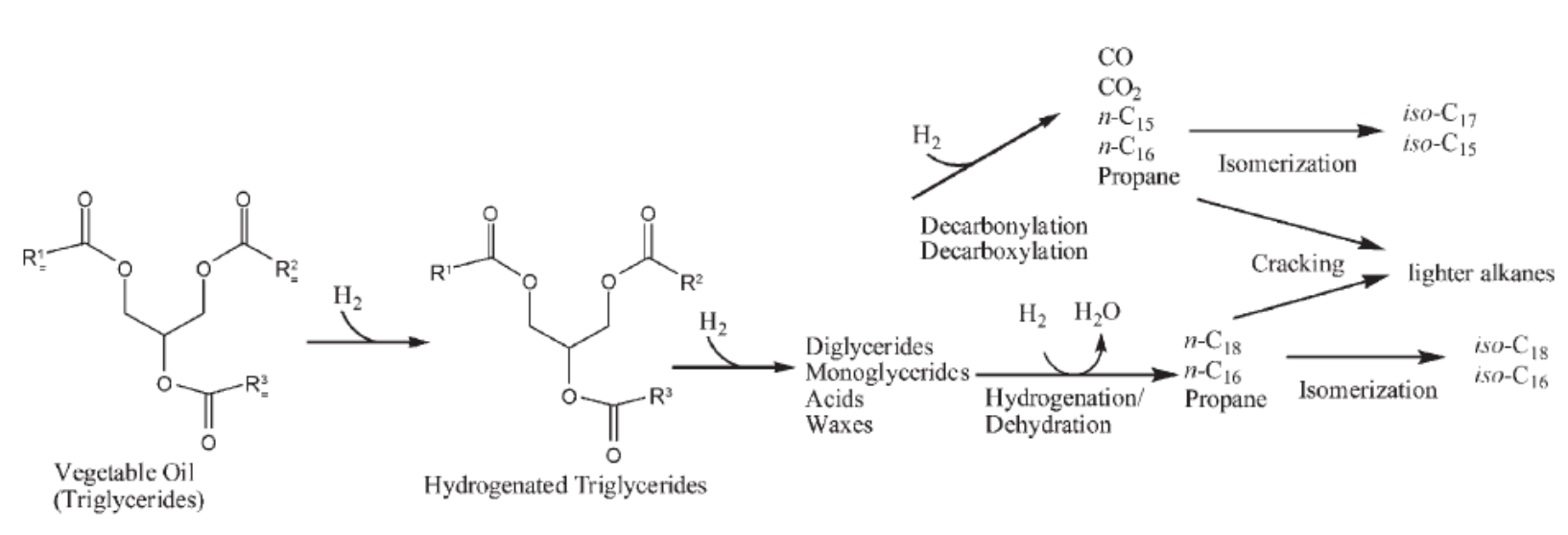

Figure 10. Reaction pathways for the conversion of triglycerides into alkanes by hydroprocessing. ${ }^{37}$ 
Hydrocracking is characterized by cleavage of C-C bond followed by hydrogen saturation of the fragments to produce lower-boiling products. Contrastingly, in hydrotreating, very little cracking is involved and hydrogen selectively converts oxygenated molecules such as triglycerides and FFAs to linear alkanes. ${ }^{96-98}$ In this context, hydrotreating process is much more selective for production of diesel range fuels.

Hydrotreating of triglycerides and FFAs to liquid hydrocarbon fuels involves (i) hydrogenation of double bonds in the fatty acid chains to triglycerides, (ii) hydrogenolysis of saturated triglycerides to FFAs and (iii) decarboxylation, decarbonylation and hydrodeoxygenation of FFAs to liquid alkanes. ${ }^{37}$ Supported noble metal catalysts such as Pd and Pt have been extensively studied for hydroprocessing of fatty acids. ${ }^{99-102}$ However, the high price of these metals demands more economical alternatives. In addition, $\mathrm{Ni}$, Co and Mo sulfides supported on metal oxides have been used for deoxygenation of bio-oils. ${ }^{103-104}$ Nevertheless, these sulfide catalysts lead to product contamination via sulfur leaching and eventually, catalyst deactivation. ${ }^{105}$

In an effort to develop sulfur-free hydrotreating catalysts, Lercher and co-workers have demonstrated the hydrodeoxygenation of microalgae oil to alkanes by cascade reactions on bifunctional catalysts based on nickel (Ni) and acidic zeolite. ${ }^{106}$ Same researchers have also shown the selectivity towards decarbonylation of FFAs using Ni catalyst supported on $\mathrm{ZrO}_{2}{ }^{107}$ Continuing on the effort to promote bio-refineries for transformation of microalgae to biofuels, the development of smart materials and stable catalysts are important for the success of biobased economy. 


\section{Mesoporous silica supported metal nanoparticles}

Ordered mesoporous silica nanomaterials with large surface area, pore volume, tunable pore size and silanol rich surface are one of the ideal supports for the synthesis of monodispersed metal nanoparticles. Among several methods for preparation of mesoporous silica supported metal nanoparticles, incipient wetness method is the most prominent due to its simplicity and therefore makes it easier to implement in industrial scale. It involves the impregnation of metal precursors in the mesopores by physical forces (i.e. capillary) followed by calcination and then reduction process either with hydrogen at elevated temperature or chemical at lower temperature. By controlling the thermodynamics and kinetics of particle formation, it is

possible to control the size and distribution of metal nanoparticles inside the pores. ${ }^{108-109}$

In the context of microalgae processing, two different integrated bio-refinery methods are reported in this thesis using mesoporous silica supported metal nanoparticle. (i) Integrated harvesting and sequestration presented in Chapter 5 that demonstrates microalgae harvesting from growth media and sequential selective sequestration of FFAs from the microalgae extract. (ii) Integrated sequestration and conversion reported in Chapter 6 which involves selective sequestration of FFAs and sequential transformation to diesel range alkanes. Additionally, a more economic mesoporous silica supported metal nanoparticle catalyst is demonstrated to efficiently convert free fatty acids to green diesel via hydrodeoxygenation route in Chapter 7.

Finally, continuing on the effort to selectively separate and purify bioactive molecules from renewable resources; the design, synthesis and application of mesoporous silica based adsorbent for selective sequestration of $\alpha$-tocopherol is reported in Chapter 8 . 


\section{Summary}

This chapter reviewed the development of mesoporous silica nanomaterials and highlighted the different techniques to incorporate adsorbent molecules and catalysts in the mesopores. The well-ordered mesostructure, large surface area, pore volume, tunable pore size and silanol rich surface to functionalize with specific organoalkoxysilane group makes mesoporous silica an ideal adsorbent for separation and storage. Similarly, the presence of inner and outer surface provides an excellent platform for incorporation of two incompatible catalysts in a single system for one pot reaction cascade and tandem catalysis. In addition, industrially relevant supported catalysts are composed of metal nanoparticles in the size range of 1-10 nm. The tunable pore size and well defined pore channel of mesoporous silica provide a confined environment for metal nanoparticle catalysts with different sizes, enhancing the reactivity and selectivity.

\section{References}

(1) Sing, K. S. W.; Everett, D. H.; Haul, R. A. W.; Moscou, L.; Pierotti, R. A.; Rouquerol, J.; Siemieniewska, T. Pure and Applied Chemistry 1985, 57, 603.

(2) Wan, Y.; Zhao Chemical Reviews 2007, 107, 2821.

(3) van Boxtel, A. J. B.; Boon, M. A.; van Deventer, H. C.; Bussmann, P. J. T. In Modern Drying Technology; Wiley-VCH Verlag GmbH \& Co. KGaA, 2011.

(4) Boyd, G. E.; Schubert, J.; Adamson, A. W. Journal of the American Chemical Society 1947, 69, 2818.

(5) Chen, N. Y.; Garwood, W. E. Catalysis Reviews 1986, 28, 185. 
(6) In Zeolites in Industrial Separation and Catalysis; Wiley-VCH Verlag GmbH \& Co. KGaA, 2010.

(7) Munsch, S.; Hartmann, M.; Ernst, S. Chemical Communications 2001, 0, 1978.

(8) Lu, L.; Wang, Q.; Liu, Y. Langmuir 2003, 19, 10617.

(9) Zhang, J.; Singh, R.; Webley, P. A. Microporous and Mesoporous Materials 2008, 111, 478.

(10) Kresge, C. T.; Leonowicz, M. E.; Roth, W. J.; Vartuli, J. C.; Beck, J. S. Nature 1992, $359,710$.

(11) Beck, J. S.; Vartuli, J. C.; Roth, W. J.; Leonowicz, M. E.; Kresge, C. T.; Schmitt, K. D.;

Chu, C. T. W.; Olson, D. H.; Sheppard, E. W. Journal of the American Chemical Society 1992, 114, 10834.

(12) Hoffmann, F.; Cornelius, M.; Morell, J.; Fröba, M. Angewandte Chemie International Edition 2006, 45, 3216.

(13) Chen, C.-Y.; Burkett, S. L.; Li, H.-X.; Davis, M. E. Microporous Materials 1993, 2, 27.

(14) Qisheng, H.; David, I. M.; Ulrike, C.; Pingyun, F.; Thurman, E. G.; Peter, S.; Rosa, L.; Pierre, M. P.; Ferdi, S.; Galen, D. S. Nature 1994, 368, 317.

(15) Huo, Q.; Margolese, D. I.; Ciesla, U.; Demuth, D. G.; Feng, P.; Gier, T. E.; Sieger, P.; Firouzi, A.; Chmelka, B. F. Chemistry of Materials 1994, 6, 1176.

(16) Monnier, A.; Schüth, F.; Huo, Q.; Kumar, D.; Margolese, D.; Maxwell, R. S.; Stucky, G. D.; Krishnamurty, M.; Petroff, P.; Firouzi, A.; Janicke, M.; Chmelka, B. F. Science 1993, $261,1299$.

(17) Israelachvili, J. N.; Mitchell, D. J.; Ninham, B. W. Journal of the Chemical Society, Faraday Transactions 2: Molecular and Chemical Physics 1976, 72, 1525. 
(18) Israelachvili, J. N.; Mitchell, D. J.; Ninham, B. W. Biochimica et Biophysica Acta (BBA) - Biomembranes 1977, 470, 185.

(19) Huo, Q.; Leon, R.; Petroff, P. M.; Stucky, G. D. Science 1995, 268, 1324.

(20) Landry, C. C.; Tolbert, S. H.; Gallis, K. W.; Monnier, A.; Stucky, G. D.; Norby, P.; Hanson, J. C. Chemistry of Materials 2001, 13, 1600.

(21) Tolbert, S. H.; Landry, C. C.; Stucky, G. D.; Chmelka, B. F.; Norby, P.; Hanson, J. C.; Monnier, A. Chemistry of Materials 2001, 13, 2247.

(22) Zhao, D.; Feng, J.; Huo, Q.; Melosh, N.; Fredrickson, G. H.; Chmelka, B. F.; Stucky, G. D. Science 1998, 279, 548.

(23) Zhao, D.; Huo, Q.; Feng, J.; Chmelka, B. F.; Stucky, G. D. Journal of the American Chemical Society 1998, 120, 6024.

(24) Göltner-Spickermann, C. Current Opinion in Colloid \& Interface Science 2002, 7, 173.

(25) Burkett, S. L.; Sims, S. D.; Mann, S. Chemical Communications 1996, 0, 1367.

(26) Sayari, A.; Hamoudi, S. Chemistry of Materials 2001, 13, 3151.

(27) Huh, S.; Wiench, J. W.; Yoo, J.-C.; Pruski, M.; Lin, V. S. Y. Chemistry of Materials 2003, $15,4247$.

(28) Brunel, D.; Cauvel, A.; Fajula, F.; DiRenzo, F. In Studies in Surface Science and Catalysis; Laurent, B., Serge, K., Eds.; Elsevier, 1995; Vol. Volume 97.

(29) Moller, K.; Bein, T. In Studies in Surface Science and Catalysis; L. Bonneviot, F. B. C. D. S. G., Kaliaguine, S., Eds.; Elsevier, 1998; Vol. Volume 117.

(30) Price, P. M.; Clark, J. H.; Macquarrie, D. J. Journal of the Chemical Society, Dalton Transactions 2000, 0, 101.

(31) Jana, S.; Mochizuki, A.; Namba, S. Catalysis Surveys from Asia 2004, 8, 1. 
(32) Yu, C.; Fan, J.; Tian, B.; Stucky, G. D.; Zhao, D. The Journal of Physical Chemistry B 2003, 107, 13368.

(33) Ulagappan, N.; Rao, C. N. R. Chemical Communications 1996, O, 2759.

(34) Namba, S.; Mochizuki, A. Res. Chem. Intermed. 1998, 24, 561.

(35) Galarneau, A.; Cambon, H.; Di Renzo, F.; Fajula, F. Langmuir 2001, 17, 8328.

(36) Nossov, A.; Haddad, E.; Guenneau, F.; Galarneau, A.; Di Renzo, F.; Fajula, F.; Gédéon, A. The Journal of Physical Chemistry B 2003, 107, 12456.

(37) Huber, G. W.; Corma, A. Angewandte Chemie International Edition 2007, 46, 7184.

(38) Alonso, D. M.; Bond, J. Q.; Dumesic, J. A. Green Chemistry 2010, 12, 1493.

(39) Ko, C.; Park, S.; Jeon, J.-K.; Suh, D.; Jeong, K.-E.; Park, Y.-K. Korean J. Chem. Eng. 2012, 29, 1657.

(40) Huber, G. W.; Dumesic, J. A. Catalysis Today 2006, 111, 119.

(41) Franckaerts, J.; Froment, G. F. Chemical Engineering Science 1964, 19, 807.

(42) León, M.; Díaz, E.; Ordóñez, S. Catalysis Today 2011, 164, 436.

(43) Ndou, A. S.; Plint, N.; Coville, N. J. Applied Catalysis A: General 2003, 251, 337.

(44) Carlini, C.; Flego, C.; Marchionna, M.; Noviello, M.; Raspolli Galletti, A. M.; Sbrana, G.; Basile, F.; Vaccari, A. Journal of Molecular Catalysis A: Chemical 2004, 220, 215.

(45) Huber, G. W.; Chheda, J. N.; Barrett, C. J.; Dumesic, J. A. Science 2005, 308, 1446.

(46) Xing, R.; Subrahmanyam, A. V.; Olcay, H.; Qi, W.; van Walsum, G. P.; Pendse, H.; Huber, G. W. Green Chemistry 2010, 12, 1933.

(47) Chheda, J. N.; Dumesic, J. A. Catalysis Today 2007, 123, 59.

(48) Chen, C.-L.; Li, T.; Cheng, S.; Xu, N.; Mou, C.-Y. Catalysis Letters 2002, 78, 223.

(49) Corma, A.; Garcia, H. Chemical Society Reviews 2008, 37, 2096. 
(50) Wan, Y.; Wang, H.; Zhao, Q.; Klingstedt, M.; Terasaki, O.; Zhao, D. Journal of the American Chemical Society 2009, 131, 4541.

(51) Thomas, J. M.; Johnson, B. F. G.; Raja, R.; Sankar, G.; Midgley, P. A. Accounts of Chemical Research 2002, 36, 20.

(52) Campelo, J. M.; Luna, D.; Luque, R.; Marinas, J. M.; Romero, A. A. ChemSusChem 2009, 2,18 .

(53) Polshettiwar, V.; Varma, R. S. Green Chemistry 2010, 12, 743.

(54) Corma, A.; Garcia, H. Topics in Catalysis 2008, 48, 8.

(55) Song, H.; Rioux, R. M.; Hoefelmeyer, J. D.; Komor, R.; Niesz, K.; Grass, M.; Yang, P.; Somorjai, G. A. Journal of the American Chemical Society 2006, 128, 3027.

(56) Corma, A.; García, H. Chemical Reviews 2003, 103, 4307.

(57) Jeong, G. H.; Kim, E. G.; Kim, S. B.; Park, E. D.; Kim, S. W. Microporous and Mesoporous Materials 2011, 144, 134.

(58) Tsai, C.-H.; Chen, H.-T.; Althaus, S. M.; Mao, K.; Kobayashi, T.; Pruski, M.; Lin, V. S. Y. ACS Catalysis 2011, 1, 729.

(59) Chen, H.-T.; Huh, S.; Wiench, J. W.; Pruski, M.; Lin, V. S. Y. Journal of the American Chemical Society 2005, 127, 13305.

(60) Kandel, K.; Althaus, S. M.; Peeraphatdit, C.; Kobayashi, T.; Trewyn, B. G.; Pruski, M.; Slowing, I. I. J. Catal. 2012, 291, 63.

(61) Kandel, K.; Althaus, S. M.; Peeraphatdit, C.; Kobayashi, T.; Trewyn, B. G.; Pruski, M.; Slowing, I. I. ACS Catalysis 2013, 3, 265.

(62) Xu, L.-W.; Yang, M.-S.; Jiang, J.-X.; Qiu, H.-Y.; Lai, G.-Q. cent.eur.j.chem. 2007, 5, 1073. 
(63) Zhen, B.; Jiao, Q.; Zhang, Y.; Wu, Q.; Li, H. Applied Catalysis A: General 2012, 445446, 239.

(64) Li, H.; Bhadury, P. S.; Song, B.; Yang, S. RSC Advances 2012, 2, 12525.

(65) Sidhpuria, K. B.; Daniel-da-Silva, A. L.; Trindade, T.; Coutinho, J. A. P. Green Chemistry 2011, 13, 340.

(66) Brunel, D.; Fajula, F.; Nagy, J. B.; Deroide, B.; Verhoef, M. J.; Veum, L.; Peters, J. A.; van Bekkum, H. Applied Catalysis A: General 2001, 213, 73.

(67) Karimi, B.; Badreh, E. Organic \& Biomolecular Chemistry 2011, 9, 4194.

(68) Crudden, C. M.; Sateesh, M.; Lewis, R. Journal of the American Chemical Society 2005, $127,10045$.

(69) Shen, J. G. C.; Herman, R. G.; Klier, K. The Journal of Physical Chemistry B 2002, 106, 9975.

(70) Mbaraka, I. K.; Radu, D. R.; Lin, V. S. Y.; Shanks, B. H. Journal of Catalysis 2003, 219, 329.

(71) Dias, A. S.; Pillinger, M.; Valente, A. A. Journal of Catalysis 2005, 229, 414.

(72) Dhepe, P.; Ohashi, M.; Inagaki, S.; Ichikawa, M.; Fukuoka, A. Catalysis Letters 2005, $102,163$.

(73) Huang, Y.; Trewyn, B. G.; Chen, H.-T.; Lin, V. S. Y. New Journal of Chemistry 2008, 32, 1311.

(74) Huang, Y.; Xu, S.; Lin, V. S. Y. Angewandte Chemie International Edition 2011, 50, 661.

(75) Huh, S.; Chen, H.-T.; Wiench, J. W.; Pruski, M.; Lin, V. S. Y. Angewandte Chemie International Edition 2005, 44, 1826. 
(76) Hair, M. L.; Hertl, W. The Journal of Physical Chemistry 1970, 74, 91.

(77) Bass, J. D.; Solovyov, A.; Pascall, A. J.; Katz, A. Journal of the American Chemical Society 2006, $128,3737$.

(78) Kubota, Y.; Goto, K.; Miyata, S.; Goto, Y.; Fukushima, Y.; Sugi, Y. Chemistry Letters $\mathbf{2 0 0 3}, 32,234$.

(79) Kubota, Y.; Yamaguchi, H.; Yamada, T.; Inagaki, S.; Sugi, Y.; Tatsumi, T. Topics in Catalysis 2010, 53, 492.

(80) Srivastava, A.; Prasad, R. Renewable and Sustainable Energy Reviews 2000, 4, 111.

(81) Knothe, G. Fuel Processing Technology 2005, 86, 1059.

(82) Singh, A.; Nigam, P. S.; Murphy, J. D. Bioresource Technology 2011, 102, 10.

(83) Brennan, L.; Owende, P. Renewable and Sustainable Energy Reviews 2010, 14, 557.

(84) Schenk, P. M.; Thomas-Hall, S. R.; Stephens, E.; Marx, U. C.; Mussgnug, J. H.; Posten, C.; Kruse, O.; Hankamer, B. Bioenergy Research 2008, 1, 20.

(85) Spolaore, P.; Joannis-Cassan, C.; Duran, E.; Isambert, A. Journal of Bioscience and Bioengineering 2006, 101, 87.

(86) Sharma, Y. C.; Singh, B.; Korstad, J. Green Chemistry 2011, 13, 2993.

(87) Molina Grima, E.; Belarbi, E. H.; Acién Fernández, F. G.; Robles Medina, A.; Chisti, Y. Biotechnology Advances 2003, 20, 491.

(88) Uduman, N.; Qi, Y.; Danquah, M. K.; Forde, G. M.; Hoadley, A. Journal of Renewable and Sustainable Energy 2010, 2, 012701.

(89) Zhang, X.; Hu, Q.; Sommerfeld, M.; Puruhito, E.; Chen, Y. Bioresource Technology 2010, 101, 5297. 
(90) Harun, R.; Singh, M.; Forde, G. M.; Danquah, M. K. Renewable and Sustainable Energy Reviews 2010, 14, 1037.

(91) Middlebrooks, E. J.; Porcella, D. B.; Gearheart, R. A.; Marshall, G. R.; Reynolds, J. H.; Grenney, W. J. Journal (Water Pollution Control Federation) 1974, 46, 2676.

(92) Ma, F.; Hanna, M. A. Bioresource Technology 1999, 70, 1.

(93) Umdu, E. S.; Tuncer, M.; Seker, E. Bioresource Technology 2009, 100, 2828.

(94) Kim, H.-J.; Kang, B.-S.; Kim, M.-J.; Park, Y. M.; Kim, D.-K.; Lee, J.-S.; Lee, K.-Y. Catalysis Today 2004, 93-95, 315.

(95) Helwani, Z.; Othman, M. R.; Aziz, N.; Kim, J.; Fernando, W. J. N. Applied Catalysis A: General 2009, 363, 1 .

(96) Tiwari, R.; Rana, B. S.; Kumar, R.; Verma, D.; Kumar, R.; Joshi, R. K.; Garg, M. O.; Sinha, A. K. Catalysis Communications 2011, 12, 559.

(97) Donnis, B.; Egeberg, R.; Blom, P.; Knudsen, K. Topics in Catalysis 2009, 52, 229.

(98) Choudhary, T. V.; Phillips, C. B. Applied Catalysis A: General 2011, 397, 1.

(99) Lestari, S.; Mäki-Arvela, P.; Simakova, I.; Beltramini, J.; Lu, G.; Murzin, D. Catalysis Letters 2009, 130, 48.

(100) Snåre, M.; Kubičková, I.; Mäki-Arvela, P.; Eränen, K.; Wärnå, J.; Murzin, D. Y. Chemical Engineering Journal 2007, 134, 29.

(101) Petrus, L.; Noordermeer, M. A. Green Chemistry 2006, 8, 861.

(102) Rozmysłowicz, B.; Mäki-Arvela, P.; Lestari, S.; Simakova, O.; Eränen, K.; Simakova, I.; Murzin, D.; Salmi, T. Topics in Catalysis 2010, 53, 1274.

(103) Kubička, D.; Kaluža, L. Applied Catalysis A: General 2010, 372, 199.

(104) Viljava, T. R.; Komulainen, R. S.; Krause, A. O. I. Catalysis Today 2000, 60, 83. 
(105) Laurent, E.; Delmon, B. Journal of Catalysis 1994, 146, 281.

(106) Peng, B.; Yao, Y.; Zhao, C.; Lercher, J. A. Angewandte Chemie International Edition 2012, 51, 2072.

(107) Peng, B.; Yuan, X.; Zhao, C.; Lercher, J. A. Journal of the American Chemical Society 2012, 134, 9400 .

(108) Shin, H. J.; Ryoo, R.; Liu, Z.; Terasaki, O. Journal of the American Chemical Society 2001, 123, 1246.

(109) Lee, B.; Ma, Z.; Zhang, Z.; Park, C.; Dai, S. Microporous and Mesoporous Materials 2009, $122,160$. 


\title{
CHAPTER 2. SUBSTRATE INHIBITION IN THE HETEROGENEOUS CATALYZED ALDOL CONDENSATION: A MECHANISTIC STUDY OF SUPPORTED ORGANOCATALYSTS
}

Modified from a paper published in Journal of Catalysis 2012, 291, 63 Kapil Kandel, Stacey M. Althaus, Chorthip Peeraphatdit, Takeshi Kobayashi, Brian G. Trewyn, Marek Pruski, Igor I. Slowing

\begin{abstract}
In this study we demonstrate how materials science can be combined with the established methods of organic chemistry to find mechanistic bottlenecks and redesign heterogeneous catalysts for improved performance. By using solid-state NMR, infrared spectroscopy, surface and kinetic analysis, we prove the existence of a substrate inhibition in the aldol condensation catalyzed by heterogeneous amines. We show that modifying the structure of the supported amines according to the proposed mechanism dramatically enhances the activity of the heterogeneous catalyst. We also provide evidence that the reaction benefits significantly from the surface chemistry of the silica support, which plays the role of a co-catalyst, giving activities up to two orders of magnitude larger than those of homogeneous amines. This study confirms that the optimization of a heterogeneous catalyst depends as much on obtaining organic mechanistic information as it does on controlling the structure of the support.
\end{abstract}

\section{Introduction}

One of the characteristics that distinguish homogeneous from heterogeneous catalysis is the intricacy of the reaction environment. The uniform nature of 
homogeneous catalysts facilitates identification of intermediates and enables understanding of the transformations in terms of reaction mechanisms. This permits optimization of the activity by slight variations to the molecular structure of the catalyst.[1] Unraveling of reaction mechanisms in heterogeneous catalysis poses additional challenges due to the different environments that the active sites can encounter on a solid support. Therefore, optimization of heterogeneous catalysts is often performed by selection or design of supports rather than by modifying the structure of the catalytic groups.[2-5] In addition, homogeneous catalysts typically exhibit superior selectivity and kinetics. Despite these disadvantages, heterogeneous catalysts are valued because they allow easy separation of products and can be reused for extended periods of time.[6]

Given its importance as a C-C bond-forming reaction, the aldol condensation has been a common target for catalyst design.[7-11] This reaction is performed in organisms by aldolases, which activate donor ketones with the amino group of a highly conserved lysine, to give enamines. The enamines attack aldehyde acceptors and are then hydrolyzed to release the product. $[12,13]$ Homogeneous catalysis of this reaction has been accomplished by strong acids or bases, combining nucleophilic addition with enolization, $[14,15]$ and recently by proline and catalytic antibodies.[16, 17] Many heterogeneous catalysts have been developed to promote this reaction, and among those with organic groups as active sites, the most commonly used are aminoalkyls.[18-24]

While supported aminoalkyls promote the aldol condensation, their catalytic efficiency is relatively low.[20, 21, 23-27] A way to solve this problem could be by introducing a secondary functional group in the material.[28] Davis and co-workers adopted this strategy and synthesized a bifunctional catalyst by introducing amine and sulfonic acid groups on mesoporous silica, which dramatically increased the activity 
due to cooperativity between both groups.[25, 26] Solin and collaborators, as well as Thiel and co-workers, obtained similar results, using different combinations of alkylamines and acidic groups in mesoporous silica supports.[23, 27] However, the poor catalytic activity of monofunctional amine on silica, which remains commonly used for the aldol and similar types of condensation, [20, 22, 24, 29-32] is still not well understood.

Herein, we investigate in detail the mechanistic causes of the poor catalytic activity of amine functionalized mesoporous silica towards the aldol condensation. Based on this understanding we demonstrate that the performance can be dramatically improved by the proper choice of the catalytic groups. Furthermore, we report activities that surpass those observed in the homogeneously catalyzed reactions, and demonstrate that these enhanced activities arise from the cooperative interactions between organocatalysts and the support.

\section{Materials and Methods}

\subsection{Materials}

Cetyltrimethylammonium bromide (CTAB), mesitylene, p-nitrobenzaldehyde, hexamethyldisilazane (HMDS) and dimethyl sulfone were purchased from SigmaAldrich. Tetraethylorthosilicate (TEOS), 3-aminopropyl trimethoxysilane, [3(Methylamino)propyl] trimethoxysilane and [3-(N,N-Dimethylamino)propyl] trimethoxysilane were purchased from Gelest. All reagents were used as received without further purification.

\subsection{Synthesis of Amine-Functionalized Mesoporous Silica Nanoparticles}

The functionalized mesoporous silica nanoparticles (MSNs) with particle sizes ranging from 80 to $150 \mathrm{~nm}$ (Figure S1) were prepared following a previously published 
method.[33] CTAB (1.0 g, $2.7 \mathrm{mmol})$ was dissolved in nanopure water (480 g, 26.7 mol), followed by the addition of $\mathrm{NaOH}$ solution $(2.0 \mathrm{M}, 3.5 \mathrm{~mL}, 7.0 \mathrm{mmol})$. The mixture was heated to $80^{\circ} \mathrm{C}$ for $1 \mathrm{~h}$. To this clear solution, TEOS (4.7 g, $23 \mathrm{mmol}$ ) was added drop wise, followed by immediate addition of 3-aminopropyl trimethoxysilane (for AP-MSN) (1.0 mL, $5.7 \mathrm{mmol}$ ) and [3-(Methylamino)propyl] trimethoxysilane (for MAP-MSN) (1.0 mL, $5.0 \mathrm{mmol})$. The reaction mixtures were stirred vigorously at $80^{\circ} \mathrm{C}$ for $2 \mathrm{~h}$ and then filtered to yield white functionalized solids. The as-synthesized materials were washed with copious amounts of water and methanol, and then dried under vacuum. The final catalysts were obtained by removing the CTAB surfactant via Soxhlet extraction with methanol for $24 \mathrm{~h}$, followed by drying overnight under vacuum. These samples were labeled AP-MSN-2.8 and MAP-MSN2.6, based on the average pore size ( $2.8 \mathrm{~nm}$ and $2.6 \mathrm{~nm}$, respectively).

\subsection{Synthesis of Pore-Expanded Functionalized Mesoporous Silica Nanoparticles}

The functionalized MSN materials with larger pores (AP-MSN-3.6 and MAPMSN-3.5) were prepared following the same procedure as described above, except for the initial step which involved adding the pore expander agent mesitylene (1.73 g, 14.4 mmol) to the original CTAB solution, as previously published.[34] A third poreexpanded catalyst was also prepared functionalized with [3-(N,NDimethylaminopropyl)] trimethoxysilane $(1.0 \mathrm{~mL}, 4.6 \mathrm{mmol})$ and labeled DMAPMSN-3.2.

\subsection{Passivation of MAP-MSN-3.5 material}

The silylation was performed by placing $1.0 \mathrm{~g}$ of MAP-MSN-3.5 material in a hexane solution of hexamethyldisilazane (HMDS) (100 mL hexane, $10 \mathrm{mmol}$ HMDS).[35],[36] The mixture was refluxed for $24 \mathrm{~h}$, the resulting solution was then filtered, washed three times with hexane, and dried under vacuum. 


\subsection{Characterization}

The surface areas and pore size distributions of the catalysts were measured by nitrogen sorption isotherms in a Micromeritics Tristar analyzer, and calculated by the Brunauer-Emmett-Teller (BET) and Barrett-Joyner-Halenda (BJH) methods, respectively (Table S1). The transmission electron microscopy (TEM) examination was completed on a Tecnai G2 F20 electron microscope operated at $200 \mathrm{kV}$ (Figure S1). For the TEM measurements, an aliquot of the powder was sonicated in methanol for 15 min. A single drop of this suspension was placed on a lacey carbon coated copper TEM grid and dried in air. The small angle powder X-ray diffraction patterns were obtained with a Rigaku Ultima IV diffractometer using $\mathrm{Cu}$ target at $40 \mathrm{kV}$ and $44 \mathrm{~mA}$ (Figure $\mathrm{S} 2)$. The $\mathrm{Cu} \mathrm{K} \beta$ radiation was removed using a monochromator. Fourier transform infrared (FT-IR) spectra were recorded on Nicolet Nexus 470. Solid-state NMR experiments are described separately below. Loading of the catalytic groups was measured by elemental analysis in a Perkin Elmer 2100 Series II CHN/S Analyzer, with acetanilide as calibration standard, and combustion and reduction temperatures of $925^{\circ} \mathrm{C}$ and $640{ }^{\circ} \mathrm{C}$. The expected precision and accuracy of the analysis was $\pm 0.3 \%$ for each element, each material was tested by triplicate.

\subsection{General Procedure for Aldol Condensation Reaction}

All catalytic reactions were performed in screw-cap vials. $p$-nitrobenzaldehyde $(0.39 \mathrm{mmol})$ was dissolved in acetone $(1.5 \mathrm{~mL})$. To this solution, a suspension of the catalyst containing $0.0117 \mathrm{mmol}$ of the amine group (corresponding to $3 \mathrm{~mol} \%$ of the $p$-nitrobenzaldehyde) in hexane $(1.5 \mathrm{~mL})$ was added. The solution was stirred at $60^{\circ} \mathrm{C}$ for specified times and set on ice to quench the reaction. The catalyst was separated by centrifugation and the supernatant was concentrated under reduced pressure. The yield 
of the products was determined by ${ }^{1} \mathrm{H}$ NMR, using dimethyl sulfone as an internal standard.

\subsection{Solid-State NMR}

Solid-state NMR experiments were used to determine the structures of surface bound species and intermediates. This technique was also used as an additional tool to evaluate the loading of the functional groups on the MSN surface by means of ${ }^{29} \mathrm{Si}$ spectra, measured using direct polarization (DP) under magic angle spinning (MAS) with Carr-Purcell-Meiboom-Gill (CPMG) refocusing of ${ }^{29} \mathrm{Si}$ magnetization,[37] as previously described (Table S1).[38]

${ }^{13} \mathrm{C}$ cross polarization (CP) MAS spectra were used to verify the structure of the functional groups and to determine the identities of intermediates formed in the APMSNs. These experiments were performed at $9.4 \mathrm{~T}$ on a Chemagnetics Infinity 400 spectrometer equipped with a 5-mm MAS probe operated at $400.0 \mathrm{MHz}\left({ }^{1} \mathrm{H}\right)$ and 79.4 $\mathrm{MHz}\left({ }^{29} \mathrm{Si}\right)$, and at $14.1 \mathrm{~T}$ on a Varian NMR System 600 spectrometer equipped with a 1.6-mm FastMAS ${ }^{\mathrm{TM}}$ probe operated at $599.6 \mathrm{MHz}\left({ }^{1} \mathrm{H}\right)$ and $150.8 \mathrm{MHz}\left({ }^{13} \mathrm{C}\right)$. Experimental parameters are given below using the following symbols: $v_{R}$ denotes the MAS rate, $v_{\mathrm{RF}}(\mathrm{X})$ the magnitude of radiofrequency magnetic field (RF) applied to $\mathrm{X}$ spins, $\tau_{\mathrm{CP}}$ the mixing time during cross polarization, $\mathrm{N}_{\mathrm{CPMG}}$ the number of $\mathrm{CPMG}$ echoes, $\tau_{\mathrm{RD}}$ the recycle delay, NS the number of scans, and AT the total acquisition time.

$$
\begin{aligned}
& { }^{29} \mathrm{Si} \text { DPMAS with CPMG: } v_{\mathrm{R}}=10 \mathrm{kHz}, v_{\mathrm{RF}}\left({ }^{29} \mathrm{Si}\right)=50 \mathrm{kHz}, v_{\mathrm{RF}}\left({ }^{1} \mathrm{H}\right)=45 \mathrm{kHz}, \mathrm{N}_{\mathrm{CPMG}} \\
& =10, \tau_{\mathrm{RD}}=300 \mathrm{~s}, \mathrm{NS}=296 \text {, and AT }=25 \mathrm{~h} . \\
& { }^{13} \mathrm{C} \text { CPMAS: } v_{\mathrm{R}}=40 \mathrm{kHz}, v_{\mathrm{RF}}\left({ }^{13} \mathrm{C}\right)=140 \mathrm{kHz}, v_{\mathrm{RF}}\left({ }^{1} \mathrm{H}\right) \text { during } \mathrm{CP}=60 \mathrm{kHz}, v_{\mathrm{RF}}\left({ }^{1} \mathrm{H}\right)
\end{aligned}
$$
during SPINAL-64 decoupling $=12 \mathrm{kHz}, \tau_{\mathrm{CP}}=3 \mathrm{~ms}, \tau_{\mathrm{RD}}=2 \mathrm{~s}, \mathrm{NS}=26,400$, and AT $=$ $15 \mathrm{hrs}$. 
The chemical shifts of ${ }^{29} \mathrm{Si},{ }^{13} \mathrm{C}$ and ${ }^{1} \mathrm{H}$ are reported using the $\delta$ scale and are referenced to tetramethylsilane (TMS) at $0 \mathrm{ppm}$.

\section{Results and Discussion}

\subsection{Catalytic Activity of Homogeneous and Heterogeneous Propylamine}

To set a reference, we measured the activity of propylamine as a homogenous catalyst for the cross-aldol condensation between $p$-nitrobenzaldehyde $\mathbf{1}$ and acetone at $60{ }^{\circ} \mathrm{C}$ in hexane (Scheme 1). Catalytic activity was determined by measuring the formation of the aldol $\mathbf{2}$ and the $\alpha, \beta$-unsaturated carbonyl $\mathbf{3}$ products. Consistent with the report by Davis and co-workers, homogenous propylamine displayed poor activity with only $4.5 \%$ conversion after 2 h.[25] Interestingly, while Davis observed a fourfold increase in yield upon supporting the amine on mesoporous silica,[25] the activity of our 3-aminopropyl-mesoporous silica nanoparticle catalyst with $2.8 \mathrm{~nm}$ pores (APMSN-2.8) was even lower than that of the homogeneous amine, giving only $2 \%$ conversion after $2 \mathrm{~h}$.

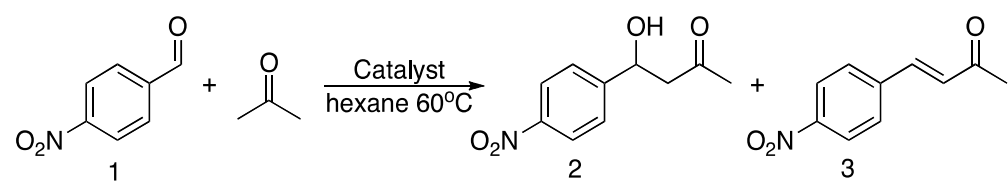

Scheme 1. Cross-aldol condensation between $p$-nitrobenzaldehyde $\mathbf{1}$ and acetone.

Considering that the pores of AP-MSN-2.8 were smaller than those previously used $(6.3 \mathrm{~nm}),[25,39]$ we examined the activity of an AP-MSN-3.6 catalyst (with 3.6 nm wide pores). Remarkably, we found that this small increase in pore size, from 2.8 $\mathrm{nm}$ to $3.6 \mathrm{~nm}$, led to a 20 -fold increase in activity: the $2 \mathrm{~h}$ yield rose from $2 \%$ to $47 \%$. The apparent pseudo first order rate constant of AP-MSN-3.6 $\left(k=3.7 \times 10^{-1} \mathrm{~h}^{-1}\right)$ was two orders of magnitude larger than that of the homogeneous propylamine $(k=2.6 \mathrm{x}$ $\left.10^{-3} \mathrm{~h}^{-1}\right)$. This large change in activity suggested that the rate of the reaction was limited 
by the molecular diffusion within the narrower pores. However, the longest dimensions of the reactants and products $(0.4 \mathrm{~nm}$ for acetone, $0.6 \mathrm{~nm}$ for $\mathbf{1}$, and $1 \mathrm{~nm}$ for $\mathbf{2}$ or $\mathbf{3})$ were small compared to the pore diameters of AP-MSN-2.8 and AP-MSN-3.6. Therefore, diffusion could not be the only factor limiting the catalytic activity.

When comparing the properties of AP-MSN-2.8 before and after the reaction, we discovered that despite the surface area of the material remaining relatively constant ( $906 \mathrm{~m}^{2} / \mathrm{g}$ before and $894 \mathrm{~m}^{2} / \mathrm{g}$ after the reaction), the pore size decreased significantly to $2.0 \mathrm{~nm}$. In addition, we observed an inhibition of the reaction kinetics at high concentrations of substrate 1 (Figure 1). The Lineweaver-Burk plot of the data obtained at concentrations lower than $100 \mathrm{mM}$ gave a Michaelis-Menten constant $\left(\mathrm{K}_{\mathrm{M}}\right)$ of 273 and a maximal rate $\left(\mathrm{V}_{\max }\right)$ of $0.594 \mathrm{mmol} \mathrm{h}^{-1}\left(\mathrm{r}^{2}=0.9992\right)$ (Figure S3). These estimates are clearly larger than the experimental values, and therefore indicate a strong substrate inhibition. $[27,40]$ These results suggested that the catalytic sites of the material could be blocked by the formation of a stable Schiff base, which has been reported to inhibit the aldol condensation by catalytic antibodies (Scheme 2).[41, 42]

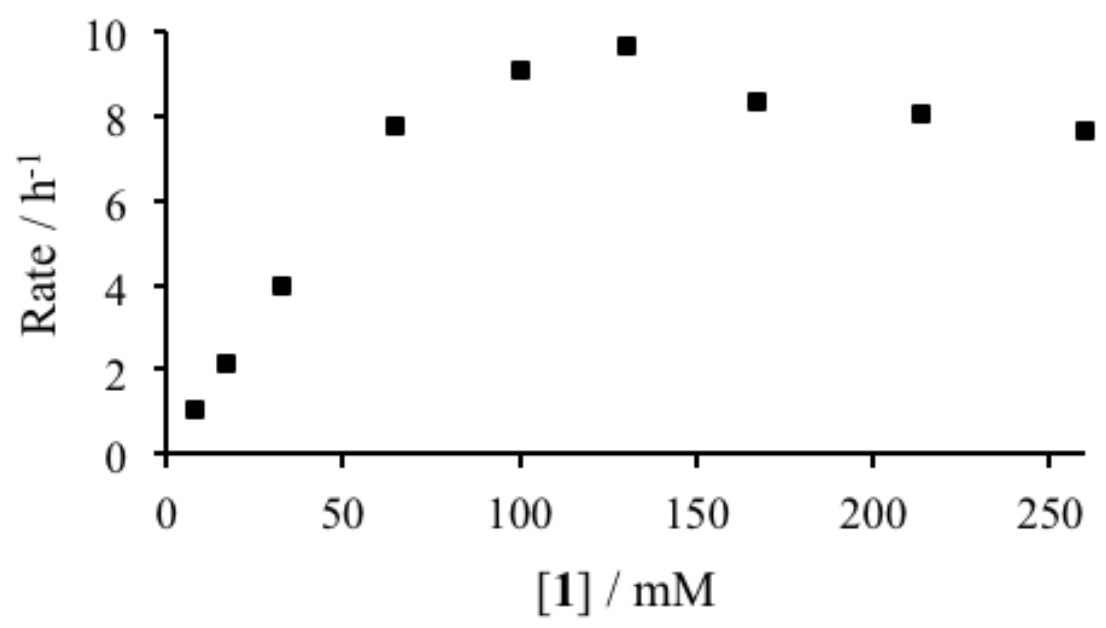

Figure 1. Effect of substrate concentration on the rate of AP-MSN-3.6 catalyzed crossaldol condensation. The drop in rate at high concentrations of 1 suggests substrate inhibition of the reaction. 


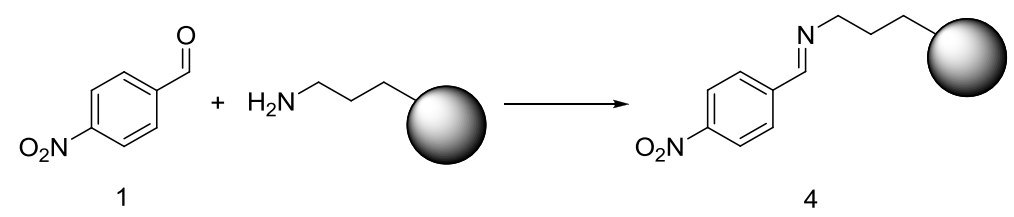

Scheme 2. Formation of a Schiff base between p-nitrobenzaldehyde substrate $\mathbf{1}$ and the aminopropyl group of AP-MSN.

\subsection{Detection of Inhibition Intermediate}

Although it has been suggested that an imine could form during the aldol condensation catalyzed by AP-MSN, no direct evidence has been provided for its existence.[23] When comparing the infrared and NMR spectra of AP-MSN-2.8 before and after the reaction we confirmed the formation of imine intermediate $\mathbf{4}$, which was stable even after washing and drying the material. While the $\mathrm{C}-\mathrm{C}$ stretching $e 2 g$ band $\left(1606 \mathrm{~cm}^{-1}\right)$ and the symmetric and asymmetric stretching bands of $-\mathrm{NO}_{2}\left(1345 \mathrm{~cm}^{-1}\right.$, $1537 \mathrm{~cm}^{-1}$ ) of 1 could be clearly identified in AP-MSN-2.8 following the reaction, the stretching frequency of $\mathrm{C}=\mathrm{O}\left(1706 \mathrm{~cm}^{-1}\right)$ was no longer visible, but was replaced with a signal at $1646 \mathrm{~cm}^{-1}$ corresponding to the $\mathrm{C}=\mathrm{N}$ stretching of the imine (Figure 2a). Solid-state ${ }^{13} \mathrm{C}$ NMR spectroscopy unambiguously confirmed the formation of $\mathbf{4}$ (Figure 2b). The resonance of carbon 'c' in AP-MSN-2.8 decreased considerably after the reaction, giving rise to a resonance at $160 \mathrm{ppm}$ corresponding to the $\mathrm{C}=\mathrm{N}$ carbon ('d') in 4, whereas no signal due to the carbonyl carbon of $\mathbf{1}$ (190 ppm) was observable. A strong downfield shift of the resonance of C-3 in AP-MSN (resonance 'c' shifting to 'c*') was also observed after the reaction with $\mathbf{1}$ (Figure $2 \mathrm{~b}$ ). This suggested a chemical transformation of the aminopropyl group rather than a mere physisorption of 1 to the surface of the particles. A fraction of unreacted aminopropyl was still visible in the sample as shown by resonance 'c' in the used catalyst. Comparison of nitrogen content of the material before and after the reaction by elemental analysis revealed that approximately $70 \%$ of amine groups formed the imine. Although the ${ }^{13} \mathrm{C}$ CPMAS 
spectra in Figure $2 b$ are not strictly quantitative, the intensity ratio of resonances ' $c$ ", and ' $\mathrm{c}$ ' is in approximate agreement with the elemental analysis.

Treatment of the poisoned AP-MSN catalyst with $0.01 \mathrm{M} \mathrm{HCl}$ for $24 \mathrm{~h}$ at room temperature led to hydrolysis of the Schiff base, as evidenced by disappearance of the signals of $\mathbf{4}$ in the infrared and NMR spectra of the treated material. The regeneration of AP-MSN catalyst was also confirmed by elemental analysis: the number of mmol of nitrogen per gram of material varied from 1.0 before reaction to 1.7 after formation of $\mathbf{4}$, to 1.16 after treatment with dilute acid.

The relatively large size of the Schiff base 4 (about $1 \mathrm{~nm}$ ) explained the reduction in the pore size of AP-MSN by $0.8 \mathrm{~nm}$, as well as the dramatic effect of the small increase in pore size on the reaction yield. The inhibition at high concentrations of $\mathbf{1}$ suggested the mechanism of the reaction is unlikely Mannich type, but should involve either enamine or enolate intermediates. 

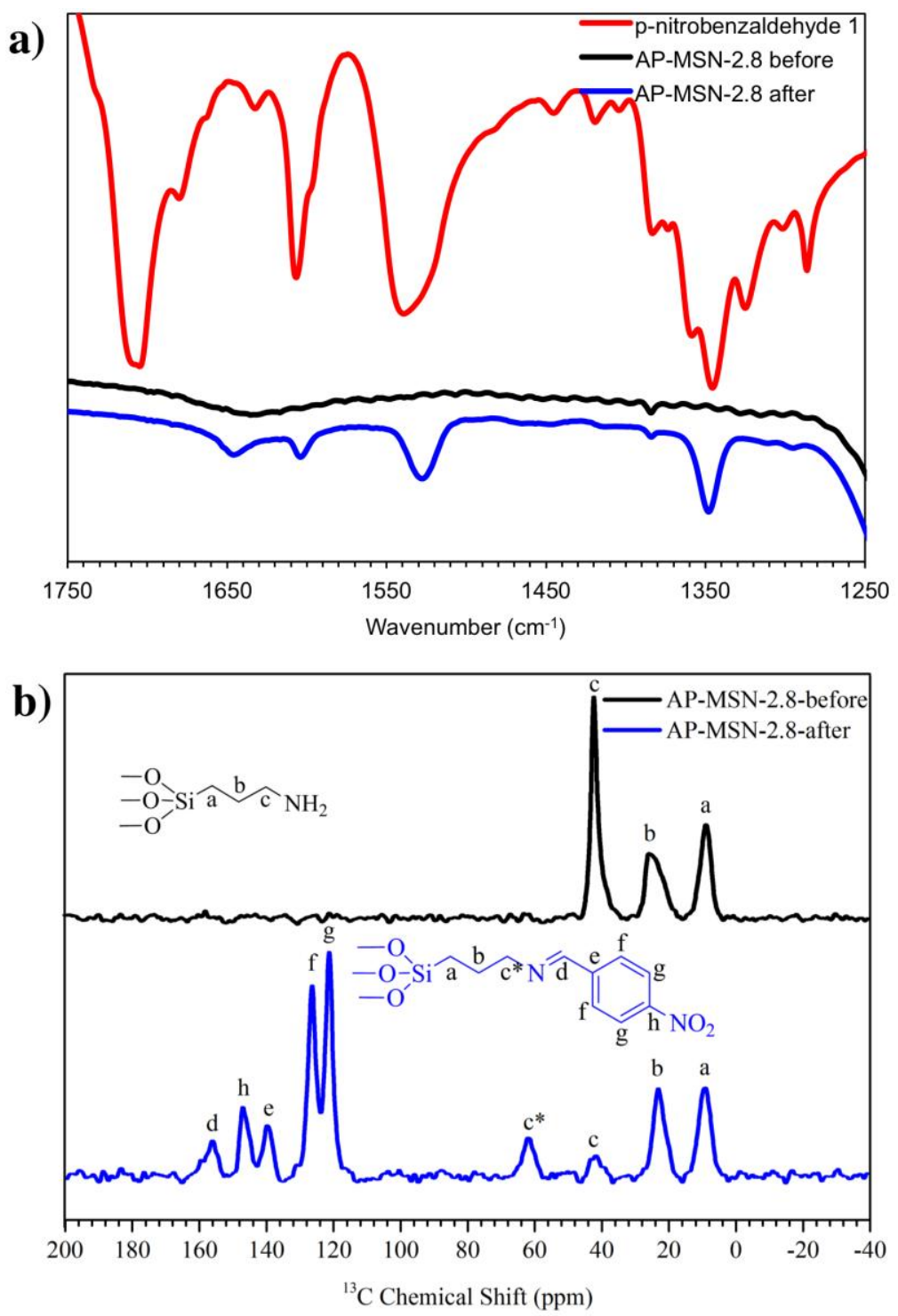

Figure 2. Infrared (a) and ${ }^{13} \mathrm{C}$ CPMAS NMR (b) spectra of AP-MSN-2.8 before (black) and after (blue) reaction with $\mathbf{1}$. Infrared spectrum of $\mathbf{1}$ (red) is included as a reference.

\subsection{Structural Modification of the Catalytic Group}

Based on the hypothesis that the low activity of AP-MSN was caused by the formation of a stable Schiff base, we functionalized the MSNs with a secondary amine, which is unable to form imines. Two catalysts containing 3-(N-methylamino)propyl (MAP) with different pore sizes were prepared (MAP-MSN-2.6 and MAP-MSN-3.5) and tested for the reaction. As expected, no imine was detected by infrared and NMR analyses of MAP-MSNs after the reaction. Remarkably, even the narrow-pore MAP- 
MSN-2.6 doubled the activity of the wide-pore AP-MSN-3.6, yielding 93\% conversion after $2 \mathrm{~h}$. Also, no inhibition of reaction kinetics was observed at high concentrations of 1 (Figure S4). The conversion using MAP-MSN-3.5 was further elevated to $97 \%$. These results suggested that imine formation with AP-MSN catalysts lowered the activity by blocking diffusion and by reducing the number of active sites.

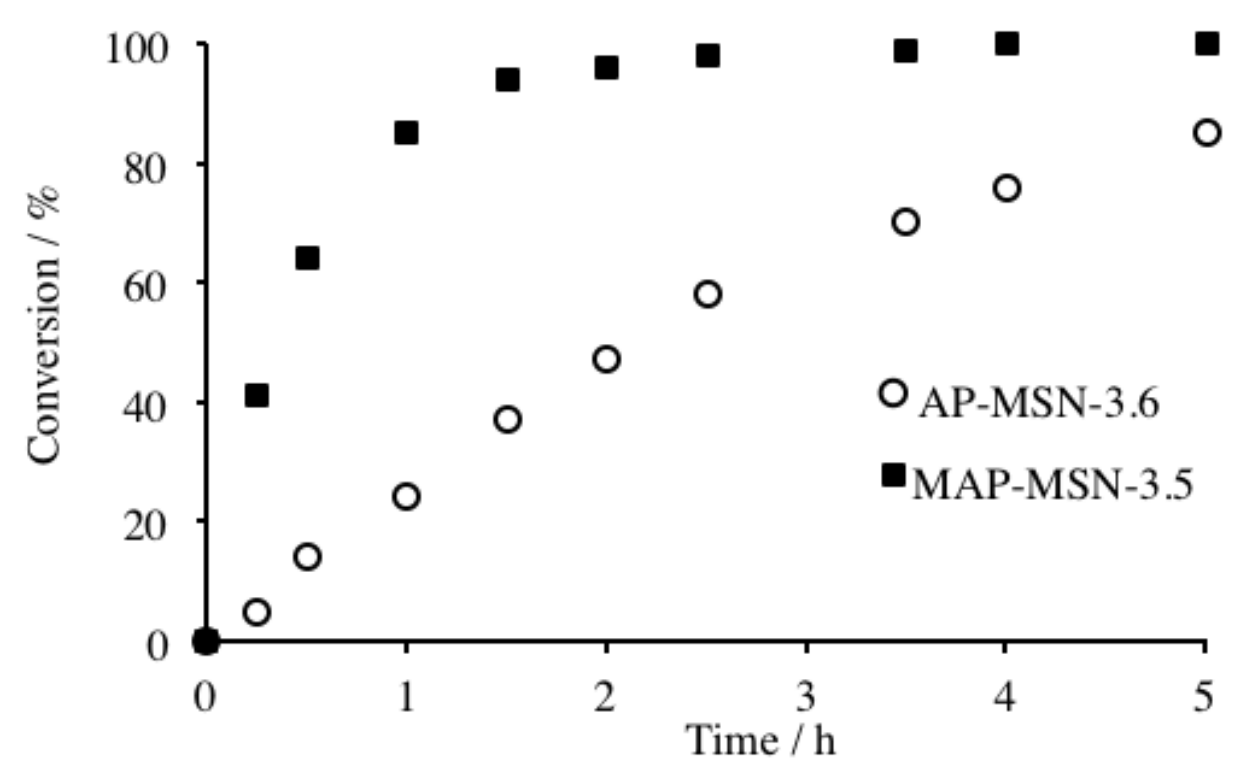

Figure 3. Kinetics of aldol condensation between 1 and acetone catalyzed by APMSN-3.6 and MAP-MSN-3.5 in hexane at $60^{\circ} \mathrm{C}$ with $3 \mathrm{~mol} \%$ catalyst.

We also noted that the apparent rate constant of MAP-MSN-3.5 $\left(k=1.35 \mathrm{~h}^{-1}\right)$ was over three times larger than that of AP-MSN-3.6 $\left(k=0.37 \mathrm{~h}^{-1}\right)$ (Figures 3 and S5). We considered the possibility that the increase in catalytic activity could be due to MAPMSN being more nucleophilic or basic than AP-MSN. This could imply a mechanism involving enolates rather than enamines. Although unlikely, due to the high $\mathrm{pK}_{\mathrm{b}}$ of amines, we tested this hypothesis by preparing a new material functionalized with a tertiary amine. The material containing 3-(N,N-dimethylamino)propyl group (DMAPMSN-3.2), failed to catalyze the reaction, proving that the conversion is not promoted by simple deprotonation. It must be pointed out that, being a tertiary amine, DMAP 
cannot form an enamine, which is consistent with the reaction proceeding through an enamine pathway.

We finally noted that the MAP-MSN catalysts are significantly more active than the previously reported amphoteric bifunctional catalysts, giving higher conversion in only $2 \mathrm{~h}$ than the bifunctional catalysts gave over $20 \mathrm{~h}$ of reaction.[25, 39, 43]

\subsection{Cooperative Effects of the Support}

Having established the role of the catalytic groups, we focused on the role of the support. As in the case of AP-MSN-3.6, the activity of the heterogeneous MAP-MSN3.5 catalyst $\left(k=1.35 \mathrm{~h}^{-1}\right)$ is much higher than that of the corresponding homogeneous catalyst $\mathrm{N}$-methyl-propylamine $\left(k=0.056 \mathrm{~h}^{-1}\right)$ (Figure S5). These unusual results contradict the general observation that homogeneous catalysis is much faster than heterogeneous catalysis,[44] and suggest that the support plays an active role in the reaction mechanism. Indeed, the weakly acidic silanol groups on the surface of silica have been previously recognized as capable of assisting various reactions.[23, 45-49]

To test the participation of silanol groups in the catalytic process, we treated MAPMSN-3.5 with hexamethyldisilazane (HMDS). ${ }^{29} \mathrm{Si}$ NMR showed that this reduced the number of silanols by $39 \%$ (from 3.8 to $2.3 \mathrm{mmol} / \mathrm{g}$, Figure 4 ). When using this passivated catalyst the yield of the reaction dropped by $34 \%$ (from the original $97 \%$ to $63 \%$ ). Furthermore, addition of non-functionalized MSN to homogeneous N-methylpropylamine increased the conversion to $51 \%$ compared to the $10 \%$ yield observed when using only the homogeneous catalyst (Figure 5). These results confirm not only that the silanol groups play an active role in the catalytic process, but also that their proximity to the amine sites is beneficial, which suggests a cooperativity between both groups. 


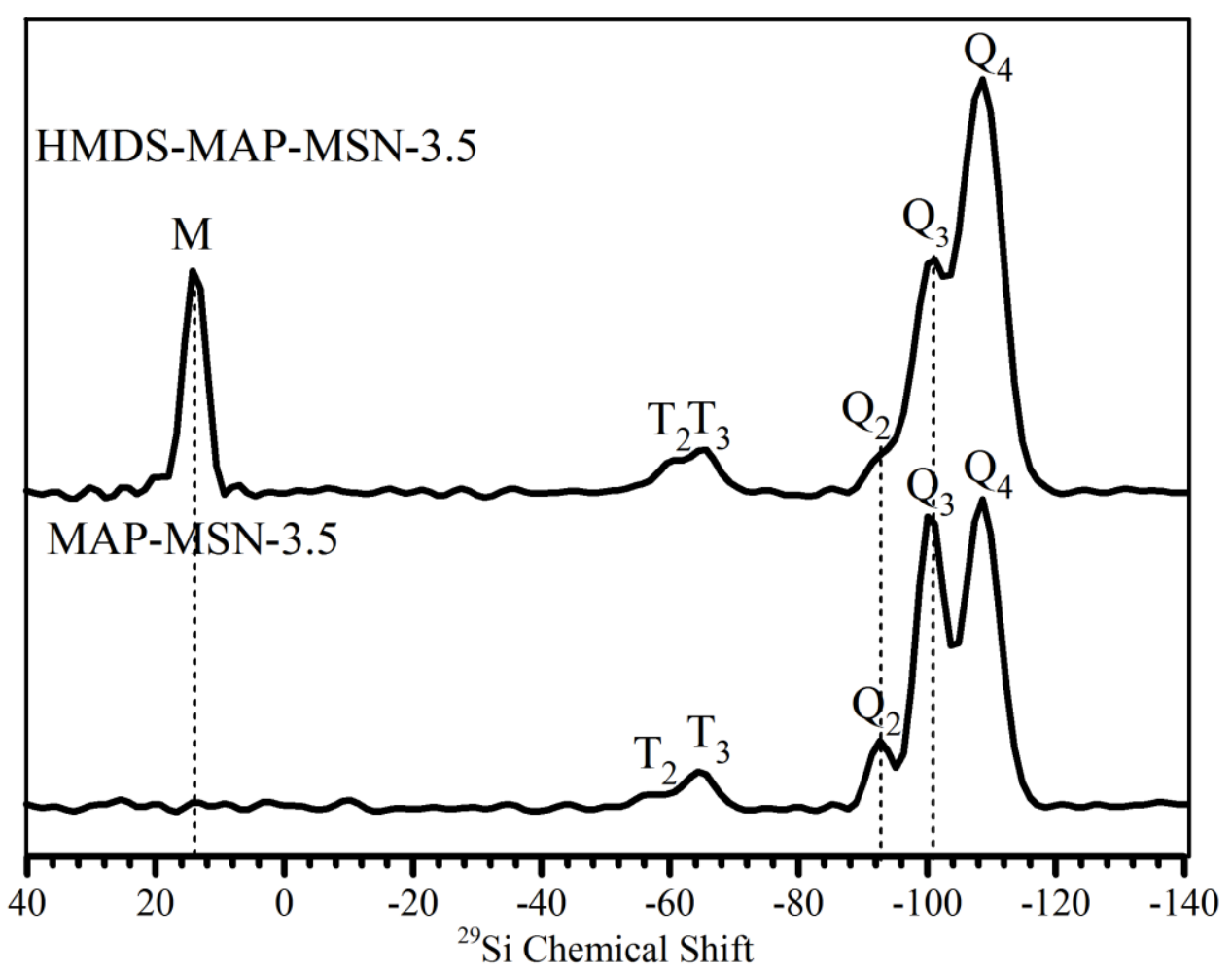

Figure 4. ${ }^{29} \mathrm{Si}$ DPMAS spectra of MAP-MSN-3.5 before (bottom) and after (top) blocking silanol groups with HMDS. Appearance of $\mathrm{M}$ sites due to the attached silane matches the conversion of the $\mathrm{Q}_{2}$ and $\mathrm{Q}_{3}$ sites of the blocked groups to $\mathrm{Q}_{3}$ and $\mathrm{Q}_{4}$, respectively.[50]

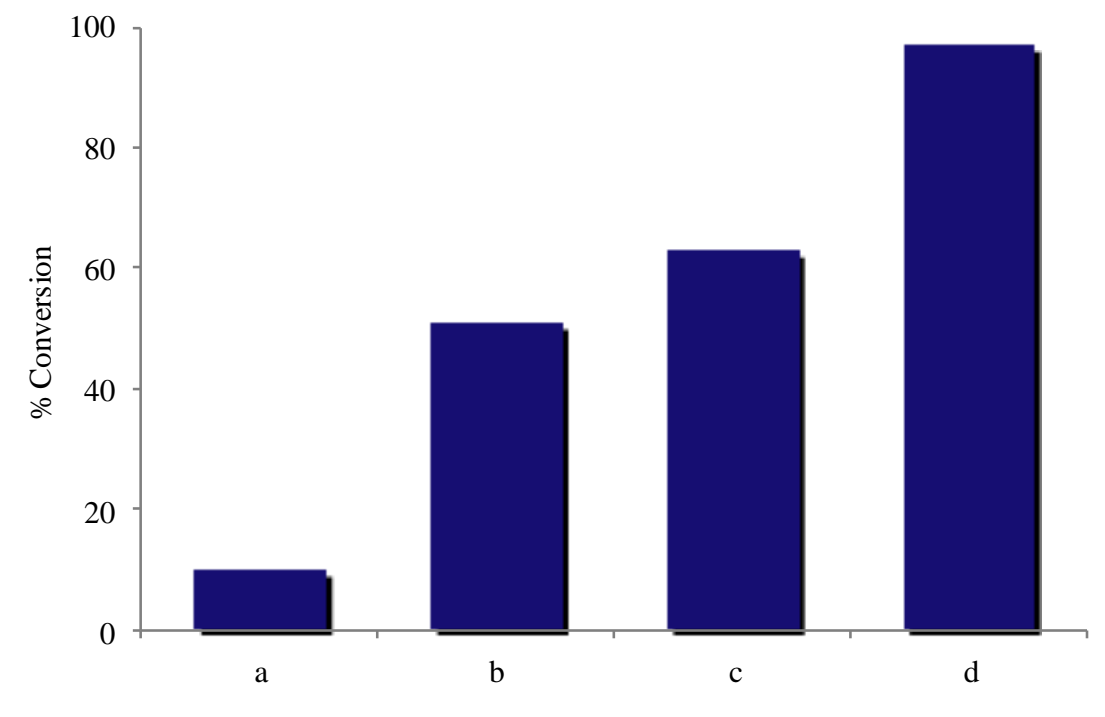

Figure 5. Effect of proximity between silanol and amine groups on the conversion of $p$ nitrobenzaldehyde. Catalytic activities are compared for: (a) homogeneous N-methylpropylamine, (b) homogeneous N-methyl-propylamine + heterogeneous MSN, (c) silanol-passivated HMDS-MAP-MSN-3.5, and (d) heterogeneous MAP-MSN-3.5. 
The role of silanols in the reaction can be explained by the fact that carbonyl compounds adsorb on the surface of silica via hydrogen bonding.[26, 51-56] We confirmed this interaction by measuring NMR spectrum of ${ }^{13} \mathrm{C}$-labeled acetone set in contact with non-functionalized MSN (Figure S6), which exhibited a downfield shift of the carbonyl carbon signal compared to that of neat acetone ( 213 ppm versus 206 ppm). Our earlier solid-state NMR and theoretical studies demonstrated that surface silanols on silica also interact with the amine functionalities.[57] These findings suggest that silanol groups play a key role in bringing all reactants and the catalytic group together for the reaction to take place. In contrast, the probability of bringing acetone, the aldehyde and the amine catalyst together is dramatically decreased in the homogeneous medium. Similarly, the probability of encounter must be lower if the amine is not covalently attached to the silica support. This explains the observed activity trend: homogeneous MAP $<$ MAP + MSN $<$ MAP-MSN (Figure 5). In addition, when introducing DMSO (hydrogen bond-acceptor, $\alpha=0.00, \beta=0.76$ ) $[23,58]$ to the reaction, we observed a significant drop in the conversion catalyzed by MAP-MSN-3.5, from $97 \%$ to $55 \%$. This drop can be attributed to the competition of DMSO with the reactants for hydrogen-binding the silanol groups.

The formation of hydrogen bonds between silanols and carbonyls may also contribute to the activation of the latter for nucleophilic attack by the amine, and may assist in the formation of the reaction intermediate by facilitating the departure of carbonyl oxygen as water (Scheme 3). The formation of the intermediate enamine involves a series of proton transfers, which may be difficult to achieve in a non-polar medium. The mildly acidic silanol groups could assist these transfers by aligning with acetone and amine groups in six-membered ring-like arrangements, as in the Zimmerman-Traxler model (Scheme 3). [59, 60] For these intermediates to form, the 
silanol groups should be as close as 5 to $6 \AA$ from each other. As mentioned earlier, ${ }^{29} \mathrm{Si}$ NMR spectroscopy of MAP-MSN revealed a silanol content of $3.8 \mathrm{mmol} / \mathrm{g}$ (Figure 4), which at a surface area of $937 \mathrm{~m}^{2} / \mathrm{g}$ gives a silanol density of 2.4 groups $/ \mathrm{nm}^{2}$. This density satisfies the inter-silanol distance required for the cyclic model. A third silanol group could also be closely located to this intermediate, providing a site for hydrogen bonding of $\mathbf{1}$, to complete the reaction by a similar proton transfer process.

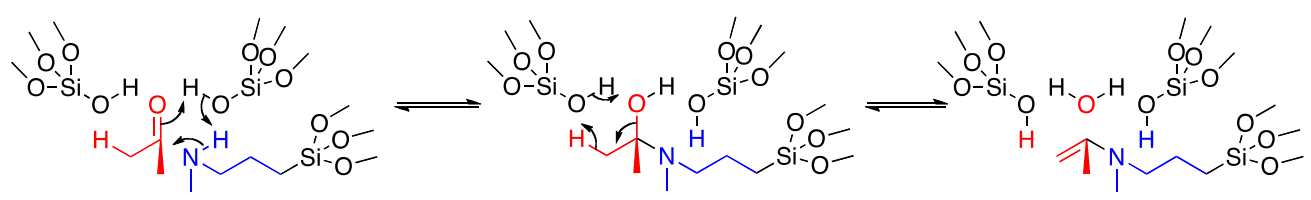

Scheme 3. Possible pathway of proton transfer assisted by silanol groups.

We also observed that the immobilization on silica led to a larger increase in the activity of the primary amine than the secondary amine $\left(k_{\text {het }} / k_{\text {homo AP }}=142, k_{\text {het }} / k_{\text {homo }}\right.$ MAP $=23$ ). This significant difference suggests that silanol groups may play yet another role in the catalysis. As mentioned above, the low catalytic activity of propylamine and AP-MSNs is attributed to the formation of a stable imine. Since imine hydrolysis is catalyzed by acids,[61] it is likely that the weakly acidic silanols assist the hydrolysis of a fraction of the imines, thus giving an additional advantage to AP-MSN compared to homogeneous propylamine. This would also explain, in part, the enhanced activity observed upon co-functionalization of aminopropyl mesoporous silica with acidic groups, as previously reported by Davis and Solin.[25-27]

\section{Conclusions}

In conclusion, the poor catalytic activity of aminopropyl functionalized mesoporous silica for the aldol condensation arises from a substrate inhibition. This 
inhibition takes place by formation of a stable Schiff base, which not only eliminates active sites but also blocks diffusion in pores $2.8 \mathrm{~nm}$ or smaller. This inhibition can be partially reduced by increasing the pore size of the support, or eliminated by modifying the structure of the amine from primary to secondary.

The silanol groups in the support assist the catalytic activity of immobilized amines by offering binding sites for the reactants in close proximity to the amines, providing pathways for proton transfer throughout all the steps of the reaction, and facilitating the departure of water during the formation of intermediates. This cooperation between the silica support and the amines dramatically improves the activity of the heterogeneous catalysts in comparison to the homogeneous catalysts in solution.

In summary, we have shown that heterogeneous organocatalysts are not only amenable to conventional mechanistic studies, but that the understanding achieved through these type of studies can guide their rational design to significantly improve their activity.

\section{Acknowledgements}

This research is supported by the U.S. Department of Energy, Office of Basic Energy Sciences, Division of Chemical Sciences, Geosciences, and Biosciences through the Ames Laboratory. The Ames Laboratory is operated for the U.S. Department of Energy by Iowa State University under Contract No. DE-AC02-07CH11358.

\section{References}

[1] B. Cornils, W.A. Herrmann, J. Catal., 216 (2003) 23.

[2] F. Rodríguez-Reinoso, Carbon, 36 (1998) 159. 
[3] X. Yu, X. Yu, S. Wu, B. Liu, H. Liu, J. Guan, Q. Kan, J. Solid State Chem., 184 (2011) 289.

[4] C.M.A. Parlett, D.W. Bruce, N.S. Hondow, A.F. Lee, K. Wilson, ACS Catal., (2011) 636.

[5] J.N. Stuecker, J.E. Miller, R.E. Ferrizz, J.E. Mudd, J. Cesarano, Ind. Eng. Chem. Res., 43 (2003) 51.

[6] A. Corma, H. Garcia, Top. Catal., 48 (2008) 8.

[7] H. Hattori, Chem. Rev., 95 (1995) 537.

[8] K.K. Rao, M. Gravelle, J.S. Valente, F. Figueras, J. Catal., 173 (1998) 115.

[9] H. Matsuhashi, H. Miyazaki, Y. Kawamura, H. Nakamura, K. Arata, Chem. Mater., 13 (2001) 3038.

[10] D. Tichit, B. Coq, S. Cerneaux, R. Durand, Catal. Today, 75 (2002) 197.

[11] T.R. Gaydhankar, P.N. Joshi, P. Kalita, R. Kumar, J. Mol. Catal. A: Chem., 265 (2007) 306.

[12] F. Tanaka, R. Fuller, H. Shim, R.A. Lerner, C.F. Barbas III, J. Mol. Biol., 335 (2004) 1007.

[13] F. Tanaka, R. Fuller, C.F. Barbas III, Biochem., 44 (2005) 7583.

[14] M. Chatterjee, K. Matsushima, Y. Ikushima, M. Sato, T. Yokoyama, H. Kawanami, T. Suzuki, Green Chem., 12 (2010) 779.

[15] S. Mukherjee, J.W. Yang, S. Hoffmann, B. List, Chem. Rev., 107 (2007) 5471.

[16] B. List, R.A. Lerner, C.F. Barbas III, J. Am. Chem. Soc., 122 (2000) 2395.

[17] S.M. Dean, W.A. Greenberg, C.-H. Wong, Adv. Synth. Catal., 349 (2007) 1308.

[18] Sujandi, S.-E. Park, D.-S. Han, S.-C. Han, M.-J. Jin, T. Ohsuna, Chem. Commun., (2006) 4131.

[19] S. Luo, J. Li, L. Zhang, H. Xu, J.-P. Cheng, Chem. Eur. J., 14 (2008) 1273. 
[20] S. Luo, X. Zheng, J.-P. Cheng, Chem. Commun., (2008) 5719.

[21] T.M. Suzuki, M. Yamamoto, K. Fukumoto, Y. Akimoto, K. Yano, J. Catal., 251 (2007) 249.

[22] K.K. Sharma, T. Asefa, Angew. Chem., 119 (2007) 2937.

[23] S. Shylesh, A. Wagner, A. Seifert, S. Ernst, W.R. Thiel, Chem. Eur. J., 15 (2009) 7052.

[24] B. Liu, S. Wu, X. Yu, J. Guan, Q. Kan, J. Coll. Interface Sci., 362 (2011) 625.

[25] R.K. Zeidan, S.-J. Hwang, M.E. Davis, Angew. Chem. Int. Ed., 45 (2006) 6332.

[26] M. Wiesner, G.g. Upert, G. Angelici, H. Wennemers, J. Am. Chem. Soc., 132 (2009) 6.

[27] D.E. Purich, Enzyme Kinetics: Catalysis and Control, Elsevier, 2002.

[28] J. Alauzun, A. Mehdi, C. Reye, R.J.P. Corriu, J. Am. Chem. Soc., 128 (2006) 8718.

[29] B.M. Choudary, M.L. Kantam, P. Sreekanth, T. Bandopadhyay, F. Figueras, A.

Tuel, J. Mol. Catal. A: Chem., 142 (1999) 361.

[30] X. Wang, K.S.K. Lin, J.C.C. Chan, S. Cheng, Chem. Commun., (2004) 2762.

[31] J. Mondal, A. Modak, A. Bhaumik, J. Mol. Catal. A: Chem., 335 (2011) 236.

[32] A. Anan, K.K. Sharma, T. Asefa, J. Mol. Catal. A: Chem., 288 (2008) 1.

[33] S. Huh, J.W. Wiench, J.-C. Yoo, M. Pruski, V.S.-Y. Lin, Chem. Mater., 15 (2003) 4247.

[34] I.I. Slowing, B.G. Trewyn, V.S.-Y. Lin, J. Am. Chem. Soc., 129 (2007) 8845.

[35] H. Yang, G. Zhang, X. Hong, Y. Zhu, Microporous Mesoporous Mat., 68 (2004) 119.

[36] D.J. Kim, B.C. Dunn, P. Cole, G. Turpin, R.D. Ernst, R.J. Pugmire, M. Kang, J.M. Kim, E.M. Eyring, Chem. Commun., (2005) 1462.

[37] S. Meiboom, D. Gill, Rev. Sci. Instrum., 29 (1958) 688. 
[38] J.W. Wiench, V.S.-Y. Lin, M. Pruski, J. Magn. Reson., 193 (2008) 233.

[39] R.K. Zeidan, M.E. Davis, J. Catal., 247 (2007) 379.

[40] K.B. Taylor, Enzyme kinetics and mechanisms, Kluwer Academic, 2002.

[41] J. Wagner, R.A. Lerner, C.F. Barbas III, Science, 270 (1995) 1797.

[42] T. Hoffmann, G. Zhong, B. List, D. Shabat, J. Anderson, S. Gramatikova, R.A. Lerner, C.F. Barbas III, J. Am. Chem. Soc., 120 (1998) 2768.

[43] N. Solin, L. Han, S. Che, O. Terasaki, Catal. Commun., 10 (2009) 1386.

[44] D.J. Cole-Hamilton, Science, 299 (2003) 1702.

[45] J.D. Bass, A. Solovyov, A.J. Pascall, A. Katz, J. Am. Chem. Soc., 128 (2006) 3737.

[46] S. Huh, H.-T. Chen, J.W. Wiench, M. Pruski, V.S.-Y. Lin, Angew. Chem. Int. Ed., $44(2005) 1826$.

[47] L. Forni, G. Fornasari, G. Giordano, C. Lucarelli, A. Katovic, F. Trifiro, C. Perri, J.B. Nagy, Phys. Chem. Chem. Phys., 6 (2004) 1842.

[48] L. Forni, G. Fornasari, G. Giordano, C. Lucarelli, A. Katovic, F. Triflrò, C. Perri, J.B. Nagy, Effect of exchange procedure and crystal size on high silica MFI zeolite as catalyst for vapor phase Beckmann rearrangement, in: M.C. E. van Steen, L.H.

Callanan (Eds.) Stud. Surf. Sci. Catal., Elsevier, 2004, 2823.

[49] L.-P.B. Beaulieu, L.B. Delvos, A.B. Charette, Org. Lett., 12 (2010) 1348.

[50] D.W. Sindorf, G.E. Maciel, Journal of Physical Chemistry, 87 (1983) 5516.

[51] V.H. Pan, T. Tao, J.-W. Zhou, G.E. Maciel, J. Phys. Chem. B, 103 (1999) 6930.

[52] M.I. Zaki, M.A. Hasan, F.A. Al-Sagheer, L. Pasupulety, Langmuir, 16 (1999) 430.

[53] J.H. Drese, A.D. Talley, C.W. Jones, ChemSusChem, 4 (2011) 379.

[54] V.Y. Borovkov, A.V. Zaiko, V.B. Kazansky, W.K. Hall, J. Catal., 75 (1982) 219.

[55] I.D. Gay, J. Phys. Chem., 78 (1974) 38. 
[56] T. Bernstein, D. Michel, H. Pfeifer, P. Fink, J. Coll. Interface Sci., 84 (1981) 310.

[57] S. Nedd, T. Kobayashi, C.-H. Tsai, I.I. Slowing, M. Pruski, M.S. Gordon, J. Phys. Chem. C, 115 (2011) 16333.

[58] M.B. Schmid, K. Zeitler, R.M. Gschwind, J. Am. Chem. Soc., 133 (2011) 7065.

[59] H.E. Zimmerman, M.D. Traxler, J. Am. Chem. Soc., 79 (1957) 1920.

[60] S. Bahmanyar, K.N. Houk, J. Am. Chem. Soc., 123 (2001) 11273.

[61] A.C. Dash, B. Dash, D. Panda, J. Org. Chem., 50 (1985) 2905. 


\section{Supplementary Information}

Table S1. Structural properties of amine-functionalized mesoporous silica nanoparticle catalysts

Amount of organic groups

Elemental $\quad{ }^{29} \mathrm{Si}$ NMR

\begin{tabular}{llllll} 
Catalyst & $\begin{array}{c}\mathrm{S}_{\mathrm{BET}} \\
\left(\mathrm{m}_{2} / \mathrm{g}\right)^{\mathrm{a}}\end{array}$ & $\begin{array}{c}\mathrm{V}_{\mathrm{p}} \\
\left(\mathrm{cm}_{3} / \mathrm{g}\right)^{\mathrm{a}}\end{array}$ & $\begin{array}{c}\mathrm{W}_{\mathrm{BJH}} \\
(\AA)^{\mathrm{a}}\end{array}$ & $\begin{array}{c}\text { analysis } \\
(\mathrm{mmol} / \mathrm{g})\end{array}$ & $\begin{array}{c}\text { evaluation } \\
(\mathrm{mmol} / \mathrm{g})^{\mathrm{b}}\end{array}$ \\
\hline AP-MSN-2.8 & 906 & 1.0 & 2.8 & 1.01 & 1.13 \\
AP-MSN-2.8 after reaction & 894 & 0.76 & 2.0 & 1.70 & \\
AP-MSN-3.6 & 807 & 1.2 & 3.6 & 1.08 & 0.98 \\
MAP-MSN-2.6 & 1008 & 1.1 & 2.6 & 0.50 & 0.54 \\
MAP-MSN-3.5 & 937 & 1.3 & 3.5 & 1.14 & 0.88 \\
HMDS-MAP-MSN-3.5 & 745 & 1.0 & 3.3 & & 1.4 \\
DMAP-MSN & 673 & 0.9 & 3.2 & 1.29 &
\end{tabular}

${ }^{a}$ The BET surface area $\left(S_{\mathrm{BET}}\right)$, the mesopore volume $\left(V_{\mathrm{p}}\right)$, and the mean mesopore widths $\left(W_{\mathrm{BJH}}\right)$ were obtained from the nitrogen sorption analysis. ${ }^{b}$ The amounts of organic functional groups incorporated to the silica materials were determined by elemental analysis and further evaluated from the ${ }^{29} \mathrm{Si}$ DPMAS NMR spectra. 

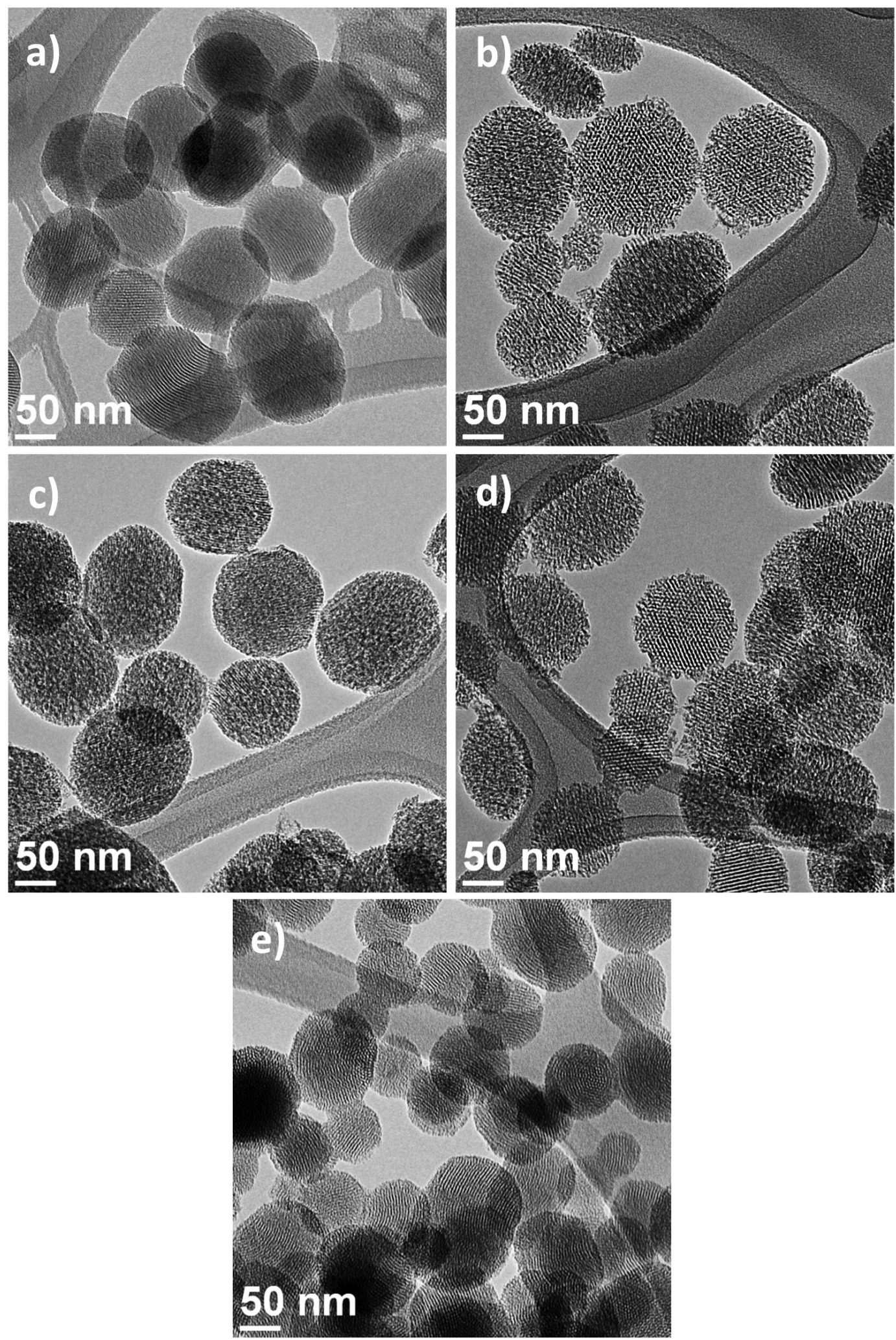

Figure S1. Transmission electron micrographs of (a) AP-MSN-2.8, (b) AP-MSN-3.6, (c) MAP-MSN-2.6, (d) MAP-MSN-3.5 and (e) DMAP-MSN-3.2. 


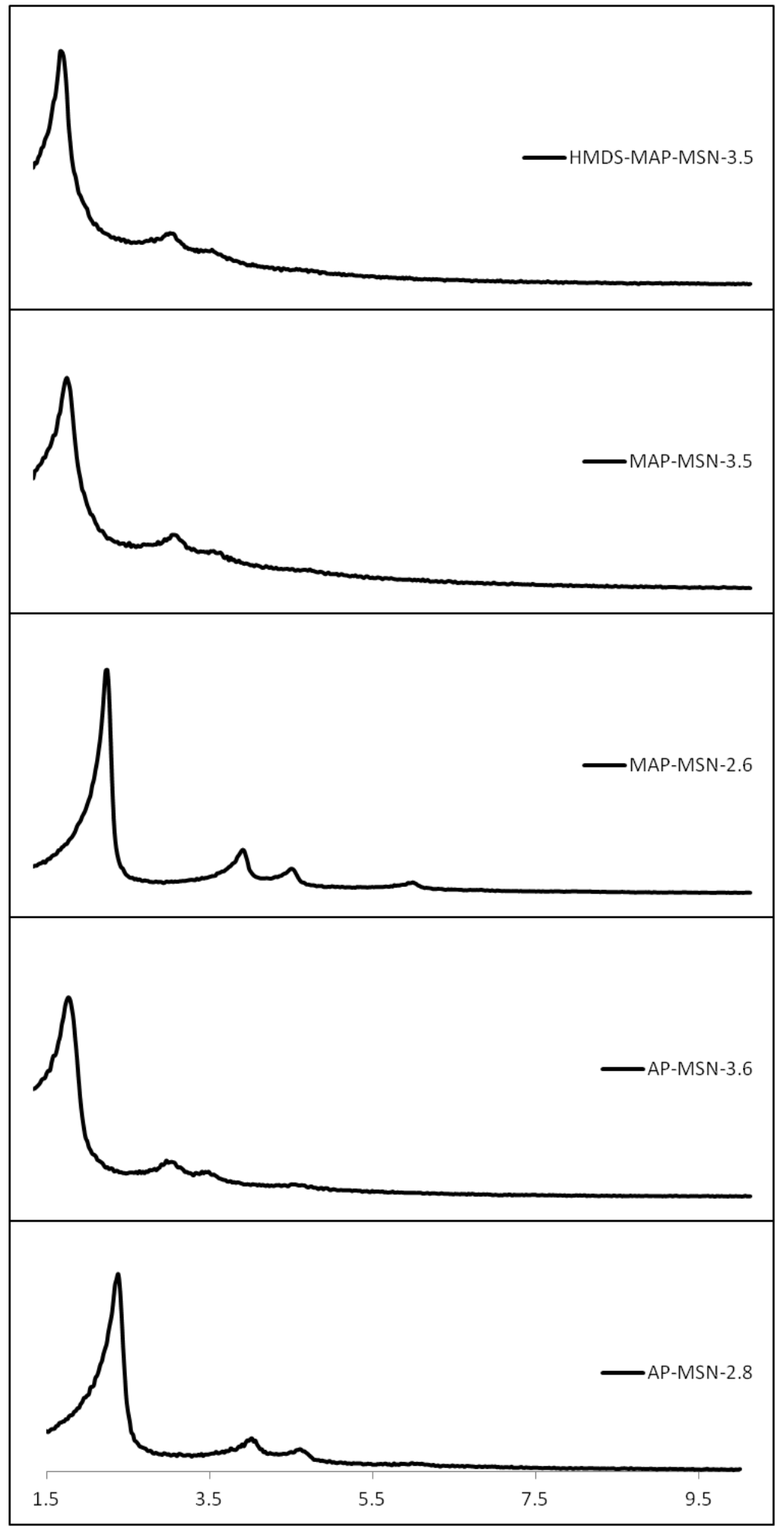

Figure S2. XRD patterns of surfactant-removed AP-MSN-2.8, AP-MSN-3.6, MAPMSN-2.6, MAP-MSN-3.5 and HMDS-MAP-MSN-3.5. 


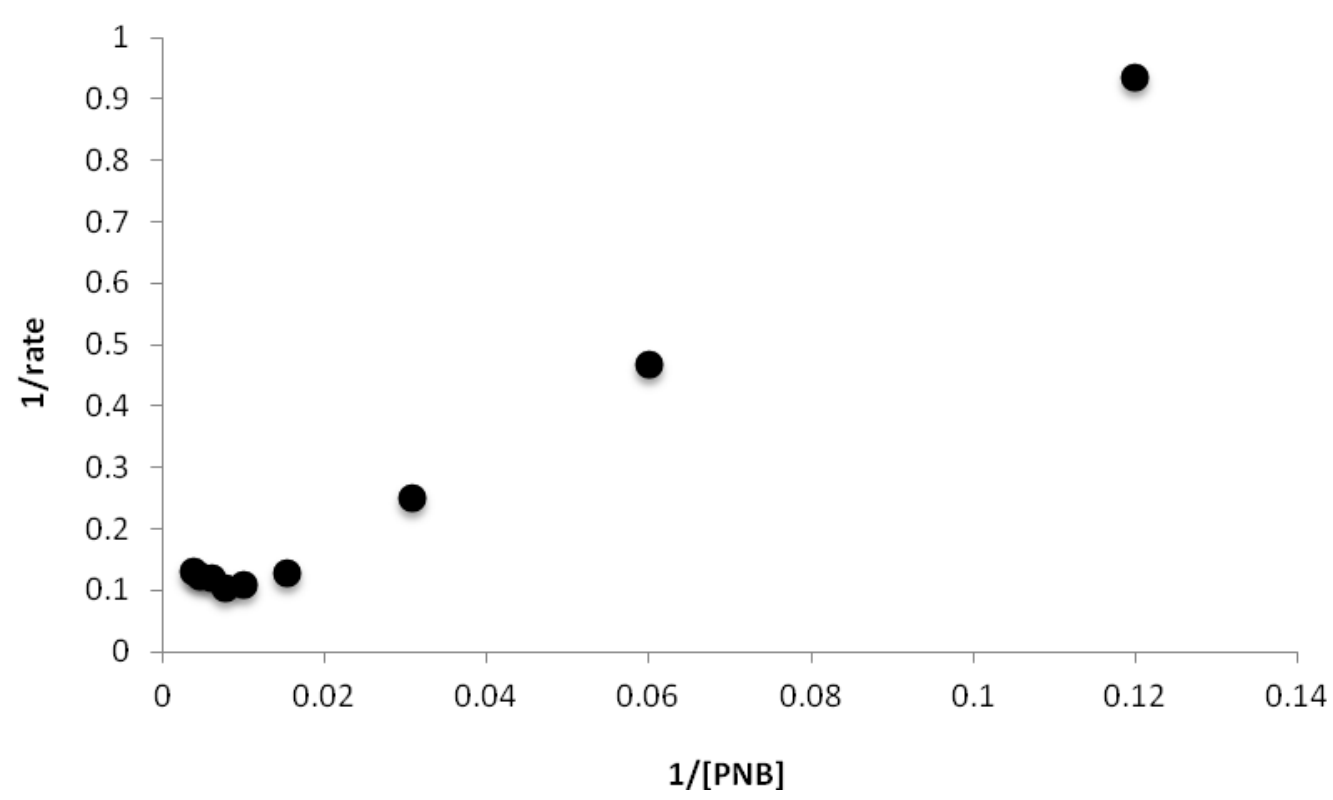

Figure S3. Lineweaver-Burk plot of AP-MSN-3.6 catalyzed aldol condensation between $p$-nitrobenzaldehyde (PNB) substrate and acetone. The five lowest concentrations of the substrate (1/[PNB] from 0.12 to 0.01$)$ give a linear trend and were used to estimate $\mathrm{K}_{\mathrm{M}}$ and $\mathrm{V}_{\text {max }}$.

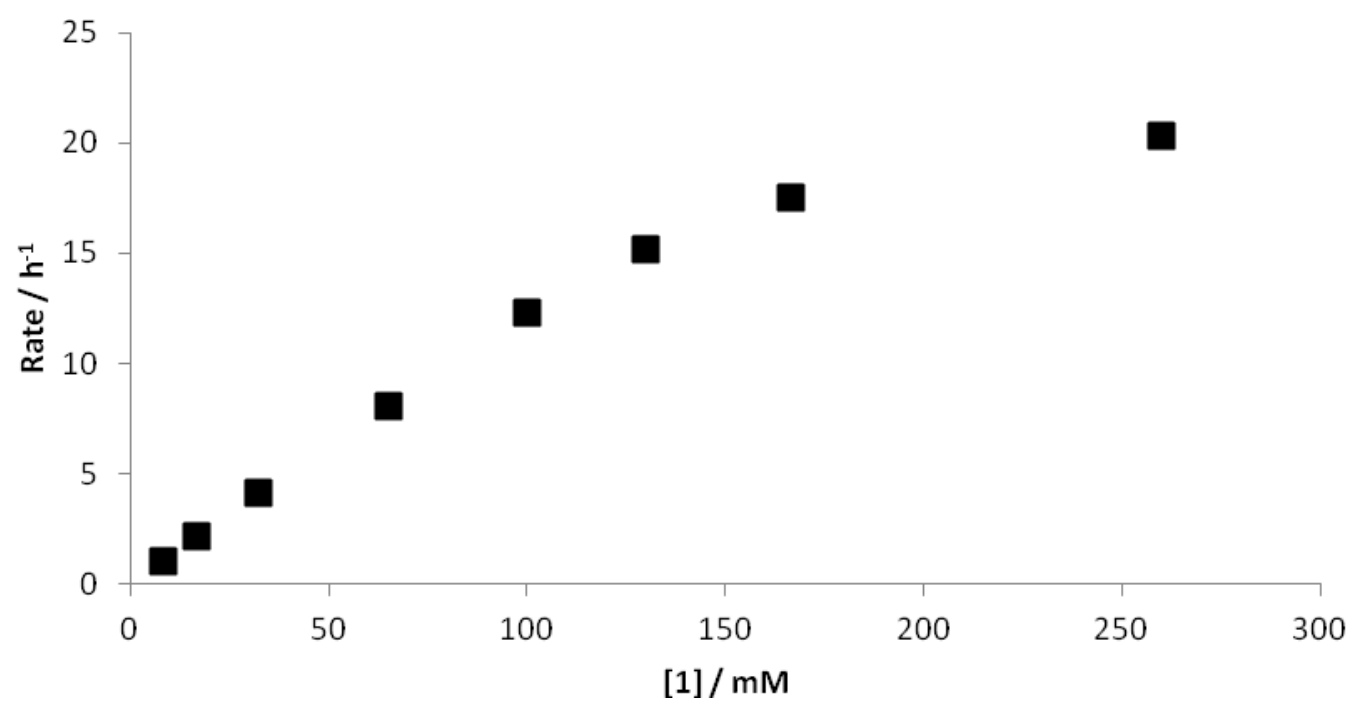

Figure S4. Effect of substrate concentration on the rate of the condensation catalyzed by MAP-MSN-3.5 in hexane: no inhibition by substrate is observed even at a ratio of substrate to MAP 67:1. 


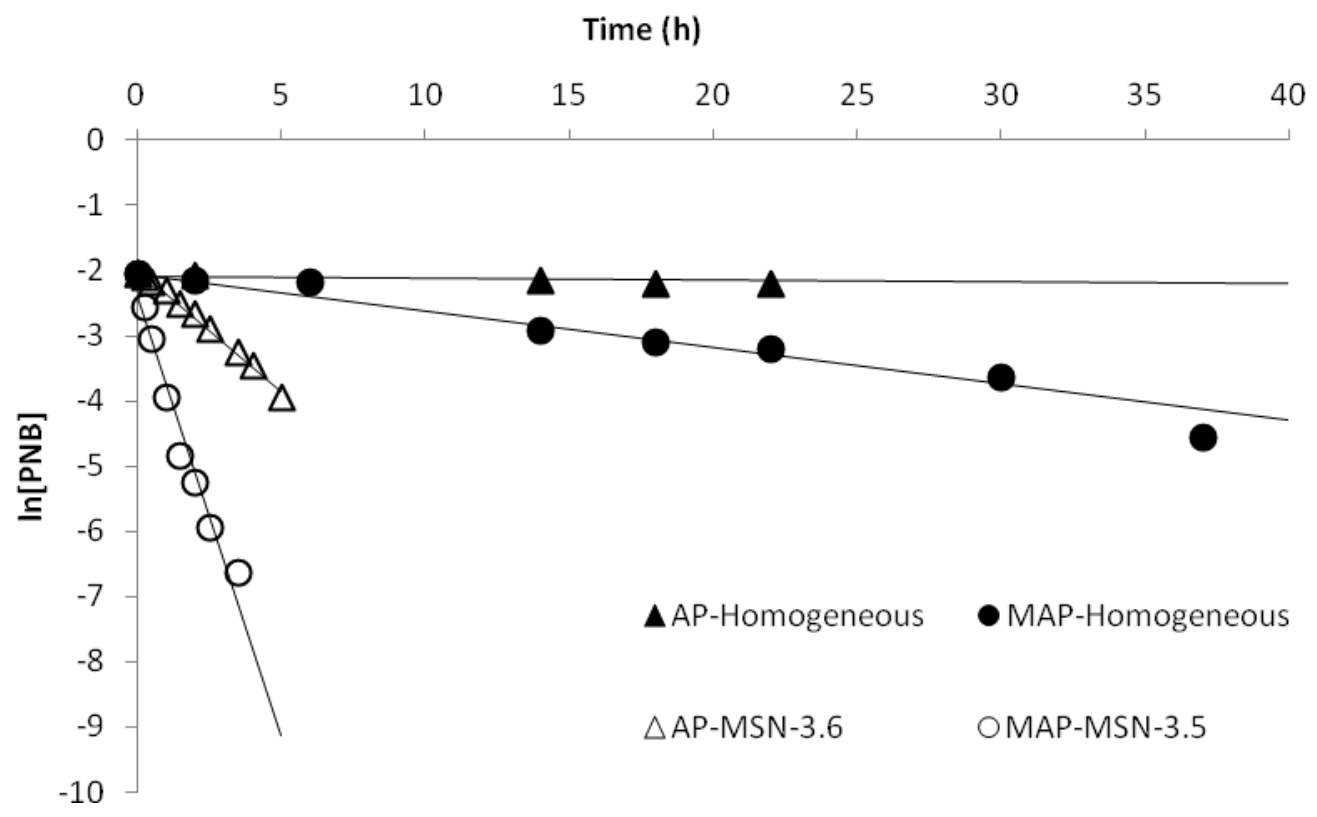

Figure S5. Pseudo-first order kinetic plots of propylamine (AP-homogeneous), methylpropylamine (MAP-homogeneous), AP-MSN-3.6 and MAP-MSN-3.5 in hexane. PNB is $p$-nitrobenzaldehyde substrate (1). 


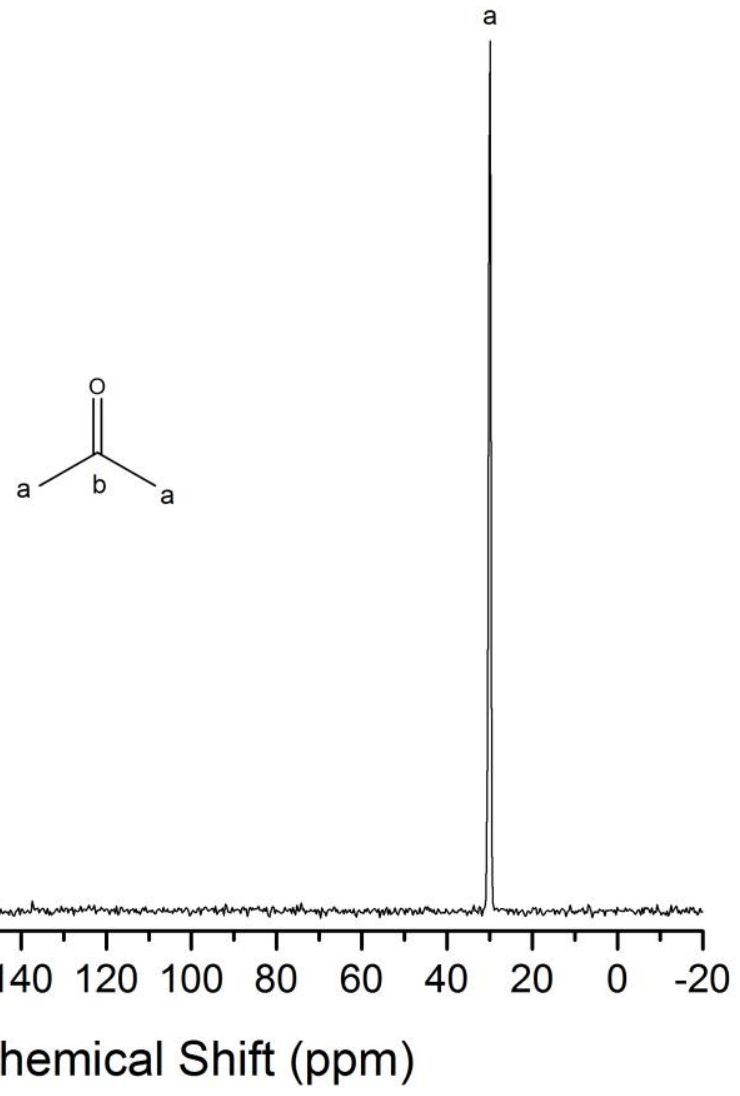

Figure S6. ${ }^{13} \mathrm{C}$ DPMAS spectrum of MSN with ${ }^{13} \mathrm{C}$ labeled acetone measured on a Varian NMR System 600 spectrometer. The carbonyl carbon resonates downfield from neat acetone ( 213 versus $206 \mathrm{ppm})$, which indicates that acetone is in an absorbed state, hydrogen-bonded with the surface silanols. Experimental parameters: $v_{R}=40 \mathrm{kHz}$, $v_{\mathrm{RF}}\left({ }^{13} \mathrm{C}\right)=100 \mathrm{kHz}, v_{\mathrm{RF}}\left({ }^{1} \mathrm{H}\right)=12 \mathrm{kHz}$ during SPINAL-64 decoupling, $\tau_{\mathrm{RD}}=3 \mathrm{~s}, \mathrm{NS}=$ 16 , and $\mathrm{AT} \sim 1.3 \mathrm{~min}$. 

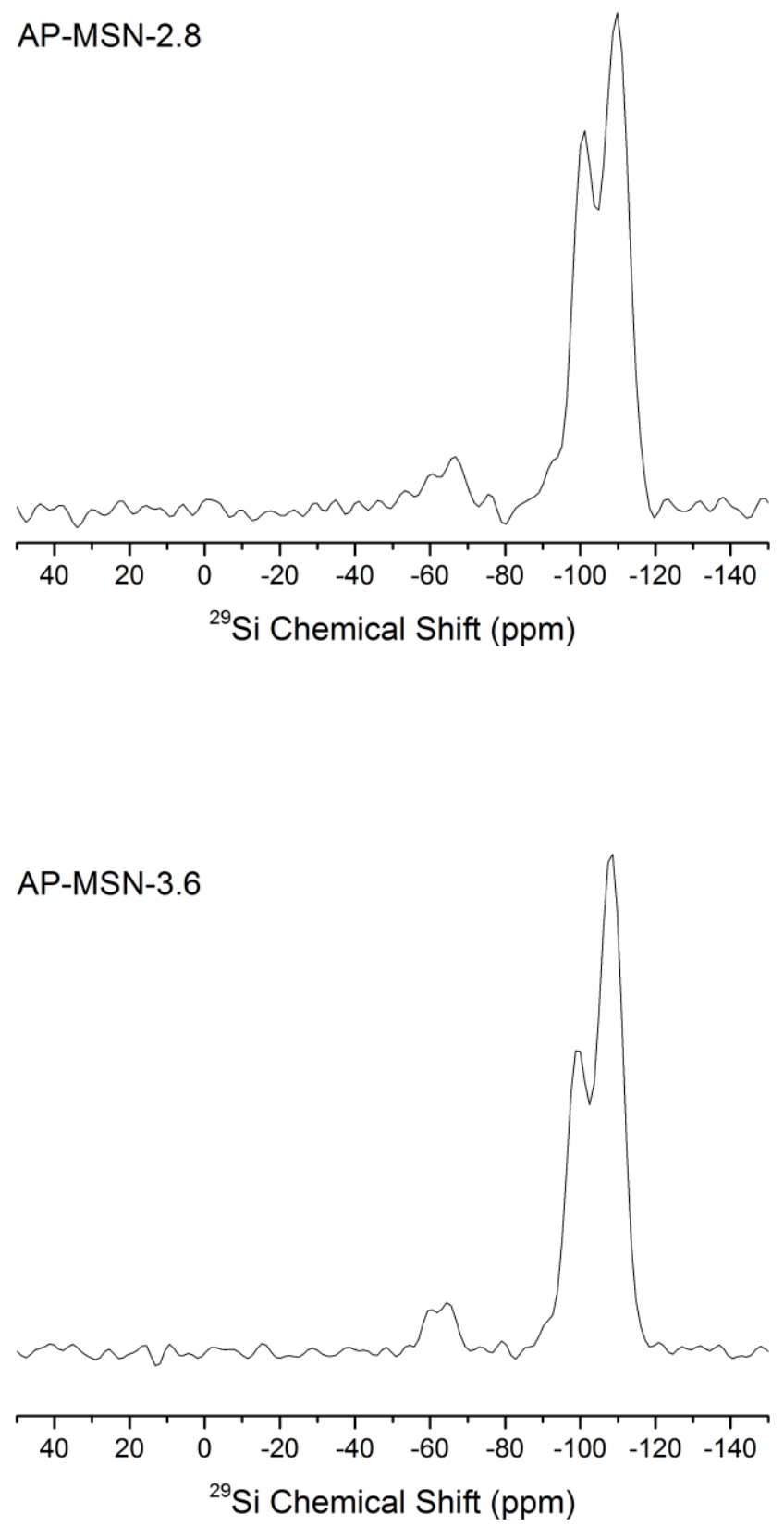

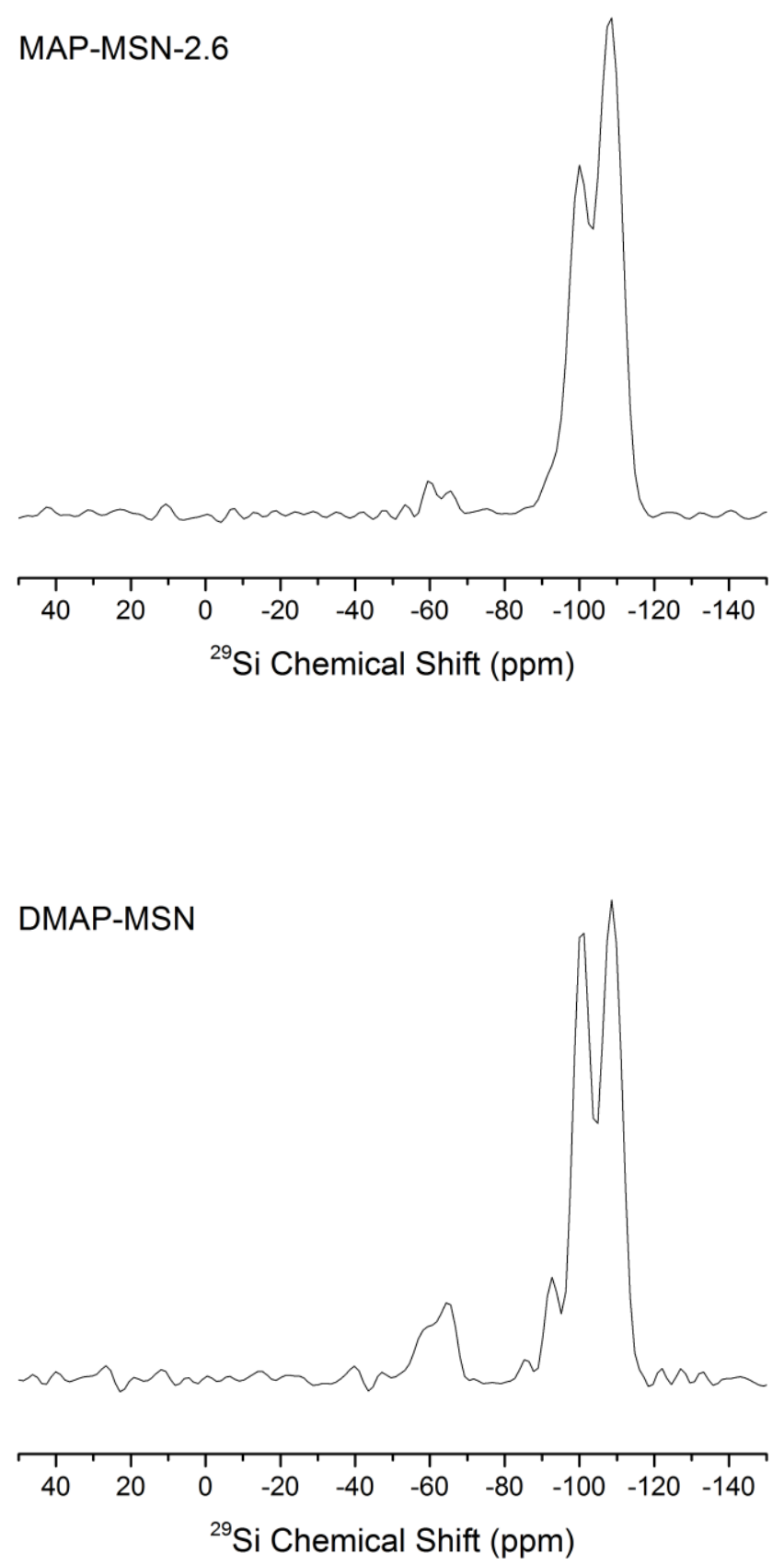

Figure S7. ${ }^{29} \mathrm{Si}$ DPMAS spectra of AP-MSN-2.8, AP-MSN-3.6, MAP-MSN-2.6 and DMAP-MSN measured on an Infinity $400 \mathrm{MHz}$ spectrometer. Experimental parameters: $v_{\mathrm{R}}=10 \mathrm{kHz}, v_{\mathrm{RF}}\left({ }^{29} \mathrm{Si}\right)=50 \mathrm{kHz}, v_{\mathrm{RF}}\left({ }^{1} \mathrm{H}\right)=45 \mathrm{kHz}$ for TPPM decoupling, $\mathrm{N}_{\mathrm{CPMG}}=10, \tau_{\mathrm{RD}}=300 \mathrm{~s}, \mathrm{NS}=296$, and $\mathrm{AT}=25 \mathrm{~h}$. 


\title{
CHAPTER 3. SOLVENT-INDUCED REVERSAL OF ACTIVITIES BETWEEN TWO CLOSELY RELATED HETEROGENEOUS CATALYSTS IN THE ALDOL REACTION
}

\author{
Modified from a paper published in ACS Catalysis 2013, 3(2), 265 \\ Kapil Kandel, Stacey M. Althaus, Chorthip Peeraphatdit, Takeshi Kobayashi, Brian G. \\ Trewyn, Marek Pruski and Igor I. Slowing
}

\begin{abstract}
The relative rates of the aldol reaction catalyzed by supported primary and secondary amines can be inverted by two orders of magnitude depending on the use of hexane or water as a solvent. Our analyses suggest that this dramatic shift in the catalytic behavior of the supported amines does not involve differences in reaction mechanism, but is caused by activation of imine to enamine equilibria and stabilization of iminium species. The effects of solvent polarity and acidity were found to be important to the performance of the catalytic reaction. This study highlights the critical role of solvent in multicomponent heterogeneous catalytic processes.
\end{abstract}

\section{Introduction}

It is well known that the selection of solvents can have an important effect on the rates of homogeneous reactions. Such an effect is commonly explained by the contribution of solvation energy to the total free energy of the systems and by stabilization of the transition states with a subsequent reduction in the free energy of activation. ${ }^{1}$ The analy- 
sis of solvent effects may be relatively simple for single-step processes, but becomes more complicated in reactions involving multiple equilibria. In such cases, the solvent effects can change preferences for various possible pathways over the potential energy surface of the reaction system. ${ }^{2-4}$

Whereas the role of solvents in homogeneous reactions has been studied thoroughly, less effort has been dedicated toward understanding their involvement in heterogeneous processes. ${ }^{1}$ Heterogeneous reactions entail greater complexity as they involve multiple equilibria and multiple components interacting with each other. Interfacial phenomena, competitive adsorption and kinetics of mass transfer are some of the additional factors that determine the apparent rates of heterogeneous reactions and complicate their understanding. For example, Drexler and Amiridis observed increased activity of $\mathrm{MgO}$ as a catalyst for the synthesis of flavanone in DMSO as compared to other polar and nonpolar solvents. They attributed the increased reaction rates to the interaction between DMSO and $\mathrm{MgO}$, which facilitated the adsorption of substrates onto the surface of the catalyst. ${ }^{5}$ Garcia and collaborators recognized that the competition between polar solvents and reactant molecules for diffusion into the pores and adsorption onto acid sites was responsible for the poor activity of Al-MCM-41 in the rearrangement of 1,2epoxyoctane. ${ }^{6}$ Using an acid-base bifunctional SBA-15 type mesoporous silica, Davis and co-workers showed how solvents with different polarities changed the equilibria of the acid-base pairs and how this affected the aldol reaction between $p$-nitrobenzaldehyde and acetone. ${ }^{7}$ They concluded that the acidic and basic groups interacted more strongly with the polar solvents than with each other, thereby inhibiting cooperative catalysis. To the contrary, in non-polar solvents, the groups associated with each other and the co- 
operative effect was clearly observed. This result was later supported by Solin, using carboxylic acid and primary amine bifunctionalized mesoporous silica catalyst in hexane and nonane. ${ }^{8}$

Scheme 1. Proposed cycle for an aldol reaction catalyzed by primary amines supported on mesoporous silica (black) and the formation of a product of inhibition (red). ${ }^{9}$

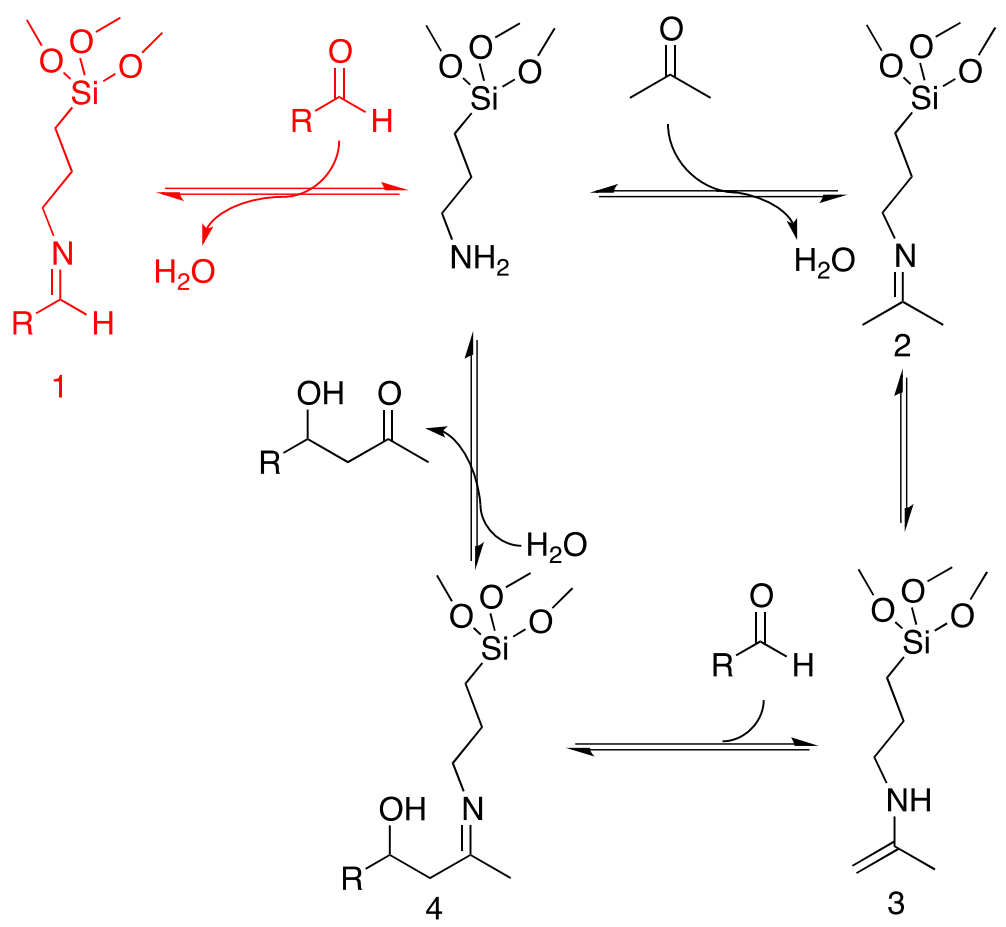

We recently reported that mesoporous silica nanoparticles (MSNs) functionalized with primary amines are poor catalysts for the aldol reaction in hexane, because of the formation of an imine intermediate 1 (Schiff base, Scheme 1). ${ }^{9}$ This intermediate was clearly identified by solid-state NMR and infrared spectroscopies. We eliminated this inhibition by replacing the primary amine with a secondary amine and achieved catalytic activities comparable to those of the previously reported bifunctional materials. ${ }^{9}$ We also showed that the imine intermediate $\mathbf{1}$ could regenerate the primary amine upon treatment with dilute aqueous $\mathrm{HCl}$. This led us to consider the possibility that the catalytic activity 
of supported primary amines toward the aldol reaction could be improved by replacing the non-polar solvent (hexane) with water.

Since water is either a reactant or a byproduct in various steps of the aldol reaction, it is difficult to predict whether its inclusion in the mixture would improve or inhibit the reaction. However, the beneficial contribution of water to the proline-catalyzed aldol condensation has been observed in homogeneous media. ${ }^{10-12}$ A recent study by Blackmond and collaborators showed that the addition of water to the homogeneous proline-catalyzed aldol reaction regenerates the active amine group at the expense of the inactive iminium form, leading to higher rates. They concluded that the reaction rate is highly dependent on the relative stabilities of the inactive imine of the acceptor aldehyde and the active enamine of the donor ketone, and that water shifts the equilibrium towards the active enamine intermediate. ${ }^{13}$ These reports suggested that using water as a solvent could improve the performance of our MSN-based catalysts.

\section{Scheme 2. Cross aldol reaction between $p$-nitrobenzaldehyde and acetone.}<smiles>CC(=O)/C=C/c1ccc([N+](=O)[O-])cc1</smiles>

\section{Experimental}

Materials. Cetyltrimethylammonium bromide (CTAB) $\left(\mathrm{CH}_{3}\left(\mathrm{CH}_{2}\right)_{15} \mathrm{~N}\left(\mathrm{CH}_{3}\right)_{3} \mathrm{Br}\right)$, mesitylene, $p$-nitrobenzaldehyde (PNB), hexamethyldisilazane (HMDS) and dimethyl sulfone were purchased from Sigma-Aldrich. Tetraethoxysilane (TEOS), 3-aminopropyl trimethoxysilane and [3-(Methylamino)propyl] trimethoxysilane were purchased from Gelest. All reagents were used as received without further purification. 
Synthesis of functionalized mesoporous silica nanoparticles. The synthesis and characterization of the materials has been described in a previous article. ${ }^{9}$ In brief, CTAB, $(1.0 \mathrm{~g}, 2.7 \mathrm{mmol})$ was dissolved in water $(480 \mathrm{~g}, 26.7 \mathrm{~mol})$, followed by the addition of $\mathrm{NaOH}$ solution $(2.0 \mathrm{M}, 3.5 \mathrm{~mL}, 7.0 \mathrm{mmol})$ and mesitylene $(1.73 \mathrm{~g}, 14.4 \mathrm{mmol})$. The mixture was heated at $80{ }^{\circ} \mathrm{C}$ for $1 \mathrm{~h}$. To this clear solution, TEOS $(4.7 \mathrm{~g}, 23 \mathrm{mmol})$ was added dropwise, followed by immediate addition of 3-aminopropyl trimethoxysilane (for AP-MSN) (1.0 mL, $5.7 \mathrm{mmol}$ ) or [3-(methylamino)propyl] trimethoxysilane (for MAPMSN) $(1.0 \mathrm{~mL}, 5.0 \mathrm{mmol})$. The solution was stirred vigorously at $80^{\circ} \mathrm{C}$ for $2 \mathrm{~h}$ and then filtered to yield a white functionalized MSN solid. The as-synthesized material was washed with copious amounts of water and methanol, then dried under vacuum. The CTAB surfactant was removed by Soxhlet extraction with methanol for $24 \mathrm{~h}$ and the resulting surfactant-removed functionalized MSN was dried overnight under vacuum.

Blocking of silanol groups of AP-MSN. AP-MSN (1.0 g) was suspended in 100 $\mathrm{mL}$ hexane. Hexamethyldisilazane (HMDS) $(10 \mathrm{mmol})$ was then added to the suspension. ${ }^{14,15}$ The suspension was heated to reflux for $24 \mathrm{~h}$, the solid was then recovered by filtration, washed with hexane, and dried overnight under vacuum.

Characterization of catalysts. Surface properties of the functionalized MSNs were measured by nitrogen sorption analysis in a Micromeritics Tristar 3000 using the Brunauer-Emmett-Teller (BET) method for surface area and the Barrett-Joyner-Halenda (BJH) method for pore size distribution. Small-angle X-ray diffractometry was performed on a Rigaku Ultima IV diffractometer using a $\mathrm{Cu}$ target at $40 \mathrm{kV}$ and $44 \mathrm{~mA}$. Loading of the catalysts was determined by elemental analysis in a Perkin Elmer 2100 Series II CHN/S Analyzer, using acetanilide as a standard, and combustion and reduction at 925 
${ }^{\circ} \mathrm{C}$ and $640{ }^{\circ} \mathrm{C}$. To measure the $\mathrm{pH}$ of the suspensions, the materials were dispersed in water:acetone mixtures at the same concentration as the ones used in the reaction. The $\mathrm{pH}$ of the suspension was measured with a $\mathrm{pH}$ meter at room temperature until a stable reading was obtained. The characterization information for each material is provided in reference 9, where AP-MSN is denoted AP-MSN-3.6 and MAP-MSN is denoted MAP-MSN3.5 .

General procedure for aldol reaction. Catalytic processes were performed in screw-cap vials. $p$-Nitrobenzaldehyde (PNB, $0.39 \mathrm{mmol})$ was dissolved in acetone (1.5 $\mathrm{mL})$. A suspension containing $3 \mathrm{~mol} \%$ of catalyst $(0.012 \mathrm{mmol})$ in the selected solvent (1.5 mL) was then added to the PNB solution. The reaction kinetics were studied by stirring the mixture at $60^{\circ} \mathrm{C}$ and quenching the reaction at desired times setting the vials on ice. The catalysts were then separated by centrifugation and the supernatants were concentrated under reduced pressure. Reaction yields were measured by ${ }^{1} \mathrm{H}$ NMR, using dimethyl sulfone as the internal standard. Resonances of the substrate and products were observed as follows: PNB (5), ${ }^{1} \mathrm{H}$ NMR (300 MHz, $\left.\mathrm{CDCl}_{3}\right) 10.16$ (s, $\left.1 \mathrm{H}\right), 8.41$ (d, $J=9.0$ $\mathrm{Hz}, 2 \mathrm{H}), 8.09$ (d, $J=9.0 \mathrm{~Hz}, 2 \mathrm{H})$; aldol product $(6),{ }^{1} \mathrm{H} \mathrm{NMR}\left(300 \mathrm{MHz}, \mathrm{CDCl}_{3}\right) 8.20$ $(\mathrm{d}, J=8.7 \mathrm{~Hz}, 2 \mathrm{H}), 7.55(\mathrm{~d}, J=9.0 \mathrm{~Hz}, 2 \mathrm{H}), 5.26(\mathrm{t}, J=6.0 \mathrm{~Hz}, 1 \mathrm{H}), 2.86(\mathrm{~d}, J=6.0 \mathrm{~Hz}$, 2H), 2.21 (s, 3H); enone product (7), ${ }^{1} \mathrm{H}$ NMR (300 MHz, $\left.\mathrm{CDCl}_{3}\right) 8.29$ (d, J=9.0 Hz, 2H), $7.71(\mathrm{~d}, J=9.0 \mathrm{~Hz}, 2 \mathrm{H}), 7.56(\mathrm{~d}, J=15 \mathrm{~Hz}, 1 \mathrm{H}), 6.847 .56(\mathrm{~d}, J=15 \mathrm{~Hz}, 1 \mathrm{H}), 2.42$ $(\mathrm{s}, 3 \mathrm{H})$.

Solid-state NMR. Solid-state ${ }^{13} \mathrm{C}$ and ${ }^{29} \mathrm{Si}$ NMR experiments were performed to determine the structure and loading of the surface groups on the MSNs. The identification of the catalytic groups and intermediates was accomplished by measuring the ${ }^{13} \mathrm{C}$ cross 
polarization spectra under magic angle spinning (CPMAS). These experiments were performed at $14.1 \mathrm{~T}$ on a Varian System 600 spectrometer equipped with a 1.6-mm FastMAS ${ }^{\mathrm{TM}}$ probe operated at 599.6 MHz $\left({ }^{1} \mathrm{H}\right)$ and $150.8 \mathrm{MHz}\left({ }^{13} \mathrm{C}\right)$.

To accurately determine the loading of both functional groups and silanols on the MSN surface, the ${ }^{29} \mathrm{Si}$ NMR measurements were performed using direct polarization under MAS (DPMAS) with Carr-Purcell-Meiboom-Gill (CPMG) refocusing. ${ }^{16,17}$ The spectra were acquired on a Chemagnetics Infinity 400 spectrometer equipped with a 5-mm MAS probe operated at 400.0 $\mathrm{MHz}\left({ }^{1} \mathrm{H}\right)$ and 79.4 $\mathrm{MHz}\left({ }^{29} \mathrm{Si}\right)$.

The experimental parameters are given using the following notation: $v_{\mathrm{R}}$ denotes the MAS rate, $v_{\mathrm{RF}}(\mathrm{X})$ is the magnitude of the RF magnetic field at the frequency of $\mathrm{X}$ nuclei, $\tau_{\mathrm{CP}}$ is the mixing time during $\mathrm{CP}, \mathrm{N}_{\mathrm{CPMG}}$ is the number of echoes acquired in $\mathrm{CPMG}$ experiment, $\tau_{\mathrm{CPMG}}$ is the corresponding time interval between $\pi$ pulses, $\tau_{\mathrm{RD}}$ is the recycle delay, NS is the number of scans, and AT is the total acquisition time.

${ }^{13} \mathrm{C}$ CPMAS (Figure 2: AP-MSN and Intermediate 2): $v_{\mathrm{R}}=40 \mathrm{kHz}, v_{\mathrm{RF}}\left({ }^{13} \mathrm{C}\right)=62$ $\mathrm{kHz}, v_{\mathrm{RF}}\left({ }^{1} \mathrm{H}\right)$ during $\mathrm{CP}=102 \mathrm{kHz}, v_{\mathrm{RF}}\left({ }^{1} \mathrm{H}\right)$ during SPINAL-64 decoupling $=12 \mathrm{kHz}, \tau_{\mathrm{CP}}$ $=2 \mathrm{~ms}, \tau_{\mathrm{RD}}=3 \mathrm{~s}, \mathrm{NS}=10240$, and $\mathrm{AT}=8.7 \mathrm{hrs}$.

${ }^{13} \mathrm{C}$ CPMAS (Figure 2: Intermediate 1): $v_{\mathrm{R}}=40 \mathrm{kHz}, v_{\mathrm{RF}}\left({ }^{13} \mathrm{C}\right)=140 \mathrm{kHz}, v_{\mathrm{RF}}\left({ }^{1} \mathrm{H}\right)$ during $\mathrm{CP}=60 \mathrm{kHz}, v_{\mathrm{RF}}\left({ }^{1} \mathrm{H}\right)$ during SPINAL-64 decoupling $=12 \mathrm{kHz}, \tau_{\mathrm{CP}}=3 \mathrm{~ms}, \tau_{\mathrm{RD}}=$ $2 \mathrm{~s}, \mathrm{NS}=26400$, and AT $=15 \mathrm{hrs}$.

${ }^{29} \mathrm{Si}$ DPMAS with CPMG: $v_{\mathrm{R}}=10 \mathrm{kHz}, v_{\mathrm{RF}}\left({ }^{29} \mathrm{Si}\right)=50 \mathrm{kHz}, v_{\mathrm{RF}}\left({ }^{1} \mathrm{H}\right)=45 \mathrm{kHz}$, $\mathrm{N}_{\mathrm{CPMG}}=10, \tau_{\mathrm{CPMG}}=10 \mathrm{~ms}, \tau_{\mathrm{RD}}=300 \mathrm{~s}, \mathrm{NS}=296$, and $\mathrm{AT}=25 \mathrm{~h}$. 


\section{Results and Discussion}

To evaluate the effects of replacing hexane with water on the activity of supported amines towards the aldol reaction, two MSN materials, AP-MSN and MAP-MSN, were tested for the cross aldol reaction between $\mathbf{5}$ and excess acetone (Scheme 2). The catalytic activity was determined by measuring the amounts of the substrate $\mathbf{5}$, and products (aldol 6 and enone 7) using NMR. In a previous report, we measured the apparent pseudo-first-order rate constant of AP-MSN in hexane, which was $k_{\mathrm{AP}-\mathrm{MSN} \text { hex }}=0.37 \mathrm{~h}^{-1}$ (Figure 1a). ${ }^{9}$ This low activity of AP-MSNs was overcome by using a secondary aminefunctionalized material (MAP-MSN), which was unable to form the imine intermediate and gave a three-fold increase in the apparent rate constant in hexane $\left(k_{\mathrm{MAP}-\mathrm{MSN} \text { hex }}=1.35\right.$ $\mathrm{h}^{-1}$, Figure 1a). ${ }^{9}$ 
a)

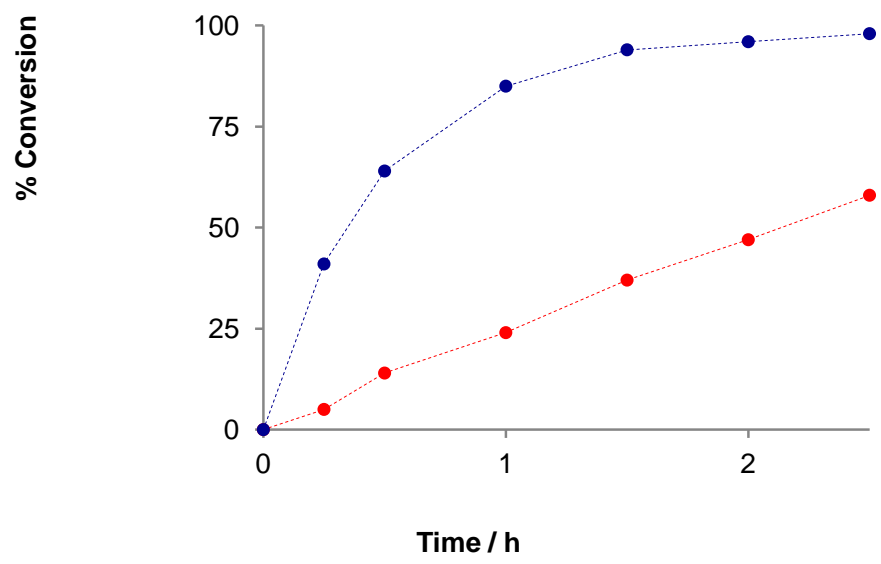

b)

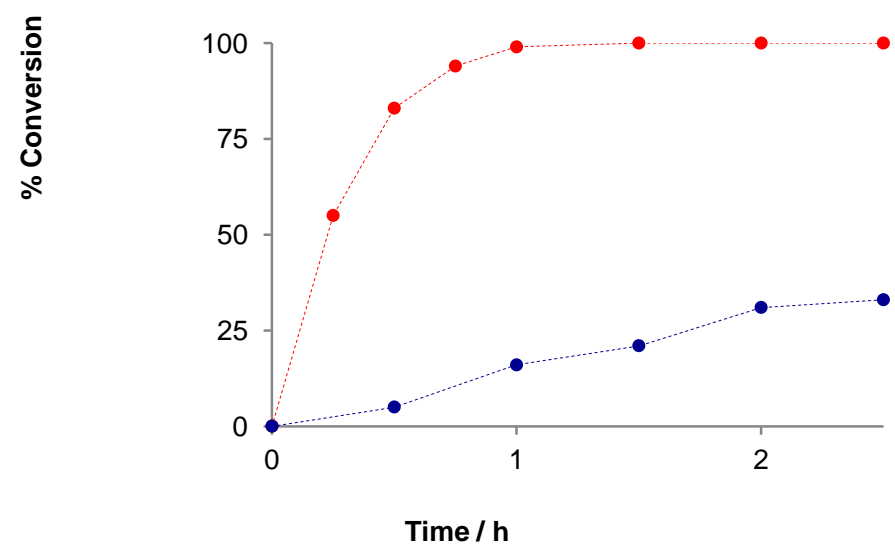

Figure 1. Kinetics of aldol reaction between 5 and acetone catalyzed by AP-MSN (red) and MAP-MSN (blue) in (a) hexane (from reference ${ }^{9}$ ) and (b) water at $60^{\circ} \mathrm{C}$ with 3 mol\% catalyst.

Replacing hexane with water had a dramatic effect on the activity of AP-MSN: the apparent rate constant increased more than tenfold $\left(k_{\mathrm{AP}-\mathrm{MSN} \text { w }}=4.98 \mathrm{~h}^{-1}\right.$, Figures $1 \mathrm{~b}$ and S1a), yielding an almost quantitative conversion after only one hour of reaction. However, the effect of replacing hexane with water on the activity of MAP-MSN was completely unexpected: instead of becoming more active like AP-MSN, the apparent rate 
constant of the reaction dropped more than tenfold to $k_{\mathrm{MAP}-\mathrm{MSN} \text { w }}=0.127 \mathrm{~h}^{-1}$ (Figures $1 \mathrm{~b}$ and S1a). These results correspond to a change in the relative activities of the two catalysts by two orders of magnitude (in hexane: $k_{\mathrm{AP}-\mathrm{MSN}} / k_{\mathrm{MAP}-\mathrm{MSN}}=0.27$, in water: $k_{\mathrm{AP}}$ $\left.\mathrm{MSN} / k_{\mathrm{MAP}-\mathrm{MSN}}=39\right)$.

This remarkable inversion of the relative activities could result from the solvents directing each catalytic reaction through different pathways. However, the inversion of activities could also result from water stabilizing to a different extent the intermediates associated with each catalyst, without necessarily altering the reaction mechanism. Thus, the solvent could have multiple effects on the reactions, with each effect having variable magnitudes depending on the structural constraints of each catalyst, and still preserve the same mechanistic pathway. While solvent polarity may be the most obvious parameter, the protic nature of water could also play a role in the mechanism of the reaction. In addition, according to Scheme 1, water participates directly as a reagent and product in different steps of the reaction. Therefore it is possible that water affects the reaction by modifying its equilibrium. To better understand the reason for this inversion in the relative activities of the catalysts in water and hexane, we evaluated each of these factors separately by testing the rate of the reaction in additional solvents.

Effects of solvent polarity. The effect of polarity on the activity of both materials was studied by comparing the kinetics of the reactions in hexane and water with those in low-polarity dichloromethane and polar aprotic acetonitrile. Figure 2 shows that increasing the polarity leads to a small decrease in activity for AP-MSN (with the exception of the rate in water) and a more significant decrease in MAP-MSN. This trend is consistent with the previous findings by Davis and co-workers on the negative effect of polarity on 
the activity of bifunctionalized materials towards the cross aldol reaction. They suggested that sulfonates and amines could undergo acid-base neutralization in polar solvents and lose their activities. ${ }^{7}$ In the case of AP-MSN in non-polar solvents, aminopropyl groups and acidic silanols have mild non-covalent interactions with each other. ${ }^{18,19}$ However, as polarity increases, proton transfer between the acidic silanols and the basic amine can take place, reducing the availability of the deprotonated amine required to perform enamine catalysis.

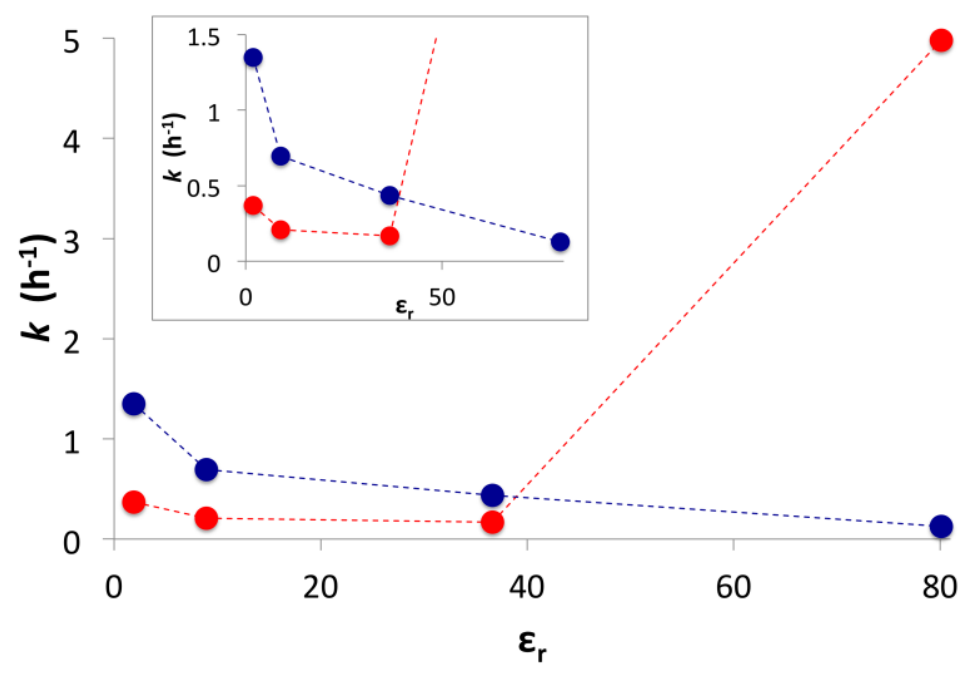

Figure 2. Rates of aldol reaction catalyzed by AP-MSN (red) and MAP-MSN (blue) in solvents of increasing dielectric constants: hexane $\left(\varepsilon_{\mathrm{r}}=1.89\right)$, dichloromethane $\left(\varepsilon_{\mathrm{r}}=\right.$ $8.93)$, acetonitrile $\left(\varepsilon_{\mathrm{r}}=36.64\right)$ and water $\left(\varepsilon_{\mathrm{r}}=80.1\right) .{ }^{20}$ Inset: same graph with the $\mathrm{x}$-axis cut at $1.5 \mathrm{~h}^{-1}$ to show the details of the lower reaction rates.

As mentioned above, the drop in the activity of MAP-MSN with polarity was larger than that of AP-MSN: as the polarities of non-aqueous solvents increase, the differences between the activities of the two catalysts lessen. We previously reported that the higher activity of MAP-MSN in hexane was caused by the formation of substrate inhibiting imine 1 in AP-MSN, whereas the methyl group in MAP-MSN prevented the formation of imine. ${ }^{9}$ Our new observation on the effect of polarity suggests that this deficit 
of AP-MSN is compensated as polarity increases. While MAP-MSN cannot form the inhibitory imine in hexane, it could form the cationic iminium intermediate $\mathbf{8}$ in a polar solvent, leading to reduced activity (Scheme 3). Being ionic, this intermediate would be further stabilized by increased solvent polarity, explaining the decrease in the difference between the two catalysts' activities with increasing polarity.

Scheme 3. Possible reaction pathways of $p$-nitrobenzaldehyde 5 and acetone in the presence of MAP-MSN and water. $R=p$-nitrophenyl.

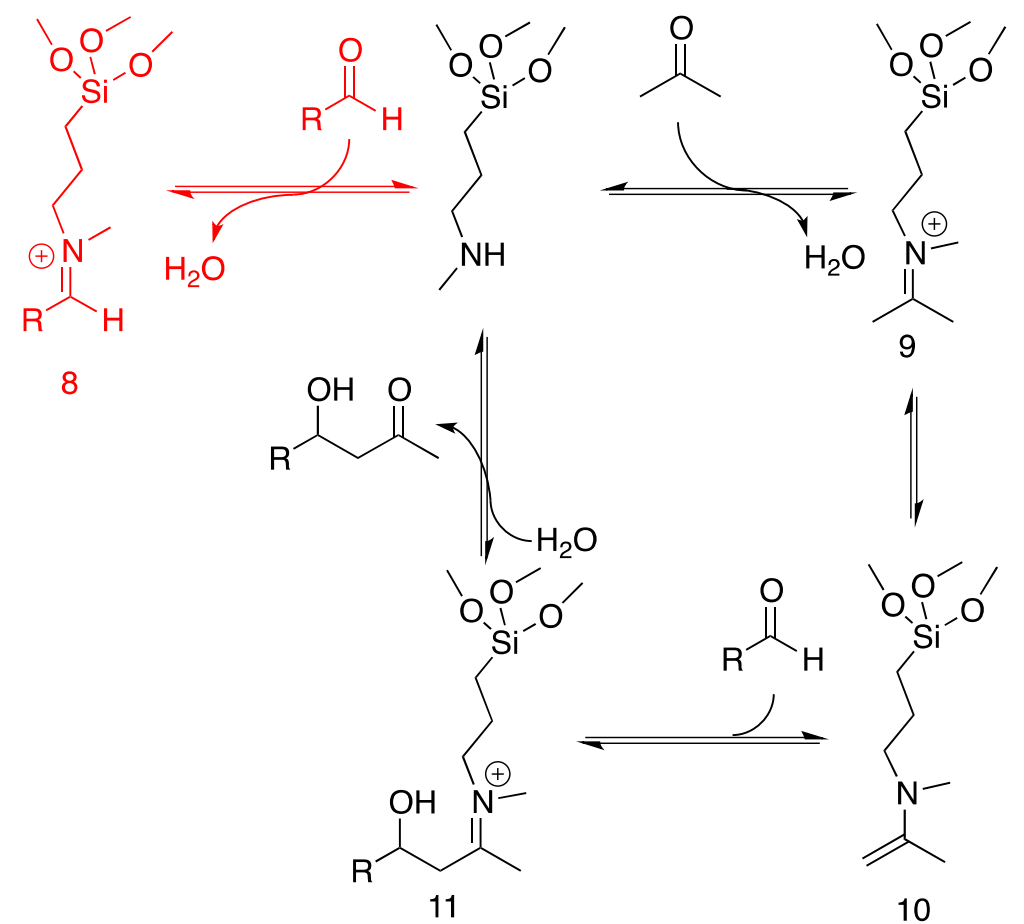

While we have been able to observe the formation of $\mathbf{1}$ in hexane by infrared and solid-state NMR, ${ }^{9}$ the detection of $\mathbf{8}$ by infrared was not straightforward because the $\mathrm{C}=\mathrm{N}^{+}$stretching band is shifted to higher frequencies compared to those of $\mathrm{C}=\mathrm{N},{ }^{21}$ so that it is likely to overlap with the $\mathrm{C}=\mathrm{O}$ stretching frequency of the unbound starting material 4. Similarly, solid-state NMR spectroscopy did not show any clear evidence of the expected iminium 8. However, iminium intermediates are not unusual in aldol and related reactions when secondary amines are used as catalysts. ${ }^{22-26}$ In fact, iminium intermediates 
are central in reactions that undergo Mannich-type pathways with secondary amines. ${ }^{19,27-}$ 30

Since the reaction catalyzed by AP-MSN in water is off the trend followed by the other solvents, the enhanced activity of the catalyst in this solvent cannot be due to polarity. Another effect must be responsible for increasing the activity of the catalyst, in spite of the negative effect that the polarity of water should have on the reaction.

Effects of solvent acidity. A second possible effect of water that might influence the reaction is its protic character. Being a weak acid, water could assist the reaction by protonating or hydrogen-binding the oxygen on carbonyls, thereby activating the molecules for nucleophilic attack. To evaluate this possibility, we tested the activity of the catalysts in methanol, whose $\mathrm{pK}_{\mathrm{a}}(15.5)$ is very close to that of water (15.7). ${ }^{20}$

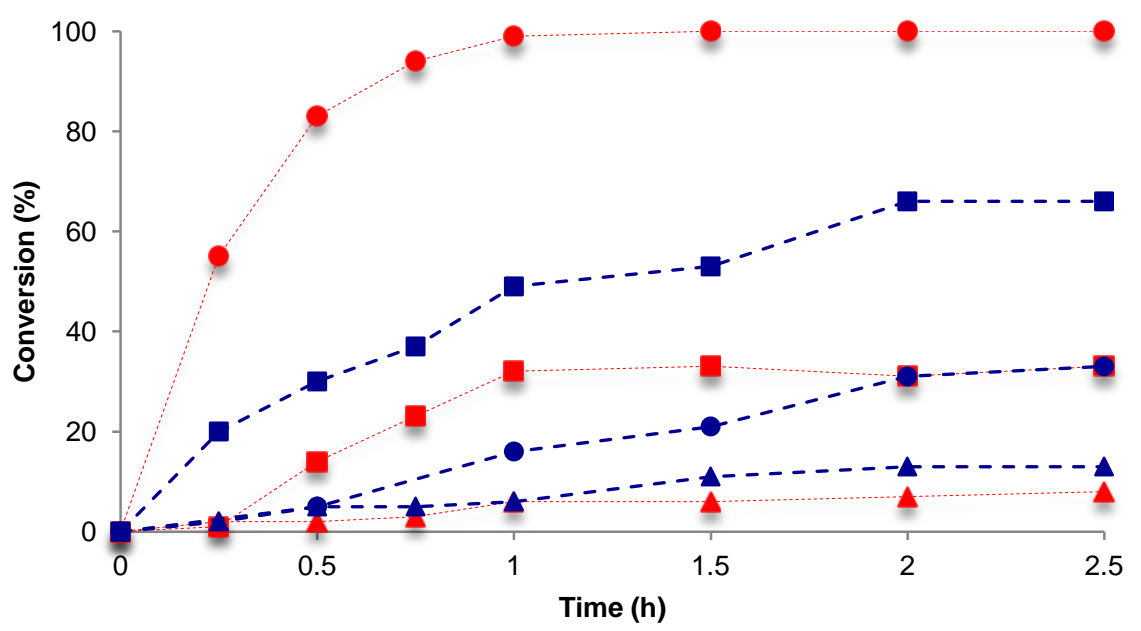

Figure 3. Effect of protic solvents on the rates of aldol reaction catalyzed by AP-MSN (red) and MAP-MSN (blue): water (circles) and methanol (triangles). The rate in polar aprotic acetonitrile (squares) is shown as a reference.

Figure 3 shows that the two catalysts gave similar reaction kinetics in methanol.

In addition, the reactions in methanol were slower than the corresponding reactions in water and in aprotic acetonitrile. Therefore, rather than improving catalysis, the acidity of 
the solvent is detrimental to the activity of the silica-supported amines. Furthermore, since the rate of the reaction catalyzed by MAP-MSN is greater in water than in methanol, it is likely that water has an additional effect on the catalysis by MAP-MSN similar to the reactions catalyzed by AP-MSN.

Effects of the solvent on equilibrium. The anomalous effect of water on the catalysis by these materials could also arise from the different equilibria involved in the reaction. According to Scheme 1, the addition of water to the reaction catalyzed by APMSN should lower the concentration of the product of inhibition 1. The same consideration, however, would also predict an inhibition of the formation of the active imine and the subsequent enamine intermediates $\mathbf{2}$ and $\mathbf{3}$.

The observed increase in the activity of AP-MSN in water may then be the result of two factors: (1) the relative values of the equilibrium constants leading to imine 2 versus imine 1, and (2) the fact that water is also a reagent in the last step of the process, where it combines with intermediate 4 to give the final product. Thus in the overall conversion (Scheme 4), water is a product only in the inhibition route (red) but is not part of the net reactants or products of the aldol route (black). Therefore, the excess of water shifts the overall equilibrium toward the formation of the aldol product and minimizes the inhibition pathway. The excess of acetone also contributes to shift the equilibrium towards the aldol product, making the impact of water on the dissociation of $\mathbf{1}$ even larger. 
Scheme 4. Overall reaction pathways for $p$-nitrobenzaldehyde and acetone in the presence of AP-MSN: inhibition (red) and aldol (black).

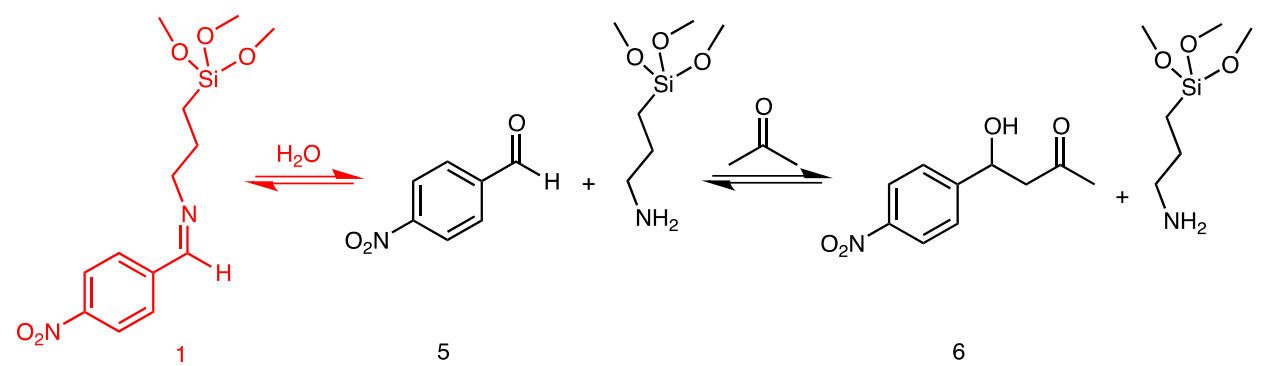

These same considerations can apply to the reaction catalyzed by MAP-MSN. If MAP-MSN is less active in polar solvents due to the formation of $\mathbf{8}$, this inhibition could be disrupted by the addition of water, which would hydrolyze this intermediate (8). Thus, the catalytic activity of both materials in water should be a balance between the inhibitory effects of polarity and the promoting effect of the solvent on equilibria.

Using ${ }^{1} \mathrm{H}_{-}{ }^{13} \mathrm{C}$ CPMAS solid-state NMR, imines 1 and 2 could be identified only in samples prepared in the hexane solution of $\mathbf{5}$ and hexane-acetone mixtures, respectively (Figure 4). However, detection of the enamine intermediates was not possible, most likely due to their short lifetimes. 


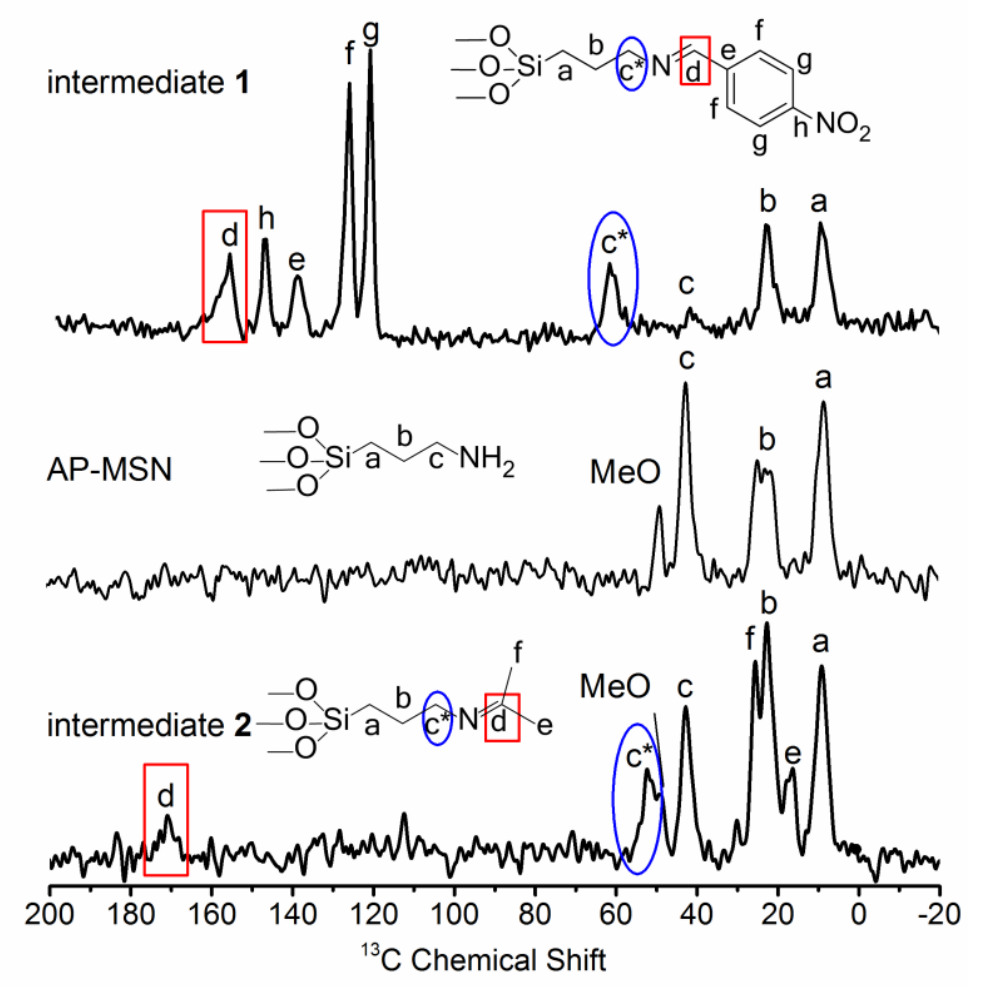

Figure 4. ${ }^{13} \mathrm{C}$ CPMAS solid-state NMR spectra of intermediate 1, AP-MSN, and intermediate 2 obtained from samples prepared in hexane. The spectra of AP-MSN and intermediate 1 were assigned according to our previous study, ${ }^{9}$ whereas resonances $\mathrm{c}^{*}, \mathrm{~d}, \mathrm{e}$ and $\mathrm{f}$ in the bottom spectrum are consistent with the existence of intermediate 2 , based on the solution NMR data reported for similar functionalities. ${ }^{\mathbf{3 1 , 3 2}}$

Product distribution and mechanistic considerations. The above interpretation of the effect of water on equilibrium assumes that the main product of the reaction is $\mathbf{6}$, which would be obtained directly if the reaction proceeded through an enamine pathway (Schemes 1 and 3). However, if the most abundant product were 7, water would be formed as a by-product of the reaction, and would therefore play no role at all in shifting the equilibrium. Product 7 can be formed by dehydration of $\mathbf{6}$, following enamine catalysis, or it can be produced via a Mannich-type mechanism following the production of intermediate $\mathbf{1}$ (or $\mathbf{8}$ for MAP-MSN). Intermediate $\mathbf{1}$ is an inhibitor in hexane, demonstrat- 
ing that the Mannich mechanism does not take place in this solvent; however, this does not indicate that this mechanism cannot take place in water.

Analysis of our product distribution revealed that aldol $\mathbf{6}$ was the major product for the reactions catalyzed by each material in all of the solvents tested (Figures S2 and S3). The selectivities for 6 ranged from 75 to $90 \%$ with AP-MSN and from $70 \%$ to $85 \%$ with MAP-MSN, with the only exception being the reaction with MAP-MSN in water, where no enone 7 was observed at all. Not only was enone $\mathbf{7}$ the minor product, but it appeared, in most cases, after longer reaction times than the aldol product 6 . The observation of constant ratios for aldol and enal in the homogeneously catalyzed selfcondensation of aldehydes has been associated with the competition between enamine and Mannich-type mechanisms throughout the reaction..$^{33}$ In contrast to these observations, in most of our experiments an increase in the amount of enone $\mathbf{7}$ seemed to correspond with a decrease of the rate of formation of aldol 6 . When the AP-MSN catalyzed reaction was carried out in water, the concentration of enone $\mathbf{7}$ increased at the later stages of the reaction and was concurrent with a measurable decrease in the concentration of aldol 6 (Figure 5). These observations suggest that the products are formed sequentially, rather than via competing pathways, i.e. it shows that the reaction does not involve a Mannich-type mechanism, but more likely, the enone is formed via dehydration of the aldol. 


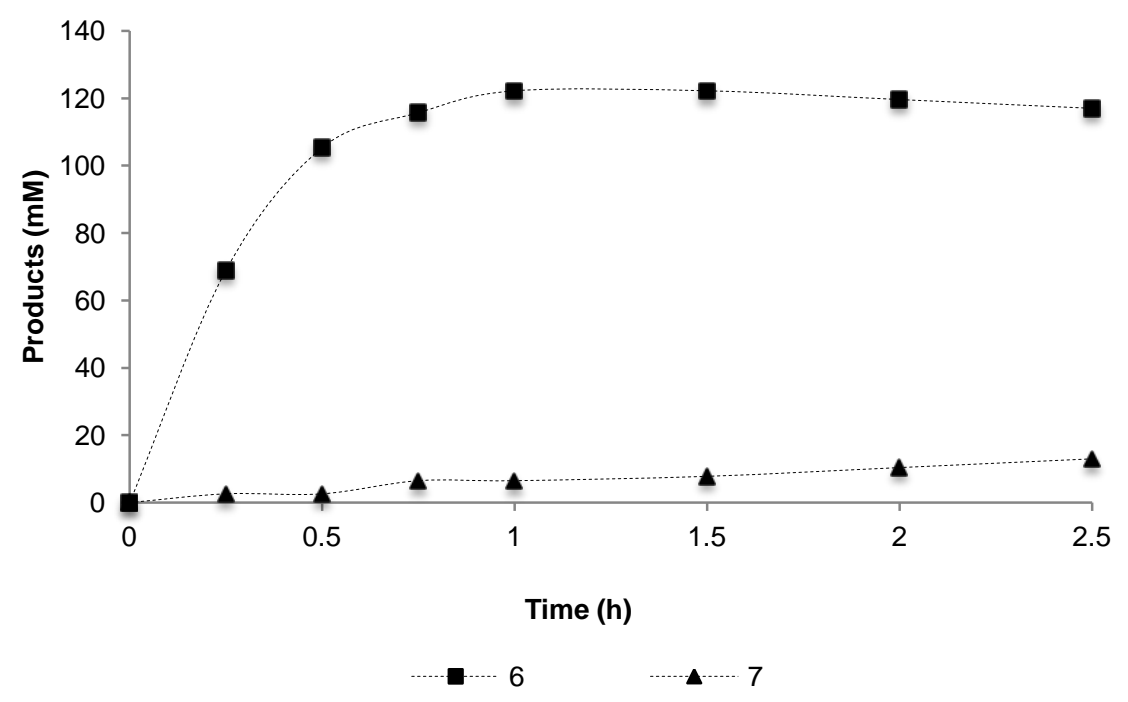

Figure 5. Formation of addition (squares) versus condensation (triangles) products in the aldol reaction between 5 and acetone catalyzed by AP-MSN in water.

While the formation of enamines in water may be deemed as counterintuitive, these intermediates have been observed in homogeneous aqueous media. ${ }^{34-37}$ The other mechanism that could account for the formation of the aldol product in water involves general-base catalysis, which tends to occur at high $\mathrm{pH}$ values $(>10)$. Other research groups have shown that buffering the aqueous media at $\mathrm{pH} 8$ directs the reaction through an enamine rather than a general base pathway, as too little of the acetone enolate could form because of its high $\mathrm{pK}_{\mathrm{a}}(10.83) .{ }^{37-39}$ Since the surface of the mesoporous silica support is rich in weakly acidic silanol groups $\left(\mathrm{pK}_{\mathrm{a}} 2-4\right.$ for isolated and 8 for geminal silanols), it is possible for it to play the role of a buffer in the reaction system. ${ }^{40,41}$ Indeed, DPMAS ${ }^{29}$ Si NMR measurements of AP-MSN and MAP-MSN indicated that the materials have a large quantity of acidic silanol groups. The ratios $\left(\mathrm{T}^{2}+\mathrm{T}^{3}\right) /\left(\mathrm{T}^{2}+2 \mathrm{Q}^{2}+\mathrm{Q}^{3}\right)$ of the materials suggest there are considerably more silanol groups than amine groups at the surface (loadings of $4.3 \mathrm{SiOH} / \mathrm{nm}^{2}$ and $4.8 \mathrm{SiOH} / \mathrm{nm}^{2}$, and $0.8 \mathrm{AP} / \mathrm{nm}^{2}$ and 0.73 
$\mathrm{MAP} / \mathrm{nm}^{2}$ respectively). ${ }^{9}$ The presence of these silanol groups prevented the aqueous suspensions of AP-MSN and MAP-MSN from reaching high $\mathrm{pH}$ values, stabilizing them at 8.1 and 8.3 , respectively, as opposed to the $\mathrm{pH}>11$ observed for the free amines at the same concentrations in water. The lower activity of MAP-MSN than AP-MSN, despite their similar basicities also supports the notion that general base catalysis does not take place in our aqueous system.

Role of the silanol groups in water. The difference between the activities of both catalysts in water is consistent with previous reports of homogeneous primary amines being more efficient catalysts than secondary amines for this reaction. ${ }^{38}$ This difference could be attributed to steric hindrance by the methyl in MAP-MSN during the C-C bond formation step. Such hindrance would lead to a higher barrier than that of the less impeded AP-MSN.

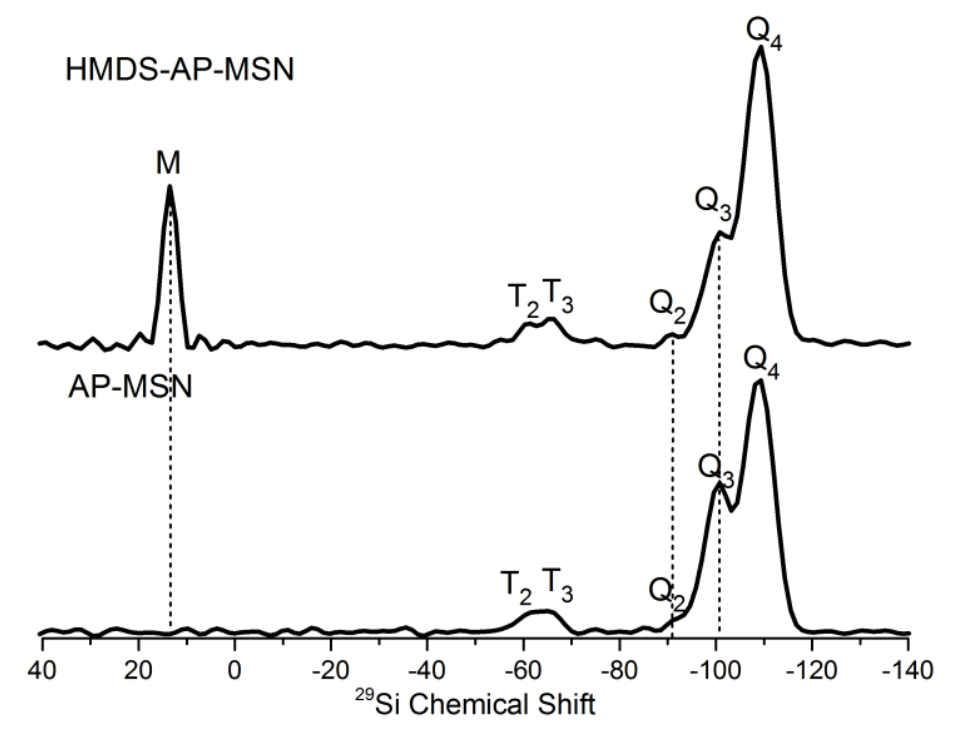

Figure 6. ${ }^{29}$ Si DPMAS spectra of AP-MSN before (bottom) and after (top) blocking silanol groups with HMDS. Appearance of M site due to the attached silane matches the conversion of the $\mathrm{Q}_{2}$ and $\mathrm{Q}_{3}$ sites of the blocked groups to $\mathrm{Q}_{3}$ and $\mathrm{Q}_{4}$, respectively. 
While silanol groups are known to actively participate in the aldol reaction in organic solvents, ${ }^{9,19,42-46}$ it is uncertain whether they do play a role when the reaction is performed in water. To evaluate if silanols assist the reaction in water they were blocked with HMDS. Silanol blocking was confirmed by ${ }^{29} \mathrm{Si}$ NMR, where the decrease in signal of $\mathrm{T}^{2}, \mathrm{Q}^{2}$ and $\mathrm{Q}^{3}$ sites was concurrent with the appearance of $\mathrm{M}$ sites (Figure 6). Integration of the signals indicated that in the resulting HMDS-AP-MSN approximately $30 \%$ of the original silanol groups were blocked. This material was ten times less active than the original AP-MSN $\left(k_{\text {HMDS-AP-MSN }}=0.43\right.$, Figure $\left.S 4\right)$. This result suggests that the silanol groups play an important role in the reaction. They likely assist the reaction by hydrogenbinding the PNB substrate 5 and acetone, which not only brings the reactants into close proximity with the catalytic sites, but also activates them for nucleophilic attack.

\section{Conclusions}

Switching the reaction media between hexane and water led to a reversal in the activities of two closely related catalytic species: while AP-MSN has a lower activity in hexane but a higher activity in water, MAP-MSN has a higher activity in hexane but a lower activity in water. Remarkably, these large differences in behavior are not associated with the change in reaction mechanism, but with the stability of inhibition products and with water inducing shifts in the reaction equilibria.

Far from being beneficial, increasing the polarity of the solvent tended to reduce the catalytic activity of both materials, presumably by enabling proton transfer from silanols to amines, thus blocking their nucleophilicity. Similarly, performing the reaction in a protic solvent, other than water, decreased the activity of both catalysts, likely due to the protonation or strong hydrogen binding of the nucleophilic amines. 
When the reaction is performed in water, the equilibrium between formation and hydrolysis of inhibited states takes place for both catalysts. Therefore, the behavior observed in water suggests that AP-MSN is intrinsically a more active catalyst for the aldol reaction than MAP-MSN.

Silanol groups indirectly participate in the reaction in water by acting as a buffer to allow the enamine pathway rather than general base catalysis, and directly by binding the carbonyl groups of the reactants. This binding of the reactants brings them close to the active sites and activates the carbonyls for nucleophilic attack.

The unusual behavior observed in this work confirms and stresses the notion that the proper choice of catalyst depends not only on its intrinsic activity but also on the environment in its specific application.

\section{ACKNOWLEDGMENT}

This research was supported at the Ames Laboratory by the U.S. Department of Energy, Office of Basic Energy Sciences. Ames Laboratory is operated for the U.S. Department of Energy by Iowa State University under Contract No.DE-AC02-07CH11358.

\section{REFERENCES}

(1) Reichardt, C.; Welton, T. In Solvents and Solvent Effects in Organic Chemistry; Wiley-VCH Verlag GmbH \& Co. KGaA: 2010, p 165-357.

(2) Nguyen Minh, T.; Ha, T. K. J. Am. Chem. Soc. 1984, 106, 599-602.

(3) Acevedo, O.; Jorgensen, W. L. In Annual Reports in Computational Chemistry;

David, C. S., Ed.; Elsevier: 2006; Vol. 2, p 263-278.

(4) Reichardt, C. Org. Process Res. Dev. 2006, 11, 105-113. 
(5) Drexler, M. T.; Amiridis, M. D. J. Catal. 2003, 214, 136-145.

(6) van Grieken, R.; Serrano, D. P.; Melero, J. A.; García, A. J. Mol. Catal. A: Chem. 2004, 222, 167-174.

(7) Zeidan, R. K.; Hwang, S.-J.; Davis, M. E. Angew. Chem. Int. Ed. 2006, 45, 63326335.

(8) Solin, N.; Han, L.; Che, S.; Terasaki, O. Catal. Commun. 2009, 10, 1386-1389.

(9) Kandel, K.; Althaus, S. M.; Peeraphatdit, C.; Kobayashi, T.; Trewyn, B. G.; Pruski, M.; Slowing, I. I. J. Catal. 2012, 291, 63-68.

(10) Nyberg, A. I.; Usano, A.; Pihko, P. M. Synlett 2004, 1891-1896.

(11) Pihko, P. M.; Laurikainen, K. M.; Usano, A.; Nyberg, A. I.; Kaavi, J. A. Tetrahedron 2006, 62, 317-328.

(12) Torii, H.; Nakadai, M.; Ishihara, K.; Saito, S.; Yamamoto, H. Angew. Chem. Int. Ed. 2004, 43, 1983-1986.

(13) Zotova, N.; Franzke, A.; Armstrong, A.; Blackmond, D. G. J. Am. Chem. Soc. 2007, $129,15100-15101$.

(14) Yang, H.; Zhang, G.; Hong, X.; Zhu, Y. Microporous Mesoporous Mater. 2004, 68, 119-125.

(15) Kim, D. J.; Dunn, B. C.; Cole, P.; Turpin, G.; Ernst, R. D.; Pugmire, R. J.; Kang, M.; Kim, J. M.; Eyring, E. M. Chem. Commun. 2005, 1462-1464.

(16) Meiboom, S.; Gill, D. Rev. Sci. Instrum. 1958, 29, 688-691.

(17) Wiench, J. W.; Lin, V. S.-Y.; Pruski, M. J. Magn. Reson. 2008, 193, 233-242.

(18) Nedd, S.; Kobayashi, T.; Tsai, C.-H.; Slowing, I. I.; Pruski, M.; Gordon, M. S. J. Phys. Chem. C 2011, 115, 16333-16339. 
(19) Bass, J. D.; Solovyov, A.; Pascall, A. J.; Katz, A. J. Am. Chem. Soc. 2006, 128, $3737-3747$.

(20) CRC Handbook of Chemistry and Physics; 93 ed.; CRC Press: Boca Raton, FL, 2012.

(21) Paukstelis, J. V.; Cook, A. G. In Enamines: Synthesis, Structure and Reactions; 2 ed.; Cook, A. G., Ed.; Marcel Dekker, Inc.: New York, 1988, p 275-346.

(22) Erkkilä, A.; Majander, I.; Pihko, P. M. Chem. Rev. 2007, 107, 5416-5470.

(23) List, B. Acc. Chem. Res. 2004, 37, 548-557.

(24) Allemann, C.; Gordillo, R.; Clemente, F. R.; Cheong, P. H.-Y.; Houk, K. N. Acc. Chem. Res. 2004, 37, 558-569.

(25) Notz, W.; Tanaka, F.; Barbas, C. F. Acc. Chem. Res. 2004, 37, 580-591.

(26) Brazier, J.; Tomkinson, N.; In Topics in Current Chemistry; List, B., Ed.; Springer Berlin / Heidelberg: 2009; Vol. 291, p 281-347.

(27) List, B.; Lerner, R. A.; Barbas, C. F. J. Am. Chem. Soc. 2000, 122, 2395-2396.

(28) List, B. Chem. Commun. 2006, 819-824.

(29) Seebach, D.; Beck, A. K.; Badine, D. M.; Limbach, M.; Eschenmoser, A.;

Treasurywala, A. M.; Hobi, R.; Prikoszovich, W.; Linder, B. Helv. Chim. Acta 2007, 90, $425-471$.

(30) Guillena, G.; Hita, M. d. C.; Nájera, C.; Viózquez, S. F. J. Org. Chem. 2008, 73, 5933-5943.

(31) Naulet, N.; Filleux, M. L.; Martin, G. J.; Pornet, J. Org. Magn. Reson. 1975, 7, 326330.

(32) Naulet, N.; Martin, G. J. Tetrahedron Lett. 1979, 20, 1493-1496. 
(33) Erkkilä, A.; Pihko, P. M. Eur. J. Org. Chem. 2007, 2007, 4205-4216.

(34) Brogan, A. P.; Dickerson, T. J.; Janda, K. D. Angew. Chem. Int. Ed. 2006, 45, 81008102.

(35) Rogers, C. J.; Dickerson, T. J.; Janda, K. D. Tetrahedron 2006, 62, 352-356.

(36) Schmid, M. B.; Zeitler, K.; Gschwind, R. M. Angew. Chem. Int. Ed. 2010, 49, 49975003.

(37) Dickerson, T. J.; Janda, K. D. J. Am. Chem. Soc. 2002, 124, 3220-3221.

(38) Reymond, J.-L.; Chen, Y. J. Org. Chem. 1995, 60, 6970-6979.

(39) Reymond, J.-L.; Chen, Y. Tetrahedron Lett. 1995, 36, 2575-2578.

(40) Rosenholm, J. M.; Czuryszkiewicz, T.; Kleitz, F.; Rosenholm, J. B.; Linden, M. Langmuir 2007, 23, 4315-4323.

(41) Ong, S.; Zhao, X.; Eisenthal, K. B. Chem. Phys. Lett. 1992, 191, 327-335.

(42) Wang, Q.; Shantz, D. F. J. Catal. 2010, 271, 170-177.

(43) Kubota, Y.; Yamaguchi, H.; Yamada, T.; Inagaki, S.; Sugi, Y.; Tatsumi, T. Top. Catal. 2010, 53, 492-499.

(44) Brunelli, N. A.; Venkatasubbaiah, K.; Jones, C. W. Chem. Mater. 2012, 24, 24332442.

(45) Kubota, Y.; Goto, K.; Miyata, S.; Goto, Y.; Fukushima, Y.; Sugi, Y. Chem. Lett. 2003, 32, 234-235.

(46) Hruby, S. L.; Shanks, B. H. J. Catal. 2009, 263, 181-188. 


\section{SUPPORTING INFORMATION}

Figure S1. Pseudo-first order kinetic plots of AP-MSN (red) and MAP-MSN (blue) in a) water, b) methanol, c) acetonitrile and d) dichloromethane. The plot in hexane can be found in reference 9 .

a)

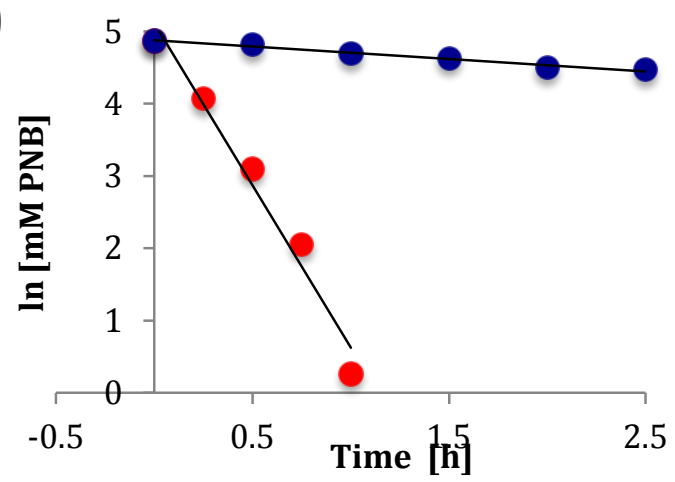

c)

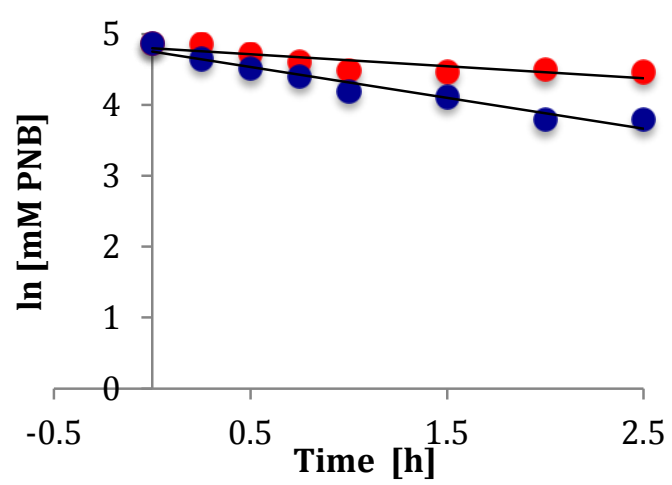

b)

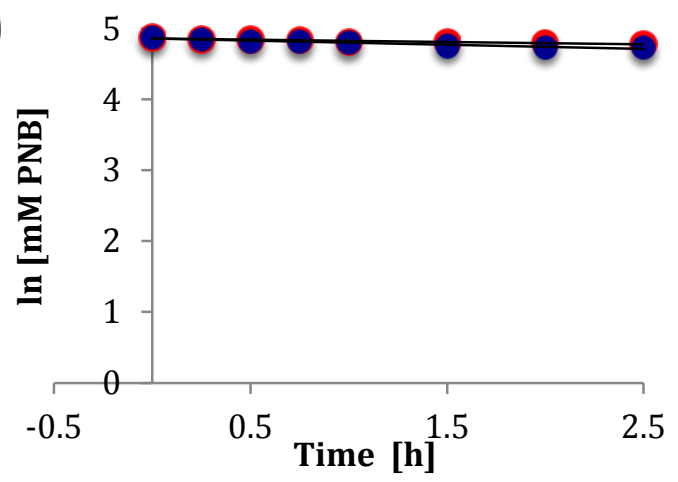

d)

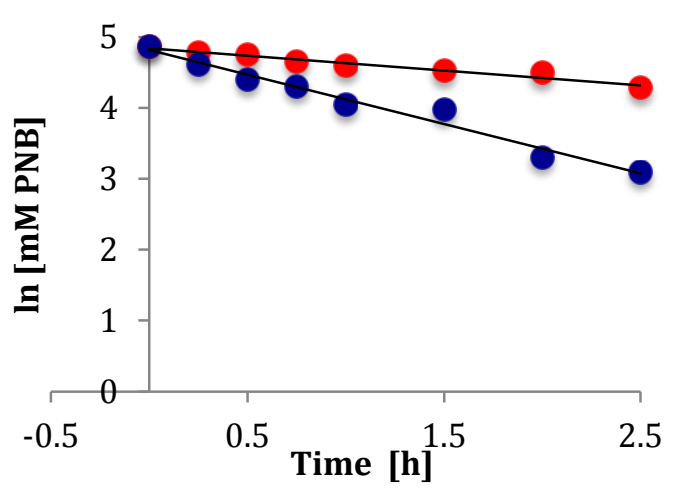


Figure S2. Product distribution for the reactions catalyzed by AP-MSN in: a) water, b) methanol, c) acetonitrile, d) dichloromethane, e) hexane. Circles correspond to aldol product (6), and triangles to enone product (7).
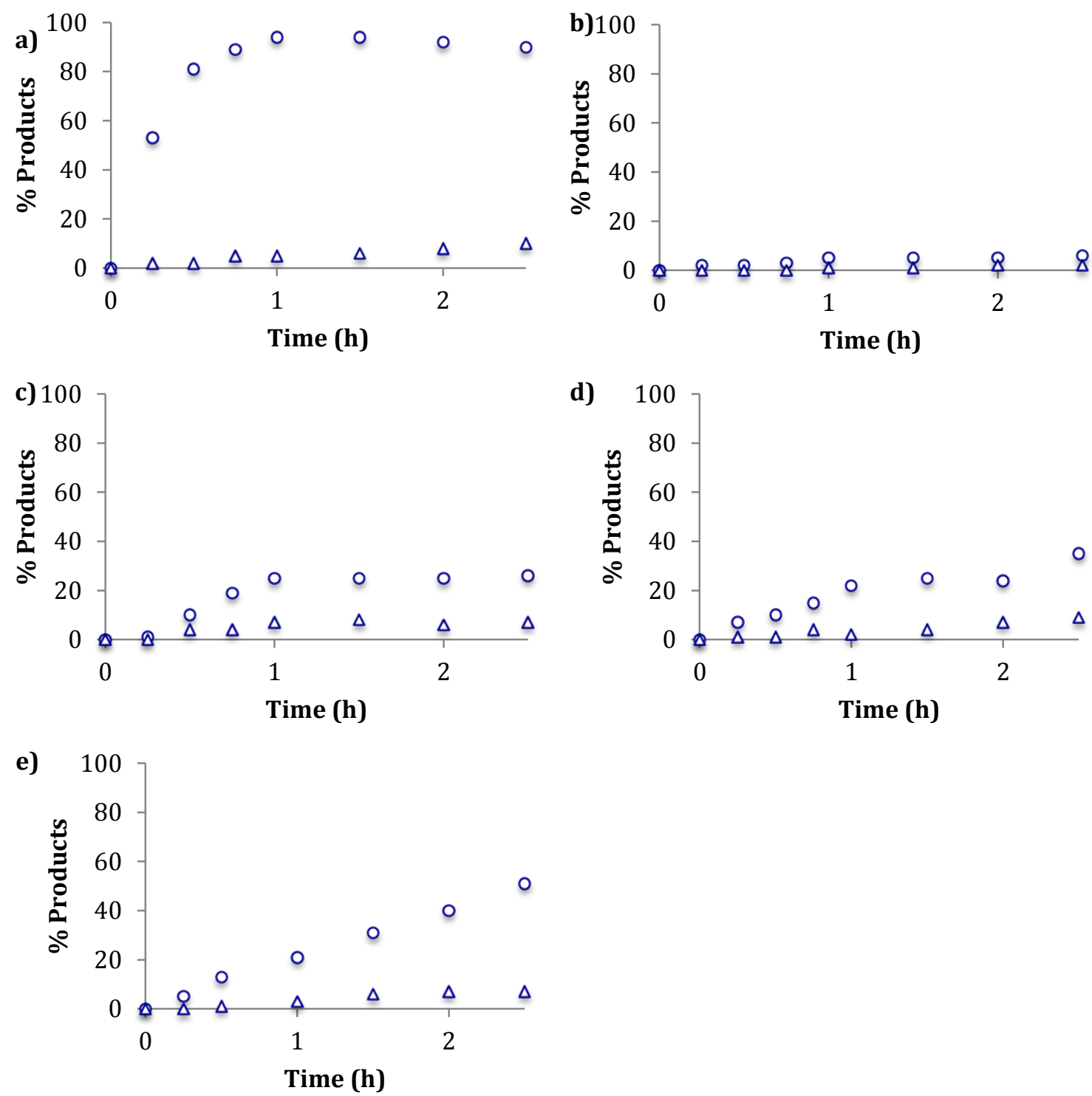
Figure S3. Product distribution for the reactions catalyzed by MAP-MSN in: a) water, b) methanol, c) acetonitrile, d) dichloromethane, e) hexane. Circles correspond to aldol product (6), and triangles to enone product (7).
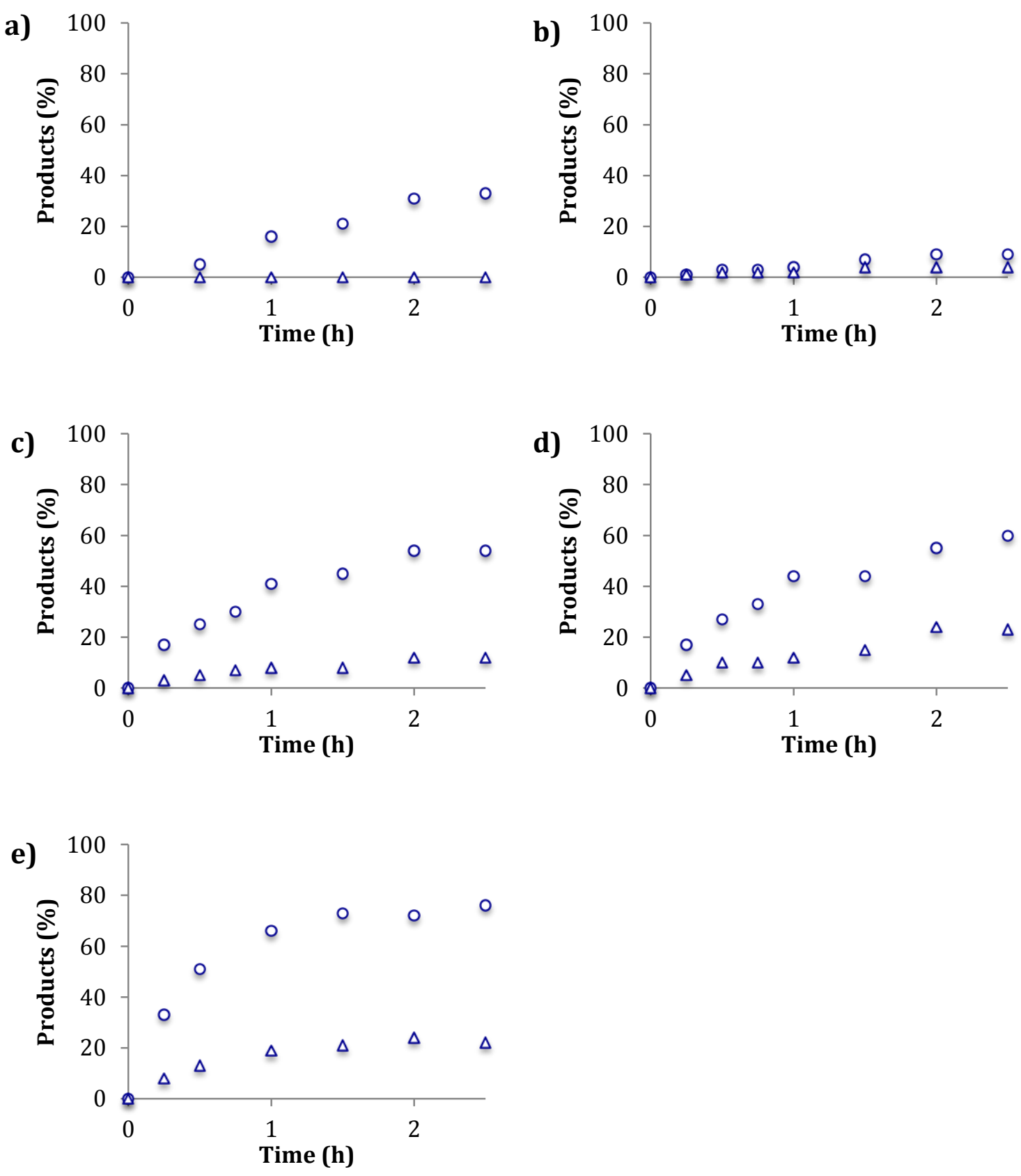
Figure S4. Kinetics of the reaction in water catalyzed by AP-MSN (black circles) and HMDS-AP-MSN (white circles).

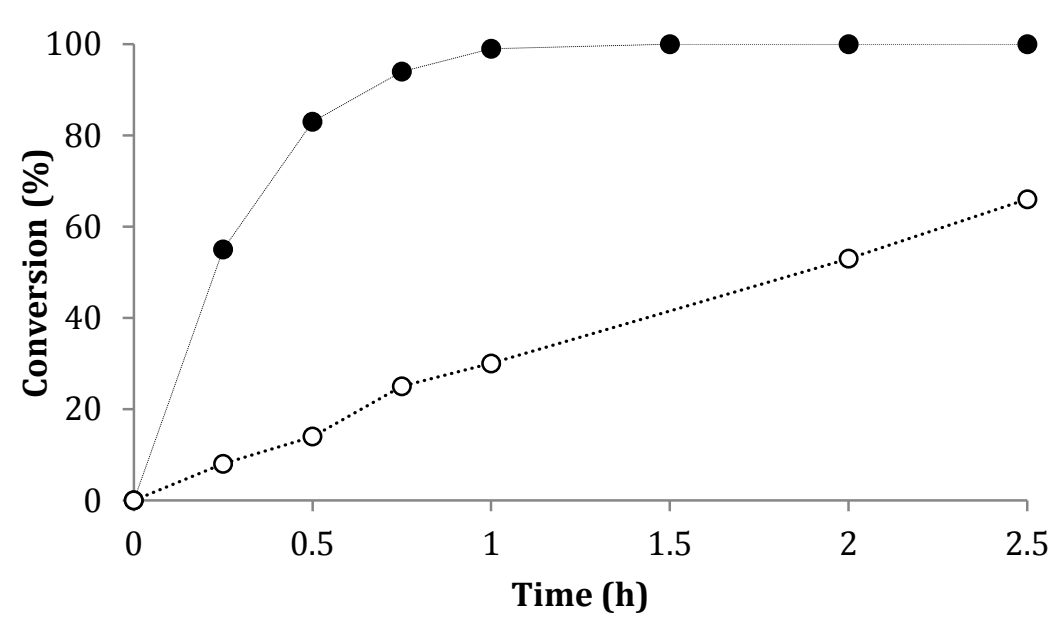

- AP-MSN $\quad \cdots . . . \cdots \cdot$. HMDS-AP-MSN 


\title{
CHAPTER 4. SUPPORTED HYBRID ENZYME-ORGANOCATALYSTS FOR UPGRADING THE CARBON CONTENT OF ALCOHOLS
}

\author{
Modified from the paper accepted in ACS Symposium Series \\ Kapil Kandel, Stacey M. Althaus, Marek Pruski and Igor I. Slowing
}

\begin{abstract}
A bicatalytic system was prepared by the immobilization of alcohol oxidase enzyme and an alkylamine organocatalyst in distinct locations of mesoporous nanoparticles. The resulting nanocomposites were able to perform a sequence of oxidation and aldol coupling reactions, which transformed short chain alcohols into longer chain molecules. The process takes place at low temperatures, but requires additional enzyme (catalase) to prevent inactivation of the catalyst. This qualitative study introduces a model of a hybrid multicomponent nanomaterial that resembles the behavior of multienzymatic systems within confined spaces.
\end{abstract}

\section{Introduction}

Despite being increasingly considered as a biorenewable alternative to gasoline for transportation fuels, the use of ethanol in combustion engines remains limited to blends with

petroleum based fuels. ${ }^{1,2}$ One of the main reasons for this limitation is the low vapor pressure of ethanol that arises from its ability to form hydrogen bonds. In addition, the low carbon to oxygen ratio of ethanol results in a low energy density, making the mileage per volume lower than that of gasoline. ${ }^{3}$ A potential solution to both of these problems is to eliminate the hydroxyl group and increase the carbon content of ethanol. This can be accomplished by deoxygenating and coupling individual molecules into an oligomer. This task has been performed using various approaches, most of them involving energy-intensive processes such as heating the alcohol at 
high temperatures in presence of suitable catalysts. ${ }^{4-6}$ However, it would be desirable to perform these conversions with as little thermal input as possible. To achieve this goal we designed a system that involves the use of two different catalytic species that perform a two step conversion of ethanol at low temperatures in a single pot. While deoxygenation is in principle a reduction, we considered an approach in which the alcohol is initially oxidized to an aldehyde and then oligomerized through a self-aldol condensation at low temperatures (Eqs. (1) and (2)).

$$
\begin{aligned}
& \mathrm{CH}_{3} \mathrm{CH}_{2} \mathrm{OH} \stackrel{\text { Ox. }}{\longrightarrow} \mathrm{CH}_{3} \mathrm{CHO} \\
& x \mathrm{CH}_{3} \mathrm{CHO} \stackrel{\text { Aldol }}{\longrightarrow} \mathrm{CH}_{3}(\mathrm{CH})_{x} \mathrm{CHO}
\end{aligned}
$$

To perform these transformations at low temperature, we chose an enzyme, alcohol oxidase from Pichia pastoris, as the oxidation catalyst that would convert ethanol to acetaldehyde by reaction with oxygen (Eq. (1)). The low temperature aldol condensation of acetaldehyde (Eq. (2)), can be promoted by amines. ${ }^{7}$ One problem with this design is that amines can be oxidized by the enzyme. ${ }^{8}$ To avoid this, mesoporous silica nanoparticles (MSN) were functionalized with amines immobilized mainly in the interior of the pores, with the much larger enzyme attached to the external surface (Fig. 1). This physical separation should prevent any mutual interference between both catalysts, allow them to act independently, yet enable sequential transformation of a substrate, thus behaving like a nanosized assembly line. 


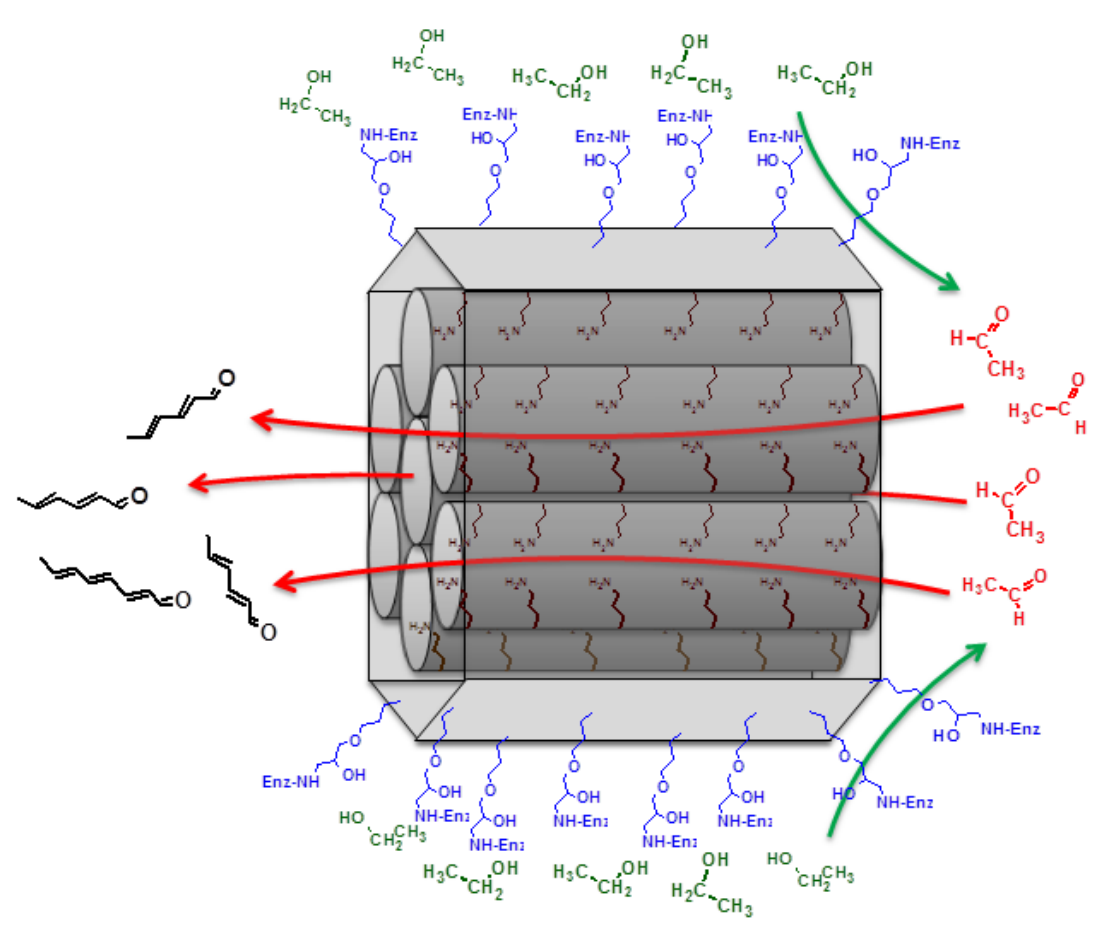

Figure 1. Design of the enzyme-organocatalyst material: an enzyme (Enz, blue.) is immobilized on the external surface of the nanoparticles to promote the oxidation of ethanol (green) to acetaldehyde (red), and an aldol catalyst (primary amine, brown) is located in the interior of the pores to oligomerize the acetaldehyde to compounds with longer carbon chains.

\section{Experimental}

Tetramethyl orthosilicate (98\%), hydrochloric acid (37\%), ethanol (99.5\%), methanol (99.8\%), 1-propanol (99.5\%), 1-butanol (99.8\%), acetaldehyde (99.5\%), toluene $(99.5 \%)$, alcohol oxidase from Pichia pastoris (1KU), catalase from bovine liver (3980 units/mg) were purchased from Sigma-Aldrich. 3-aminopropyl trimethoxysilane (97\%), 3-glycidoxypropyl dimethyl methoxysilane (97\%) were purchased from Gelest. Block copolymer Pluronic P104 was obtained from BASF. All reagents were used as received without further purification. 


\section{Catalyst Preparation}

The MSN catalyst was prepared by co-condensation of 3-aminopropyl trimethoxysilane $(2.1 \mathrm{~mL})$ with tetramethyl orthosilicate $(10.64 \mathrm{~g})$ in presence of the templating agent nonionic block copolymer Pluronic P104 (7 g). The condensation was performed in an acidic medium (164 $\mathrm{g} \mathrm{H}_{2} \mathrm{O}$ and $109 \mathrm{~g} 4 \mathrm{M} \mathrm{HCl}$ ) under constant stirring (400 rpm) for $24 \mathrm{~h}$ at $50{ }^{\circ} \mathrm{C}$. The mixture was then set in a teflon-lined autoclave and heated at $120^{\circ} \mathrm{C}$ for additional $24 \mathrm{~h}$. The white solid obtained was filtered, washed with methanol, and dried in air at room temperature. The templating agent was then removed by Soxhlet extraction in ethanol for $24 \mathrm{~h}$ and the porous solid identified as AP-MSN was dried overnight under vacuum at room temperature.

To immobilize the enzyme, AP-MSN (1.0 g) was reacted with 3-glycidoxypropyl dimethyl methoxysilane linker $(500 \mu \mathrm{L})$ by refluxing in anhydrous toluene $(150 \mathrm{~mL})$ for $3 \mathrm{~h}$. The reaction product was filtered, washed with dry toluene, and dried overnight under vacuum at room temperature. The enzyme immobilization was achieved by mixing the linker-AP-MSN (20 mg) with a sucrose solution of alcohol oxidase from Pichia pastoris (50 $\mu \mathrm{L}, 100$ units) in

phosphate saline buffer (PBS, $\mathrm{pH} 7.4,1.5 \mathrm{~mL})$ at room temperature. The mixture was swirled at $75 \mathrm{rpm}$ in an orbital shaker at room temperature for $6 \mathrm{~h}$. For the catalase containing material, both enzymes (catalase and alcohol oxidase, $1.0 \mathrm{mg}$ and $50 \mu \mathrm{L}$, respectively) were premixed in $0.5 \mathrm{~mL}$ PBS, $\mathrm{pH} 7.4$, and a fresh suspension of linker-AP-MSN in $1.5 \mathrm{~mL}$ PBS was added. The mixture was then swirled at $75 \mathrm{rpm}$ in an orbital shaker for $6 \mathrm{~h}$ at room temperature.

\section{Characterization}

Surface analysis was performed by nitrogen physisorption isotherms in a Micromeritics Tristar surface analyzer. The surface areas were calculated by the Brunauer-Emmett-Teller 
(BET) method and the pore size distributions were calculated from the adsorption branch by the Barrett-Joyner-Halenda (BJH) method. Small angle powder X-ray diffraction patterns were obtained with a Rigaku Ultima IV diffractometer using $\mathrm{Cu}$ target at $40 \mathrm{kV}$ and $44 \mathrm{~mA}$. For transmission electron microscopy (TEM) imaging, an aliquot of the powder was sonicated in methanol. A single drop of this suspension was placed on a lacey carbon coated copper TEM grid and dried in air. The TEM examination was completed on a Tecnai G2 F20 electron microscope operated at $200 \mathrm{kV}$. Dynamic light scattering and $\xi$-potential measurements were performed in a Malvern Nanosizer ZS90 using suspensions of the materials with pH 7.4.

\section{Solid-state NMR}

${ }^{13} \mathrm{C}$ cross polarization magic angle spinning (CPMAS) solid-state NMR experiments were used to confirm the structures of the surface bound species. These experiments were preformed at 14.1 T on a Varian NMR System 600 spectrometer equipped with a 1.6-mm Fast MAS ${ }^{\mathrm{TM}}$ probe operated at 599.6 MHz $\left({ }^{1} \mathrm{H}\right)$ and $150.8 \mathrm{MHz}\left({ }^{13} \mathrm{C}\right)$. Experimental parameters are given in the figure caption using the following symbols: $v_{R}$ is the MAS rate, $v_{R F}(X)$ is the magnitude of radiofrequency magnetic field $(\mathrm{RF})$ applied to $\mathrm{X}$ spins, $\tau_{\mathrm{CP}}$ is the mixing time during cross polarization, $\tau_{\mathrm{RD}}$ is the recycle delay, $\mathrm{NS}$ is the number of scans, and AT is the total acquisition time. The chemical shifts of ${ }^{13} \mathrm{C}$ and ${ }^{1} \mathrm{H}$ are reported using the $\delta$ scale and referenced to tetramethylsilane (TMS) at $0 \mathrm{ppm}$.

\section{Catalytic Reactions}

Self-aldol reaction was performed by stirring an aqueous suspension of AP-MSN or linker-AP-MSN (20.0 mg, $10.0 \mathrm{~mL})$ and acetaldehyde $(0.100 \mathrm{~mL}, 1.8 \mathrm{mmol})$ at $40{ }^{\circ} \mathrm{C}$ for $20 \mathrm{~h}$. 
The reaction was monitored by extraction with $1.0 \mathrm{~mL}$ diethyl ether and analysis of the extract by gas chromatography with a mass spectrometry detector (GC MS).

The sequential oxidation-self-aldol reaction was performed by adding ethanol ( $5 \mu \mathrm{L}, 86$ $\mu \mathrm{mol})$ to a freshly prepared suspension of the enzyme-AP-MSN material in PBS (3.0 mL). Oxygen gas was bubbled into the suspension for $1 \mathrm{~min}$, and the mixture was stirred at $40{ }^{\circ} \mathrm{C}$ for $20 \mathrm{~h}$. Reaction products were monitored by extraction with $1.0 \mathrm{~mL}$ diethyl ether and GC MS analysis.

\section{Results and Discussion}

\section{Synthesis of AP-MSN and Catalysis of Self-Aldol Condensation}
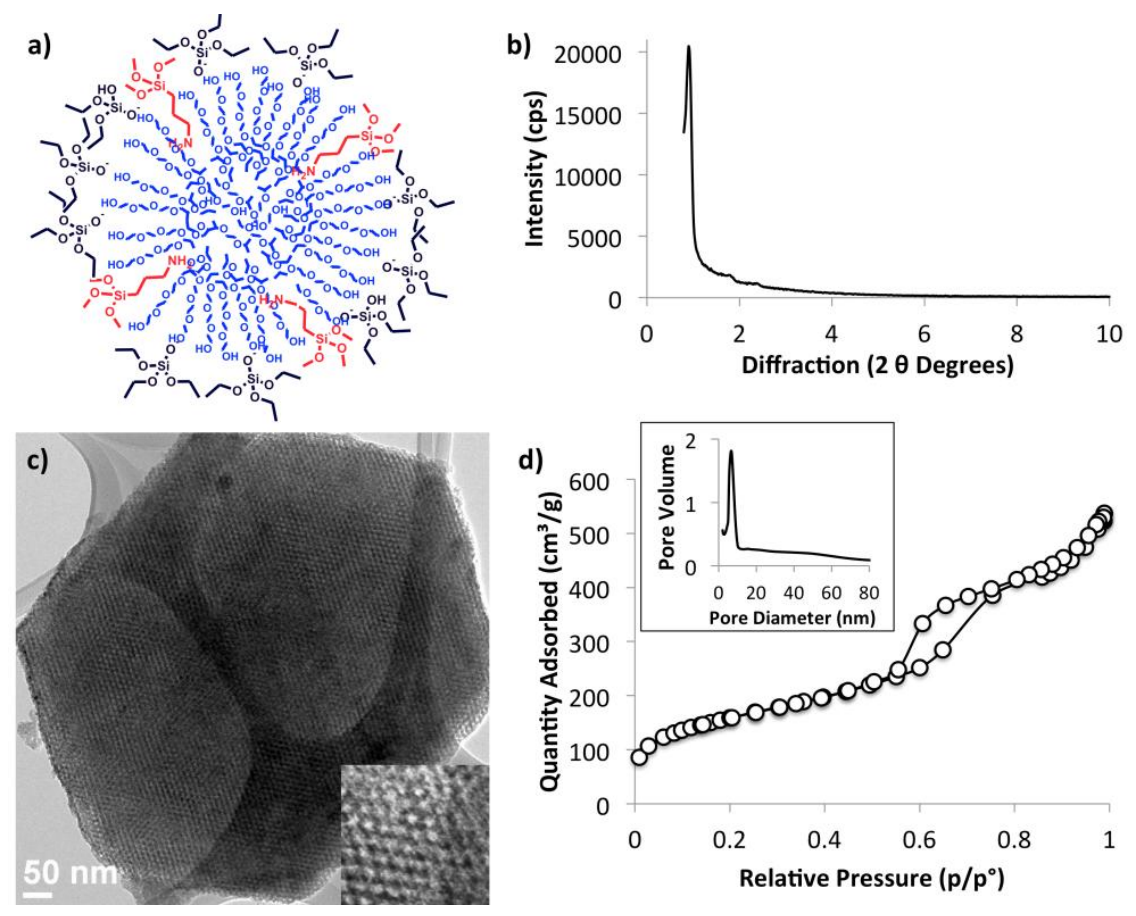

Figure 2. AP-MSN: a) Co-condensation of 3-aminopropyl groups at the interface between the growing silica polymer and the templating surfactant micelles, b) small angle powder X-ray diffraction pattern, c) transmission electron micrograph (insert: zoomed in detail of the micrograph showing the hexagonal pore order), and d) nitrogen physisorption isotherms (insert: pore size distribution in nanometers) of the material. 
The co-condensation of organosilanes with orthosilicates in the presence of surfactants is a valuable technique for achieving homogeneous functionalization of mesoporous silicas. The interaction between the 3-aminopropyl group and the surfactant micelles during the synthesis of the material tends to favor its localization at the interface between the surfactant and the surface of silica (Fig. 2a). This interface corresponds to the pore surface of the resulting materials. ${ }^{9,10}$ Powder X-ray diffraction of the material suggests a highly ordered 2D-hexagonal array of mesopores (Fig. 2b), as confirmed by transmission electron microscopy (Fig. 2c). Dynamic light scattering measurements were consistent with the sub-micron particle size observed by TEM $(750 \times 400 \mathrm{~nm}$ sized particles). Nitrogen sorption analysis, following surfactant extraction, confirmed the material possessed a high surface area $\left(575 \mathrm{~m}^{2} / \mathrm{g}\right)$ and a narrow pore size distribution centered at $6.6 \mathrm{~nm}$ (Fig. 2d). A positive $\xi$-potential of the material $(+28.0 \mathrm{mV}$ at $\mathrm{pH}$ 7.4) was consistent with the presence of the 3-aminopropyl functionality on the surface of the material.

The catalytic activity of AP-MSN for the self-aldol reaction was tested by addition of acetaldehyde to an aqueous suspension of AP-MSN. Within five minutes the white AP-MSN material started to gradually change color to a light yellow and eventually turned brown. This color change appears to result from the adsorption of hydroxylated oligomers on the surface of the the material through hydrogen bonding with surface silanols. GC MS analysis of the ether extracts showed a mixture of products (Fig. 3), the most abundant being the dimerization product 3-hydroxy-butanal (65\% of the products observed). Increasing the amount of acetaldehyde lead to a more complex distribution of products than observed at low concentrations. A tenfold increase in acetaldehyde concentration altered the distribution of products towards higher 
molecular weights, with the trimer 2,4-hexadienal being the most abundant species (36\% of the detected products), and the distinct formation of a tetramer (Fig. 3c).

a)<smiles>CC=CC=O</smiles><smiles>CC(O)CC=O</smiles><smiles>CC1CC(O)OC(C)O1</smiles>

b)<smiles>CC=CC=CC=O</smiles><smiles>CC(O)C/C=C/C=O</smiles><smiles>CC1CC=CC(O)O1</smiles><smiles>C=C/C(C=O)=C\C</smiles>

c)<smiles>CC=CC=CC=CC=O</smiles>

Figure 3. The most abundant products from the self-aldol reaction of acetaldehyde catalyzed by AP-MSN observed by GC MS analysis of the ether extracts $\left(20 \mathrm{~h}\right.$ at $\left.40^{\circ} \mathrm{C}\right)$. Products are classified as a) dimers, b) trimers, and c) tetramer.

\section{Incorporation of Enzyme and Catalysis for Sequential Conversion}

AP-MSN was then grafted with the glycidoxypropyl silane linker and the presence of both groups was confirmed by solid-state NMR (Fig. 4). The incorporation of the glycidoxypropyl group was expected to take place mainly at the most accessible external surface. ${ }^{11,12}$ This glycidoxypropyl modified AP-MSN suspended better in water and had a slightly more positive $\xi$-potential $(+30.5 \mathrm{mV})$, consistent with the reduction of the number of 
silanol groups by the grafting procedure. This material was still capable of catalyzing the selfaldol reaction of acetaldehyde with a distribution of products similar to that of AP-MSN.

a)

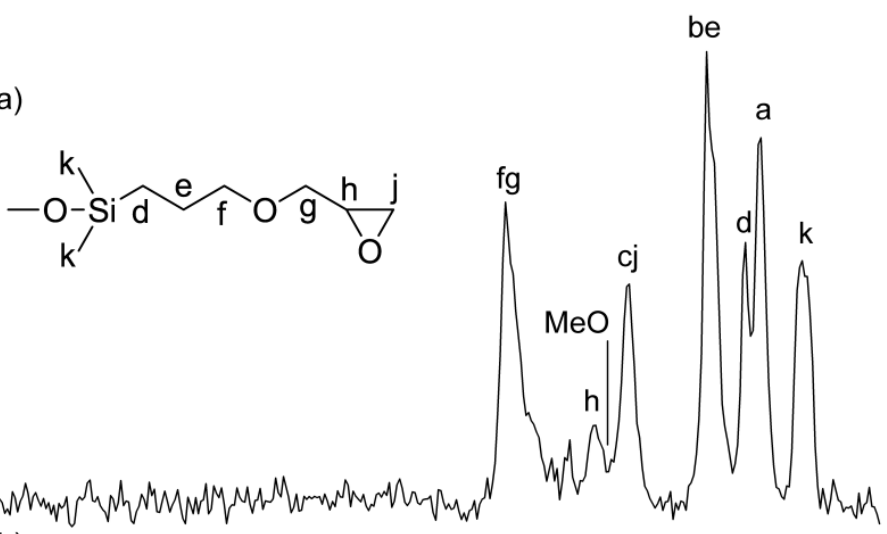

b)

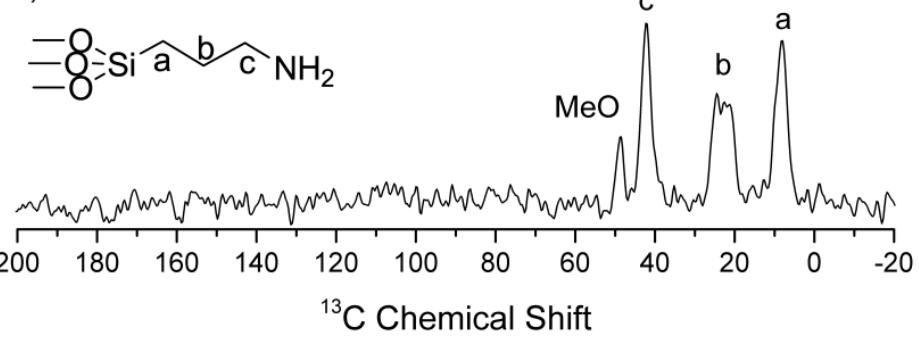

Figure $4 .{ }^{13} \mathrm{C}$ CPMAS NMR spectra of a) glycidoxypropyl-AP-MSN and b) AP-MSN. Spectrum a) was acquired using $v_{\mathrm{R}}=40 \mathrm{kHz}, v_{\mathrm{RF}}\left({ }^{13} \mathrm{C}\right)=100 \mathrm{kHz}, v_{\mathrm{RF}}\left({ }^{1} \mathrm{H}\right)$ during $\mathrm{CP}=60 \mathrm{kHz}, v_{\mathrm{RF}}\left({ }^{1} \mathrm{H}\right)$ during SPINAL-64 decoupling $=10 \mathrm{kHz}, \tau_{\mathrm{CP}}=1 \mathrm{~ms}, \tau_{\mathrm{RD}}=3 \mathrm{~s}, \mathrm{NS}=12288$, and AT $=10.3 \mathrm{~h}$. Spectrum b) used $v_{\mathrm{R}}=40 \mathrm{kHz}, v_{\mathrm{RF}}\left({ }^{13} \mathrm{C}\right)=60 \mathrm{kHz}, v_{\mathrm{RF}}\left({ }^{1} \mathrm{H}\right)$ during $\mathrm{CP}=100 \mathrm{kHz}, v_{\mathrm{RF}}\left({ }^{1} \mathrm{H}\right)$ during SPINAL-64 decoupling $=11 \mathrm{kHz}, \tau_{\mathrm{CP}}=2 \mathrm{~ms}, \tau_{\mathrm{RD}}=3 \mathrm{~s}, \mathrm{NS}=10240$, and AT $=8.7 \mathrm{~h}$.

Alcohol oxidase was immobilized on the material by covalently binding free amine groups of the enzyme with the glycidoxypropyl linker (Eq. (3)). ${ }^{13}$ The enzyme was added to a suspension of linker-AP-MSN and the mixture was shaken for $6 \mathrm{~h}$ at room temperature. This led to a red colored mixture, which became a pink solid after centrifugation and washing, indicative of the retention of the enzyme. The addition of ethanol to a suspension of the enzyme-AP-MSN nanocomposite produced an immediate color change to bright yellow, indicative of the irreversible inactivation of the enzyme. GC MS analysis of ether extracts gave no indication of 
catalytic activity. To evaluate the possibility that the bound enzyme could be blocking the pores of the material, a sample was prepared by reacting linker-AP-MSN (100 mg) with bovine serum albumin $(10 \mathrm{mg})$ as a model of the alcohol oxidase enzyme. Nitrogen physisorption analysis of the composite revealed that the binding of the protein significantly reduced the surface area of the material from the original $575 \mathrm{~m}^{2} / \mathrm{g}$ to $282 \mathrm{~m}^{2} / \mathrm{g}$, while the pore size decreased only moderately (from 6.6 to $5.6 \mathrm{~nm}$ ). However, this reduction in porosity would not justify the lack of activity of the composite.

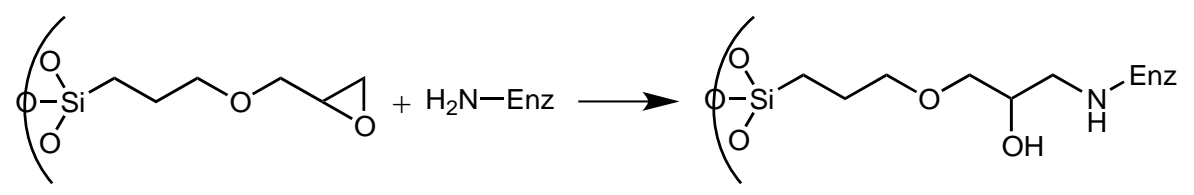

Hydrogen peroxide is a byproduct of the oxidation of alcohols catalyzed by alcohol oxidase, and this substance is a potent inhibitor of this enzyme (Eq. (4)). ${ }^{14}$ One way to circumvent this problem is to introduce into the reaction system a second enzyme (catalase) to facilitate the conversion of hydrogen peroxide to oxygen (Eq. (5)). ${ }^{15}$ The addition of catalase to the alcohol oxidase-AP-MSN suspension, followed by bubbling with oxygen and addition of ethanol, enabled the material to catalyze the tandem conversion of alcohol into acetaldehyde oligomers. No obvious signs of enzyme inactivation were observed during the first $20 \mathrm{~h}$ of the reaction. However, after $20 \mathrm{~h}$ at $40{ }^{\circ} \mathrm{C}$ the material failed to catalyze the conversion of additional ethanol, indicating the inactivation of the enzyme.

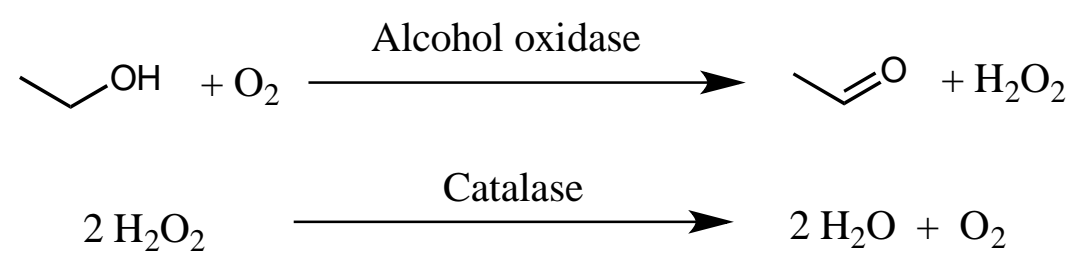


Surprisingly, contrary to the complex mixtures obtained from the AP-MSN catalyzed self-aldol reaction of acetaldehyde, the sequential oxidation-aldol reaction catalyzed by the enzyme-AP-MSN material gave a simple mixture consisting mainly of the linear trimer $(2,4-$ hexadienal, 72\% of the observed products), and two dimers (2-hydroxybutanal and 2-butenal, 10 and $18 \%$ of the detected products, respectively) (Fig. 5). It should be stressed that the main product of the AP-MSN catalyzed self-aldol condensation was a dimer, whereas the tandem conversion catalyzed by the enzyme-AP-MSN material produced mainly a trimer. This suggests that the sequential reaction takes place in a more controlled fashion than the single step self-aldol reaction.

a)
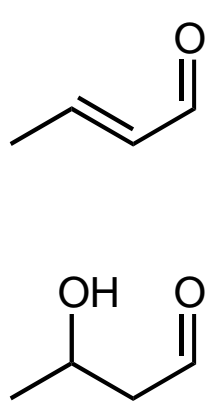

b)

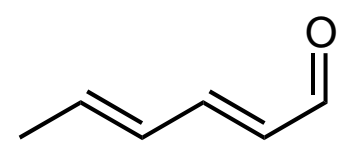

c)

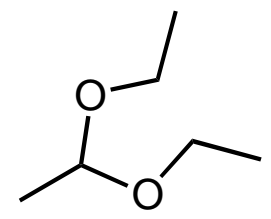

Figure 5. Products observed in the tandem oxidation-aldol conversion of ethanol catalyzed by the alcohol oxidase-AP-MSN nanocomposite: a) dimers, b) trimer, and c) acetal formed only upon addition of excess ethanol.

In contrast to the single step self-aldol reaction, a 10-fold increase in substrate did not have an effect on the product distribution, as the trimer (2,4-hexanedial) remained the main product of the sequential oxidation-aldol. However, increasing the amount of ethanol from 29 to $290 \mathrm{mM}$ had two significant effects. First, it led to denaturing of the enzyme after only $1 \mathrm{~h}$ of reaction, as evidenced by the color change of the reaction media to a bright yellow and loss of activity. This change in color could not be reversed by bubbling additional oxygen. According to 
Eq. (4) addition of an excess of ethanol must have led to the production of high concentrations of hydrogen peroxide. If the concentration of this byproduct became too large, it could not be completely degraded by the limited amount of catalase available, and would therefore irreversibly deactivate alcohol oxidase. $(14,15)$ The second effect of the excess of ethanol was evidenced by the formation of an acetal as detected by GC MS analysis (Fig. 5c). This product was formed upon acetaldehyde trapping by unreacted ethanol (Eq. (6)). This side-reaction prevented the already limited amount of acetaldehyde from undergoing further self-aldolization. Therefore the excess of alcohol inhibited both catalytic processes: the enzymatic oxidation and the self-aldol condensation.

$$
\mathrm{CH}_{3} \mathrm{CHO}+2 \mathrm{CH}_{3} \mathrm{CH}_{2} \mathrm{OH} \longrightarrow \mathrm{CH}_{3} \mathrm{CH}\left(\mathrm{OCH}_{2} \mathrm{CH}_{3}\right)_{2}
$$

The product distribution observed in the sequential oxidation-aldol process in comparison to the one-step self-aldol catalyzed by AP-MSN was likely controlled by the limited availability of the intermediate acetaldehyde. The availability of acetaldehyde was regulated not only by the enzymatic activity, but also by the presence of excess ethanol that could capture the intermediate as an acetal. Therefore, optimization of the process is highly dependent on the rate of ethanol feeding. Low ethanol concentrations minimize formation of acetals (Eq. (6)), and also slow the production of hydrogen peroxide by-product allowing for its efficient degradation by catalase (Eqs. (4) and (5)).

Other alcohols were tested to evaluate the scope of application of this bifunctional catalyst. Alcohol oxidase is known to be a good substrate for short chain alcohols, with activity decreasing with increasing bulkiness of the organic group. ${ }^{14,16,17}$ Addition of propanol and butanol to suspensions of the enzyme-AP-MSN material in presence of catalase yielded the 
corresponding dimers with almost 100\% selectivity (Eqs. (7) and (8)). The crossed-aldol reaction between methanol and acetone was attempted but no aldol products were observed.

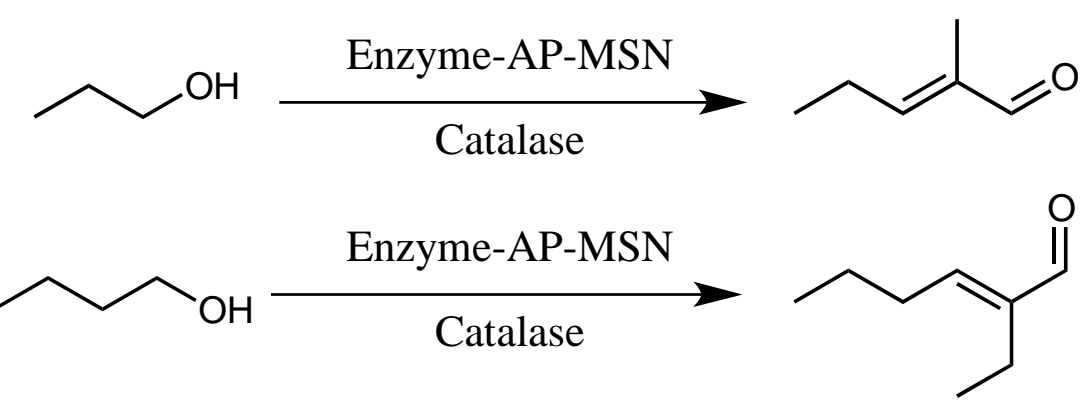

\section{Conclusions}

We developed a bifunctional heterogeneous catalyst comprised of an enzyme (alcohol oxidase) and an organocatalytic amine supported on high surface area mesoporous nanoparticles. This bicatalytic material is capable of promoting the sequential conversion of small chain alcohols into longer chain aldehydes with good selectivity. Site-separation of the two catalytic moieties within different domains of the nanoparticles prevented oxidation of the amine by the enzyme. Addition of catalase to the system degraded the by-product hydrogen peroxide, preventing inhibition of the alcohol oxidase enzyme. The reaction catalyzed by the multifunctional material displayed high selectivity for the product of trimerization, independent of the initial concentration of substrate alcohol. However, excess alcohol affected the stability of the enzyme due to accumulation of hydrogen peroxide. Further work is currently in progress to improve yields and enzyme stability. Fine tuning the amount of the aminopropyl active sites on the support, along with incorporation of an enzyme stabilizer, should provide improved conversion. This exploratory study demonstrates the enormous potential that the hybrid enzymatic-organocatalytic multifunctional nanodevices have for the transformation of small 
molecules into more complex and valuable products, despite the complexity and difficulties associated with the creation of such nanosized assembly lines.

\section{Acknowledgement}

This research was supported at the Ames Laboratory by the U.S. Department of Energy, Office of Basic Energy Sciences. Ames Laboratory is operated for the U.S. Department of Energy by Iowa State University under Contract No. DE-AC02-07CH11358. The authors wish to thank BASF Co. for the generous donation of P104 triblock copolymer.

\section{References}

(1) Abdel-Rahman, A. A.; Osman, M. M. Int. J. Energy Res. 1997, 21, 31.

(2) Wallner, T.; Miers, S. A.; McConnell, S. J. Eng. Gas Turbines Power 2009, 131, 032802.

(3) Jeuland, N.; Montagne, X.; Gautrot, X. Oil Gas Sci. Technol. - Rev. IFP 2004, 59, 559.

(4) Oudejans, J. C.; Van Den Oosterkamp, P. F.; Van Bekkum, H. Appl. Catal. 1982, $3,109$.

(5) Takahara, I.; Saito, M.; Inaba, M.; Murata, K. Catal. Lett. 2005, 105, 249.

(6) Sun, J.; Zhu, K.; Gao, F.; Wang, C.; Liu, J.; Peden, C. H. F.; Wang, Y. J. Am. Chem. Soc. 2011, 133, 11096.

(7) Kandel, K.; Althaus, S. M.; Peeraphatdit, C.; Kobayashi, T.; Trewyn, B. G.; Pruski, M.; Slowing, I. I. J. Catal. 2012, 291, 63.

(8) Fitzpatrick, P. F. J. Labelled Compd. Radiopharm. 2007, 50, 1016. 
(9) Huh, S.; Wiench, J. W.; Yoo, J.-C.; Pruski, M.; Lin, V. S.-Y. Chem. Mater. 2003, $15,4247$.

(10) Yokoi, T.; Yoshitake, H.; Tatsumi, T. Chem. Mater. 2003, 15, 4536.

(11) Mal, N. K.; Fujiwara, M.; Tanaka, Y. Nature 2003, 421, 350.

(12) De Juan, F.; Ruiz-Hitzky, E. Adv. Mater. 2000, 12, 430.

(13) Haginaka, J. J. Chromatogr., A 2001, 906, 253.

(14) Couderc, R.; Baratti, J. Agric. Biol. Chem. 1980, 44, 2279.

(15) Geissler, J.; Ghisla, S.; Kroneck, P. M. H. Eur. J. Biochem. 1986, 160, 93.

(16) Sahm, H.; Schütte, H.; Kula, M.-R. In Methods Enzymol.; Willis, A. W., Ed.; Academic Press: 1982; Vol. 89, p 424.

(17) Menon, V.; Hsieh, C. T.; Fitzpatrick, P. F. Bioorg. Chem. 1995, 23, 42. 


\title{
CHAPTER 5. TOWARDS MICROALGAE BIOREFINERY: UTILIZING MAGNETIC MESOPOROUS SILICA NANOTECHNOLOGY FOR HARVESTING, EXTRACTION, AND SELECTIVE SEQUESTRATION OF VALUE-ADDED MOLECULES
}

\author{
Modified from a paper submitted to Energy and Environmenal Science \\ Kapil Kandel, Igor I. Slowing, Justin S. Valenstein, Yannan Zhao, Young-Jin Lee, Victor S.-Y. \\ Lin $^{\$}$ and Brian G. Trewyn \\ ${ }^{\$}$ In memory of Professor Dr. Victor S.-Y. Lin, Deceased May 2010
}

\begin{abstract}
We report a novel application of aminopropyl functionalized magnetic mesoporous silica nanomaterials ( $\mathrm{AP}-\mathrm{Fe}_{3} \mathrm{O}_{4}-\mathrm{MSN}$ ) for microalgae harvesting followed by sequestration of naturally produced free fatty acid (FFAs) molecules. Nearly $70 \%$ of microalgae biomass was magnetically removed due to binding of positively charged $\mathrm{AP}-\mathrm{Fe}_{3} \mathrm{O}_{4}-\mathrm{MSN}$ to the negatively charged surface of microalgae cells. Upon removal, the ionic liquid 1-butyl-3methylimidazolium chloride [BMIm] $\mathrm{Cl}$ was used to hydrolyze the wet microalgae biomass allowing the release of microalgae-produced oil feedstock. As high as $79 \%$ of the available FFAs present in the microalgae oil feedstock was selectively sequestered using identical $\mathrm{AP}-\mathrm{Fe}_{3} \mathrm{O}_{4^{-}}$ MSN making it more favorable for biodiesel production. The results presented here provide a proof-of-principle application for utilizing the surface functionalized magnetic mesoporous nanomaterials in biorefinery to produce advanced biofuel and bioproducts.
\end{abstract}




\section{Introduction}

Most microalgae are single-cell free floating organisms with minimal tendency to aggregate in colonies due to the dilute nature of microalgae cultures. ${ }^{1,2}$ Because of the high water content in microalgae cultures, harvesting (dewatering) and downstream processing requires separating microalgae from water prior to extraction of lipids. ${ }^{3}$ Dewatering maximizes the microalgae biomass concentration, which in turn facilitates the extraction process that follows by increasing solvent-to-algae contact ratio. However, due to small algal cell size, similar density to water, and low biomass concentrations in cultures; current means of dewatering is extremely capital and energy intensive. ${ }^{1-5}$

The major techniques currently employed in microalgae dewatering and recovery include centrifugation, flocculation and filtration. ${ }^{5,6}$ Centrifugation is rapid and the preferred method for microalgae cell recovery but it is energy intensive and processing large volumes of culture is time consuming and expensive. Even though flocculation has proven to be a superior method for concentrating microalgae, sedimentation of microalgae floculations (flocs) is challenging because these flocs have a specific gravity close to, and even below, that of water when exposed to light, releasing photosynthetic oxygen. ${ }^{3,7}$ The major challenges associated with filtration are that microalgae tend to bind to and foul the filter, requiring regular backwashes. Several efforts on enhancement of dewatering by combining these techniques has been investigated, however additional steps require substantial energy input and high operational cost. ${ }^{3}$ While there has been much research on optimization of algal growth, ${ }^{1,8}$ extraction $^{9,10}$ and conversion ${ }^{11,12}$; research on economical harvesting technique is ongoing and there is a dearth of published reports on this subject. 
Scheme 1. Illustration of integrated biorefinery involving microalgae harvesting, extraction and selective sequestration of FFAs

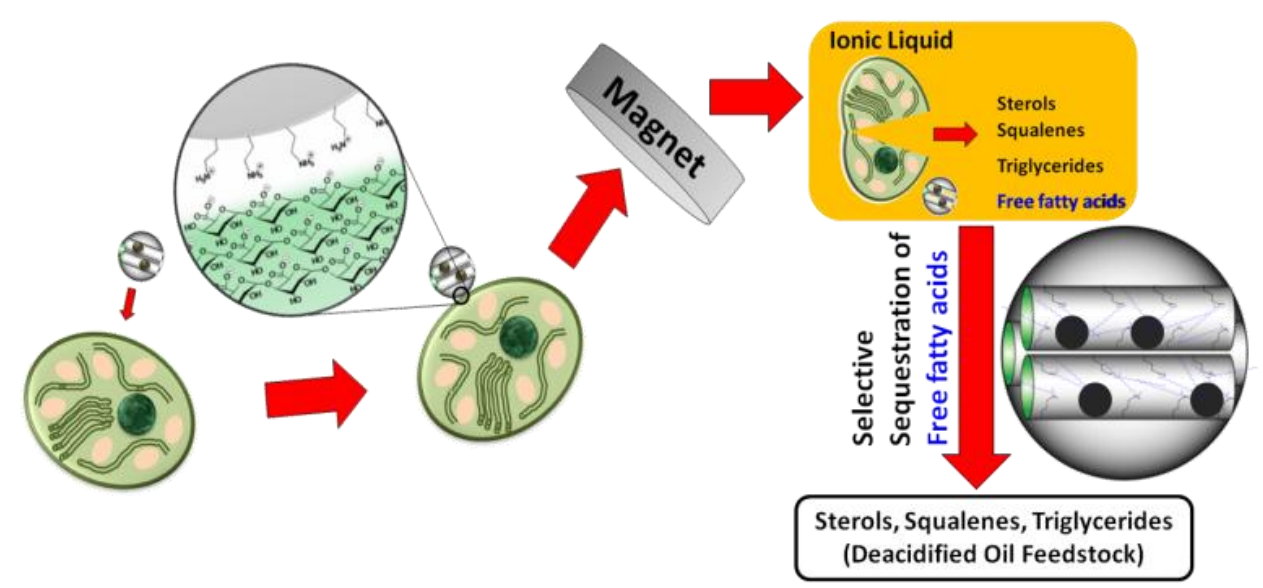

In recent years, magnetic nanoparticles have been used for bioseparation, ${ }^{13}$ cell isolation, ${ }^{14}$ enzyme immobilization, ${ }^{15}$ protein purification, ${ }^{16}$ wastewater treatment, ${ }^{17}$ etc.

Moreover, our group has reported the biomedical application of mesoporous silica nanomaterials (MSN) capped with superparamagnetic iron oxide nanoparticles as a controlled release drug delivery vehicle in the presence of an external magnetic field. ${ }^{18}$ Considering the stable physiochemical property of magnetic nanoparticles and high surface area, pore volume and tunable pore sizes of MSNs, we envisioned a hybrid magnetic mesoporous silica nanomaterial $\left(\mathrm{Fe}_{3} \mathrm{O}_{4}-\mathrm{MSN}\right)$ by growing iron oxide nanoparticles inside the pores of MSN. Additionally, owing to our recent demonstration on the selective sequestration of free fatty acids from crude bio-oil using amine functionalized mesoporous silica nanomaterials $(\mathrm{AP}-\mathrm{MSN})^{19}$, we further envisioned that decorating the surface of $\mathrm{Fe}_{3} \mathrm{O}_{4}-\mathrm{MSN}$ with amine groups has two important advantages during biodiesel production from microalgae. First, amine functionalization generates a positive charge on the outer surface of $\mathrm{Fe}_{3} \mathrm{O}_{4}$-MSN and aids in neutralizing the negative surface charge of microalgae cells thereby leading to cell flocculation. ${ }^{20,21}$ Secondly, amine groups on the pore 
surface of $\mathrm{Fe}_{3} \mathrm{O}_{4}-\mathrm{MSN}$ creates a specific binding sites for selective sequestration of free fatty acids and helps in deacidification of microalgae oil making it more favorable to be used as a biodiesel source. ${ }^{19}$ To the best of our knowledge, this is the first report on an application of nanotechnology for an integrated biorefinery process involving dewatering of microalgae, extraction of lipids and selective sequestration of high-value hydrocarbon present in microalgae cells (Scheme 1).

Herein, we report the synthesis, characterization and application of amine functionalized magnetic mesoporous silica nanomaterials ( $\left.\mathrm{AP}-\mathrm{Fe}_{3} \mathrm{O}_{4}-\mathrm{MSN}\right)$ to concentrate microalgae in the dewatering step of biodiesel production. In addition, we used an ionic liquid to extract lipids from the dewatered microalgae and finally, demonstrated the selective sequestration of free fatty acids from the lipid extract using $\mathrm{AP}-\mathrm{Fe}_{3} \mathrm{O}_{4}-\mathrm{MSN}$. We describe the proof-of-principle of an advanced nanotechnology that has the potential to solely incorporate dewatering ability followed by molecular level selective sequestration.

\section{Experimental Section}

Materials. Pluronic was provided by BASF. Tetramethylorthosilicate (TMOS) and 1butyl-3-methylimidazolium chloride [BMIm]Cl were purchased from Sigma Aldrich. 3aminoproyltrimethoxysilane (APTMS) was purchased from Gelest. Iron(III) nitrate $\left[\mathrm{Fe}\left(\mathrm{NO}_{3}\right)_{3} \bullet 9 \mathrm{H}_{2} \mathrm{O}\right]$ was purchased from Fisher Scientific.

Synthesis of $\mathrm{Fe}_{3} \mathrm{O}_{4}-\mathrm{MSN}$. Initially, MSN was prepared using a nonionic block copolymer Pluronic P104 surfactant. ${ }^{22}$ For a typical synthesis, P104 (7 g) was dissolved in a solution containing $\mathrm{H}_{2} \mathrm{O}(164 \mathrm{~g})$ and $4 \mathrm{M} \mathrm{HCl}(109 \mathrm{~g})$ at $55^{\circ} \mathrm{C}$ under constant stirring for an hour. Tetramethylorthosilicate (TMOS, $10.64 \mathrm{~g}, 0.070 \mathrm{~mol}$ ) was added to the surfactant solution and 
the mixture was stirred for $24 \mathrm{~h}$ at $55^{\circ} \mathrm{C}$. The reaction mixture was then transferred into a Teflon-lined autoclave and hydrothermally treated at $150{ }^{\circ} \mathrm{C}$ for $24 \mathrm{~h}$. The resultant white precipitate was filtered, washed with methanol and dried in air. The surfactant was removed by calcination in air at $550{ }^{\circ} \mathrm{C}$ for $6 \mathrm{~h}$. Iron(III) nitrate $\left(\mathrm{Fe}\left(\mathrm{NO}_{3}\right)_{3} \bullet 9 \mathrm{H}_{2} \mathrm{O}\right)$ was used as the iron precursor. ${ }^{23} \mathrm{Fe}\left(\mathrm{NO}_{3}\right)_{3} \bullet 9 \mathrm{H}_{2} \mathrm{O}(1.26 \mathrm{~g}, 3.1 \mathrm{mmol})$ was completely dissolved in $10 \mathrm{ml}$ ethanol and $0.5 \mathrm{~g}$ of MSN was suspended in $\mathrm{Fe}\left(\mathrm{NO}_{3}\right)_{3} /$ ethanol solution. The suspension was left to dry in air at $30^{\circ} \mathrm{C}$ with constant stirring. The solid was then calcined in air at a heating rate of $10{ }^{\circ} \mathrm{C} \mathrm{min}^{-1}$ to $300{ }^{\circ} \mathrm{C}$ followed by reduction in a constant flow of $\mathrm{H}_{2}\left(1.67 \mathrm{~mL} \mathrm{~s}^{-1}\right)$ at $300^{\circ} \mathrm{C}$ for $5 \mathrm{~h}$. The resulting powder was denoted as $\mathrm{Fe}_{3} \mathrm{O}_{4}-\mathrm{MSN}$.

Synthesis of $\mathbf{A P}-\mathrm{Fe}_{3} \mathbf{O}_{4}-\mathbf{M S N}$. Amine functionalized $\mathrm{Fe}_{3} \mathrm{O}_{4}-\mathrm{MSN}$ was prepared by grafting 3-aminopropyltrimethoxysilane (APTMS, 2 mmol) to the surface of $\mathrm{Fe}_{3} \mathrm{O}_{4}-\mathrm{MSN}(1 \mathrm{~g})$ in refluxing toluene $(100 \mathrm{~mL})$ for $24 \mathrm{~h}$. The resulting solid was separated by magnetic decantation using an external neodymium magnet, washed with methanol and dried under vacuum for $24 \mathrm{~h}$.

Characterization. Surface analysis of the catalyst was performed by nitrogen sorption isotherms in a Micromeritics Tristar 3000 surface area and porosity analyzer. The surface areas were calculated by the Brunauer-Emmett-Teller (BET) method and the pore size distribution were calculated by the Barrett-Joyner-Halenda $(\mathrm{BJH})$ method. The small angle powder X-ray diffraction patterns were obtained with a Rigaku Ultima IV diffractometer using $\mathrm{Cu}$ target at 40 $\mathrm{kV}$ and $44 \mathrm{~mA} . \mathrm{Cu} \mathrm{K} \beta$ was removed using a monochromator. For transmission electron microscopy measurements, an aliquot of the powder was sonicated in methanol for $15 \mathrm{~min}$. A single drop of this suspension was placed on a lacey carbon coated copper TEM grid and dried in air. The TEM examination was completed on a Tecnai G2 F20 electron microscope operated at $200 \mathrm{kV}$. For cell fixation and sample embedding: The algae cell suspension was mixed with 
MSN suspension at $100 \mu \mathrm{g} \mathrm{mL}^{-1}$ and incubated at room temperature for $30 \mathrm{~min}$. The samples were then fixed by resuspending in a $3 \%$ glutaraldehyde solution and further incubated at $37{ }^{\circ} \mathrm{C}$ for $1.5 \mathrm{~h}$, followed by post-fixation with $1 \%$ osmium tetroxide for $1.5 \mathrm{~h}$. Cells were dehydrated in increasing concentrations of ethanol $(50,60,70,80,90$, and $100 \%)$ for $15 \mathrm{~min}$ each, and stained with $2 \%$ uranyl acetate in $70 \%$ ethanol at room temperature overnight. The cells were washed three times with acetone and embedded in Epon. The embedded samples were sectioned in $60 \mathrm{~nm}$ thick slices on a sliding ultramicrotome. Thin sections supported on copper grids were examined in a Tecnai G2 F20 microscope operated at $200 \mathrm{kV}$.

Magnetic property of $\mathrm{AP}-\mathrm{Fe}_{3} \mathrm{O}_{4}-\mathrm{MSN}$ was characterized using a superconducting quantum interference device (SQUID) magnetometer with fields up to $5 \mathrm{~T}$. Zeta potential ( $\zeta$ potential) measurements were carried out by sonicating $10 \mathrm{mg}$ of sample in $10 \mathrm{~mL}$ of $154 \mathrm{mM}$ PBS buffer ( $\mathrm{pH} 7.4)$ in a Malvern Nano HT zetasizer.

General Procedure for Microalgae Harvesting. $\mathrm{AP}-\mathrm{Fe}_{3} \mathrm{O}_{4}-\mathrm{MSN}$ (2 mg) was dispersed in PBS buffer (2.5 ml, pH 7.4) by sonication for $30 \mathrm{~min}$. To this solution, $5 \mathrm{~mL}$ of Dunaliella salina (acquired from UTEX) was added and the microalgae mixture was shaken for $30 \mathrm{~min}$. The AP- $\mathrm{Fe}_{3} \mathrm{O}_{4}-\mathrm{MSN}$ along with adsorbed microalgae was captured by an external magnet and dried in oven at $100{ }^{\circ} \mathrm{C}$ to remove water and calculate the adsorbed dry weight of algae. Flow cytometry experiments were conducted on the microalgae culture before and after harvesting experiments in order to count the number of microalgae cells that were not adsorbed. Similar experiment was done for Nannochloris sp. microalgae.

Extraction of lipids from microalgae cells. In order to ensure that the microalgae used in this experiment had adequate amounts of lipids, we obtained Nannochloropsis $\mathrm{s} p$. microalgae 
from our National Alliance for Advanced Biofuels and Bioproducts (NAABB) collaborators. This microalga was dewatered following the similar procedure described above. The wet microalgae-nanomaterial composite was added to $2 \mathrm{~g}$ of 1-butyl-3-methylimidazolium chloride [BMIm] $\mathrm{Cl}$ ionic liquid in a screw cap vial at $120^{\circ} \mathrm{C}$ and was mixed at that temperature for 12 h. ${ }^{24}$ The ionic liquid lysate was mixed with chloroform. The material along with left over microalgae biomass was removed by magnetic separation. The chloroform and ionic liquid lysate mixture was extracted with hexanes, followed by dilution to a final volume of $20 \mathrm{~mL}$ with hexanes.

Selective sequestration of FFAs. $10 \mathrm{mg}$ of $\mathrm{AP}-\mathrm{Fe}_{3} \mathrm{O}_{4}-\mathrm{MSN}$ was added to $5 \mathrm{~mL}$ of hexane extract and mixed for $6 \mathrm{~h}$. Similar experiments were performed with unfunctionalized $\mathrm{Fe}_{3} \mathrm{O}_{4}$-MSN. After $6 \mathrm{~h}$, nanomaterials were removed by magnetic separation and the remaining hexanes were quantified for FFAs. In order to quantify, the hexanes were removed under reduced pressure. $0.01 \mathrm{M} \mathrm{HCl}$ in methanol $(4 \mathrm{~mL})$ was added to the remaining residue and the mixture was heated at $80^{\circ} \mathrm{C}$ for $1 \mathrm{~h}$. The mixture was cooled to room temperature followed by the addition of $1 \% \mathrm{NaCl}(1 \mathrm{~mL})$ to increase the recovery of fatty acid methyl esters (FAMEs) from the reaction mixture by solvent extraction. The FAMEs were extracted with hexane ( 3 X $3 \mathrm{~mL})$ and were quantified by GC/MS after adding nonadecanoic methyl ester $(1 \mathrm{mM}, 0.5 \mathrm{~mL})$ as an internal standard. ${ }^{19}$ As a control, the total FFA present in microalgae extract was quantified without adsorbent treatment. 


\section{Results and Discussion}

Physiochemical properties of $\mathrm{Fe}_{3} \mathrm{O}_{4}-\mathrm{MSN}$ and $\mathrm{AP}-\mathrm{Fe}_{3} \mathrm{O}_{4}-\mathrm{MSN}$
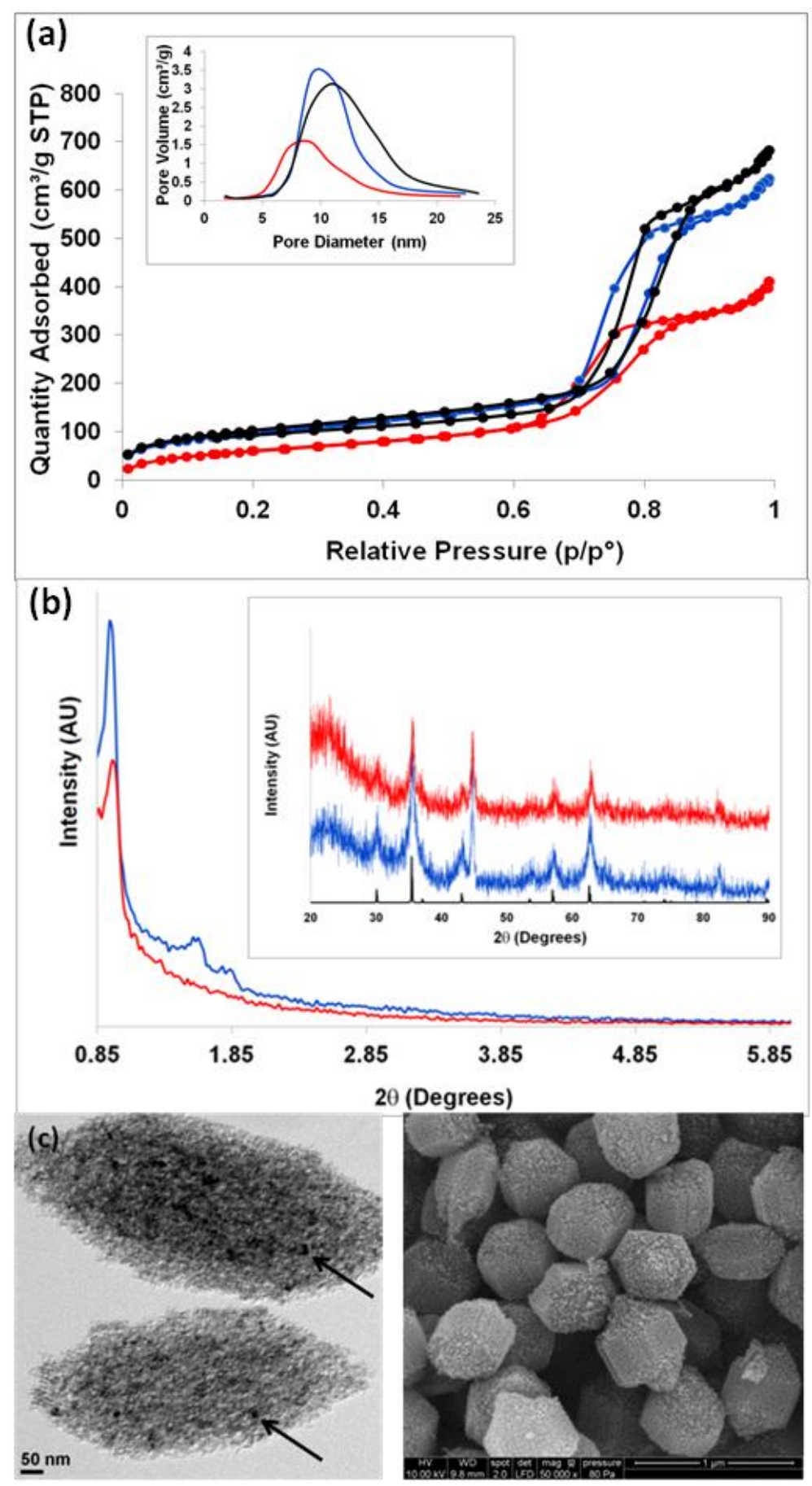

Figure 1. (a) BET isotherms and $\mathrm{BJH}$ pore size distribution (inset) of $\mathrm{MSN}$ (black), $\mathrm{Fe}_{3} \mathrm{O}_{4}-\mathrm{MSN}$ (blue) and $\mathrm{AP}-\mathrm{Fe}_{3} \mathrm{O}_{4}-\mathrm{MSN}$ (red), (b) low angle and wide angle (inset) XRD patterns of $\mathrm{Fe}_{3} \mathrm{O}_{4}$ - 
MSN (blue) and $\mathrm{AP}-\mathrm{Fe}_{3} \mathrm{O}_{4}-\mathrm{MSN}$ (red). (c) TEM and SEM images of $\mathrm{AP}-\mathrm{Fe}_{3} \mathrm{O}_{4}-\mathrm{MSN}$. Iron oxide nanoparticles are indicated by the black arrows in the TEM image.

The textural properties of $\mathrm{Fe}_{3} \mathrm{O}_{4}-\mathrm{MSN}$ and $\mathrm{AP}-\mathrm{Fe}_{3} \mathrm{O}_{4}-\mathrm{MSN}$ were obtained from nitrogen sorption analysis using BET and BJH calculations and compared to unfunctionalized MSN (Figure 1a). Both materials possess a type IV isotherm, which is characteristic of mesoporosity. ${ }^{25}$ The values for all the structural parameters are summarized in Table 1. Figure $1 \mathrm{~b}$ shows the low and wide angle X-ray diffraction pattern for both materials. The observed diffraction patterns with intense $\left(d_{100}\right)$ peaks are characteristic of highly ordered two-dimensional (2D) hexagonal mesostructures with uniform channels. ${ }^{26}$ The characteristic peaks of $\mathrm{Fe}_{3} \mathrm{O}_{4}$ in high angle $\mathrm{X}$-ray diffraction confirm the formation of crystalline $\mathrm{Fe}_{3} \mathrm{O}_{4}$ phase. ${ }^{23}$ The morphology of nanomaterials and homogeneous distribution of $\mathrm{Fe}_{3} \mathrm{O}_{4}$ nanoparticles in the channels of MSN was further confirmed by TEM and SEM images (Figure 1c). The saturation magnetization value for AP$\mathrm{Fe}_{3} \mathrm{O}_{4}-\mathrm{MSN}$ is $14 \mathrm{emu} \mathrm{g}^{-1}$ (Figure $\mathrm{S} 1$ ). The values for $\zeta$-potential of $\mathrm{Fe}_{3} \mathrm{O}_{4}-\mathrm{MSN}$ before and after amine functionalization are also summarized in Table 1.

Table 1. Structural Properties of MSN Materials

\begin{tabular}{lllll}
\hline Sample & $\begin{array}{l}S_{\mathrm{BET}}{ }^{a} \\
\left(\mathrm{~m}^{2} \mathrm{~g}^{-1}\right)\end{array}$ & $\begin{array}{l}\mathrm{PV}^{a} \\
\left(\mathrm{~cm}^{3} \mathrm{~g}^{-1}\right)(\AA)\end{array}$ & $\begin{array}{l}W_{\mathrm{BJH}}{ }^{a} \\
\text { MSN }\end{array}$ & $\begin{array}{l}\text { Zeta Potential } \\
(\mathrm{mV})\end{array}$ \\
$\mathrm{Fe}_{3} \mathrm{O}_{4}-\mathrm{MSN}$ & 376 & 1.1 & 107.2 & -28.1 \\
$\mathrm{AP}_{-\mathrm{Fe}_{3} \mathrm{O}_{4}-\mathrm{MSN}}$ & 229 & 0.6 & 90.0 & +20.1
\end{tabular}

${ }^{a} S_{\mathrm{BET}}$ represents the surface area; PV represents the pore volume; $W_{\mathrm{BJH}}$ represents the pore diameter 


\section{Microalgae harvesting with $\mathrm{AP}-\mathrm{Fe}_{3} \mathrm{O}_{4}-\mathrm{MSN}$}

Due to the presence of negatively charged-gel forming polysaccharides on the cell wall matrix, most microalgae have a negatively charged cell surface which prevents them from selfaggregation within suspension. ${ }^{20}$ Upon addition of positively charged ions to the solution, the negative surface charge is neutralized and aids in cell flocculation. ${ }^{3}$ In contrast to the $\zeta$-potential of $-18.8 \mathrm{mV}$ for $\mathrm{Fe}_{3} \mathrm{O}_{4}-\mathrm{MSN}$, the value of $\zeta$-potential increased to $+20.1 \mathrm{mV}$ after amine functionalization (Table 1). Considering this positive surface charge, we hypothesized that the negatively charged microalgae should get adsorbed on the positively charged $\mathrm{AP}-\mathrm{Fe}_{3} \mathrm{O}_{4}-\mathrm{MSN}$ nanomaterials and this microalgae-nanomaterial composite should respond to external magnetic field because of the superparamagnetic nature of $\mathrm{AP}-\mathrm{Fe}_{3} \mathrm{O}_{4}-\mathrm{MSN}$. Furthermore, the presence of an external magnetic field should assist in magnetically separating the microalgae-nanomaterial composite thereby concentrating the microalgae biomass for next step in biodiesel production.

Scheme 2. Process illustrating microalgae harvesting with $\mathrm{AP}-\mathrm{Fe}_{3} \mathrm{O}_{4}-\mathrm{MSN}$

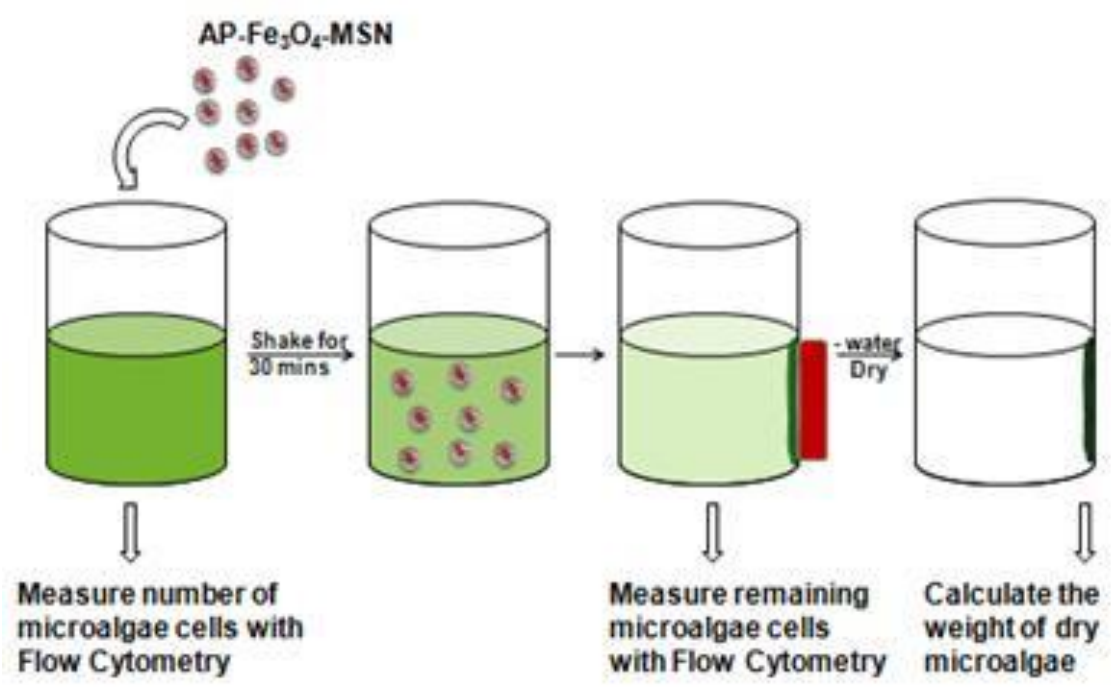


The harvesting experiment was performed by mixing AP- $\mathrm{Fe}_{3} \mathrm{O}_{4}-\mathrm{MSN}$ nanomaterials with a microalgae suspension. An external magnet was used to collect the microalgae-nanomaterial composite (Scheme 2). The kinetics for concentration of microalgae was measured to determine the time required for accumulation of optimum microalgae biomass weight. The mass of the dry weight of Nannochloris sp. microalgae adsorbed per mg of $\mathrm{AP}-\mathrm{Fe}_{3} \mathrm{O}_{4}-\mathrm{MSN}$ reached $9 \mathrm{mg}$ after 30 min and then plateaued at extended time periods (Figure S2). The fast kinetics for concentration of microalgae-nanomaterial composite in response to an external magnet makes this dewatering technique very promising in industries for biodiesel and value-added chemical production.

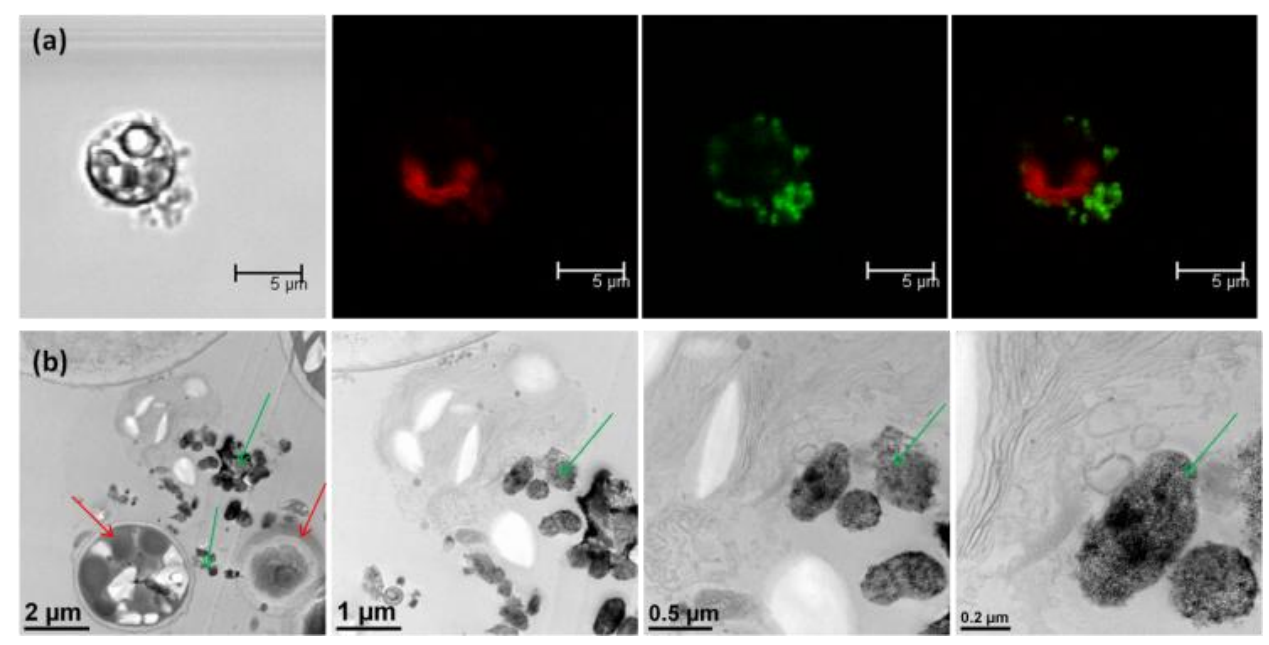

Figure 2. (a) Bright field and confocal fluorescence images of Dunaliella salina adsorbed on AP-FITC-MSN. (b) TEM images of microtomed slices of Nannochloris sp. (red arrows) after adsorption with $\mathrm{AP}-\mathrm{Fe}_{3} \mathrm{O}_{4}-\mathrm{MSN}$ (green arrows).
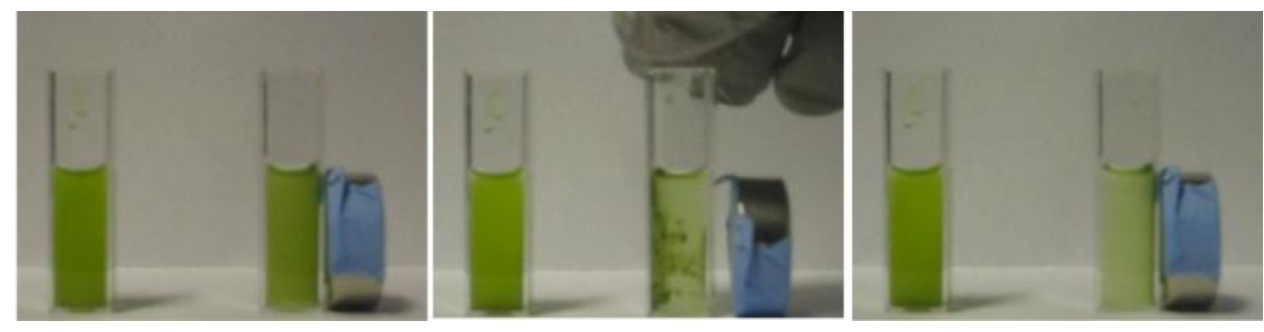

Figure 3. Movie stills captured during the adsorption of Dunaliella salina by $\mathrm{AP}-\mathrm{Fe}_{3} \mathrm{O}_{4}-\mathrm{MSN}$. Left cuvette is the control and the right cuvette shows the algae accumulation using an external magnet. 
To study the proximity of the nanomaterials to the microalgae cells, FITC labeled APMSN (AP-FITC-MSN) ${ }^{27}$ with Dunaliella salina was monitored by confocal fluorescence microscopy. The green fluorescent spots in Figure 2a show that AP-FITC-MSN nanomaterials were able to aggregate on the surface of microalgae cells, represented by red fluorescence due to the chlorophyll. There was no evidence of endocytosis of nanomaterials from confocal images and this observation was consistent with TEM images obtained from ultramicrotomed samples seen in Figure 2b. Figure 3 shows the movie stills obtained during the dewatering of Dunaliella salina cells with $\mathrm{AP}-\mathrm{Fe}_{3} \mathrm{O}_{4}-\mathrm{MSN}$. The complete video of this experiment is attached in the Supporting Information (Figure S3). The ability of the MSN to surround the individual microalgae cells and not be internalized is important for recycling these materials.

To investigate the number of microalgae cells adsorbed on $\mathrm{AP}-\mathrm{Fe}_{3} \mathrm{O}_{4}-\mathrm{MSN}$, flow cytometry experiments were performed by quantifying microalgae cells that exhibited fluorescence due to the presence of chlorophyll, before and after adsorption with $\mathrm{AP}-\mathrm{Fe}_{3} \mathrm{O}_{4}$ MSN. Flow cytometry experiments were examined with two different microalgae species: Dunaliella salina, microalgae with negative membrane potential but lacking a rigid cell wall ${ }^{28}$ and Nannochloris sp., microalgae with a rigid cell wall. ${ }^{29}$ The percentage and number of microalgae cells in the suspension before and after adsorption with $\mathrm{AP}-\mathrm{Fe}_{3} \mathrm{O}_{4}-\mathrm{MSN}$ is shown in Figure 4a and Table S1, respectively. In case of Dunaliella salina, $67 \%$ of microalgae cells were captured by $\mathrm{AP}-\mathrm{Fe}_{3} \mathrm{O}_{4}-\mathrm{MSN}$ and $68 \%$ of Nannochloris $s p$. were concentrated by $\mathrm{AP}^{-} \mathrm{Fe}_{3} \mathrm{O}_{4-}$ MSN. While not all of the microalgae cells were captured by AP- $-\mathrm{Fe}_{3} \mathrm{O}_{4}-\mathrm{MSN}$, we believe that the remaining cells will be useful for the continuous growth of microalgae cells in the culture. The adsorption capacity of $\mathrm{AP}-\mathrm{Fe}_{3} \mathrm{O}_{4}-\mathrm{MSN}$ corresponds to $2.7 \mathrm{mg}$ of dry weight of Dunaliella salina per mg of adsorbate and $9 \mathrm{mg}$ of dry weight of Nannochloris sp. per mg of adsorbate 
(Figure 4b). In the absence of amine functional group, the adsorption capacity decreased to 0.5 $\mathrm{mg}$ for Dunaliella salina and $3.3 \mathrm{mg}$ for Nannochloris $s p$. These results suggest that the positive surface charge of $\mathrm{AP}-\mathrm{Fe}_{3} \mathrm{O}_{4}-\mathrm{MSN}$ is important for optimum adsorption of microalgae and an ideal characteristic for this dewatering technology. The surface functionalization and surface charge of future generation materials will be fine tuned for internalization and potential applications in intracellular catalysis. ${ }^{30}$
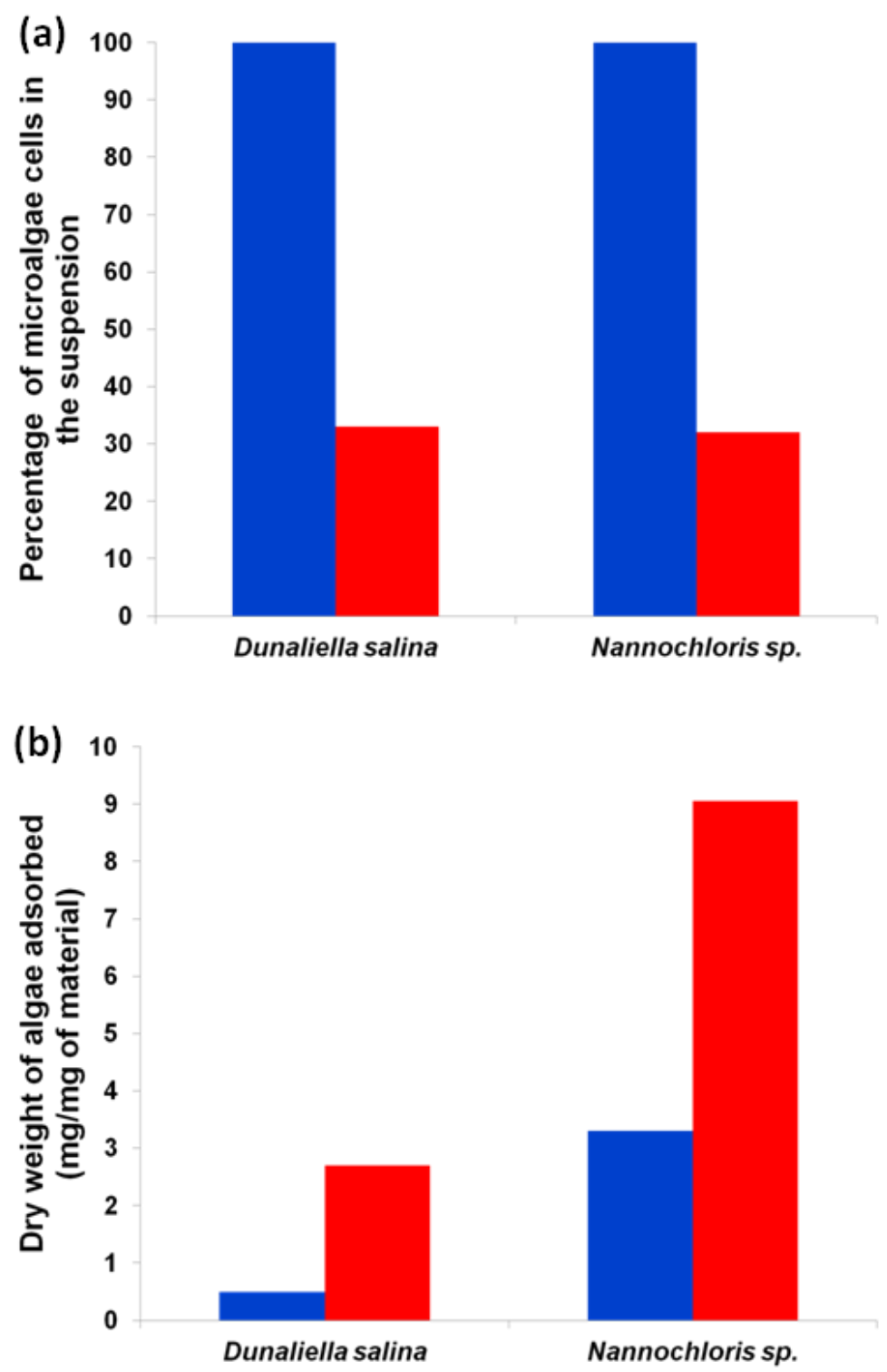
Figure 4. (a) Percentage of microalgae cells in the supernatant before (blue) and after (red) AP$\mathrm{Fe}_{3} \mathrm{O}_{4}$-MSN treatment. (b) Dry weight of Dunaliella salina and Nannochloris sp. adsorbed per mg of unfunctionalized $\mathrm{Fe}_{3} \mathrm{O}_{4}-\mathrm{MSN}$ (blue) and $\mathrm{AP}-\mathrm{Fe}_{3} \mathrm{O}_{4}-\mathrm{MSN}$ (red) nanomaterials.

\section{Extraction and Selective sequestration of Free Fatty Acids (FFAs) from microalgae}

Existing methods of lipid extraction with organic solvents involve complete drying of microalgae after the dewatering step. ${ }^{31-33}$ One way to reduce the cost in microalgae biorefinery is to extract the lipids from wet microalgae biomass, avoiding the energy-intensive drying step. Recently, Teixeira has reported the use of hydrophilic ionic liquids to dissolute and soften the cell wall microfibril network thereby lysing the cells in order to extract lipids and a wider range of molecules from microalgae cells. ${ }^{24}$ Following Teixeira's observation, the dewatering experiment was performed on Nannochloropsis sp., microalgae known for high FFA content, ${ }^{11}$ and the wet microalgae-nanomaterial composite was treated with [BMIm] Cl ionic liquid in order to lyse the microalgae cells. The lipids were extracted with chloroform and hexanes from the ionic liquid layer. The FFA content in the lipid extract was measured with GC-MS (Figure S4) and most of other lipids were analyzed with APCI-HRMS (Figure S5). ${ }^{34}$ The ionic liquid was recovered and analyzed via ${ }^{1} \mathrm{H}$ NMR after the extraction (Figure S7).

Scheme 3. Challenges associated with processing of FFA containing feedstock for biodiesel production

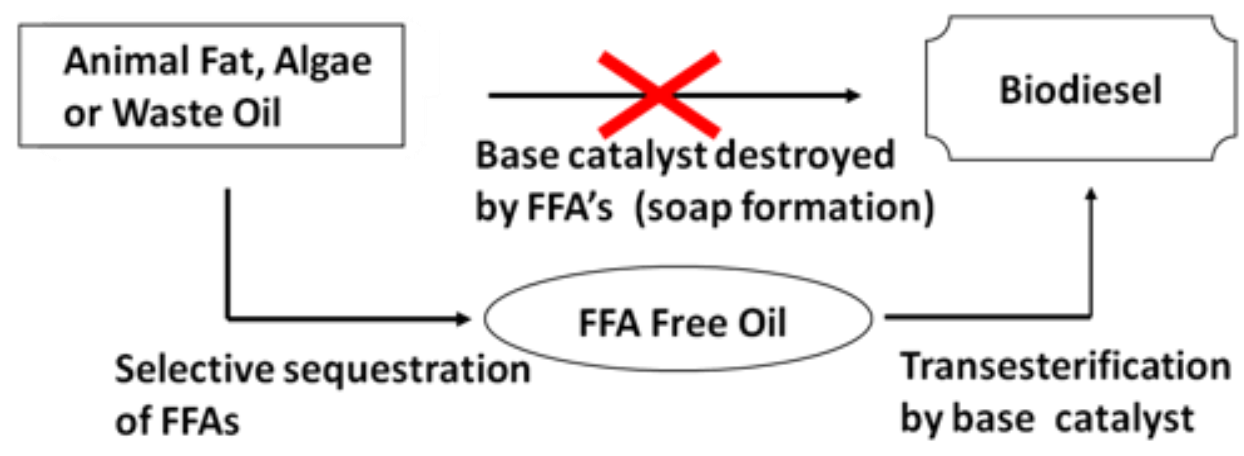


The lipid extract was further processed to remove FFAs because FFAs are known to neutralize the basic catalyst used for transesterification during biodiesel production (Scheme 3). The current techniques for separation and purification of organic acids involve extraction and distillation using organic solvents and supercritical fluids, ${ }^{35,36}$ which makes the process expensive and energy intensive. To test the adsorption of FFAs, the unfunctionalized and amine functionalized $\mathrm{Fe}_{3} \mathrm{O}_{4}-\mathrm{MSN}$ was added to the lipid extract collected after [BMIm]Cl treatment. As shown in Table 2, the unfunctionalized $\mathrm{Fe}_{3} \mathrm{O}_{4}$-MSN nanomaterials sequestered $23 \%$ of FFA present in the extract whereas amine functionalized $\mathrm{AP}-\mathrm{Fe}_{3} \mathrm{O}_{4}-\mathrm{MSN}$ sequestered $79 \%$ of total FFA. Additionally, to examine the selectivity of $\mathrm{AP}-\mathrm{Fe}_{3} \mathrm{O}_{4}-\mathrm{MSN}$ for FFA over other lipids, microalgae extract before and after $\mathrm{AP}-\mathrm{Fe}_{3} \mathrm{O}_{4}-\mathrm{MSN}$ treatment were analyzed with APCI-HRMS. The concentration of sterols, diglycerides and triglycerides did not change significantly after treatment with $\mathrm{AP}-\mathrm{Fe}_{3} \mathrm{O}_{4}-\mathrm{MSN}$ (Figure $\mathrm{S} 6$ ). This suggests that besides the high sequestration capacity of $\mathrm{AP}-\mathrm{Fe}_{3} \mathrm{O}_{4}-\mathrm{MSN}$, these amine functionalized nanomaterials are selective for FFAs over other lipids present in microalgae.

Table 2. Sequestration of FFAs from Microalgae Extract

\begin{tabular}{lll}
\hline $\begin{array}{l}\text { Microalgae extract after } \\
{[\mathrm{BMIm}] \mathrm{Cl} \text { treatment }}\end{array}$ & $\mathrm{Fe}_{3} \mathrm{O}_{4}-\mathrm{MSN}$ & $\mathrm{AP}^{-\mathrm{Fe}_{3} \mathrm{O}_{4}-\mathrm{MSN}}$ \\
\hline $\begin{array}{l}\text { FFA before sequestration } \\
\left.(\mathrm{mg} \mathrm{L})^{-1}\right)\end{array}$ & 134 & 134 \\
$\begin{array}{l}\text { FFA remaining after } \\
\text { sequestration (mg L }\end{array}$ & 103 & 28 \\
$\%$ FFA sequestered & 23 & 79 \\
\hline
\end{tabular}




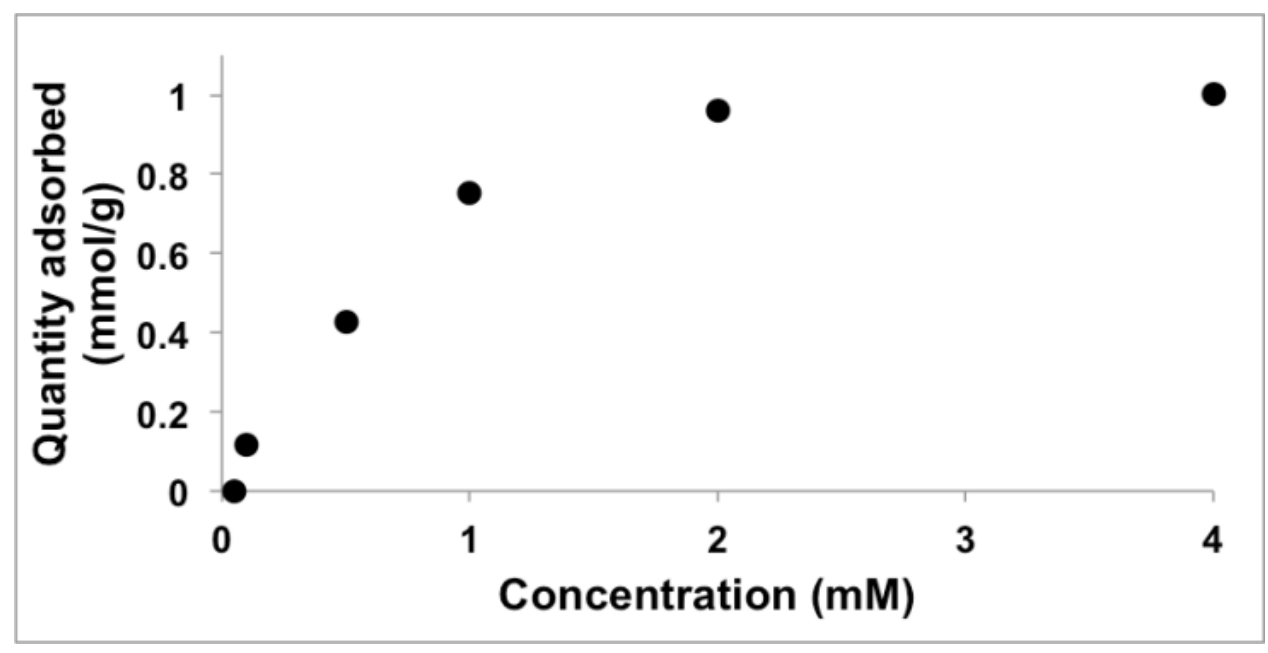

Figure 5. Adsorption isotherm of palmitic acid adsorbed on $\mathrm{AP}-\mathrm{Fe}_{3} \mathrm{O}_{4}-\mathrm{MSN}$ after $6 \mathrm{~h}$.

Furthermore, the maximum sequestration capacity of $\mathrm{AP}-\mathrm{Fe}_{3} \mathrm{O}_{4}-\mathrm{MSN}$ was determined by mixing the adsorbate with varying concentration of palmitic acid, one of the most abundant FFA in microalgae oil. Figure 5 shows the adsorption isotherm of palmitic acid adsorbed on AP$\mathrm{Fe}_{3} \mathrm{O}_{4}$-MSN with maximum adsorption capacity of $1 \mathrm{mmol} \mathrm{g}^{-1}$. This adsorption capacity of FFA is much higher than the recently reported adsorption $\left(0.44 \mathrm{mmol} \mathrm{g}^{-1}\right)$ using $\mathrm{Fe}_{3} \mathrm{O}_{4}$ nanoparticles by Larpent and co-workers. ${ }^{37}$ Besides higher adsorption and easy magnetic separation, the selectivity of $\mathrm{AP}-\mathrm{Fe}_{3} \mathrm{O}_{4}$-MSN for FFA over other lipids is remarkably significant compared to Larpent's recent work.

\section{Conclusion}

In summary, a novel application of amine functionalized magnetic mesoporous silica nanomaterials for an integrated microalgae bio-refinery process involving microalgae harvesting, lipids extraction and selective sequestration of FFAs was demonstrated. The positive surface charge of magnetic nanomaterials after amine functionalization is important for optimal microalgae harvesting. These nanomaterials adhere to the outer surface of microalgae cells as 
revealed by fluorescence and electron microscopy analysis. The lipids from the wet-harvested microalgae are effectively extracted when treated with hydrophilic ionic liquids. Following extraction, these magnetic nanomaterials demonstrated highly selective sequestration of FFAs from the lipid extract. It is expected that our novel design and application of $\mathrm{AP}-\mathrm{Fe}_{3} \mathrm{O}_{4}-\mathrm{MSN}$ can serve as an effective, efficient and economic way to harvest microalgae and downstream processing of crude oil feedstock for biofuels and bioproducts. Currently, we are investigating procedures to separate the nanomaterials from the microalgae biomass remaining after the lipid extraction. Further catalytic chemical transformation of FFA adsorbed on the amine functionalized magnetic nanomaterial and their direct application in biodiesel production is also active investigations in our laboratories.

\section{ACKNOWLEDGMENT}

The authors would like to acknowledge funding of this work by the US Department of Energy under contract DE-EE0003046 awarded to the National Alliance for Advanced Biofuels and Bioproducts.

\section{REFERENCES}

1. Y. C. Sharma, B. Singh and J. Korstad, Green Chem., 2011, 13, 2993-3006.

2. E. Molina Grima, E. H. Belarbi, F. G. Acién Fernández, A. Robles Medina and Y. Chisti, Biotechnol. Adv., 2003, 20, 491-515.

3. N. Uduman, Y. Qi, M. K. Danquah, G. M. Forde and A. Hoadley, J. Renew. Sustain. Energy, 2010, 2, 012701-012715.

4. X. Zhang, Q. Hu, M. Sommerfeld, E. Puruhito and Y. Chen, Bioresour. Technol., 2010, 101, 5297-5304. 
5. R. Harun, M. Singh, G. M. Forde and M. K. Danquah, Renew. Sustain. Energy Rev., 2010, 14, 1037-1047.

6. E. J. Middlebrooks, D. B. Porcella, R. A. Gearheart, G. R. Marshall, J. H. Reynolds and W. J. Grenney, Journal (Water Pollution Control Federation), 1974, 46, 2676-2695.

7. R. Divakaran and V. N. Sivasankara Pillai, J. Appl. Phycol., 2002, 14, 419-422.

8. P. Spolaore, C. Joannis-Cassan, E. Duran and A. Isambert, J. Chem. Technol. Biotechnol., 2006, 81, 1049-1056.

9. R. Halim, B. Gladman, M. K. Danquah and P. A. Webley, Bioresour. Technol., 2011, 102, 178-185.

10. L. Soh and J. Zimmerman, Green Chem., 2011, 13, 1422-1429.

11. E. S. Umdu, M. Tuncer and E. Seker, Bioresour. Technol., 2009, 100, 2828-2831.

12. P. D. Patil, V. G. Gude, A. Mannarswamy, S. Deng, P. Cooke, S. Munson-McGee, I. Rhodes, P. Lammers and N. Nirmalakhandan, Bioresour. Technol., 2011, 102, 118-122.

13. I. J. Bruce and T. Sen, Langmuir, 2005, 21, 7029-7035.

14. R. Weissleder, K. Kelly, E. Y. Sun, T. Shtatland and L. Josephson, Nat. Biotechnol., 2005, 23, 1418-1423.

15. J. Kim, J. Lee, H. B. Na, B. C. Kim, J. K. Youn, J. H. Kwak, K. Moon, E. Lee, J. Kim, J. Park, A. Dohnalkova, H. G. Park, M. B. Gu, H. N. Chang, J. W. Grate and T. Hyeon, Small, 2005, 1, 1203-1207.

16. H. Gu, K. Xu, C. Xu and B. Xu, Chem. Commun., 2006, 941-949.

17. I. Urban, N. M. Ratcliffe, J. R. Duffield, G. R. Elder and D. Patton, Chem. Commun., 2010, 46, 4583-4585. 
18. S. Giri, B. G. Trewyn, M. P. Stellmaker and V. S. Y. Lin, Angew. Chem. Int. Ed., 2005, 44, 5038-5044.

19. J. S. Valenstein, K. Kandel, F. Melcher, I. I. Slowing, V. S. Y. Lin and B. G. Trewyn, ACS Appl. Mater. Interf., 2012, 4, 1003-1009.

20. P. Mariani, C. Tolomio, B. Baldan and P. Braghetta, Phycologia, 1990, 29, 253-262.

21. I. Slowing, B. G. Trewyn and V. S. Y. Lin, J. Am. Chem. Soc., 2006, 128, 14792-14793.

22. T.-W. Kim, I. I. Slowing, P.-W. Chung and V. S.-Y. Lin, ACS Nano, 2010, 5, 360-366.

23. H. H. P. Yiu, M. A. Keane, Z. A. D. Lethbridge, M. R. Lees, A. J. E. Haj and J. Dobson, Nanotechnology, 2008, 19, 255606.

24. R. E. Teixeira, Green Chem., 2012, 14, 419-427.

25. Y. Wan and D. Zhao, Chem. Rev., 2007, 107, 2821-2860.

26. D. Zhao, Q. Huo, J. Feng, B. F. Chmelka and G. D. Stucky, J. Am. Chem. Soc., 1998, 120, 6024-6036.

27. I. I. Slowing, J. L. Vivero-Escoto, Y. Zhao, K. Kandel, C. Peeraphatdit, B. G. Trewyn and V. S. Y. Lin, Small, 2011, 7, 1526-1532.

28. D. V. Lynch and G. A. Thompson, Plant Physiol., 1982, 69, 1369-1375.

29. M. Yamamoto, H. Nozaki, Y. Miyazawa, T. Koide and S. Kawano, J. Phycol., 2003, 39, 172-184.

30. X. Sun, Y. Zhao, V. S. Y. Lin, I. I. Slowing and B. G. Trewyn, J. Am. Chem. Soc., 2011, 133, 18554-18557.

31. K. Vijayaraghavan and K. Hemanathan, Energy Fuels, 2009, 23, 5448-5453.

32. B. D. Wahlen, R. M. Willis and L. C. Seefeldt, Bioresour. Technol., 2011, 102, 27242730. 
33. J.-Y. Lee, C. Yoo, S.-Y. Jun, C.-Y. Ahn and H.-M. Oh, Bioresour. Technol., 2010, 101, S75-S77.

34. Y. J. Lee, R. C. Leverence, E. A. Smith, J. S. Valenstein, K. Kandel and B. G. Trewyn, Lipids, 2013, 48, 297-305.

35. C. E. C. Rodrigues and A. J. A. Meirelles, J. Chem. Eng. Data, 2008, 53, 1698-1704.

36. N. Dunford and J. King, J. Am. Oil Chem. Soc., 2001, 78, 121-125.

37. M. Cano, K. Sbargoud, E. Allard and C. Larpent, Green Chem., 2012, 14, 1786-1795. 


\section{SUPPORTING INFORMATION}

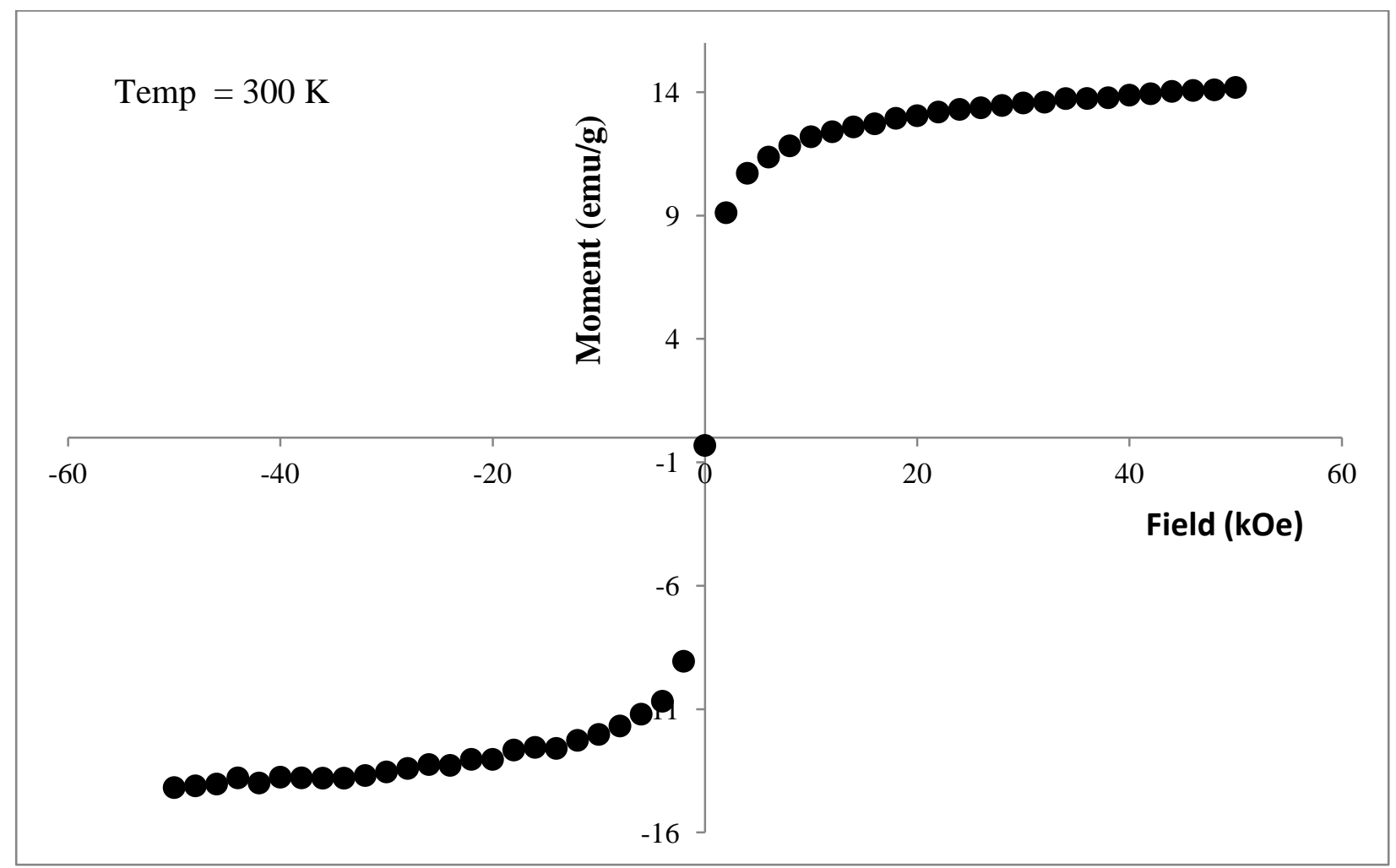

Figure S1. Magnetic Susceptibility of $\mathrm{AP}-\mathrm{Fe}_{3} \mathrm{O}_{4}-\mathrm{MSN}$ 


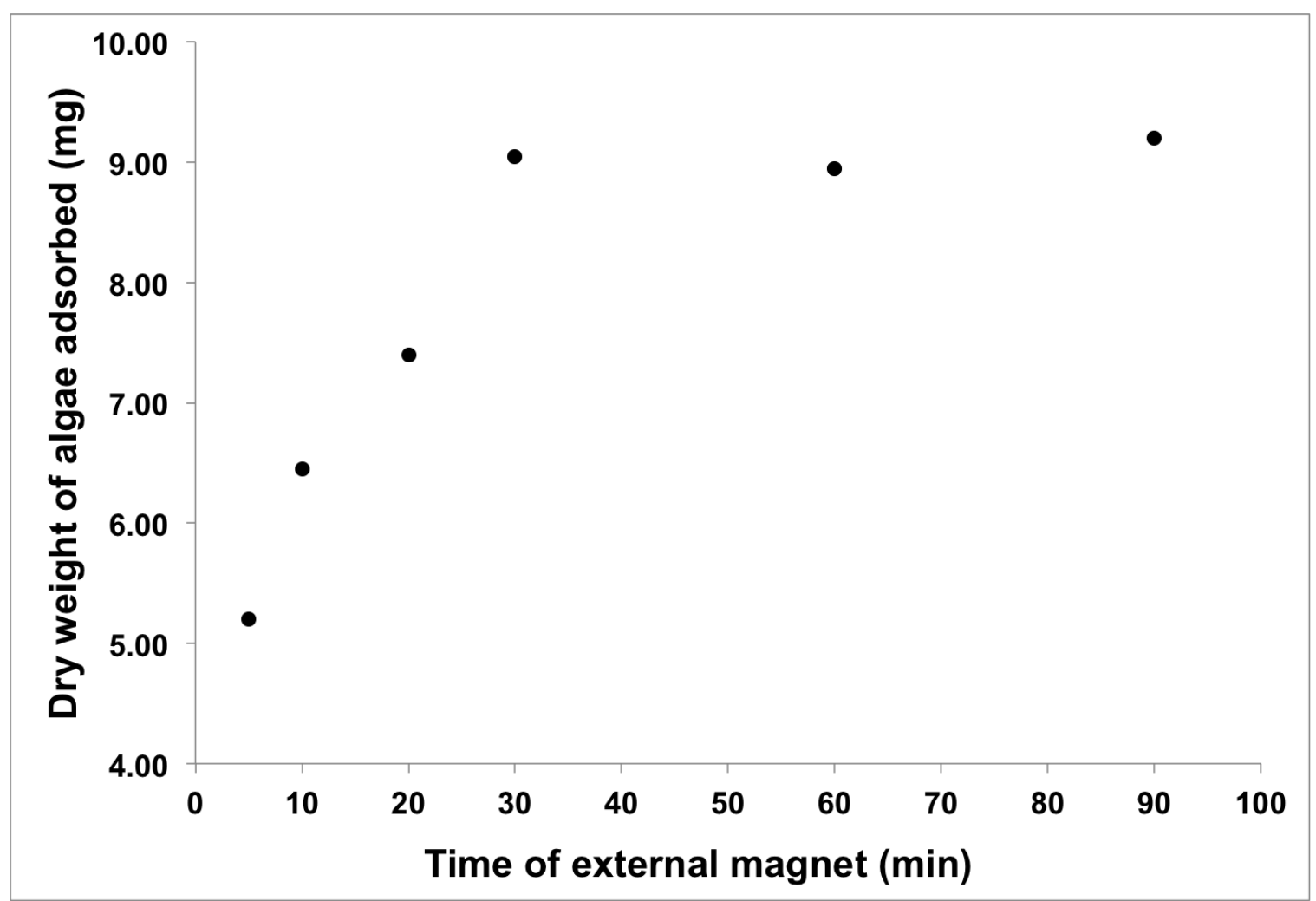

Figure S2. Kinetics of concentrating Nannochloris sp. with $\mathrm{AP}-\mathrm{Fe}_{3} \mathrm{O}_{4}-\mathrm{MSN}$ for different amounts of time of external magnet exposure.

Table S1. Number of microalgae cells in the suspension before and after $\mathrm{AP}-\mathrm{Fe}_{3} \mathrm{O}_{4}-\mathrm{MSN}$ treatment

\begin{tabular}{|c|c|c|}
\hline Microalgae & Before $\mathrm{AP}-\mathrm{Fe}_{3} \mathrm{O}_{4}$-MSN treatment & After AP-Fe ${ }_{3} \mathrm{O}_{4}$-MSN treatment \\
\hline Dunaliella salina & $7.81 \times 10^{5}$ & $2.54 \times 10^{5}$ \\
\hline Nannochloris sp. & $3.24 \times 10^{6}$ & $1.04 \times 10^{6}$ \\
\hline
\end{tabular}


Figure S3. Recorded movie of $\mathrm{AP}-\mathrm{Fe}_{3} \mathrm{O}_{4}-\mathrm{MSN}$ magnetically mediated accumulation. 


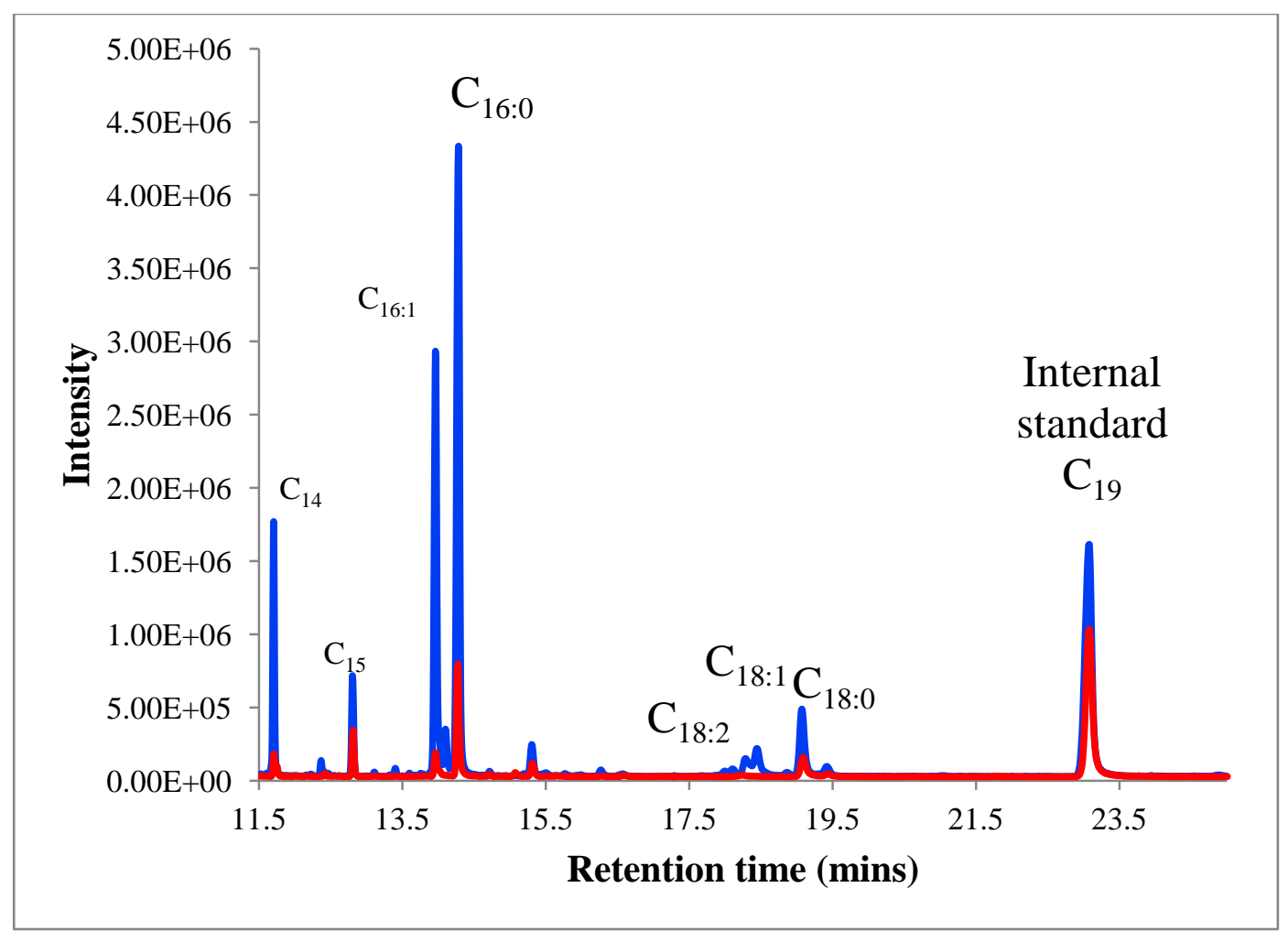

Figure S4. Chromatograph showing FFA profile present in lipids of Nannochloropsis sp. after extraction with ionic liquid (blue) and remaining FFA after selective sequestration with AP$\mathrm{Fe}_{3} \mathrm{O}_{4}-\mathrm{MSN}$ (red). 


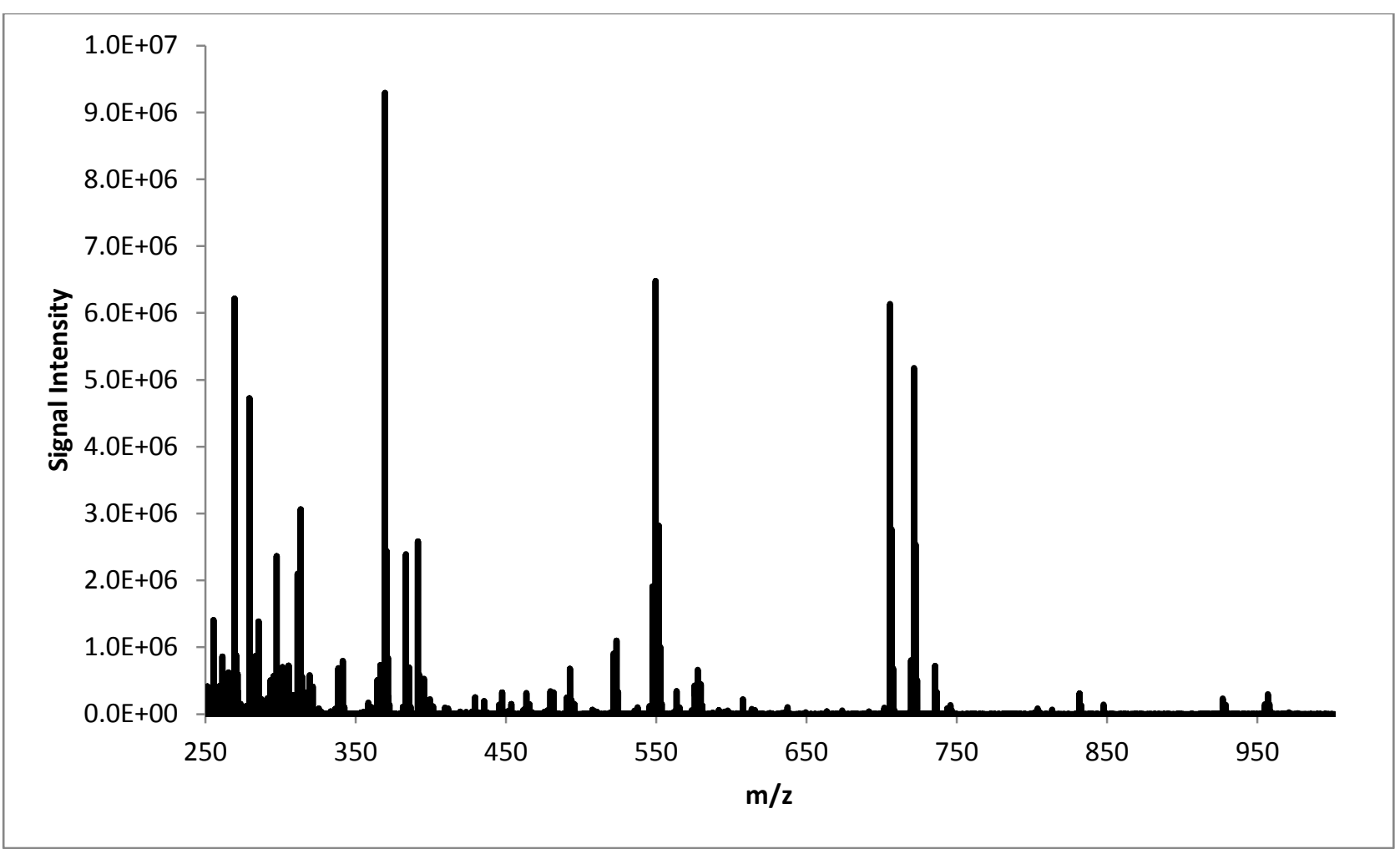

Figure S5. APCI high-resolution mass spectrum of lipids in Nannochloropsis sp. after extraction with ionic liquid. 


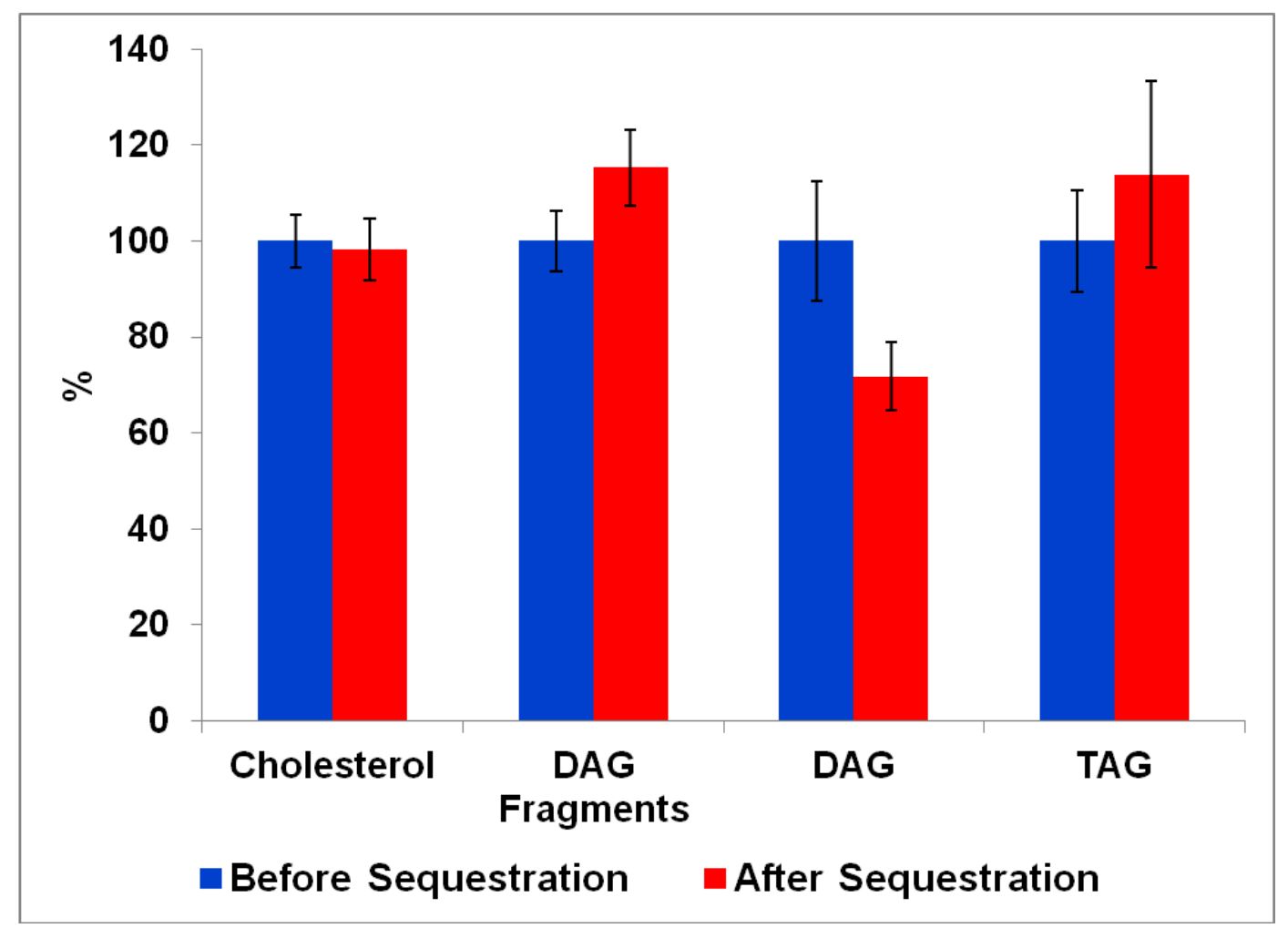

Figure S6. Percentage of cholesterol, DAG fragments, DAG and TAG before and after mixing with $\mathrm{AP}-\mathrm{Fe}_{3} \mathrm{O}_{4}-\mathrm{MSN}$.
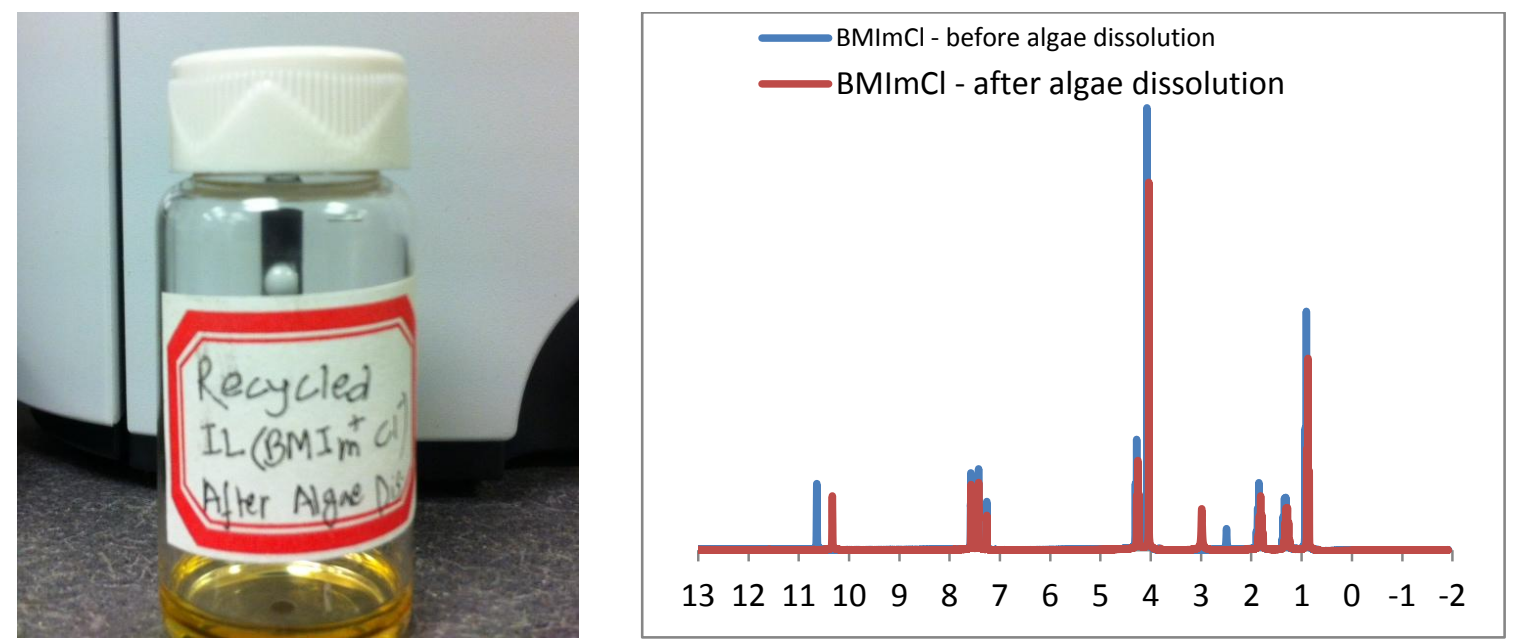

Figure S7. Recycled [BMIm] Cl ionic liquid after extraction of lipids from Nannochloropsis sp. (left) and ${ }^{1} \mathrm{H}$ NMR of [BMIm] $\mathrm{Cl}$ before and after lipid extraction (right). 


\title{
CHAPTER 6. SORBENT-ASSISTED CATALYSIS: AN INTEGRATED APPROACH FOR THE REFINERY OF RENEWABLE FEEDSTOCKS
}

Modified from a paper submitted to Energy and Environmental Science Kapil Kandel, Conerd Frederickson, Erica A. Smith, Young-Jin Lee and Igor I. Slowing

\begin{abstract}
A hybrid adsorbent-catalytic nanostructured material consisting of aminopropyl groups and nickel nanoparticles immobilized in mesoporous silica nanoparticles (AP-Ni-MSN) was employed to capture free fatty acids (FFAs) and convert them into saturated hydrocarbons. The working principle of these sorbentcatalytic particles was initially tested in the hydrogenation of oleic acid. Synergistic interactions between the amine groups and the nickel nanoparticles were evidenced by the mode of adsorption of the substrate and the selectivity of its hydrogenation. Modulation of the catalytic activity by the adsorbent shifted the chemistry from hydrocracking-based (Ni) to hydrotreating-based with improved carbon economy. This approach was ultimately evaluated by the selective sequestration of FFAs from crude microalgal oil and their subsequent conversion into liquid hydrocarbons, demonstrating the suitability of this design for the refinery of renewable feedstocks.
\end{abstract}




\section{Introduction}

The refining of crude bio-diesel to remove oxygenated impurities is required to meet the specifications for transportation fuels. ${ }^{1-3}$ Free fatty acids (FFAs) are the most prominent oxygenated impurities in bio-diesel feedstocks, and are undesirable because they react with the basic catalyst used for transesterification to form soap. ${ }^{4}$ The FFA content in the feedstock must be lower than $0.5 \mathrm{wt} \%$, and thus requires the use of highly refined oils. ${ }^{1,5}$ We recently demonstrated that aminopropylfunctionalized mesoporous silica nanoparticles (AP-MSNs) can be used for the selective sequestration of FFAs to purify crude algal oil and meet the specifications of feedstocks for bio-diesel. ${ }^{6,7}$ The sequestered FFAs could still be converted into biodiesel by acid catalyzed esterification with methanol.

FFAs can also be converted into fuel by hydrogenation. The products of the reaction are liquid hydrocarbons, which are more similar to petroleum-based fuels. ${ }^{8-10}$ Because they lack oxygen, hydrocarbons are more stable and have higher energy density than FFAs or bio-diesel. ${ }^{10,11}$ Furthermore, hydrogenation also eliminates unsaturations common in algal or plant oils, increasing their cetane number. ${ }^{12}$ The hydrogenation of FFAs can be performed using supported noble metal catalysts such as Pd and Pt. ${ }^{13-20}$ However, the high price of these metals demands more economical alternatives. While supported $\mathrm{Ni}$ is fairly active in the hydrogenation of methyl esters of FFA, it has poor selectivity, favoring cracking over hydrodeoxygenation to give broad hydrocarbon distributions. ${ }^{21}$ It is well known that modifying the composition of catalysts changes their activity and selectivity. ${ }^{22-26}$ In this sense, Ni, Co and Mo sulfides supported on metal oxides have been evaluated for the deoxygenation of bio- 
oils. ${ }^{27,28}$ Nevertheless, gradual desulfurization of these catalysts leads to loss of activity and contamination of the fuel with the leached sulfides. ${ }^{29-31}$ Using nickel phosphide instead of the sulfide avoids these problems and preserves carbon economy by increasing the selectivity for hydrodeoxygenation and decarbonylation over cracking. $^{21}$

The activity and selectivity of heterogeneous catalysts can also be improved using auxiliary groups capable of cooperative interactions. ${ }^{32,33}$ In this regard, it is particularly attractive to use groups that can selectively adsorb reactants or byproducts to control the course of catalytic processes. For example, Sano and co-workers observed recently that the photodegradation of formic acid and phenol by $\mathrm{TiO}_{2}$ was dramatically improved after addition of amine functionalized mesoporous silica nanomaterials. The amines facilitated the process by adsorbing the $\mathrm{CO}_{2}$ evolved during the reaction. ${ }^{34}$ Lercher and co-workers have applied the synergism between adsorbents and catalysts to the hydrogenation of FFAs. ${ }^{35,36}$ In a recent work they supported $\mathrm{Ni}$ on $\mathrm{ZrO}_{2}$ and observed efficient conversion of FFAs to hydrocarbons. ${ }^{35}$ They showed that adsorption of the acids to oxygen vacancies in $\mathrm{ZrO}_{2}$ led to a parallel reaction involving $\alpha$-hydrogen abstraction to ketene that was later reduced and decarbonylated by nickel. Thus, the product was obtained simultaneously by the direct reduction on nickel, and through the $\mathrm{ZrO}_{2}$ mediated reaction, both processes giving high selectivity for decarbonylation.

Since bio-oils are complex mixtures containing raw materials for diverse applications, a catalyst for hydrogenation could benefit from the incorporation of an auxiliary group capable of selectively sequestering their FFA substrates. This group 
would feed the catalyst with FFAs, leaving all other substances in the mixture unmodified and available for downstream processing. While $\mathrm{ZrO}_{2}$ could be a good adsorbent for FFAs, it also binds sterols, ${ }^{37}$ which are common in bio-oils. Based on our previous observation of the selectivity of AP-MSN for sequestering FFAs from algal oils, ${ }^{6,7}$ we decided to use amines as auxiliary groups for the Ni catalyzed hydrogenation of FFAs. In our design, amine groups within a mesoporous support would capture the FFAs and control their access to the catalyst (Fig. 1). We expected that regulating the feed of substrate to the catalytic sites at the molecular level would also affect the activity and selectivity of the hydrogenation. We used oleic acid as a model to explore the application of this design to the treating of FFAs and applied this integrated approach to the conversion of crude algal oil into liquid hydrocarbons.

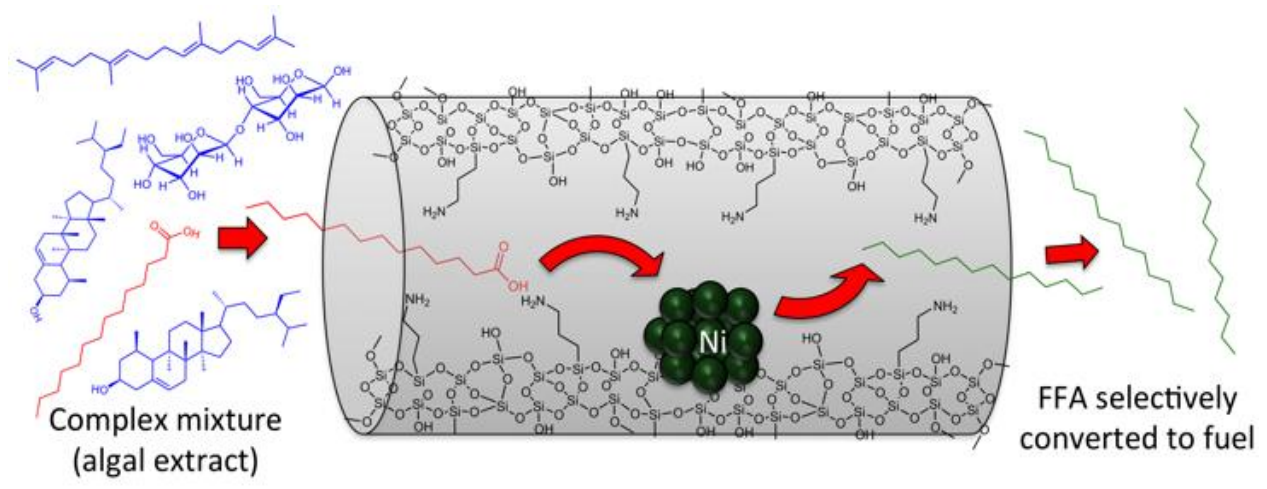

Fig. 1 Representation of the sorbent-assisted catalytic system.

\section{Experimental}

Pluronic was provided by BASF. Tetramethyl orthosilicate (TMOS) was purchased from Sigma Aldrich. 3-aminopropyl trimethoxysilane (APTMS) was purchased from Gelest. Nickel nitrate hexahydrate $\left[\mathrm{Ni}\left(\mathrm{NO}_{3}\right)_{2} \cdot 6 \mathrm{H}_{2} \mathrm{O}\right]$ and Ammonium 
Phosphate $\left[\left(\mathrm{NH}_{4}\right)_{2} \mathrm{HPO}_{4}\right]$ were purchased from Fisher Scientific.

\subsection{Synthesis of Mesoporous Silica Nanoparticles (MSN)}

MSN was prepared using a nonionic block co-polymer Pluronic P104 surfactant. ${ }^{38}$ For a typical synthesis, P104 (7.0 g) was added to $\mathrm{HCl}(273.0 \mathrm{~g}, 1.6 \mathrm{M})$. After stirring for $1 \mathrm{~h}$ at $56{ }^{\circ} \mathrm{C}$, tetramethylorthosilicate (TMOS, $10.64 \mathrm{~g}$ ) was added and stirred for an additional $24 \mathrm{~h}$. The resulting mixture was further post hydrothermally treated for $24 \mathrm{~h}$ at $150{ }^{\circ} \mathrm{C}$ in a high-pressure reactor. Upon cooling to room temperature, the white solid was collected by filtration, washed with copious amounts of methanol and dried in air. To remove the surfactant P104 by calcination, the MSN material was heated at a ramp rate of $1.5^{\circ} \mathrm{C} \mathrm{min}^{-1}$ and maintained at $550{ }^{\circ} \mathrm{C}$ for $6 \mathrm{~h}$.

\subsection{Synthesis of Nickel nanoparticles in the pores of MSN (Ni-MSN)}

MSN was mixed with water and stirred at room temperature in order to rehydrate and regenerate the silanol groups, followed by filtration and drying. $\mathrm{Ni}\left(\mathrm{NO}_{3}\right)_{2} \cdot 6 \mathrm{H}_{2} \mathrm{O}(0.55 \mathrm{mmol}, 0.16 \mathrm{~g})$ was completely dissolved in water $(0.48 \mathrm{~mL})$. To this solution, the rehydrated MSN ( $0.4 \mathrm{~g})$ was added and mixed. The solid mixture was calcined in air at a heating rate of $2{ }^{\circ} \mathrm{C} \min ^{-1}$ to $500{ }^{\circ} \mathrm{C}$ and maintained at that temperature for $6 \mathrm{~h}$ followed by reduction at $450{ }^{\circ} \mathrm{C}$ for 5 hours in a constant flow of $\mathrm{H}_{2}(0.5 \mathrm{~mL} / \mathrm{s})$.

\subsection{Synthesis of Nickel Phosphide nanoparticles in the pores of MSN $\left(\mathrm{Ni}_{2} \mathrm{P}-\mathrm{MSN}\right)$}

$\mathrm{Ni}\left(\mathrm{NO}_{3}\right)_{2} \cdot 6 \mathrm{H}_{2} \mathrm{O}(0.55 \mathrm{mmol}, 0.16 \mathrm{~g})$ and $\left(\mathrm{NH}_{4}\right)_{2} \mathrm{HPO}_{4}$ were completely dissolved in water $(0.48 \mathrm{~mL})$. To this solution, the rehydrated MSN $(0.4 \mathrm{~g})$ was added 
and mixed. The solid mixture was calcined in air at a heating rate of $2{ }^{\circ} \mathrm{C} \min ^{-1}$ to 500 ${ }^{\circ} \mathrm{C}$ and maintained at that temperature for $6 \mathrm{~h}$ followed by temperature programmed reduction (TPR) at $650^{\circ} \mathrm{C}$.

\subsection{Synthesis of 3-aminopropyl trimethoxysilane functionalized Ni-MSN (AP-Ni-} MSN)

Amine functionalized materials were prepared by grafting APTMS $(0.5 \mathrm{mmol}$, $0.09 \mathrm{~g}$ for AP-Ni-MSN-0.5 and $2 \mathrm{mmol}, 0.36 \mathrm{~g}$ for AP-Ni-MSN-2) to the surface of Ni-MSN $(1.0 \mathrm{~g})$ in refluxing toluene $(100 \mathrm{~mL})$ for 24 hours. The resulting solid was filtered, washed with methanol and dried under vacuum for $24 \mathrm{~h}$.

\subsection{Characterization}

Surface analysis of the catalyst was performed by nitrogen sorption isotherms in a Micromeritics Tristar surface area and porosity analyzer. The surface areas were calculated by the Brunauer-Emmett-Teller (BET) method and the pore size distribution were calculated by the Barrett-Joyner-Halenda (BJH) method. The small angle powder X-ray diffraction patterns were obtained with a Rigaku Ultima IV diffractometer using $\mathrm{Cu}$ target at $40 \mathrm{kV}$ and $44 \mathrm{~mA} . \mathrm{Cu} \mathrm{K} \beta$ was removed using a monochromator. For transmission electron microscopy measurements, an aliquot of the powder was sonicated in methanol for $15 \mathrm{~min}$. A single drop of this suspension was placed on a lacey carbon coated copper TEM grid and dried in air. The TEM examination was completed on a Tecnai G2 F20 electron microscope operated at 200 kV. Fourier transform infrared (FT-IR) spectra were recorded on Nicolet Nexus 470. Perkin Elmer ICP-MS was used to measure Ni loading and Agilent GC-MS was used 
to measure reaction products.

\subsection{General Procedure for One-pot Batch Reaction}

All catalytic reactions were performed in a batch reactor (Parr Instrument). In a typical experiment, the catalyst $(10 \mathrm{mg})$ and oleic acid solution in hexanes $(1 \mathrm{mM}$, $10 \mathrm{~mL}$ ) were added in the reactor. The reactor was purged with $\mathrm{H}_{2}$ at ambient temperature and was finally pressurized by $\mathrm{H}_{2}$ to 30 bar. The reaction was then carried out at $290{ }^{\circ} \mathrm{C}$ for $6 \mathrm{~h}$ with constant stir rate. The reaction was allowed to cool to room temperature and the products were subjected to esterification in order to derivatize the remaining oleic acid to oleic acid methyl ester for analysis by GC-MS. In order to derivatize, the hexanes were removed under reduced pressure followed by the addition of $\mathrm{HCl}(1 \mathrm{M}, 2 \mathrm{~mL})$. The mixture was stirred for $1 \mathrm{~h}$ at $80{ }^{\circ} \mathrm{C}$. After cooling to room temperature, $\mathrm{NaCl}(1 \%, 1 \mathrm{~mL})$ was added to the reaction mixture to increase the recovery of oleic acid methyl ester by solvent extraction. The ester of oleic acid was extracted with hexanes ( 3 X $3 \mathrm{~mL}$ ) and was analyzed by GC-MS using Methyl Nonadecanoate as internal standard.

\subsection{General Procedure for Sequential Batch Reaction}

In a typical two-step process, the catalyst $(10 \mathrm{mg})$ was added to a test tube containing the oleic acid solution in hexanes $(1 \mathrm{mM}, 10 \mathrm{~mL})$, mixed for $6 \mathrm{~h}$ and then the suspension was centrifuged. The amount sequestered was calculated by measuring the oleic acid remaining in the supernatant. To convert the sequestered oleic acid to hydrocarbons, the catalyst remaining after centrifugation was mixed with $10 \mathrm{~mL}$ hexanes and the mixture was loaded to the reactor. After purging with $\mathrm{H}_{2}$, the reaction 
mixture was pressurized by $\mathrm{H}_{2}$ to 30 bar and kept at $290{ }^{\circ} \mathrm{C}$ for $6 \mathrm{~h}$ with constant stirring. The reaction was allowed to cool to room temperature and the liquid samples were analyzed by GC-MS using Methyl Nonadecanoate internal standard.

\subsection{Analysis of lipids in algal extracts}

The APCI-HRMS analysis of the algal extracts was done on a linear-traporbitrap hybrid mass spectrometer (LTQ-Orbitrap Discovery, Thermo Scientific, San Jose, CA, USA). The oil, before and after mixing with the AP-Ni-MSN, was manually injected with a divert valve at $0.01 \%(\mathrm{v} / \mathrm{v})$ with $50 \%$ methanol in toluene. Further details about the APCI-HRMS conditions can be found elsewhere. ${ }^{7}$ 


\section{Results and discussion}

\subsection{Synthesis and catalytic activity of Ni-MSN}
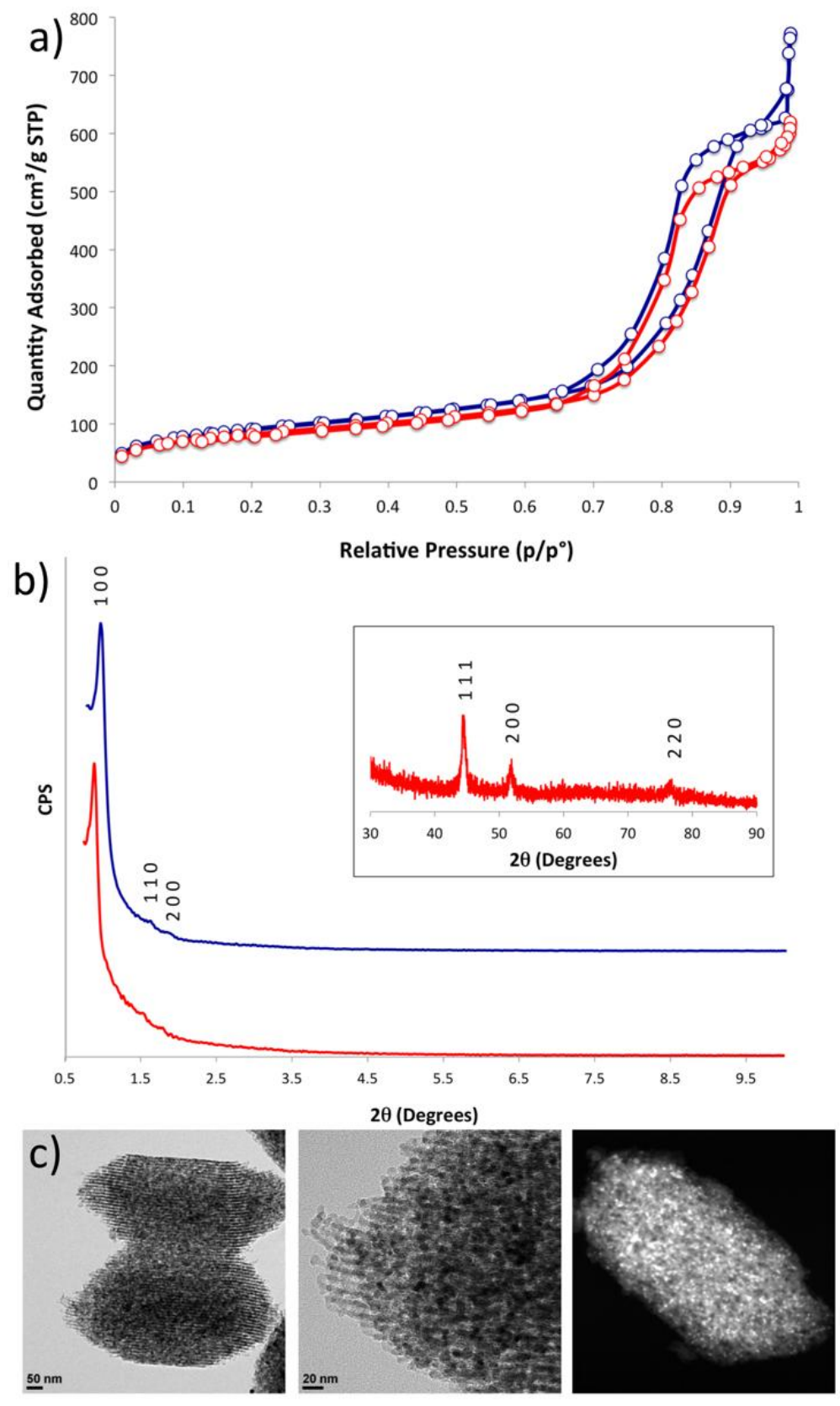

Fig. 2 a) Nitrogen sorption isotherms, b) wide (inset) and small angle XRD patterns of MSN support (blue) and Ni-MSN (red). c) TEM (left and center) and STEM (right) images of Ni-MSN. The dark spots in the TEMs and the bright spots in the STEM correspond to Ni nanoparticles. 
The mesoporous silica nanoparticle (MSN) support was prepared according to a previously published method, ${ }^{38}$ and consisted of elongated particles about $650 \times 400$ $\mathrm{nm}$ in size. XRD analysis indicated hexagonal arrangement of pores typical of SBA15 type materials, ${ }^{39}$ and nitrogen sorption analysis revealed a type IV isotherm characteristic of mesoporous materials (Fig. 2). BET and BJH calculations indicated large surface area and a sharp pore size distribution centered at $11.1 \mathrm{~nm}$ (Table 1). The catalytic Ni nanoparticles were prepared by impregnation of the support with aqueous $\mathrm{Ni}\left(\mathrm{NO}_{3}\right)_{2} \cdot 6 \mathrm{H}_{2} \mathrm{O}$, followed by calcination in air, and reduction under $\mathrm{H}_{2}$ stream at $450{ }^{\circ} \mathrm{C}$. The resulting Ni-MSN material had 6.9 wt \% Ni, with XRD pattern indicating crystalline elemental nickel exclusively in the fcc phase (Fig. 2b). ${ }^{40}$ TEM, STEM and EDX measurements suggested that most of the Ni nanoparticles formed within the pores of MSN (Fig. 2c). The structure of the support was not affected by the growth of the Ni nanoparticles, as the small angle XRD patterns still displayed the reflections corresponding to a hexagonal array of pores. The material retained the type IV nitrogen sorption isotherm confirming it was still mesoporous (Fig. 2a). ${ }^{41}$ As expected, the surface area and pore volume of the parent MSN decreased upon formation of Ni nanoparticles (each by 10\%), however the pore size remained almost constant at $11.0 \mathrm{~nm}$ (Table 1). These results are consistent with the formation of the particles inside of the pores. 
Table 1 Summary of textural properties of catalysts.

\begin{tabular}{cccccc}
\hline Sample & Surface & Pore & Pore & Ni \\
& Area & Volume & Size & Loading \\
& $\left(\mathrm{m}^{2} / \mathrm{g}\right)$ & $\left(\mathrm{cm}^{3} / \mathrm{g}\right)$ & $(\mathrm{nm})$ & $($ wt. $\%)$ \\
\hline MSN & 331 & 0.97 & 11.1 & - \\
Ni-MSN & 298 & 0.88 & 11.0 & 6.9 \\
AP-Ni-MSN & 209 & 0.60 & 8.9 & 6.5 \\
$\mathrm{Ni}_{2} \mathrm{P}-\mathrm{MSN}$ & 317 & 1.0 & 11.0 & 5.2 \\
\hline
\end{tabular}

Oleic acid was used as a model to evaluate the catalytic activity of Ni-MSN in the hydrogenation of FFAs. The reaction was performed by adding $10 \mathrm{mg}$ of catalyst to $10 \mathrm{~mL}$ of $1 \mathrm{mM}$ oleic acid solution in hexane, and heating at $290{ }^{\circ} \mathrm{C}$ under 30 bar $\mathrm{H}_{2}$ for $6 \mathrm{~h}$ in batch mode. The selectivity of the reaction was defined according to three main types of hydrocarbon products: hydrocracking $\left(<\mathrm{C}_{17}\right)$, decarbonylation $\left(\mathrm{C}_{17}\right)$ and hydrodeoxygenation $\left(\mathrm{C}_{18}\right)$ (Fig. 3). The reaction proceeded with full conversion using Ni-MSN as a catalyst. Consistent with the results by Serrano et al. on methyl esters of FFAs, our Ni-MSN catalyst favored cracking (72\%) over decarbonylation (25\%) and hydrodeoxygenation (3\%) (Fig. 4). ${ }^{21}$ 


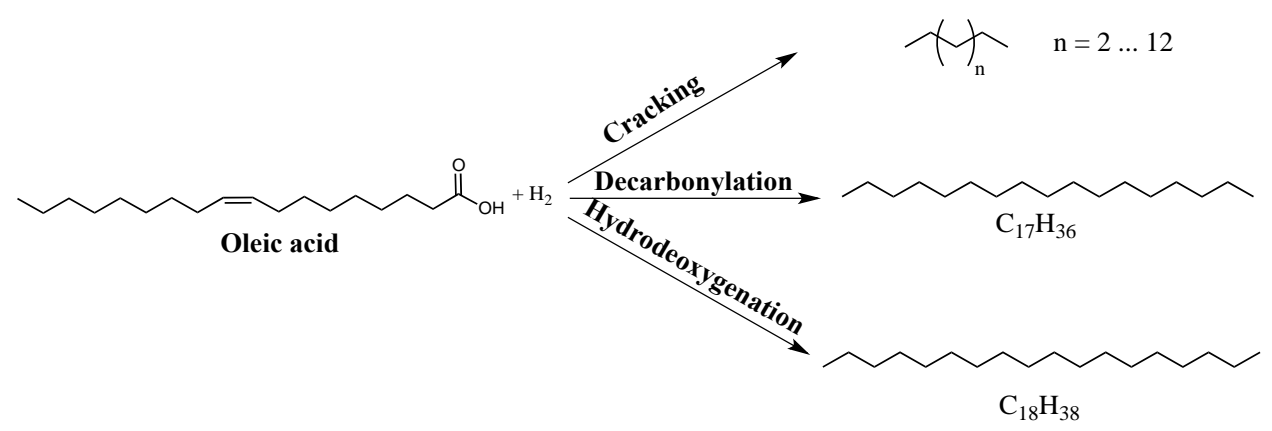

Fig. 3 Possible reaction routes.

\subsection{Aminopropyl modification of Ni-MSN}

The current technologies for separation and purification of organic acids involve extraction and distillation using organic solvents and supercritical fluids, which makes the process expensive and energy intensive. ${ }^{42,}{ }^{43}$ Recently, we have shown the selective sequestration of free fatty acids from complex mixtures using 3aminopropyl functionalized MSN (AP-MSN). ${ }^{6}$ Therefore, to incorporate adsorption and catalysis into a single unit, Ni-MSN was grafted with 3-aminopropyl trimethoxysilane. While the resulting AP-Ni-MSN material was still mesoporous, a decrease in pore volume, pore size and surface area was observed after functionalization (Table 1). This drop in surface properties has been previously observed upon AP grafting of mesoporous silicas. ${ }^{44-46}$ Elemental analysis indicated a load of $1.4 \mathrm{mmol}$ AP groups per gram, suggesting the formation of a dense layer of amines on the material, which is consistent with the decrease in surface properties of Ni-MSN. 


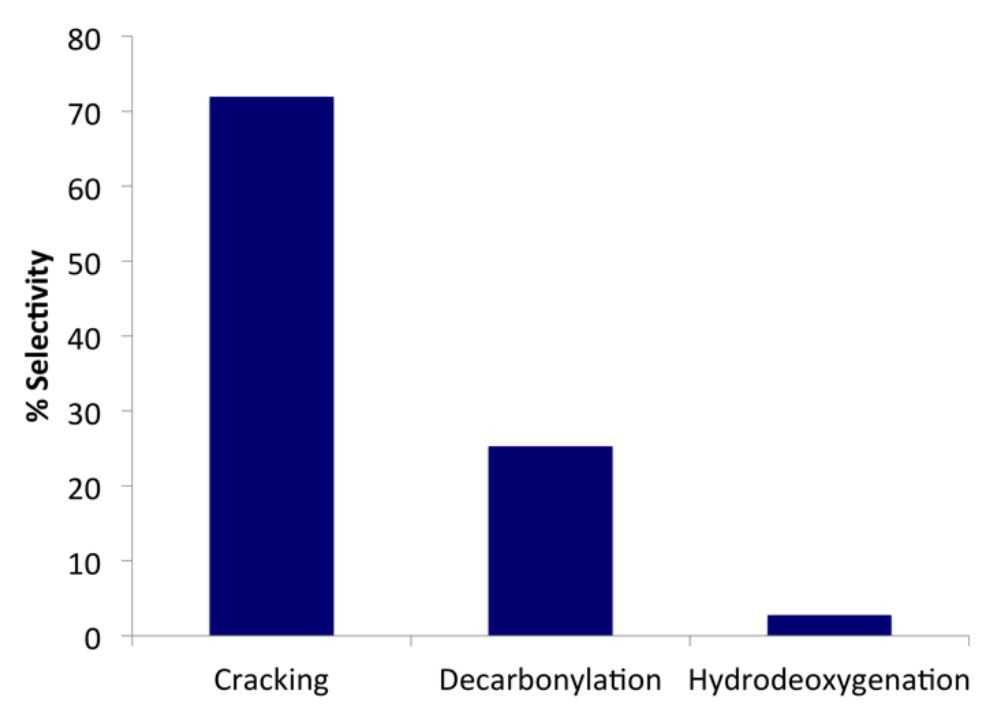

Fig. 4 Product distribution in the hydrogenation of oleic acid catalyzed by Ni-MSN (10 mL $1 \mathrm{mM}$ oleic acid in hexane, $10 \mathrm{mg} \mathrm{Ni}-\mathrm{MSN}, 290{ }^{\circ} \mathrm{C}, 30$ bar $_{2}, 6 \mathrm{~h}$ ).

To examine the capacity of the material to sequester FFAs, AP-Ni-MSN was added to solutions of oleic acid in hexane and the mixtures were shaken at room temperature for $6 \mathrm{~h}$. Fitting the adsorption isotherm (Fig. 5) to the Langmuir model gave a maximum adsorption of $0.76 \mathrm{mmol}$ oleic acid per gram of material, corresponding to a $0.54: 1$ molar ratio of sequestered oleic acid to amine groups. This result is in a sharp contrast with our previous report in which the maximum adsorption of FFA to AP-MSN with a similar amine load and surface properties gave a $1: 1$ molar ratio. The limited binding of FFAs by AP-Ni-MSN in this work, suggests that a fraction of the amines are unavailable, possibly due to a strong interaction with the surface of Ni. Comparison of the FTIR spectra of AP-Ni-MSN with those of AP-MSN supports this hypothesis (Fig. S1). In AP-MSN the absorption due to scissor vibrations of amine $\left(1621 \mathrm{~cm}^{-1}\right)$ overlaps with the broad scissoring band of adsorbed water $\left(1630 \mathrm{~cm}^{-1}\right)$. However, in AP-Ni-MSN the same vibration is downshifted to 
$1587 \mathrm{~cm}^{-1}$, very likely due to ligand binding to the surface of the nickel, similarly to previous reports on the interaction of amines with other nanoparticles. ${ }^{47}$ In absence of aminopropyl group Ni-MSN adsorbs a maximum of $0.15 \mathrm{mmol} / \mathrm{g}$ of oleic acid.

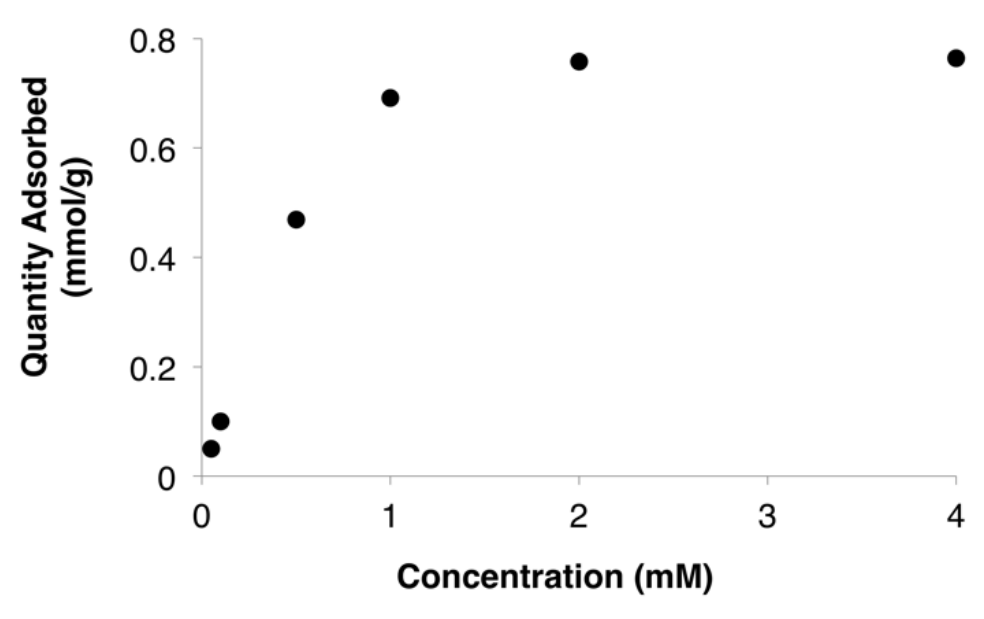

Fig. 5 Adsorption isotherm of oleic acid on AP-Ni-MSN.

The sequestration of oleic acid by AP-Ni-MSN was confirmed by the sharp C$\mathrm{H}$ stretching bands at $2926 \mathrm{~cm}^{-1}$ and $2850 \mathrm{~cm}^{-1}$ and the asymmetric and symmetric carboxylate vibrations at $1562 \mathrm{~cm}^{-1}$ and $1407 \mathrm{~cm}^{-1}$ respectively (Fig. 6). Interestingly, while the FTIR analysis indicated that the oleic acid was adsorbed to AP-Ni-MSN exclusively as a carboxylate ion, the adsorption of oleic acid to Ni-MSN and to APMSN showed only the $\mathrm{C}=\mathrm{O}$ stretching band at $1710 \mathrm{~cm}^{-1}$ indicative of nondissociated carboxylic acid. This suggested that the conversion of oleic acid into oleate during its adsorption to AP-Ni-MSN was a synergistic effect resulting from the interaction between the amines and the Ni nanoparticles. 


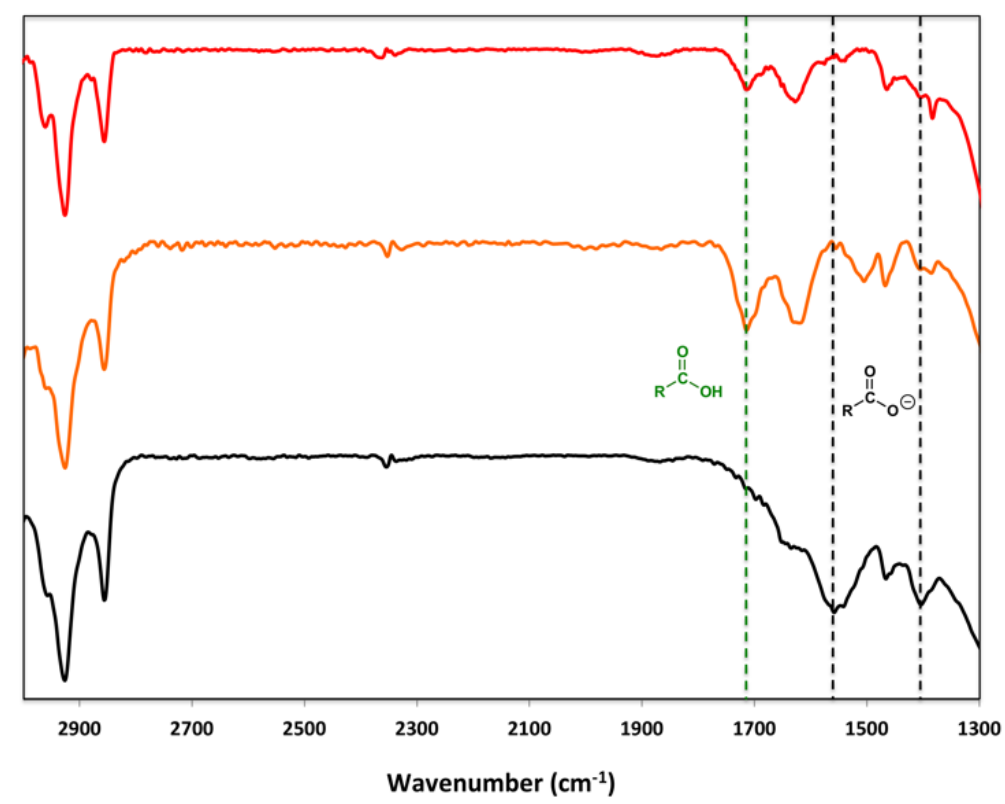

Fig. 6 FTIR spectra of Ni-MSN (red), AP-MSN (orange) and AP-Ni-MSN (black) following adsorption of oleic acid. Discontinuous lines show the absorption by the acid (green, $1710 \mathrm{~cm}^{-1}$ ), and the carboxylate ion (black, $1562 \mathrm{~cm}^{-1}$ and $1407 \mathrm{~cm}^{-1}$ ).

Thus, the amine groups in AP-Ni-MSN had two main effects on the adsorption of oleic acid: 1) an increase in the concentration of oleate close to the catalytic sites, and 2) the formation of carboxylate, which is more electron rich than the original carboxylic acid. These two important effects were expected to influence the behavior of the Ni-catalyzed hydrogenation of FFAs.

\subsection{Effect of amine functionalization on catalytic activity}

As expected, the presence of amine in the material led to a dramatic change in the catalytic hydrogenation of oleic acid (Fig. 7). The AP-Ni-MSN catalyzed reaction showed a sharp decrease in the yield of cracking (from $72 \%$ to $11 \%$ ) compared to Ni-MSN. While decarbonylation to heptadecane was the major product of the reaction (76\%), the yield of hydrodeoxygenation to octadecane increased four times (from 3 
to $13 \%$ ), improving the carbon economy of the reaction. Thus, the incorporation of amines to the material turned our initial hydrocracking catalyst into a hydrotreating catalyst.

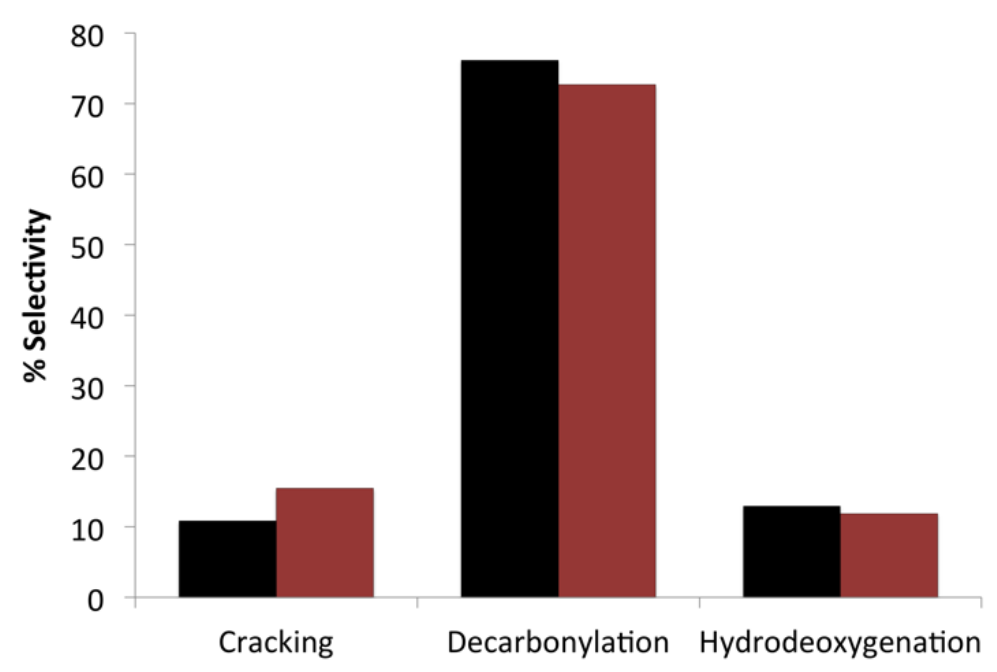

Fig. 7 Product selectivity in the hydrotreatment of oleic acid with AP-Ni-MSN (black) and $\mathrm{Ni}_{2} \mathrm{P}-\mathrm{MSN}$ (brown).

As mentioned before, $\mathrm{Ni}_{2} \mathrm{P}$ supported on SBA-15 was recently reported to improve the yield of hydrodeoxygenation of methyl esters of fatty acids when compared to Ni on SBA-15. ${ }^{21}$ Therefore, we decided to prepare a $\mathrm{Ni}_{2} \mathrm{P}-\mathrm{MSN}$ material to compare its selectivity with the one obtained with AP-Ni-MSN. Interestingly, both materials exhibited a very similar product distribution in the hydrogenation of oleic acid (Fig. 7). It has been reported that the phosphide in $\mathrm{Ni}_{2} \mathrm{P}$ reduces the $3 \mathrm{~d}$ electron density in Ni decreasing its specific activity for hydrogenation of alkenes. ${ }^{48}$ The electron deficiency in $\mathrm{Ni}_{2} \mathrm{P}$, however, should increase adsorption strength of electron rich species such as the oxygen atoms in carboxylic acids, thus explaining the observed increase in the selectivity for hydrodeoxygenation. In our case it is likely 
that the increased selectivity for decarbonylation and hydrodeoxygenation results from two factors: 1) an increase in the electron density of the substrate (conversion of carboxylic acid into carboxylate), which in turn would coordinate more efficiently to the surface of $\mathrm{Ni}$, and 2) an efficient shuttling of the substrate to the active sites by the immobilized amine groups.

The changes in product distribution were proportional to the amount of amine introduced into AP-Ni-MSN (Fig. 8). The fraction of cracking decreased from $72 \%$ in Ni-MSN to $14 \%$ in AP-Ni-MSN with $0.4 \mathrm{mmol} / \mathrm{g}$ of amine and further to $11 \%$ in AP-Ni-MSN with $1.4 \mathrm{mmol} / \mathrm{g}$ of amine. Conversely, the selectivity for hydrodeoxygenation increased from $3 \%$ to $7 \%$ to $13 \%$ with Ni-MSN, AP-Ni-MSN $(0.4 \mathrm{mmol} / \mathrm{g})$ and AP-Ni-MSN (1.4 mmol/g) respectively. This demonstrated further the impact of the amine groups in controlling the course of the reaction.

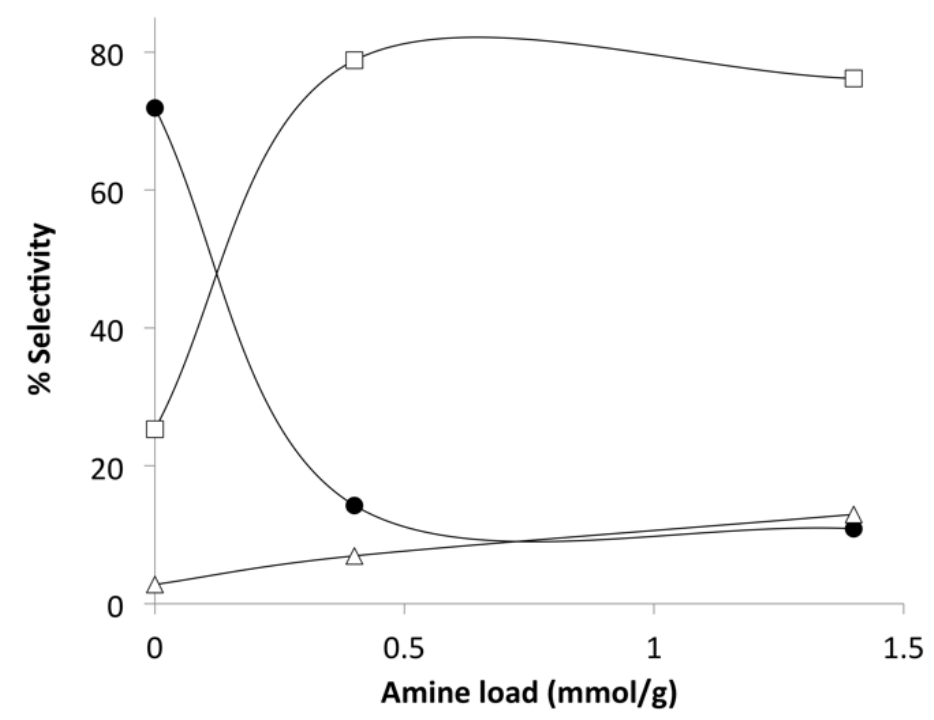

Fig. 8 Effect of amine loading of AP-Ni-MSN on the selectivity for cracking (black circles), decarbonylation (white squares) and hydrodeoxygenation (white triangles) in the hydrogenation of oleic acid. 
Interestingly, performing the reaction using a physical mixture of AP-MSN and Ni-MSN as a catalyst led to only $9 \%$ conversion compared to the $72 \%$ conversion achieved using the hybrid AP-Ni-MSN as a catalyst (Fig. 9). This result further confirmed the importance of having the amine groups located close to the catalytic sites: while in AP-Ni-MSN the amine groups increased the local concentration of the substrate in the immediacy of the catalytic sites, in the mixed experiment the amine groups of AP-MSN prevented the oleic acid from transferring to the particles containing the catalyst (Ni-MSN). It is remarkable that the interaction between the amine groups and the acid was strong enough to prevent interparticle migration of the substrate even at the high temperatures of the reaction.

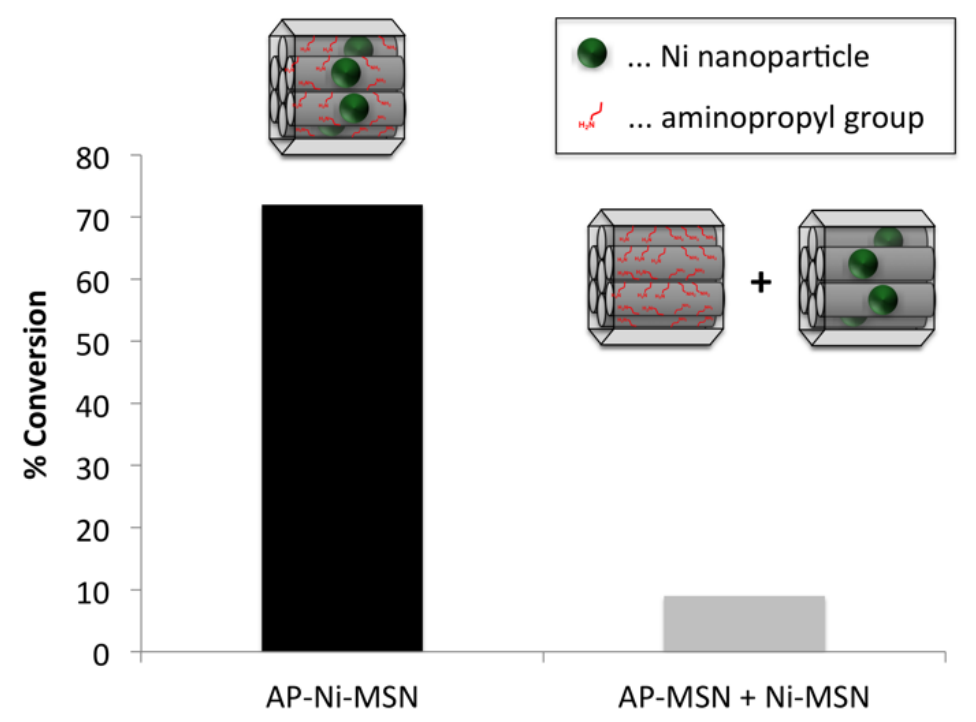

Fig. 9 Inhibition of the catalytic hydrogenation of oleic acid by Ni-MSN in the presence of AP-MSN. The conversion obtained using the hybrid AP-Ni-MSN (black) is shown as a reference. 


\subsection{Enhancement of hydrodeoxygenation selectivity by the sequential sequestration-catalysis approach}

Next, we considered that if the FFA was adsorbed and allowed to accumulate in the pores of AP-Ni-MSN before performing the hydrogenation, the conditions should be significantly different than in the single-pot adsorption-catalysis process described above. To test this hypothesis, the AP-Ni-MSN material was first suspended in a solution of oleic acid in hexane and equilibrated for $6 \mathrm{~h}$ at room temperature and atmospheric pressure in a mechanical shaker. The catalyst was then separated by centrifugation, resuspended in hexane, and subjected to hydrogenation at the previously described conditions.

Surprisingly, the selectivity for hydrodeoxygenation $\left(\mathrm{C}_{18}\right)$ increased by more than threefold (43\%, Fig. 10) compared to that of the one-pot process (13\%, Fig. 7). The fraction of cracking remained very similar to the one in the single-pot procedure ( $8 \%$ sequential versus $11 \%$ one-pot), therefore the increase in hydrodeoxygenation took place mainly at the expense of the decarbonylation (49\% sequential versus $76 \%$ one-pot). This remarkable increase in the carbon economy of the reaction was likely caused by saturation of the pores with the preloaded oleate. The small volume remaining in the pores after adsorption could restrict the access of atoms other than the carboxylate oxygens to the surface of the Ni nanoparticles. 


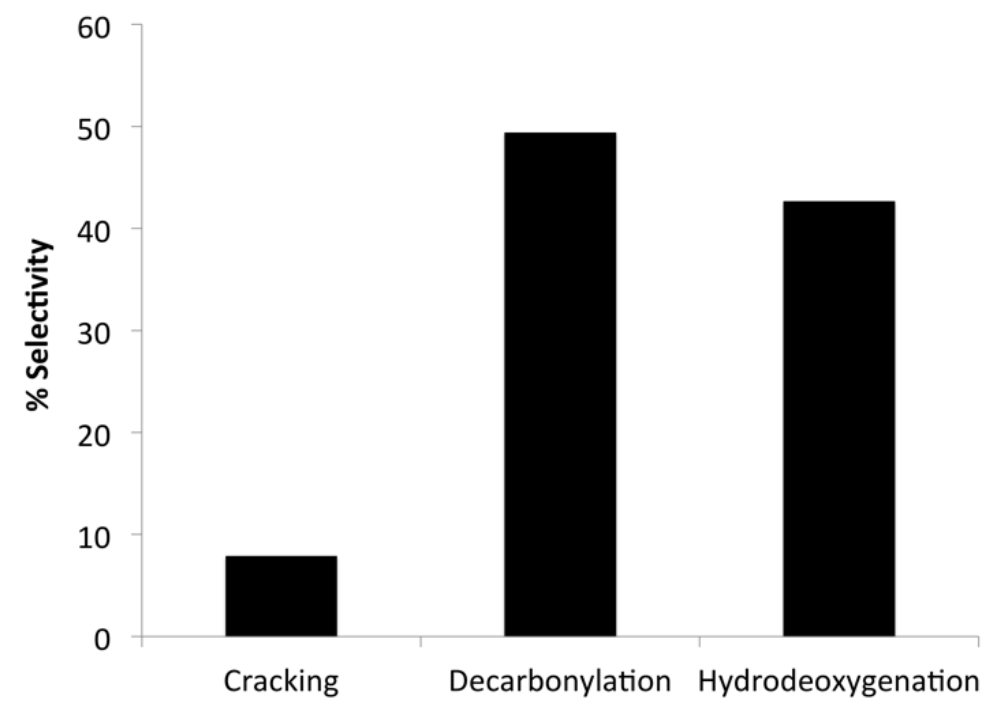

Fig. 10 Product distribution observed following the sequential sequestration-catalysis of oleic acid by AP-Ni-MSN.

\subsection{Selective sequestration and hydrogenation of crude microalgal oil with AP-}

\section{Ni-MSN}

Microalgal oil feedstock is typically rich in FFAs, containing mainly saturated $\mathrm{C}_{16}(50 \mathrm{wt} \%)$ and unsaturated $\mathrm{C}_{16}$ fatty acids $(30 \mathrm{wt} \%) .{ }^{49,50}$ As mentioned above, in biodiesel production, a refinery process is required to selectively remove these FFAs and make the feedstock suitable for processing. Thus, the AP-Ni-MSN based sequestration-catalysis could be well integrated into the production chain of biodiesel as it would remove the acidic FFAs that neutralize the transesterification catalyst, and selectively upgrade the FFAs to diesel-range alkanes (Fig. 11). 


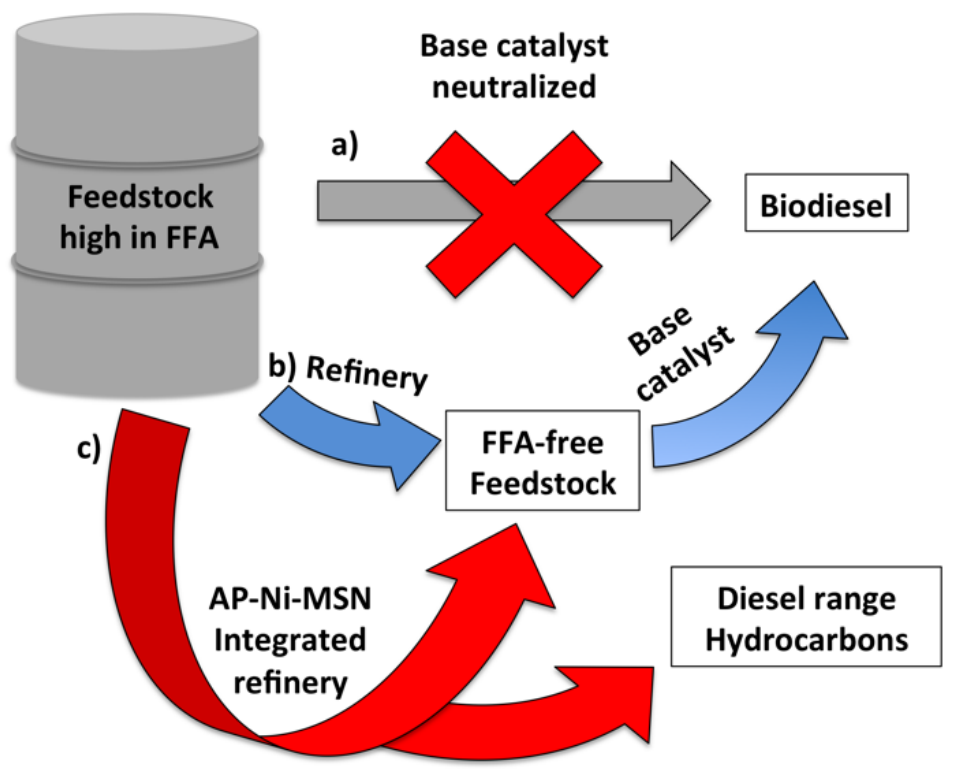

Fig. 11 Pathways for the production of biofuels from FFA-rich feedstocks. a) Direct conversion is prevented when FFAs neutralize the catalyst, b) FFA is removed before transesterification, c) FFAs are sequestered with AP-Ni-MSN and hydrogenated to hydrocarbons, and the remaining feedstock is transesterified into bio-diesel.

To show the integration of this approach into the biodiesel production chain, we treated microalgal oil with AP-Ni-MSN. A hexane extract from microalgae was first analyzed by atmospheric pressure chemical ionization-high resolution mass spectrometry (APCI-HRMS) and GC-MS to establish the lipid composition and determine the amount of FFAs present. The chain length of FFAs detected in microalgae extract ranged from $C_{12}$ to $C_{20}$ (Fig. 12). The extract (10 mL) was then mixed with AP-Ni-MSN (10 mg), the material was then isolated and subsequently hydrogenated at the same conditions used before for oleic acid. GC-MS analysis revealed that the AP-Ni-MSN sequestered up to 47 wt $\%$ of the FFAs in the microalgal extract, and catalyzed the conversion of $66 \%$ of them into liquid hydrocarbons. The most abundant fatty acid in the original extract was $\mathrm{C}_{16}$, and it was 
also the most sequestered FFA (68 wt \%). $n$-Pentadecane was the major liquid hydrocarbon obtained, which presumably resulted from the decarbonylation of sequestered $\mathrm{C}_{16}$ FFAs (Fig. 12). APCI-HRMS analysis revealed that the concentrations of triglycerides, diglycerides, terpenes and sterols in the microalgal extract remained constant after sequestration of the FFAs with AP-Ni-MSN (Fig. S3).

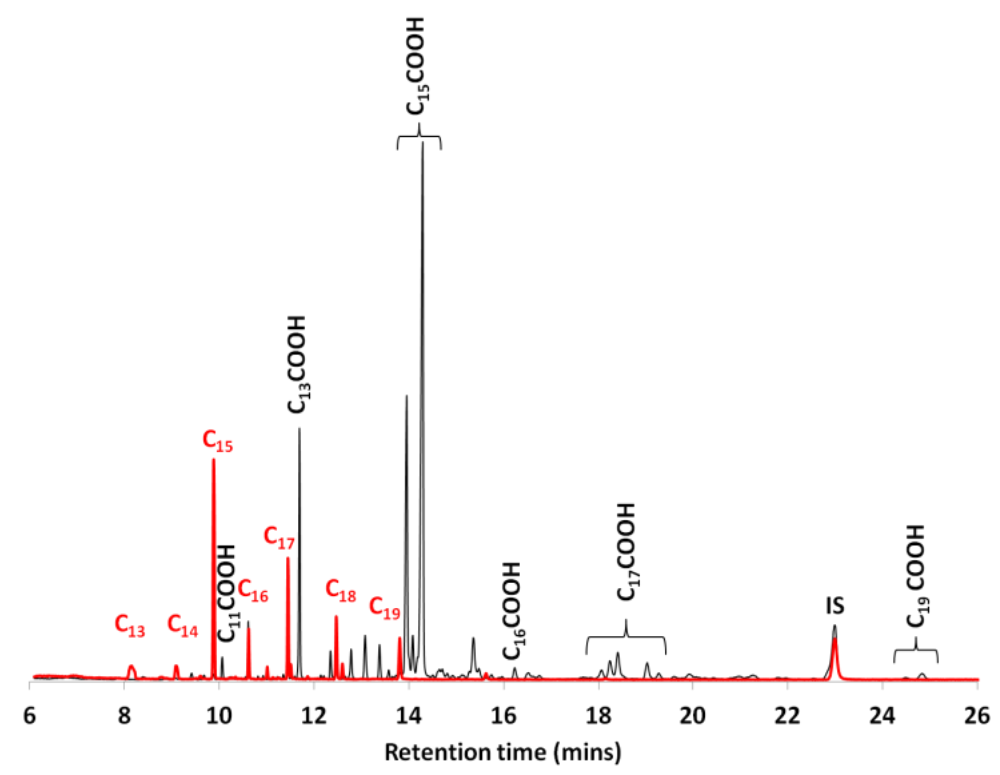

Fig. 12 FFA profile of microalgal extract (black), and hydrocarbon distribution (red) resulting from the selective sequestration and catalytic processing of the FFAs with AP-Ni-MSN.

\section{Conclusions}

The catalytic activity of Ni nanoparticles towards the hydrogenation of FFAs can be modulated by tethered amines. The amines adsorb FFAs from liquid mixtures and control their access to the catalytic sites, acting synergistically with Ni to give less cracking and more hydrodeoxygenation than amine-free Ni-MSN. The effect of amine groups on catalysis is likely to involve an increase in the local concentration and proximity of the FFAs to the catalytic centers, as well as their activation to form 
carboxylates. Saturating the AP-Ni-MSN material with FFAs prior to performing the hydrogenation reduces further the decarbonylation of the substrate, and consequently improves the carbon economy of the process. AP-Ni-MSN can be efficiently employed to sequester FFAs from crude microalgal oil and convert them into hydrocarbons with significant carbon economy. This sequestration-catalysis approach can be integrated to the refinery of FFA-rich renewable feedstocks to isolate and transform FFAs for bio-fuel production, leaving other valuable chemicals available for downstream processing.

\section{Acknowledgments}

This research was supported at the Ames Laboratory by the U.S. Department of Energy, Office of Basic Energy Sciences. Ames Laboratory is operated for the U.S. Department of Energy by Iowa State University under Contract No.DE-AC0207CH11358. C.F. would like to thank U.S. Department of Energy's Summer Undergraduate Internship Program (SULI) for the support to contribute to this research.

\section{References}

1. I. M. Atadashi, M. K. Aroua, A. R. A. Aziz and N. M. N. Sulaiman, Applied Energy, 2011, 88, 4239-4251.

2. F. Karaosmanoğlu, K. B. Ciğızoğlu, M. Tüter and S. Ertekin, Energy \& Fuels, 1996, 10, 890-895.

3. M. Al-Sabawi, J. Chen and S. Ng, Energy \& Fuels, 2012, 26, 5355-5372. 
4. W.-Y. Lou, M.-H. Zong and Z.-Q. Duan, Bioresource Technology, 2008, 99, 87528758.

5. S. Yan, S. O. Salley and K. Y. Simon Ng, Applied Catalysis A: General, 2009, 353, 203-212.

6. J. S. Valenstein, K. Kandel, F. Melcher, I. I. Slowing, V. S. Y. Lin and B. G. Trewyn, ACS Appl. Mater. Interfaces, 2012, 4, 1003-1009.

7. Y. Lee, R. Leverence, E. Smith, J. Valenstein, K. Kandel and B. Trewyn, Lipids, 2013, 1-9.

8. L. Li, E. Coppola, J. Rine, J. L. Miller and D. Walker, Energy \& Fuels, 2010, 24, 1305-1315.

9. P. Šimáček, D. Kubička, G. Šebor and M. Pospíšil, Fuel, 2009, 88, 456-460.

10. B. Donnis, R. Egeberg, P. Blom and K. Knudsen, Topics in Catalysis, 2009, 52, 229-240.

11. L. Petrus and M. A. Noordermeer, Green Chem., 2006, 8, 861-867.

12. R. C. Santana, P. T. Do, M. Santikunaporn, W. E. Alvarez, J. D. Taylor, E. L. Sughrue and D. E. Resasco, Fuel, 2006, 85, 643-656.

13. S. Lestari, I. Simakova, A. Tokarev, P. Mäki-Arvela, K. Eränen and D. Murzin, Catalysis Letters, 2008, 122, 247-251.

14. P. Mäki-Arvela, I. Kubickova, M. Snåre, K. Eränen and D. Y. Murzin, Energy \& Fuels, 2006, 21, 30-41.

15. M. Snåre, I. Kubičková, P. Mäki-Arvela, K. Eränen and D. Y. Murzin, Industrial \& Engineering Chemistry Research, 2006, 45, 5708-5715. 
16. M. Snåre, I. Kubičková, P. Mäki-Arvela, K. Eränen, J. Wärnå and D. Y. Murzin, Chemical Engineering Journal, 2007, 134, 29-34.

17. S. Lestari, P. i. Mäki-Arvela, H. Bernas, O. Simakova, R. Sjöholm, J. Beltramini, G. Q. M. Lu, J. Myllyoja, I. Simakova and D. Y. Murzin, Energy \& Fuels, 2009, 23, 3842-3845.

18. S. Lestari, P. Mäki-Arvela, I. Simakova, J. Beltramini, G. Lu and D. Murzin, Catalysis Letters, 2009, 130, 48-51.

19. B. Rozmysłowicz, P. Mäki-Arvela, S. Lestari, O. Simakova, K. Eränen, I. Simakova, D. Murzin and T. Salmi, Topics in Catalysis, 2010, 53, 1274-1277.

20. P. Do, M. Chiappero, L. Lobban and D. Resasco, Catalysis Letters, 2009, 130, 9-18.

21. Y. Yang, C. Ochoa-Hernández, V. A. de la Peña O’Shea, J. M. Coronado and D. P. Serrano, ACS Catal., 2012, 2, 592-598.

22. N. R. Shiju and V. V. Guliants, Appl. Catal. A, 2009, 356, 1-17.

23. K. Zhang, X. Hu, J. Liu, J.-J. Yin, S. Hou, T. Wen, W. He, Y. Ji, Y. Guo, Q. Wang and X. Wu, Langmuir, 2011, 27, 2796-2803.

24. J. Y. Park, Y. Zhang, M. Grass, T. Zhang and G. A. Somorjai, Nano Lett., $2008,8,673-677$.

25. W. Hou, N. A. Dehm and R. W. J. Scott, J. Catal., 2008, 253, 22-27.

26. J. Paterson, M. Potter, E. Gianotti and R. Raja, Chem. Commun., 2011, 47, 517-519.

27. D. Kubička and L. Kaluža, Applied Catalysis A: General, 2010, 372, 199-208. 
28. G. W. Huber, P. O'Connor and A. Corma, Applied Catalysis A: General, 2007, 329, 120-129.

29. D. Kubička and J. Horáček, Applied Catalysis A: General, 2011, 394, 9-17.

30. T. R. Viljava, R. S. Komulainen and A. O. I. Krause, Catalysis Today, 2000, 60, 83-92.

31. E. Laurent and B. Delmon, Journal of Catalysis, 1994, 146, 281-291.

32. S. Crossley, J. Faria, M. Shen and D. E. Resasco, Science, 2010, 327, 68-72.

33. Y. Huang, S. Xu and V. S. Y. Lin, ChemCatChem, 2011, 3, 690-694.

34. Y. Ide, N. Kagawa, M. Sadakane and T. Sano, Chemical Communications, 2012, 48, 5521-5523.

35. B. Peng, X. Yuan, C. Zhao and J. A. Lercher, Journal of the American Chemical Society, 2012, 134, 9400-9405.

36. B. Peng, Y. Yao, C. Zhao and J. A. Lercher, Angew. Chem. Int. Ed., 2012, 51, 2072-2075.

37. I. Mendiara, C. Domeño and C. Nerín, J. Sep. Sci., 2012, 35, 3308-3316.

38. T.-W. Kim, I. I. Slowing, P.-W. Chung and V. S.-Y. Lin, ACS Nano, 2010, 5, 360-366.

39. D. Zhao, J. Feng, Q. Huo, N. Melosh, G. H. Fredrickson, B. F. Chmelka and G. D. Stucky, Science, 1998, 279, 548-552.

40. M. Richard-Plouet, M. Guillot, S. Vilminot, C. Leuvrey, C. Estournès and M. Kurmoo, Chem. Mater., 2007, 19, 865-871.

41. Y. Wan and Zhao, Chem. Rev., 2007, 107, 2821-2860. 
42. C. E. C. Rodrigues and A. J. A. Meirelles, J. Chem. Eng. Data, 2008, 53, 1698-1704.

43. N. Dunford and J. King, J. Am. Oil Chem. Soc., 2001, 78, 121-125.

44. A. M. Liu, K. Hidajat, S. Kawi and D. Y. Zhao, Chem. Commun., 2000, 0, 1145-1146.

45. M. Mureseanu, A. Reiss, I. Stefanescu, E. David, V. Parvulescu, G. Renard and V. Hulea, Chemosphere, 2008, 73, 1499-1504.

46. K. K. Sharma, A. Anan, R. P. Buckley, W. Ouellette and T. Asefa, J. Am. Chem. Soc., 2008, 130, 218-228.

47. J. K. Cooper, A. M. Franco, S. Gul, C. Corrado and J. Z. Zhang, Langmuir, 2011, 27, 8486-8493.

48. Y. Okamoto, Y. Nitta, T. Imanaka and S. Teranishi, J. Chem. Soc., Farady Trans., 1979, 75, 2027-2039.

49. G. Van Vooren, F. Le Grand, J. Legrand, S. Cuiné, G. Peltier and J. Pruvost, Bioresour. Technol., 2012, 124, 421-432.

50. M. Olofsson, T. Lamela, E. Nilsson, J. P. Bergé, V. del Pino, P. Uronen and C. Legrand, Energies, 2012, 5, 1577-1592. 


\section{SUPPLEMENTARY INFORMATION}

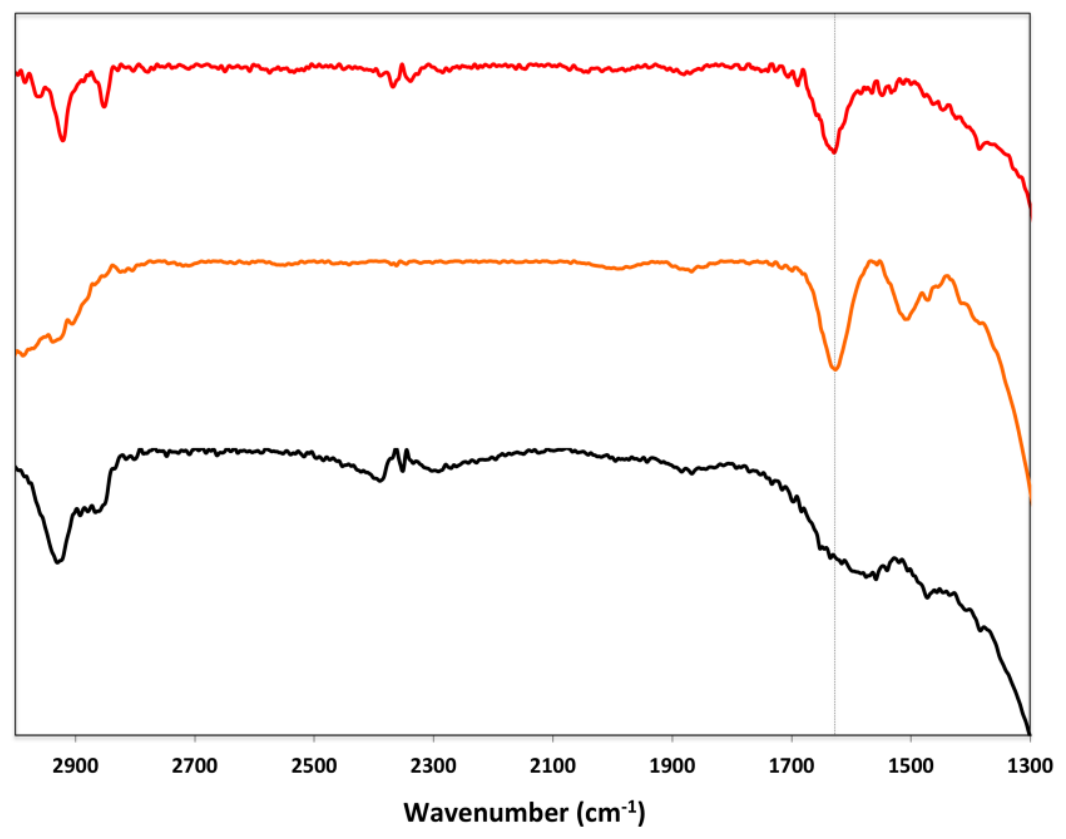

Fig. S1 FTIR spectra of Ni-MSN (red), AP-MSN (orange) and AP-Ni-MSN (black). 


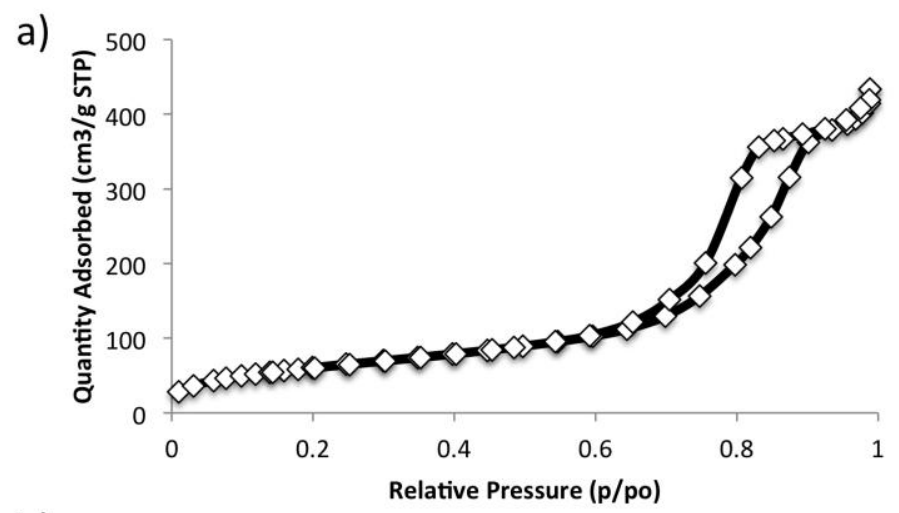

b)
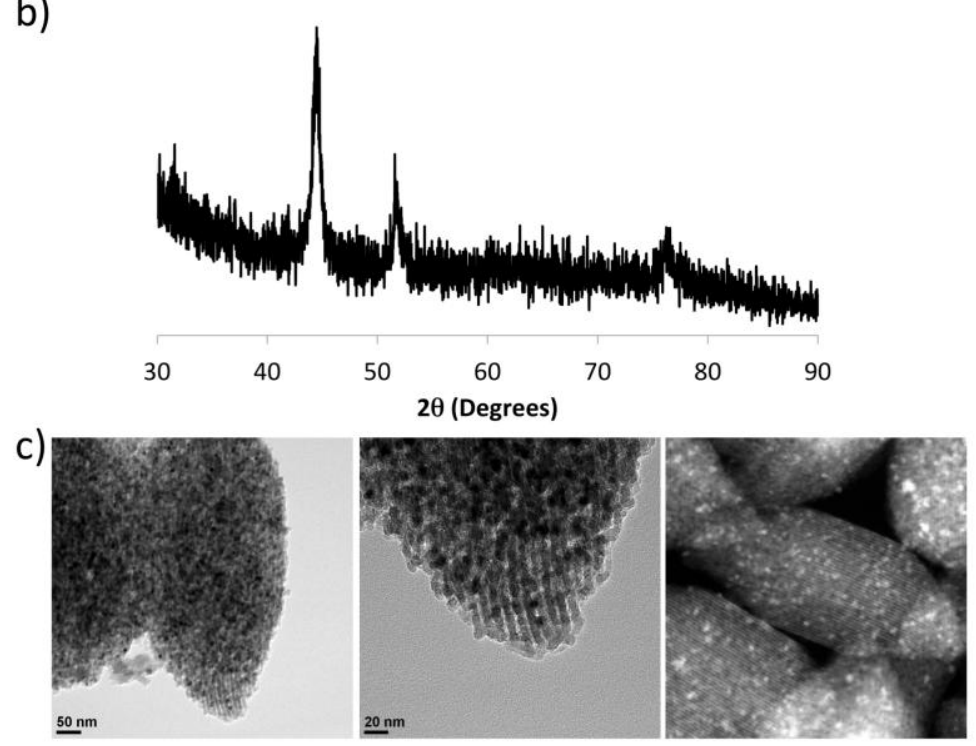

Fig. S2 a) Nitrogen sorption isotherm, b) wide angle XRD pattern, and c) TEM (left and center) and STEM images of AP-Ni-MSN (right). The dark spots in the TEMs and the bright spots in the STEM correspond to Ni nanoparticles. 

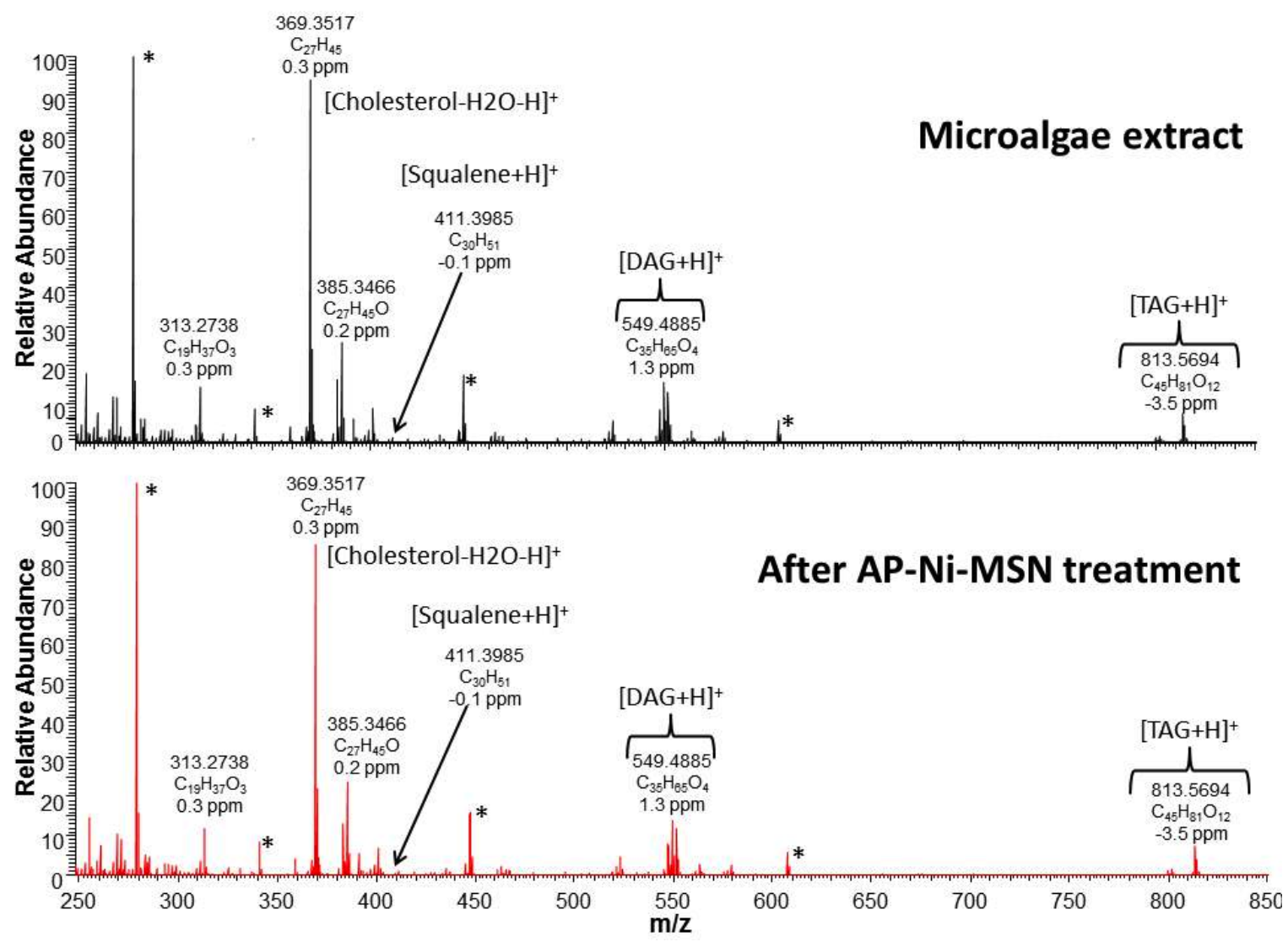

Fig. S3 APCI-HRMS spectra of microalgal oil extract before (black) and after (red) mixing with AP-Ni-MSN. Solvent contamination peaks are designated with * and the peaks at $\mathrm{m} / \mathrm{z} 313.2738$ and 385.3466 are tentatively assigned as the methyl ester of ricinoleic acid and Cholest-4-en-3-one, respectively. 


\title{
CHAPTER 7. IRON NANOPARTICLES SUPPORTED ON MESOPOROUS SILICA FOR THE HYDRODEOXYGENATION OF MICROALGAE OIL TO \\ GREEN DIESEL
}

\author{
Modified from a paper to be submitted to Journal of Catalysis \\ Kapil Kandel, Igor I. Slowing
}

\begin{abstract}
Iron nanoparticles were prepared within the pores of mesoporous silica and employed for the hydrotreating of microalgal oil. High selectivity for hydrodeoxygenation and full conversion is observed after $6 \mathrm{~h}$ of reaction at $290{ }^{\circ} \mathrm{C}$ and 30 bar $\mathrm{H}_{2}$. Kinetic studies of the hydrotreatment of oleic acid under varying temperatures and pressures, as well as identification of reaction intermediates allowed mechanistic interpretation.
\end{abstract}

\section{Introduction}

The increasing energy demand and concerns over the gradual depletion of fossil fuels have attracted significant amount of research to the exploration of alternative energy sources.[1,2] In this context, microalgae are considered as one of the most promising renewable energy resources owing to their short harvest cycle, small cultivation area, high lipid content (up to $80 \%$ of their dry weight) and minimum greenhouse gas emission.[3, 4]

The major components of microalgal oil are free fatty acids (FFAs) and triglycerides. These can be converted to fatty acid methyl esters (FAMEs) by catalytic reaction with methanol and used as biodiesel. However, due to the degree of unsaturation and high oxygen content of the FAMEs, issues such as poor storage 
stability, marginal cold flow and engine compatibility limit their widespread use.[5, 6] An alternate technology to produce biofuels from microalgal oil is through hydrotreating with $\mathrm{Ni}, \mathrm{Co}$ and Mo sulfides or noble metal catalysts such as $\mathrm{Pd}$ and $\mathrm{Pt}$ supported on metal oxides.[7-13] While the high price of the noble metals can be avoided by using the sulfided catalysts, slow desulfurization reduces their activity and contaminates the fuel.[7, 9, 14] Furthermore, these catalysts have shown poor selectivity, favoring cracking and decarbonylation over hydrodeoxygenation to produce broad hydrocarbon distributions.[15] In an effort to establish a more economical sulfurfree catalyst to upgrade microalgae oil, Lercher's group reported recently the hydrodeoxygenation of microalgae oil to alkanes by cascade reactions on bifunctional catalysts based on $\mathrm{Ni}$ and an acidic zeolite at $260{ }^{\circ} \mathrm{C}$ and 40 bar hydrogen pressure.[16] Following work by the same group illustrated the selectivity towards decarbonylation route by supporting $\mathrm{Ni}$ catalyst on $\mathrm{ZrO}_{2}$ which directed the conversion through two parallel pathways.[17]

While replacing the acidic zeolite support with $\mathrm{ZrO}_{2}$ has proven to increase the activity and selectivity of Ni catalyst for hydrotreatment of FFAs, the substitution of $\mathrm{Ni}$ with more economical metals has not been much explored. As opposed to the tendency of Ni catalysts to break C-C bonds,[18] iron catalysts are well known to promote formation of these bonds in the conversion of synthesis gas to hydrocarbons by the Fischer-Tropsch (FT) process.[19, 20] In contrast to bulk iron, supported iron catalysts have enhanced mechanical stability and display higher activity due to dispersion of the active phase.[21-23] While research groups have been studying supported iron nanoparticle catalysts in the FT synthesis for several decades, the activity and selectivity of these catalysts for the hydrodeoxygenation of aliphatic carboxylic acid has not been much explored. 
To contribute to the efforts for more economical and efficient catalysts to upgrade microalgal oil to green diesel, we report the synthesis of an iron nanoparticle catalyst supported on mesoporous silica nanomaterials (Fe-MSN). We explored the activity and selectivity of Fe-MSN for the hydrotreatment of oleic acid and examined the effects of temperature and pressure on the kinetics of the reaction. Based on these studies, we proposed a reaction mechanism and applied the material as a catalyst for the conversion of crude microalgal oil into green diesel.

\section{Materials and Methods}

\subsection{Materials}

Pluronic P104 was generously provided by BASF. Tetramethyl orthosilicate (TMOS), oleic acid and Sylon (BSTFA (N,O-bis(trimethylsilyl)trifluoroacetamide) and TMCS (trimethylchlorosilane), 99:1) were purchased from Sigma Aldrich. Iron (III) Nitrate $\left[\mathrm{Fe}\left(\mathrm{NO}_{3}\right)_{3} \cdot 9 \mathrm{H}_{2} \mathrm{O}\right]$ was purchased from Fisher Scientific. All reagents were used as received without further purification.

\subsection{Catalyst Preparation}

MSN was prepared using a nonionic block co-polymer Pluronic P104 surfactant.[24] In a typical synthesis, P104 (7.0 g) was dissolved in aqueous $\mathrm{HCl}(273.0$ $\mathrm{g}, 1.6 \mathrm{M}$ ). After stirring for $1 \mathrm{~h}$ at $56^{\circ} \mathrm{C}$, tetramethylorthosilicate (TMOS, $10.64 \mathrm{~g}$ ) was added and stirred for additional $24 \mathrm{~h}$. The resulting mixture was further hydrothermally treated for $24 \mathrm{~h}$ at $150{ }^{\circ} \mathrm{C}$ in a high-pressure reactor. Upon cooling to room temperature, the white solid was collected by filtration, washed with copious amounts of methanol and dried in air. To remove the surfactant P104, the MSN material was heated at a ramp rate of $1.5^{\circ} \mathrm{C} \min ^{-1}$ and maintained at $550{ }^{\circ} \mathrm{C}$ for $6 \mathrm{~h}$. MSN was then mixed with water and stirred at room temperature in order to rehydrate and regenerate the silanol groups, followed by filtration and drying. For impregnation, $\mathrm{Fe}\left(\mathrm{NO}_{3}\right)_{3} \cdot 9 \mathrm{H}_{2} \mathrm{O}(0.40$ 
mmol, $0.16 \mathrm{~g})$ was completely dissolved in water $(0.48 \mathrm{~mL})$. To this solution, the rehydrated MSN (0.4 g) was added and mixed. The solid mixture was calcined in air at a heating rate of $10{ }^{\circ} \mathrm{C} \min ^{-1}$ to $300{ }^{\circ} \mathrm{C}$ and maintained at that temperature for $3 \mathrm{~h}$ followed by reduction at $400{ }^{\circ} \mathrm{C}$ for 6 hours in a constant flow of $\mathrm{H}_{2}(1.67 \mathrm{~mL} / \mathrm{s})$.

\subsection{Characterization}

Surface analysis of the catalyst was performed by nitrogen sorption isotherms in a Micromeritics Tristar surface area and porosity analyzer. The surface areas were calculated by the Brunauer-Emmett-Teller (BET) method and the pore size distribution were calculated by the Barrett-Joyner-Halenda (BJH) method. The small angle powder X-ray diffraction patterns were obtained with a Rigaku Ultima IV diffractometer using $\mathrm{Cu}$ target at $40 \mathrm{kV}$ and $44 \mathrm{~mA}$. $\mathrm{Cu} \mathrm{K} \beta$ was removed using a monochromator. For transmission electron microscopy measurements, an aliquot of the powder was sonicated in methanol for 15 min. A single drop of this suspension was placed on a lacey carbon coated copper TEM grid and dried in air. The TEM examination was completed on a Tecnai G2 F20 electron microscope operated at $200 \mathrm{kV}$. Fourier transform infrared (FT-IR) spectra were recorded on Nicolet Nexus 470. Perkin Elmer ICP-MS was used to measure Ni loading and Agilent GC-MS was used to measure reaction products.

\subsection{Catalytic Activity Measurements}

All catalytic reactions were performed in a batch reactor (Parr Instrument). In a typical experiment, the catalyst $(10 \mathrm{mg})$ and oleic acid solution in hexanes (1mM, 10 $\mathrm{mL}$ ) were added in the reactor. The reactor was purged with $\mathrm{H}_{2}$ at ambient temperature and was finally pressurized by $\mathrm{H}_{2}$ to 30 bar. For kinetics study, the reaction was carried out at $290{ }^{\circ} \mathrm{C}$ for $1,2,3,4,5$, and $6 \mathrm{~h}$ with constant stir rate. The reaction was allowed to cool to room temperature and the catalyst was separated. The reaction product was 
mixed with $1 \mathrm{~mL}$ Sylon (BSTFA (N,O-bis(trimethylsilyl)trifluoroacetamide) and TMCS (trimethylchlorosilane), 99:1) and heated to $70{ }^{\circ} \mathrm{C}$ for $2 \mathrm{~h}$ for further derivatization. The final mixture was analyzed by GC-MS. Similar experiment was conducted on hexane extract of Nannochloropsis $s p$.

\section{Results and Discussion}

\subsection{Synthesis of Fe-MSN}

The textural properties of MSN support and Fe-MSN catalyst are summarized in Table 1. ICP measurement indicated $6.0 \mathrm{wt} \%$ Fe was immobilized in the MSN support. Formation of the Fe nanoparticles led to approximately $10 \%$ decrease in the surface area and pore volume of the support, however its nitrogen sorption isotherm remained type IV confirming retention of the mesoporous character (Fig. 1a).[25]. TEM and STEM imaging suggested that the Fe nanoparticles were located mainly inside the pores of the MSN (Fig. 1b). Low angle XRD analysis confirmed that the structure of the support was not affected by the formation of Fe nanoparticles as it displayed the diffraction pattern corresponding to the hexagonal arrangement of pores typical of SBA-15 type materials (Fig. 1c).[26] Wide-angle XRD showed a pattern of peaks corresponding to the body centered cubic phase of crystalline iron nanoparticles (Fig. 1d).[27, 28] The relatively wide reflections indicated small crystallite size of the iron nanoparticles, estimation using the Scherrer equation indicated their size was on the same order as the width of the mesopores, which suggested nanoparticle growth was restricted by the size of the pores.[29] 
Table 1. Textural properties of the support and catalyst.

\begin{tabular}{lll}
\hline & MSN & Fe-MSN \\
\hline Surface area $\left(\mathrm{m}^{2} \mathrm{~g}^{-1}\right)$ & 331 & 295 \\
Pore volume $\left(\mathrm{cm}^{3} \mathrm{~g}^{-1}\right)$ & 0.97 & 0.88 \\
Pore diameter $(\mathrm{nm})$ & 11.1 & 10.9 \\
\hline
\end{tabular}

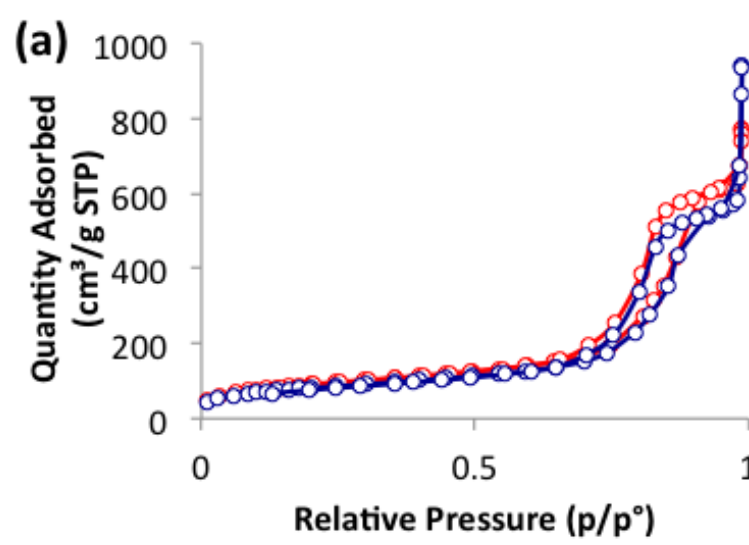

(c)

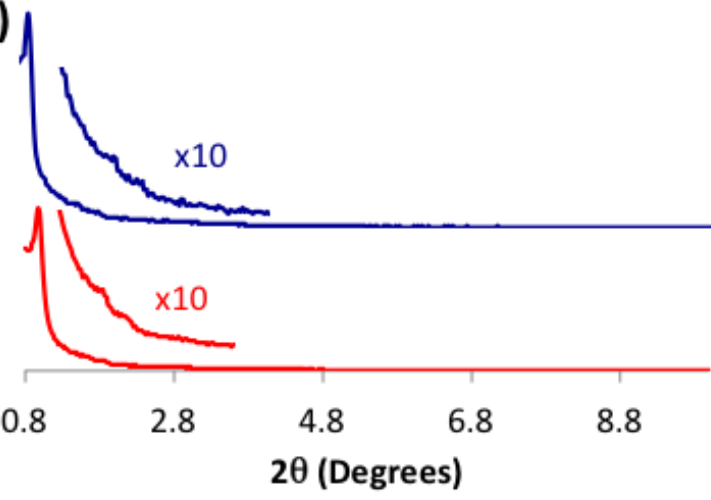

(b)
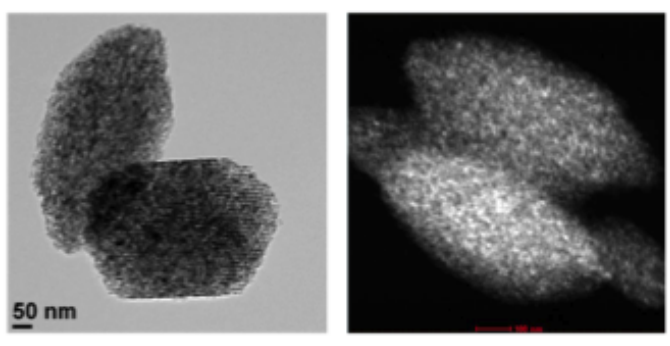

(d)

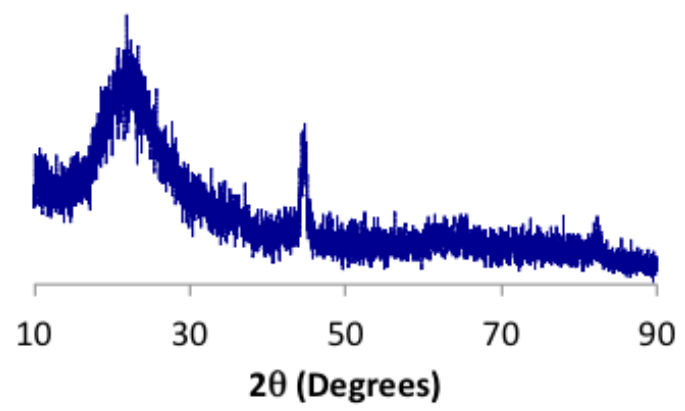

Fig. 1. (a) $\mathrm{N}_{2}$ sorption isotherms of MSN (red) and Fe-MSN (blue), (b) TEM (left) and STEM (right) images of Fe-MSN, (c) XRD of MSN (red) and Fe-MSN (blue) insets show 10x magnified 110 and 200 peaks, and (d) wide angle XRD of Fe-MSN.

\subsection{Oleic Acid Hydrotreatment with Fe-MSN}

The kinetics of the hydrotreatment of oleic acid (1mM, $10 \mathrm{~mL})$ with Fe-MSN (10 $\mathrm{mg}$ ) at $290^{\circ} \mathrm{C}$ and 30 bar $\mathrm{H}_{2}$ pressure are shown in Fig. 2. No oleic acid was detected after $0.5 \mathrm{~h}$ and the mayor hydrocarbon product obtained after $6 \mathrm{~h}$ was $n$-octadecane, indicating deoxygenation was the major reaction route. The yield of $\mathrm{C}_{18} n$-octadecane increased continuously to $83 \%$ in $6 \mathrm{~h}$, while that of $\mathrm{C}_{17} n$-heptadecane grew slowly to 
$12 \%$ after $6 \mathrm{~h}$ (Fig. 2a). In sharp contrast to the hydrotreatment of oleic acid using nickel supported on MSN at the same reaction conditions (72\% cracking, $25 \% \mathrm{C}_{17}$ and $3 \%$ $\mathrm{C}_{18}$ ), the hydrocracking was almost eliminated with Fe-MSN catalyst as it was only observed after $6 \mathrm{~h}$ ( $3 \%$ yield).
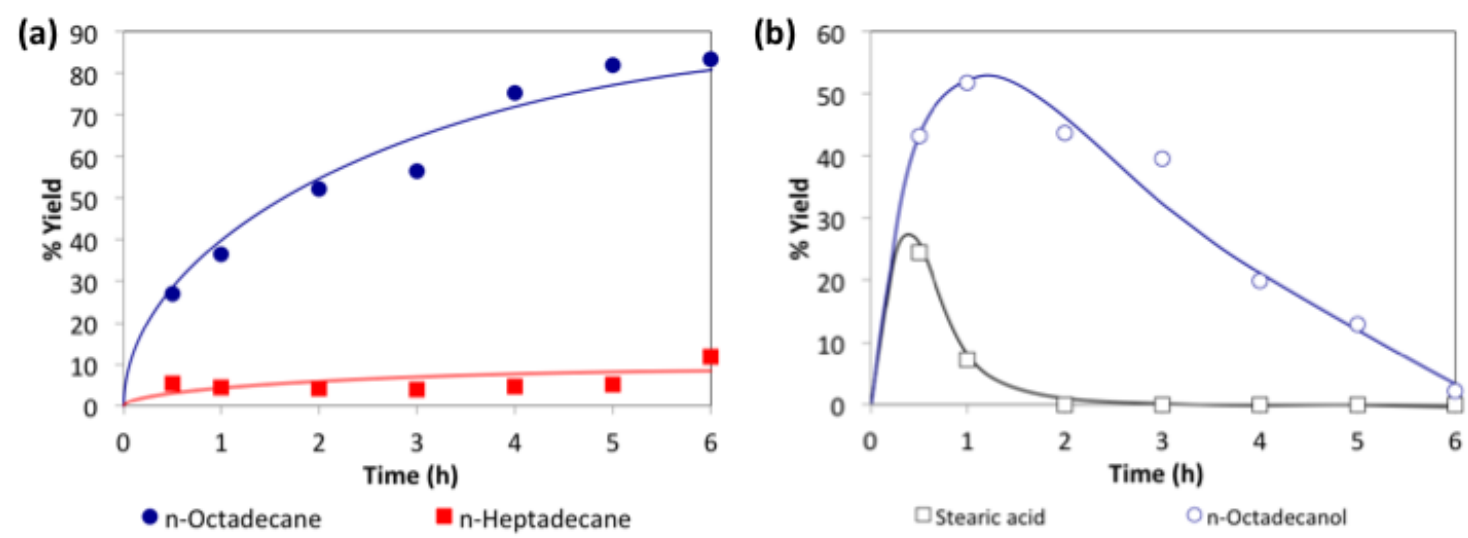

Fig. 2. Kinetics of oleic acid hydrotreatment catalyzed by Fe-MSN: (a) hydrocarbon products, and (b) reaction intermediates.

Stearic acid and 1-octanol were observed with highest yields at early reaction times, peaking before 0.5 and $2 \mathrm{~h}$ respectively and then decreasing, suggesting both species are reaction intermediates (Fig. 2b). Since stearic acid disappeared earlier than octadecanol and octadecenol was not observed, it is likely that the reaction proceeded initially by hydrogenation of $\mathrm{C}=\mathrm{C}$, followed by reduction of the $\mathrm{COOH}$ group to alcohol, which eventually underwent deoxygenation to give the major reaction product. The yield of $n$ octadecane increased linearly with the decrease in 1-octadecanol until 5h supporting the idea that the alcohol is an intermediate in the hydrodeoxygenation pathway (Fig. 3). After $5 \mathrm{~h}$ the production of $n$-octadecane plateaued suggesting the system reached equilibrium. [30] 


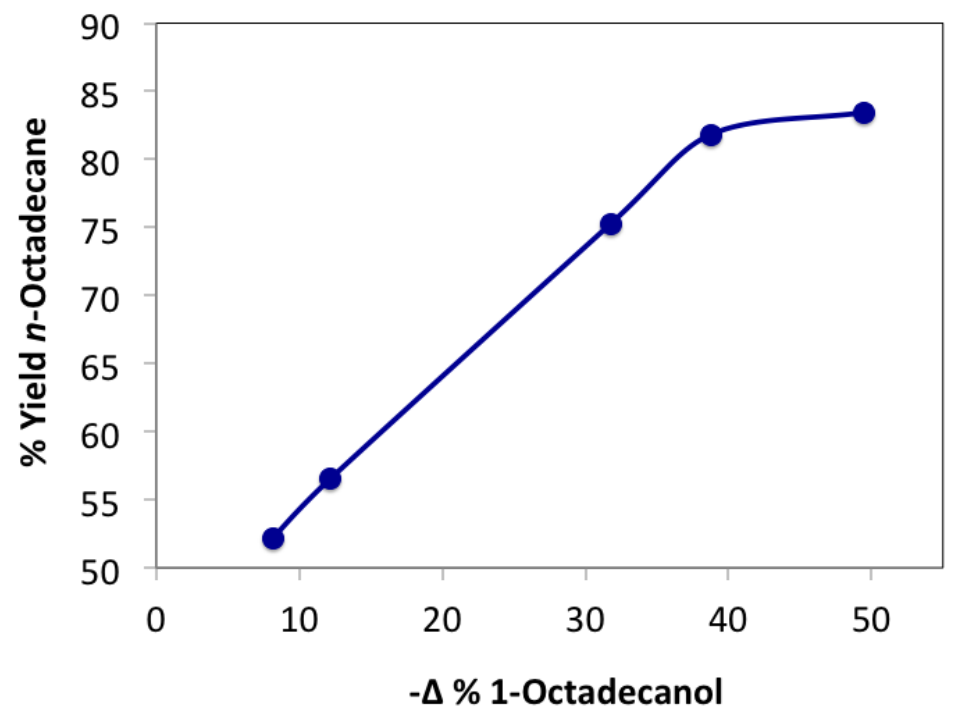

Fig. 3. Production of n-octadecane as a function of the decrease in yield of 1octadecanol.

The formation of $n$-octadecane from 1-octadecanol could take place as a two-step process, first involving dehydration of 1-octadecanol to give 1-octadecene, which would then be hydrogenated to the saturated product (Scheme 1, pathway a). $n$ Heptadecane could form either by direct decarboxylation of stearic acid or by decarbonylation of octadecanal, which would be an intermediate in the formation of 1octadecanol (Scheme 1, pathway b). It must be stated, though, that neither octadecanal nor octadecene intermediates were detected in our experiments, therefore their hypothetical participation in the reaction would be possible only if they are short lived under the employed conditions. Formation of transient octadecanal is reasonably expected, as Fe-based catalysts have been reported to yield aldehydes with high selectivity at low temperature and pressure.[31-33] Similarly, the hydrogenation of double bonds was a fast process at the conditions employed, as can be deduced from the rapid formation of stearic acid. Based on these assumptions we decided to investigate the effects of temperature and pressure on the catalytic reaction. 
Scheme 1. Possible mechanisms for the conversion of oleic acid into $n$-octadecane (blue, a) and $n$-heptadecane (red, b) from the intermediates 1-octadecanol and octadecanal, respectively. $\mathrm{R}=n$-pentadecyl.

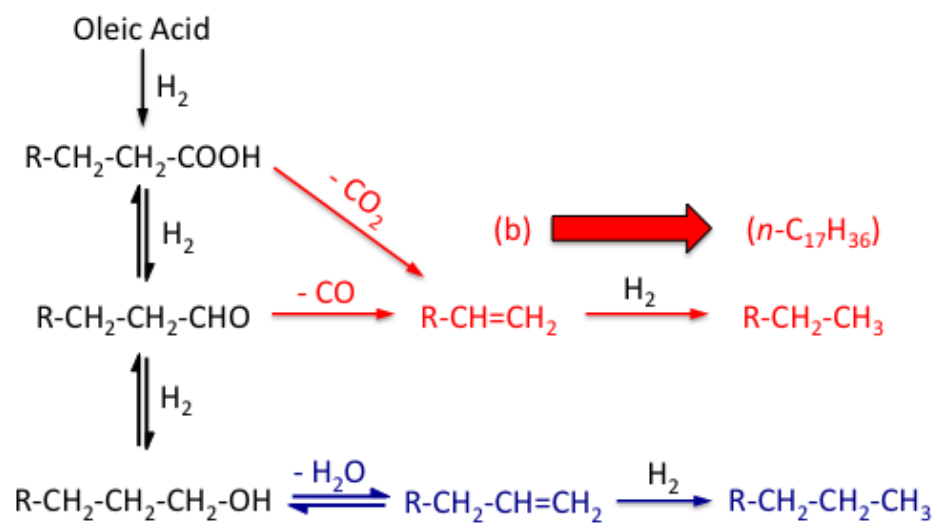

(a)

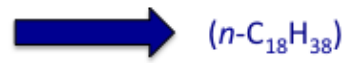

\subsection{Effect of Reaction Temperature}

The conversion of oleic acid into liquid hydrocarbons catalyzed by Fe-MSN had a sharp dependence on temperature in the range from $230^{\circ} \mathrm{C}$ to $290^{\circ} \mathrm{C}$ (Fig. 4a). The $6 \mathrm{~h}$ conversion went from less than $5 \%$ at $230^{\circ} \mathrm{C}$ to nearly quantitative at $290^{\circ} \mathrm{C}$ as described before. The little conversion observed at $230^{\circ} \mathrm{C}$ consisted mainly of incomplete reaction pathways as most of the species identified corresponded to reaction intermediates (77\%, Fig. 4b). In contrast, only small amounts of intermediates (exclusively 1-octadecanol) were observed at temperatures above $230^{\circ} \mathrm{C}$ (samples taken at $6 \mathrm{~h})$. Performing the reaction at $230^{\circ} \mathrm{C}$ allowed the identification of octadecanal $(60 \%$ selectivity), however this species was not observed at higher temperatures. The equilibrium constant for the hydrogenation of octadecanal to 1 -octadecanol at $260^{\circ} \mathrm{C}$ and 30 bar has been recently reported to be around 30, which explains why too little intermediate aldehyde was available at the conditions described in the previous section.[17] 
(a)

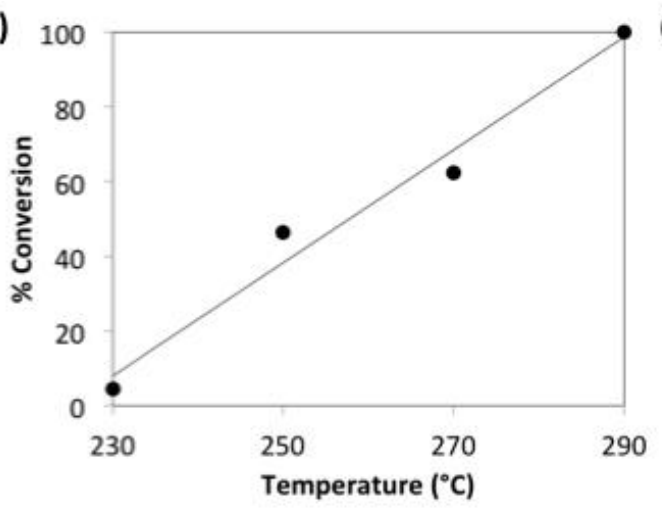

(b) 100

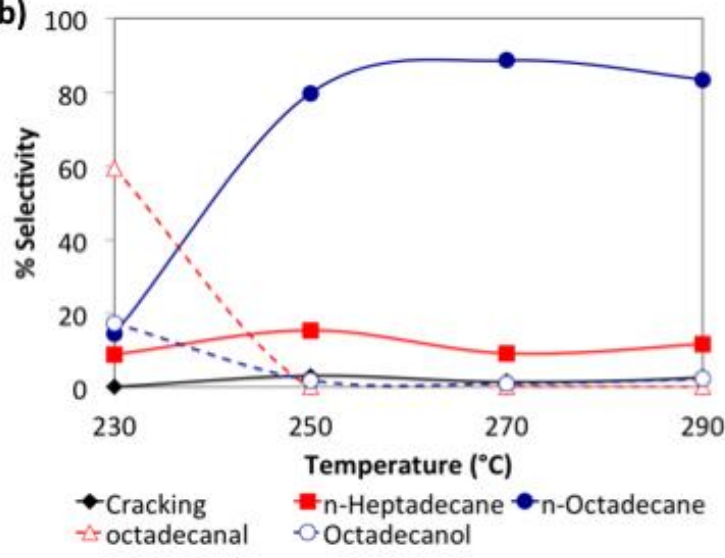

Fig. 4. (a) Conversion of oleic acid and (b) product distribution as a function of reaction temperature. Data points correspond to $6 \mathrm{~h}$ reaction time at $30 \mathrm{bar} \mathrm{H}_{2}$.

The selectivity of $n$-octadecane rose sharply from $14 \%$ at $230^{\circ} \mathrm{C}$ to values ranging between 80 and $89 \%$ with an apparent maximum at $270^{\circ} \mathrm{C}$. To the contrary, $n$ heptadecane remained between 9 and $15 \%$ with no obvious tendency to increase or decrease with temperature within the range tested. While the low $n$-heptadecane selectivity could be attributed to low equilibrium concentrations of octadecanal, the amount of this intermediate is also low with other catalysts, for which decarbonylation is the major reaction pathway.[13,17] Thus, the low selectivity of $n$-heptadecane must be inherent to the capacity of the catalyst to decrease the activation energy for the steps that lead to deoxygenation rather than decarbonylation. The same statement applies to cracking, which is the major pathway observed using Ni-MSN under the same reaction conditions, but is absent at $230^{\circ} \mathrm{C}$ or less than $4 \%$ at temperatures between $250^{\circ} \mathrm{C}$ and $290^{\circ} \mathrm{C}$ using $\mathrm{Fe}-\mathrm{MSN}$ as a catalyst.

\subsection{Effect of hydrogen pressure}

As expected, the conversion of oleic acid was proportional to the pressure of hydrogen applied (Fig. 5a). However, at $270^{\circ} \mathrm{C}$ the conversion showed little sensitivity to an increase in pressure from 10 to 20 bar, going only from $33 \%$ to $36 \%$ and requiring higher pressures to approach to full conversion (Fig. 5a). The main effect of increasing 
the pressure from 10 to 20 bar was on the selectivity of the reaction, by driving the reaction pathways to completion through further reduction of intermediates (Fig. 5b). The use of relatively low hydrogen pressures allowed identifying two of the intermediates that were not observed at 30 bar: 1-heptadecene and 1-octadecene, which should be the immediate precursors of $n$-octadecane and $n$-heptadecane products respectively (Scheme 1). As previously reported, low hydrogen pressures increased the selectivity for decarbonylation to give n-heptadecane, while the higher pressures favored the hydrodeoxygenation product n-octadecane.[2, 17] This dependence of selectivity on hydrogen pressure is likely the result of the participation of $\mathrm{H}_{2}$ in the equilibrium between octadecanal and octadecanol, the branching step in the process. As hydrogen is required to convert the octadecanal into 1-octadecanol, increasing the amount of the gas shifts the equilibrium towards the alcohol favoring the route to octadecane, while decreasing the amount of the gas has the opposite effect leading to the heptadecane pathway.
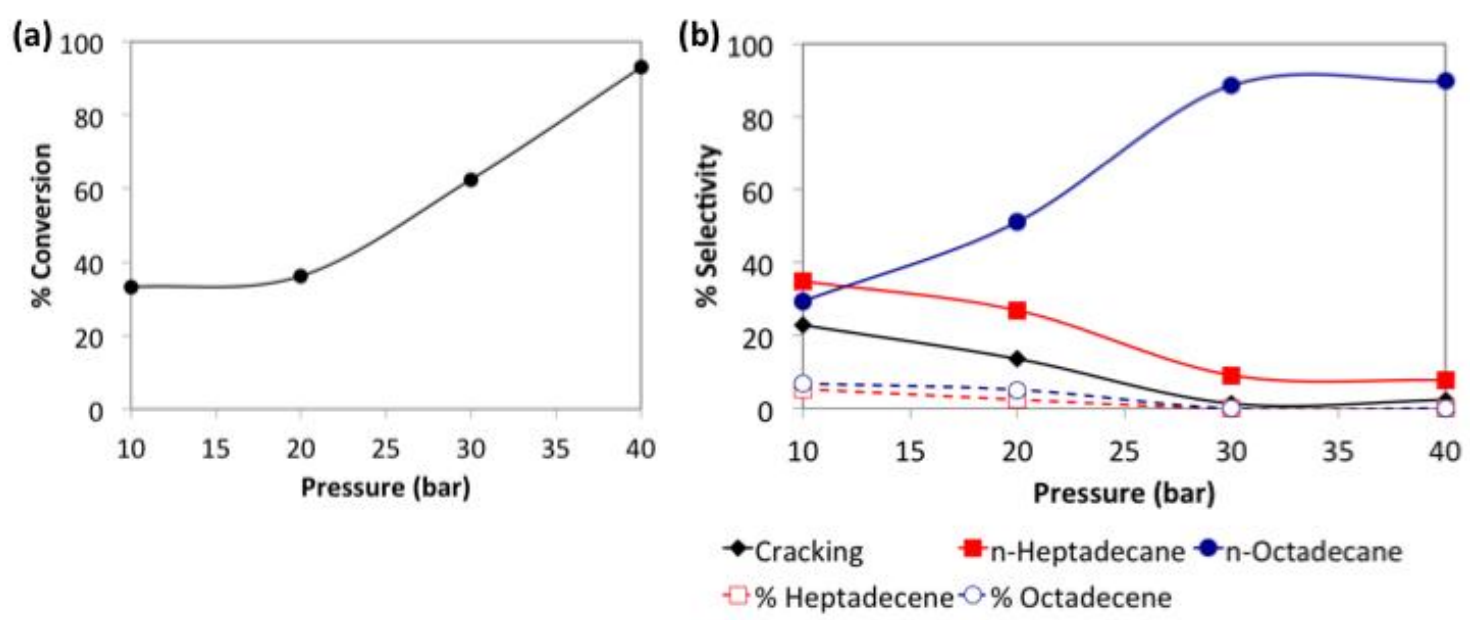

Fig. 5. (a) Conversion of oleic acid at $270{ }^{\circ} \mathrm{C}$ for $6 \mathrm{~h}$ and different $\mathrm{H}_{2}$ pressures, (b) effect of reaction pressure on product distribution. 


\subsection{Mechanism of oleic acid hydrotreatment with Fe-MSN}

Iron oxides have been reported as catalysts for the selective reduction of carboxylic acids to aldehydes.[34] Ponec and co-workers demonstrated that the reduction of acetic acid to acetaldehyde over iron oxides requires the formation of an iron(0) phase on the surface of the oxide.[32] They proposed that hydrogen binds at the metallic sites and then spills over to reduce the acid, which is bound at oxygen defect sites in the oxide.[33, 35, 36] Kinetic studies by Rachmady and Vannice supported this mechanism as they demonstrated the reaction fits a Langmuir-Hinshelwood model for two reactants binding at two different sites prior to reacting with each other.[31, 37] In contrast to those experiments, our catalyst consisted of metallic iron, as clearly demonstrated by the XRD pattern (Fig. 1d). However, the absence of an oxide phase cannot be completely ruled out, as iron oxide could exist either in small amounts or in noncrystalline state, which would not be detected by XRD. Indeed, XPS analysis of the catalyst confirmed the presence of the oxide (Fig. 6a). The emergence of a reflection at $35^{\circ}$ in the XRD pattern of the spent catalyst suggested the formation of iron oxide during the reaction, which could form by a Mars-Van Krevelen mechanism in which oxygen from the acid reacts with the surface of the catalyst to form an iron oxide layer. Combining these information, we believe the reaction proceeds by the combination of two mechanisms: (i) spillover mechanism which involves the dissociation of hydrogen molecules on metallic iron phase of the catalyst and migration of hydrogen atoms to the iron oxide phase and (ii) Mars-Van Krevelen mechanism involving the adsorption of oleic acid at oxygen defect sites of iron oxide phase and conversion to intermediates (Fig. 6b). 
(a)

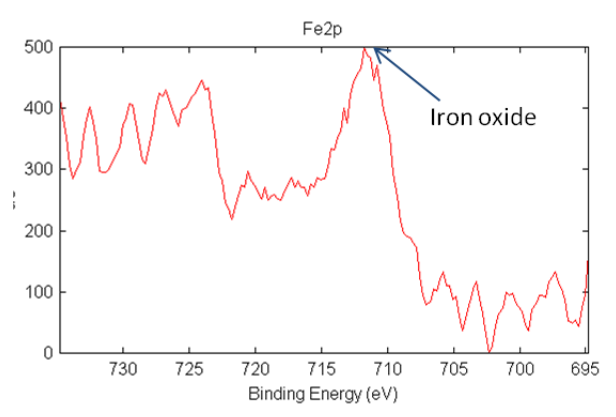

(b)

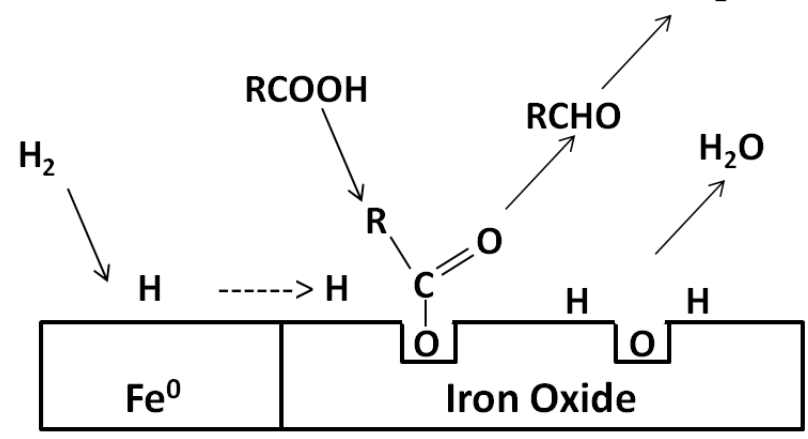

Hydrogen Hydrogenation Vacancy activation creation

Fig. 6. (a) Fe 2p XPS spectra of Fe-MSN catalyst, (b) proposed mechanism for oleic acid conversion on the catalyst surface.

\subsection{Conversion of microalgae oil into green diesel}

The lipids from Nannochloropsis sp. microalgae were extracted with hexanes. This crude microalgae extract was directly hydrotreated with $10 \mathrm{mg}$ of $\mathrm{Fe}-\mathrm{MSN}$ at $290{ }^{\circ} \mathrm{C}$ under 30 bar $\mathrm{H}_{2}$ for $6 \mathrm{~h}$ in batch mode. The hydrocarbons distribution obtained after 6 $\mathrm{h}$ reaction time is shown in Figure (7). All the fatty acids remaining after the reaction were saturated proving that the hydrogenation of double bonds in fatty acids occurs fast in hydrotreatment of microalgae extract with Fe-MSN. The high ratio of octadecane: heptadecane (10:1) after hydrotreatment of microalgae extract strongly supports our previous claim that the Fe-MSN favours hydrodeoxygenation route rather than decarbonylation and cracking.

To our surprise, octadecene (15.3 wt \%) was the major hydrocarbon product. To better understand, the fatty acid composition of the crude microalgae extract was analysed in GC-MS and was found to consist: saturated $\mathrm{C}_{14}$ fatty acids (11.1\%), saturated $\mathrm{C}_{16}$ fatty acids $(49.6 \%)$, unsaturated $\mathrm{C}_{16}$ fatty acids $(29.6 \%)$, saturated $\mathrm{C}_{18}$ fatty acids $(1.3 \%)$, unsaturated $\mathrm{C}_{18}$ fatty acids $(3.3 \%)$, along with smaller amounts of $\mathrm{C}_{12}, \mathrm{C}_{15}, \mathrm{C}_{17}$ and $\mathrm{C}_{20}$ fatty acids (5.15 wt \% total) (Figure $\left.\mathrm{SI}\right)$. However, the higher 
yield of $\mathrm{C}_{18}$ hydrocarbons after hydrotreatment of crude microalgae extract implies that Fe-MSN might be able to hydrogenolyse and subsequently hydrodeoxygenate neutral lipids like di- and triglyceride to alkanes. This influences the hydrogen consumption and therefore the product yield and distribution.[38] The presence of octadecene after hydrotreatment of crude microalgae extract is consistent with the observation of unsaturated hydrocarbons at lower pressure (Fig. 7). Further study to elucidate the detailed kinetics and mechanism on hydrotreatment of triglycerides with Fe-MSN and pathways to decrease the hydrogen consumption are being investigated in our laboratory.

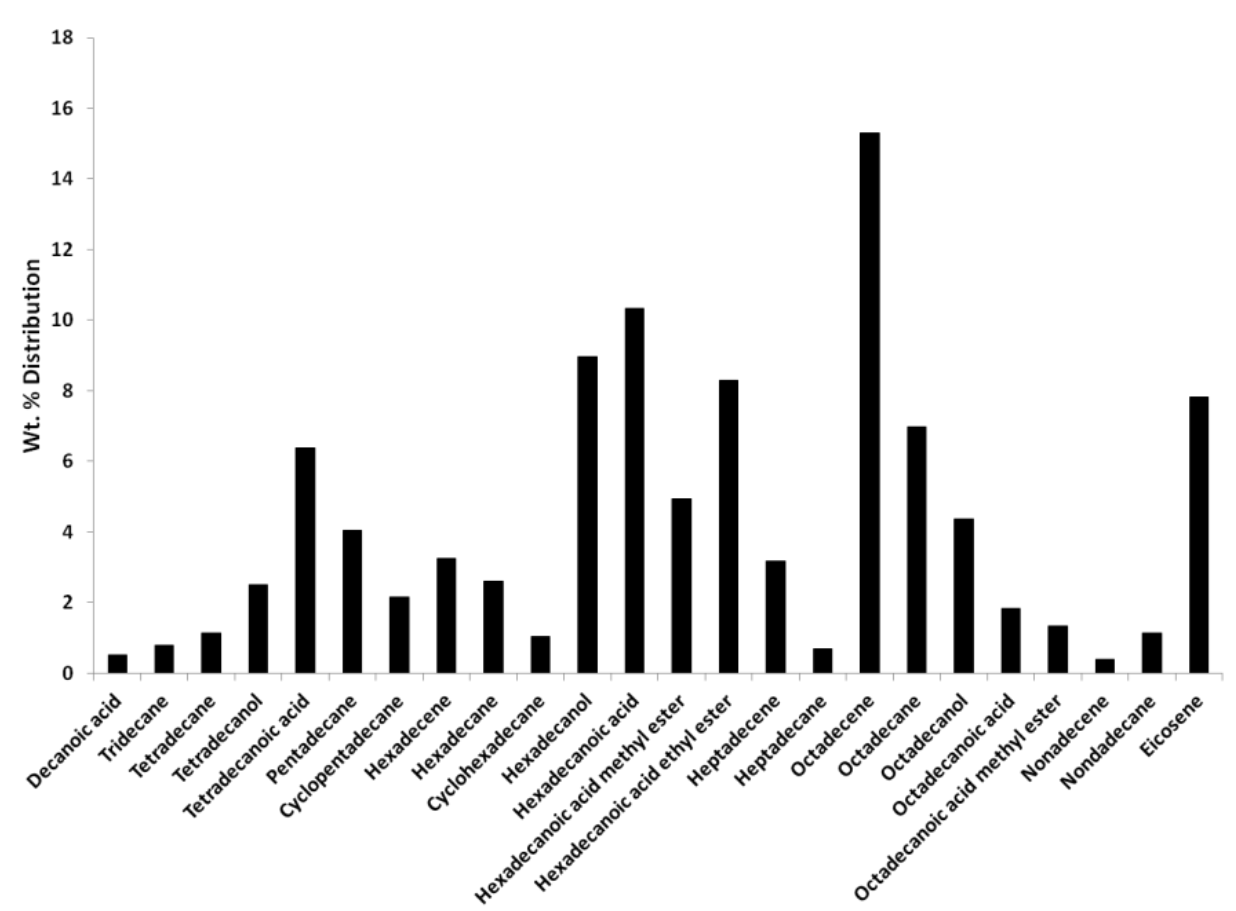

Fig 7. Distribution of hydrocarbons after hydrotreatment of microalgae extract with Fe-MSN.

\section{Conclusions}

In conclusion, an economical and efficient sulfur-free iron nanoparticle based catalyst has been shown to convert microalgae oil to green diesel. The detailed mechanism on hydrotreatment was explored by studying the kinetics and the effect of 
different temperatures and pressures of hydrogenation of oleic acid with Fe-MSN. Iron nanoparticles efficiently hydrogenate oleic acid to stearic acid and subsequently convert to aldehyde and alcohol intermediates. Depending on temperature and pressure, the aldehyde gets decarbonylated (minor route) and alcohol gets dehydrated (major route) giving unsaturated alkanes which further get hydrogenated to give saturated alkane products. The product distribution obtained from hydrotreatment of crude microalgae extract implies that the triglycerides are first hydrogenolysed to fatty acids by Fe-MSN. This understanding of each step during conversion of microalgae oil to diesel-range liquid hydrocarbon fuels allows the possibilities to further design the catalyst in order to influence the product yields and decrease the hydrogen consumption.

\section{Acknowledgements}

This work was supported by the U.S. Department of Energy, Office of Basic Energy Sciences under Contract No. DE-AC02-07CH11358.

\section{References}

[1] R. Xing, A.V. Subrahmanyam, H. Olcay, W. Qi, G.P. van Walsum, H. Pendse, G.W. Huber, Production of jet and diesel fuel range alkanes from waste hemicellulosederived aqueous solutions, Green Chemistry, 12 (2010) 1933-1946.

[2] S. Lestari, P. Mäki-Arvela, J. Beltramini, G.Q.M. Lu, D.Y. Murzin, Transforming Triglycerides and Fatty Acids into Biofuels, ChemSusChem, 2 (2009) 1109-1119. [3] E. Molina Grima, E.H. Belarbi, F.G. Acién Fernández, A. Robles Medina, Y. Chisti, Recovery of microalgal biomass and metabolites: process options and economics, Biotechnology Advances, 20 (2003) 491-515. 
[4] Y.C. Sharma, B. Singh, J. Korstad, A critical review on recent methods used for economically viable and eco-friendly development of microalgae as a potential feedstock for synthesis of biodiesel, Green Chemistry, 13 (2011) 2993-3006.

[5] P. Šimáček, D. Kubička, G. Šebor, M. Pospíšil, Hydroprocessed rapeseed oil as a source of hydrocarbon-based biodiesel, Fuel, 88 (2009) 456-460.

[6] P. Priecel, D. Kubička, L. Čapek, Z. Bastl, P. Ryšánek, The role of Ni species in the deoxygenation of rapeseed oil over NiMo-alumina catalysts, Applied Catalysis A: General, 397 (2011) 127-137.

[7] G.W. Huber, P. O’Connor, A. Corma, Processing biomass in conventional oil refineries: Production of high quality diesel by hydrotreating vegetable oils in heavy vacuum oil mixtures, Applied Catalysis A: General, 329 (2007) 120-129.

[8] D. Kubička, L. Kaluža, Deoxygenation of vegetable oils over sulfided Ni, Mo and NiMo catalysts, Applied Catalysis A: General, 372 (2010) 199-208.

[9] D. Kubička, J. Horáček, Deactivation of HDS catalysts in deoxygenation of vegetable oils, Applied Catalysis A: General, 394 (2011) 9-17.

[10] M. Snåre, I. Kubičková, P. Mäki-Arvela, K. Eränen, J. Wärnå, D.Y. Murzin, Production of diesel fuel from renewable feeds: Kinetics of ethyl stearate decarboxylation, Chemical Engineering Journal, 134 (2007) 29-34.

[11] S. Lestari, P.i. Mäki-Arvela, H. Bernas, O. Simakova, R. Sjöholm, J. Beltramini, G.Q.M. Lu, J. Myllyoja, I. Simakova, D.Y. Murzin, Catalytic Deoxygenation of Stearic Acid in a Continuous Reactor over a Mesoporous Carbon-Supported Pd Catalyst, Energy \& Fuels, 23 (2009) 3842-3845.

[12] B. Rozmysłowicz, P. Mäki-Arvela, S. Lestari, O. Simakova, K. Eränen, I. Simakova, D. Murzin, T. Salmi, Catalytic Deoxygenation of Tall Oil Fatty Acids Over 
a Palladium-Mesoporous Carbon Catalyst: A New Source of Biofuels, Topics in Catalysis, 53 (2010) 1274-1277.

[13] P. Do, M. Chiappero, L. Lobban, D. Resasco, Catalytic Deoxygenation of MethylOctanoate and Methyl-Stearate on Pt/Al\&lt;sub\&gt;2\&lt;/sub\&gt;O\&lt;sub\&gt;3\&lt;/sub\&gt, Catalysis Letters, 130 (2009) 9-18.

[14] T.R. Viljava, R.S. Komulainen, A.O.I. Krause, Effect of H2S on the stability of CoMo/A12O3 catalysts during hydrodeoxygenation, Catalysis Today, 60 (2000) 83-92. [15] Y. Yang, C. Ochoa-Hernández, V.A. de la Peña O’Shea, J.M. Coronado, D.P. Serrano, Ni2P/SBA-15 As a Hydrodeoxygenation Catalyst with Enhanced Selectivity for the Conversion of Methyl Oleate Into n-Octadecane, ACS Catalysis, 2 (2012) 592598.

[16] B. Peng, Y. Yao, C. Zhao, J.A. Lercher, Towards Quantitative Conversion of Microalgae Oil to Diesel-Range Alkanes with Bifunctional Catalysts, Angewandte Chemie International Edition, 51 (2012) 2072-2075.

[17] B. Peng, X. Yuan, C. Zhao, J.A. Lercher, Stabilizing Catalytic Pathways via Redundancy: Selective Reduction of Microalgae Oil to Alkanes, Journal of the American Chemical Society, 134 (2012) 9400-9405.

[18] R.T. Vang, K. Honkala, S. Dahl, E.K. Vestergaard, J. Schnadt, E. Laegsgaard, B.S. Clausen, J.K. Norskov, F. Besenbacher, Controlling the catalytic bond-breaking selectivity of Ni surfaces by step blocking, Nature Materials, 4 (2005) 160-162. [19] G.P. Van Der Laan, A.A.C.M. Beenackers, Kinetics and Selectivity of the Fischer-Tropsch Synthesis: A Literature Review, Catalysis Reviews, 41 (1999) 255318. 
[20] D.L. Huber, Synthesis, Properties, and Applications of Iron Nanoparticles, Small, $1(2005)$ 482-501.

[21] M.D. Shroff, D.S. Kalakkad, K.E. Coulter, S.D. Kohler, M.S. Harrington, N.B. Jackson, A.G. Sault, A.K. Datye, Activation of Precipitated Iron Fischer-Tropsch Synthesis Catalysts, Journal of Catalysis, 156 (1995) 185-207.

[22] J.-Y. Park, Y.-J. Lee, P.K. Khanna, K.-W. Jun, J.W. Bae, Y.H. Kim, Aluminasupported iron oxide nanoparticles as Fischer-Tropsch catalysts: Effect of particle size of iron oxide, Journal of Molecular Catalysis A: Chemical, 323 (2010) 84-90.

[23] H.M. Torres Galvis, J.H. Bitter, C.B. Khare, M. Ruitenbeek, A.I. Dugulan, K.P. de Jong, Supported Iron Nanoparticles as Catalysts for Sustainable Production of Lower Olefins, Science, 335 (2012) 835-838.

[24] T.-W. Kim, I.I. Slowing, P.-W. Chung, V.S.-Y. Lin, Ordered Mesoporous Polymer-Silica Hybrid Nanoparticles as Vehicles for the Intracellular Controlled Release of Macromolecules, ACS Nano, 5 (2010) 360-366.

[25] Y. Wan, Zhao, On the Controllable Soft-Templating Approach to Mesoporous Silicates, Chemical Reviews, 107 (2007) 2821-2860.

[26] D. Zhao, J. Feng, Q. Huo, N. Melosh, G.H. Fredrickson, B.F. Chmelka, G.D. Stucky, Triblock Copolymer Syntheses of Mesoporous Silica with Periodic 50 to 300 Angstrom Pores, Science, 279 (1998) 548-552.

[27] S. Peng, C. Wang, J. Xie, S. Sun, Synthesis and Stabilization of Monodisperse Fe Nanoparticles, Journal of the American Chemical Society, 128 (2006) 10676-10677. [28] L.-M. Lacroix, N. Frey Huls, D. Ho, X. Sun, K. Cheng, S. Sun, Stable SingleCrystalline Body Centered Cubic Fe Nanoparticles, Nano Letters, 11 (2011) 1641-1645. 
[29] H. Borchert, E.V. Shevchenko, A. Robert, I. Mekis, A. Kornowski, G. Grübel, H.

Weller, Determination of Nanocrystal Sizes: A Comparison of TEM, SAXS, and XRD Studies of Highly Monodisperse CoPt3 Particles, Langmuir, 21 (2005) 1931-1936.

[30] D.W. Rogers, O.P.A. Hoyte, R.K.C. Ho, Heats of hydrogenation of large molecules. Part 2.-Six unsaturated and polyunsaturated fatty acids, Journal of the Chemical Society, Faraday Transactions 1: Physical Chemistry in Condensed Phases, 74 (1978) 46-52.

[31] W. Rachmady, M.A. Vannice, Acetic Acid Reduction to Acetaldehyde over Iron Catalysts: I. Kinetic Behavior, Journal of Catalysis, 208 (2002) 158-169.

[32] E.J. Grootendorst, R. Pestman, R.M. Koster, V. Ponec, Selective Reduction of Acetic Acid to Acetaldehyde on Iron Oxides, Journal of Catalysis, 148 (1994) 261-269. [33] R. Pestman, R.M. Koster, E. Boellaard, A.M. van der Kraan, V. Ponec, Identification of the Active Sites in the Selective Hydrogenation of Acetic Acid to Acetaldehyde on Iron Oxide Catalysts, Journal of Catalysis, 174 (1998) 142-152.

[34] J.C. Kuriacose, S.S. Jewur, Studies on the surface interaction of acetic acid on iron oxide, Journal of Catalysis, 50 (1977) 330-341.

[35] R. Pestman, R.M. Koster, J.A.Z. Pieterse, V. Ponec, Reactions of Carboxylic Acids on Oxides: 1. Selective Hydrogenation of Acetic Acid to Acetaldehyde, Journal of Catalysis, 168 (1997) 255-264.

[36] C. Doornkamp, V. Ponec, The universal character of the Mars and Van Krevelen mechanism, Journal of Molecular Catalysis A: Chemical, 162 (2000) 19-32.

[37] W. Rachmady, M.A. Vannice, Acetic Acid Reduction to Acetaldehyde over Iron Catalysts: II. Characterization by Mössbauer Spectroscopy, DRIFTS, TPD, and TPR, Journal of Catalysis, 208 (2002) 170-179. 
[38] B. Donnis, R. Egeberg, P. Blom, K. Knudsen, Hydroprocessing of Bio-Oils and

Oxygenates to Hydrocarbons. Understanding the Reaction Routes, Topics in Catalysis, 52 (2009) 229-240. 


\title{
CHAPTER 8. PENTAFLUOROPHENYL FUNCTIONALIZED MESOPOROUS SILICA NANOMATERIALS FOR SELECTIVE ADSORPTION OF $\alpha$-TOCOPHEROL IN BIOREFINERY
}

\author{
Modified from a paper to be submitted to Chemical Communications \\ Kapil Kandel, Stacey M. Althaus, Justin S. Valenstien, Igor I. Slowing, Marek Pruski, Brian G. Trewyn
}

\begin{abstract}
The selective sequestration of $\alpha$-tocopherol from organic solutions using mesoporous silica nanomaterials was investigated. Pentafluorophenyl functionalized materials (PFP-MSN) showed the maximum adsorption capacity of $\left(0.75 \mathrm{mmol} \mathrm{g}^{-1}\right)$. Solid state NMR of PFP-MSN after $\alpha$-tocopherol adsorption revealed a $\pi$ - $\pi$ ring stacking interaction. Desorption of $\alpha$-tocopherol was achieved upon treatment with acetone. The selectivity of PFP-MSN for $\alpha$-tocopherol was demonstrated in a mixture containg free fatty acids (FFAs) and squalene, simulating the microalgae oil.
\end{abstract}

\section{Introduction}

The success of the bio-based economy depends on the development of a highly efficient and economic biorefinery system for processing of biological feedstocks and a range of biobased products. ${ }^{1}$ In this context, the selective separation and purification of bioactive molecules from renewable resources are extremely important processes in industrial technology and have attracted many scientific investigations over the past decade, leading to the development of various structural and functional adsorbents. ${ }^{2-5}$ Recently, we demonstrated that aminopropylfunctionalized mesoporous silica nanomaterials (AP-MSN) can be used for the selective sequestration of free fatty acids (FFAs) to purify crude microalgae oil and meet the specifications 
of feedstocks for biodiesel production. ${ }^{6}$ Still, the economic production of biodiesel is a challenge, therefore, the co-production of chemicals, materials, food, and feed can generate the necessary added value. $^{1}$

Vitamin E is comprised of a group of fat-soluble vitamins, of which $\alpha$-tocopherol is the most abundant and functions as a membrane bound antioxidant that protects membranes against photo-oxidative damage. ${ }^{7,8}$ In humans $\alpha$-tocopherol plays a major role in the prevention of lightinduced pathologies of both the skin and eyes and in degenerative disorders such as astherosclerosis, cardiovascular diseases and cancer. ${ }^{9}$ The bioavailability of naturally occurring $\alpha$-tocopherol is two times more than that of synthetic one, due to the presence of different isomers. ${ }^{10}$ This has led to an increased interest in enrichment of $\alpha$-tocopherol from natural resources like microalgae. Several studies on the adsorption of $\alpha$-tocopherol on solid surfaces have been reported; however those adsorbents either required rigorous synthesis or did not show selectivity for $\alpha$-tocopherol. ${ }^{8,11-13}$

In an effort to develop an efficient adsorbent with high selectivity for $\alpha$-tocopherol, we report the synthesis of pentafluorophenyl functionalized mesoporous silica nanomaterials (PFPMSN) and its application in selective adsorption at ambient condition. Our hypothesis is based on using electron deficient aromatic ring of pentafluorophenyl group to strongly bind the electron-rich phenyl group of $\alpha$-tocopherol. ${ }^{13}$ 


\section{Experimental}

\subsection{Synthesis of PFP-MSN}

PFP-MSN was synthesized using a previously reported co-condensation method. ${ }^{14}$ In general, a mixture of CTAB $(2.0 \mathrm{~g}, 5.49 \mathrm{mmol}), \mathrm{NaOH}(\mathrm{aq})(2.0 \mathrm{M}, 7.0 \mathrm{~mL}, 14.0 \mathrm{mmol})$ and water $(480 \mathrm{~g}, 26.67 \mathrm{~mol})$ was heated at $80{ }^{\circ} \mathrm{C}$ for $1 \mathrm{~h}$. To this clear solution, TEOS $(9.34 \mathrm{~g}, 44.8$ mmol) and PFP-TMS (1.0 g, $3.27 \mathrm{mmol})$ were injected rapidly and sequentially. The reaction temperature was maintained at $80{ }^{\circ} \mathrm{C}$ for $2 \mathrm{~h}$. The as-synthesized PFP-MSN was obtained after hot filtration, washed with copious amount of water and methanol, and dried under vacuum. In order to remove CTAB surfactant and generate pores, the as-synthesized material (1.0 g) was refluxed in a methanol $(100 \mathrm{~mL})$ mixture of hydrochloric acid $(2.0 \mathrm{M}, 1 \mathrm{~mL})$. The resulting material was filtered, washed with methanol and dried under vacuum. A similar procedure was followed to synthesize cyanopropyltrimethoxysilane (CP-MSN) and phenylethyltrimethoxysilane (Ph-MSN) functionalized mesoporous silica nanomaterials.

\subsection{Adsorption Experiments}

Adsorption experiments were conducted using a 16 x $125 \mathrm{~mm}$ culture tube. For the adsorption isotherm experiment, PFP-MSN (25 mg) was mixed in a $10 \mathrm{~mL}$ hexane solution of $\alpha$ tocopherol with varying concentrations for $12 \mathrm{~h}$. After adsorption, PFP-MSN was separated and the remaining hexanes solution was analyzed in GC-MS. The structural properties of the dried PFP-MSNs after adsorption experiments were measured using using $\mathrm{N}_{2}$ adsorption/desorption measurements in a Micromeritics ASAP 2000 BET surface analyzer system. For desorption experiments, the dried PFP-MSN was mixed with $10 \mathrm{~mL}$ of ethanol/ acetone solvents. 


\subsection{Characterization}

The surface areas and pore size distributions of the catalysts were measured by nitrogen sorption isotherms in a Micromeritics Tristar analyzer, and calculated by the Brunauer-EmmettTeller (BET) and Barrett-Joyner-Halenda (BJH) methods, respectively. The transmission electron microscopy (TEM) examination was completed on a Tecnai G2 F20 electron microscope operated at $200 \mathrm{kV}$. For the TEM measurements, an aliquot of the powder was sonicated in methanol for $15 \mathrm{~min}$. A single drop of this suspension was placed on a lacey carbon coated copper TEM grid and dried in air. The small angle powder X-ray diffraction patterns were obtained with a Rigaku Ultima IV diffractometer using $\mathrm{Cu}$ target at $40 \mathrm{kV}$ and $44 \mathrm{~mA}$. The $\mathrm{Cu}$ $\mathrm{K} \beta$ radiation was removed using a monochromator. Solid-state NMR experiments are described separately below.

\section{Results and Discussion}

\subsection{Synthesis of PFP-MSN}

To test our hypothesis, PFP-MSN was synthesized by introducing pentafluorophenyltrimethoxysilane to a $\mathrm{NaOH}$-catalyzed, cetyltrimethyammonium bromide (CTAB)-templated co-condensation reaction of tetraethoxysilane (TEOS), as described in supporting information. The pores were generated after refluxing the as-synthesized material in acidic methanol to remove CTAB. The scanning electron microscopy (SEM) images showed that PFP-MSN exhibited elliptical morphology and the transmission electron microscopy (TEM) images revealed an aspect ratio of $1.5-3.0$ and an average length of 350-400 nm (Figure 1). The mesoporous channels were arranged in a 2D hexagonal array as observed in X-ray diffraction 
(XRD). The $\mathrm{N}_{2}$ sorption analysis showed a type IV isotherm, which is characteristic of a cylindrical mesoporous structure. Additionally, the measured Brunauer-Emmet-Teller (BET) surface area was $686 \mathrm{~m}^{2} \mathrm{~g}^{-1}$ and the average pore volume and pore size calculated using the Barrett-Joyner-Halenda (BJH) method was $0.6 \mathrm{~cm}^{3} \mathrm{~g}^{-1}$ and $2.6 \mathrm{~nm}$.
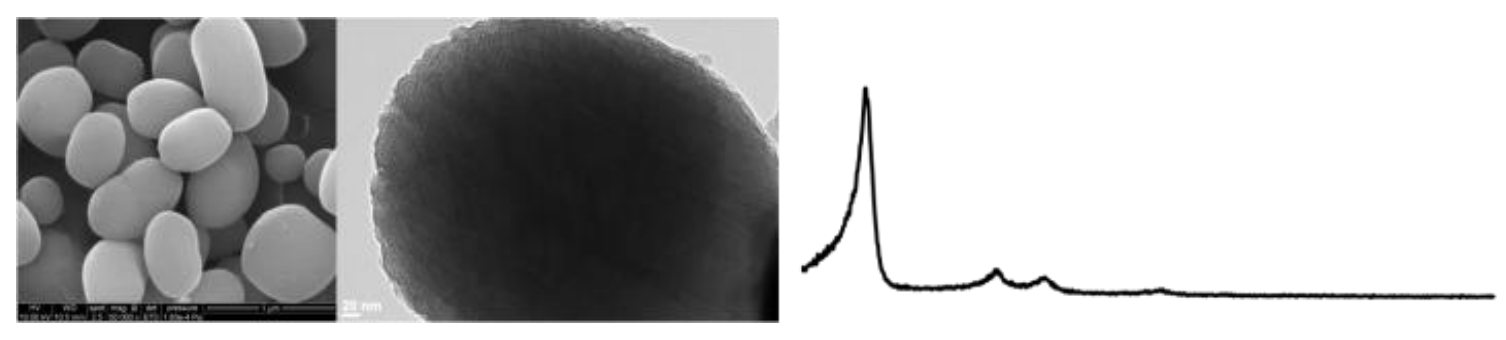

Figure 1. SEM, TEM images and powder X-ray diffraction of PFP-MSN.

The total concentration of PFP groups covalently bound to mesoporous silica surface was measured using ${ }^{29}$ Si DPMAS SSNMR (detailed in supporting information) and was determined to be 1.5 mmol g ${ }^{-1} .{ }^{13} \mathrm{C}$ CPMAS and ${ }^{19} \mathrm{~F}$ DPMAS SSNMR confirmed the covalent immobilization of PFP groups and the integrity of their chemical structures.

\subsection{Adsorption of $\alpha$-tocopherol}

To explore the adsorption capacity of PFP-MSN, the adsorbent $(25 \mathrm{mg})$ was mixed with different concentrations of $\alpha$-tocopherol solution in hexanes i.e. $1 \mathrm{mM}, 2 \mathrm{mM}, 4 \mathrm{mM}, 8 \mathrm{mM}$ and $16 \mathrm{mM}$. The adsorption isotherm is shown in Figure $2 \mathrm{a}$ after $12 \mathrm{~h}$ adsorption time to reach equilibrium. The adsorption data are fit with the Langmuir isotherm model and show the maximum adsorption capacity of $0.75 \mathrm{mmol} \mathrm{g}^{-1}$ for PFP-MSN. This adsorption capacity is much higher than previous reports with polymer adsorbents that offer strong hydrogen-bond accepting sites $\left(0.025 \mathrm{mmol} \mathrm{g}^{-1}\right)$ and ionic liquid functionalized porous silica nanomaterials $(0.49 \mathrm{mmol} \mathrm{g}$ 
$\left.{ }^{1}\right) .{ }^{12,13}$ The adsorption capacity of cyanopropyltrimethoxysilane (CP-MSN) and phenylethyltrimethoxysilane ( $\mathrm{Ph}-\mathrm{MSN}$ ) functionalized mesoporous silica nanomaterials were $0.05 \mathrm{mmol} \mathrm{g}^{-1}$ and $0.07 \mathrm{mmol} \mathrm{g}^{-1}$ respectively (Figure S3). This low adsorption capacity with aliphatic and electron rich phenyl group, respectively, further supports our hypothesis about the significance of electron deficient PFP group for optimum adsorption of $\alpha$-tocopherol.
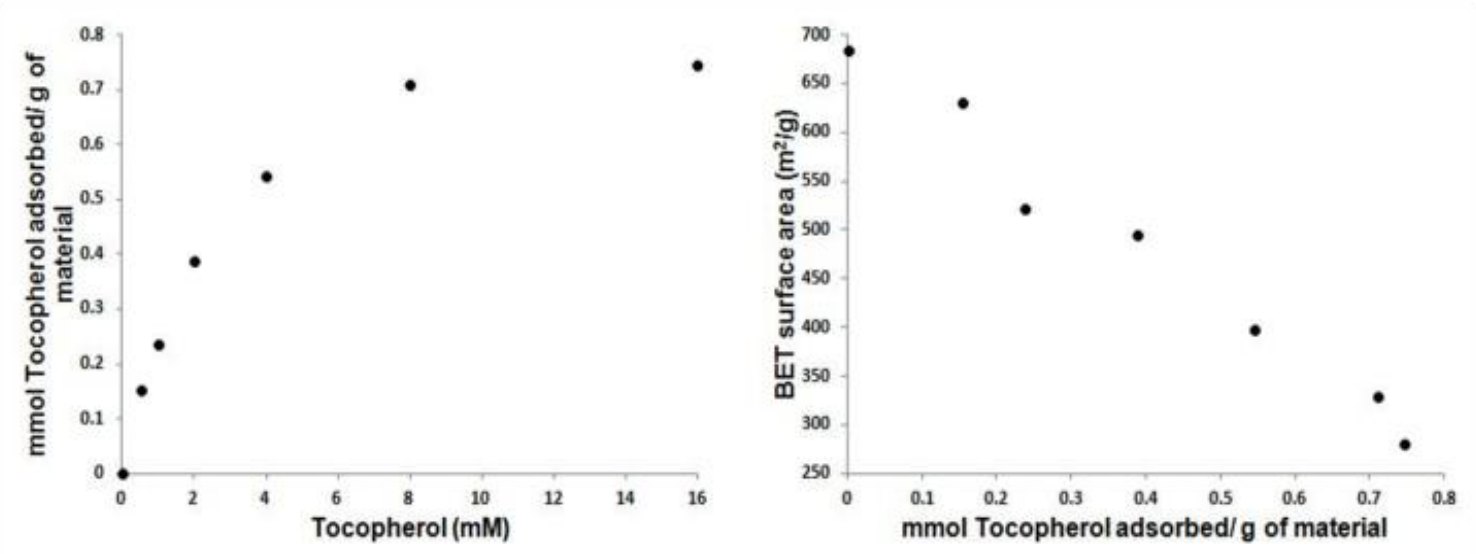

Figure 2. (a) Adsorption isotherm of $\alpha$-tocopherol adsorbed on PFP-MSN (left) and (b)change in surface area of PFP-MSN with increase in $\alpha$-tocopherol adsorption (right).

The change in textural properties of PFP-MSN before and after $\alpha$-tocopherol adsorption was characterized using $\mathrm{N}_{2}$ sorption. Figure $2 \mathrm{~b}$ shows the decrease in surface area of PFP-MSN with increase in $\alpha$-tocopherol adsorption. Both surface area and pore volume were reduced by about $50 \%$ after adsorption of $\alpha$-tocopherol at higher concentration. This implies that the $\alpha$ tocopherol molecules are adsorbed inside the mesopores of PFP-MSN. 


\subsection{SSNMR after adsorption}

The interaction between PFP-MSN and $\alpha$-tocopherol was investigated using SSNMR (details in supporting information). The acquired 2D ${ }^{19} \mathrm{~F}\left\{{ }^{13} \mathrm{C}\right\}$ HETCOR of PFP-MSN after adsorption of $\alpha$-tocopherol (Figure S1) suggested there may be an interaction between Fa on the PFP ring and C3-6 on the $\alpha$-tocopherol rings, however, this could not be confirmed. In order to investigate the interaction further, a $2 \mathrm{D}{ }^{1} \mathrm{H}\left\{{ }^{13} \mathrm{C}\right\}$ HETCOR spectrum of PFP-MSN after the adsorption of $\alpha$-tocopherol was acquired (Figure 3). This spectrum shows correlation between

the ${ }^{1} \mathrm{H}$ resonances on the $\alpha$-tocopherol (HC, HB, and HD) and the ${ }^{13} \mathrm{C}$ resonances in the PFP ring (C33 and C34). This correlation shows an interaction between the PFP and the $\alpha$-tocopherol rings, implying a $\pi-\pi$ ring stacking interaction. 


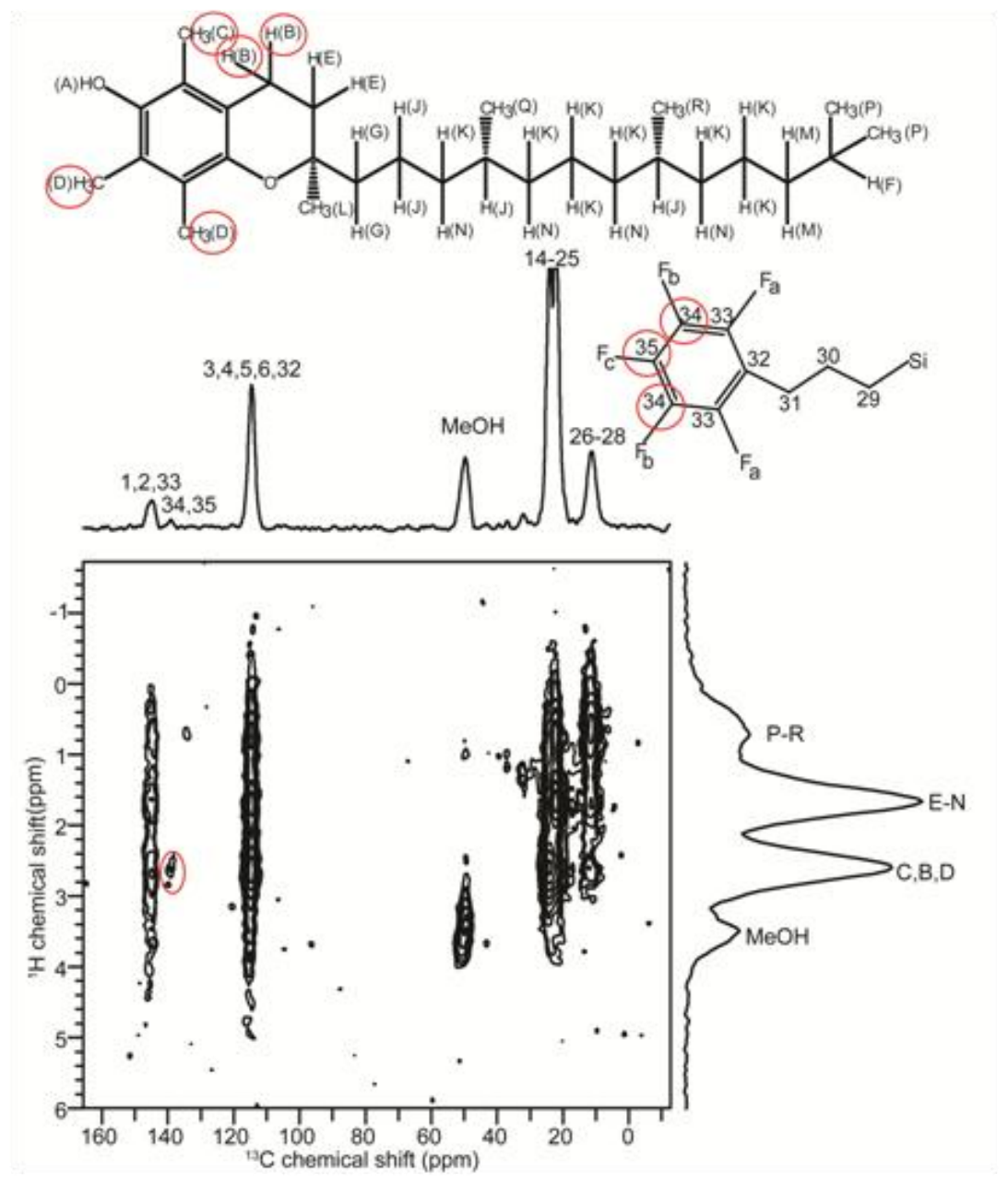

Figure 3. ${ }^{1} \mathrm{H}-{ }^{13} \mathrm{C}$ indirectly detected spectrum of PFP-MSN with adsorbed $\alpha$-tocopherol.

\subsection{Desorption of $\alpha$-tocopherol}

For an efficient separation system, it is important to regenerate the adsorbent for repeated use. The PFP-MSN after $\alpha$-tocopherol adsorption was mixed with two different solvents: ethanol and acetone. The desorption results from the replacement of the $\pi-\pi$ ring stacking interaction between PFP and $\alpha$-tocopherol with the $\mathrm{O}^{\cdots} \pi$ interaction between the oxygen atom of the solvent and the PFP group. The $\mathrm{O}^{\cdots} \pi$ interaction between alcoholic oxygen and perfluorinated aromatic ring has been demonstrated by Sakai and co-workers and is estimated to be stronger than $\pi-\pi$ 
interaction. ${ }^{15}$ In our system acetone desorbed $92 \%$ of the $\alpha$-tocopherol adsorbed on PFP-MSN, which proves it to be a better desorbing solvent when compared to the $26 \%$ desorbed in ethanol. This is most likely due to the greater electron density around the oxygen atom of acetone, therefore making the $\mathrm{O}^{\cdots} \pi$ interaction between acetone and PFP groups stronger than between ethanol and PFP groups. ${ }^{16,17}$

\subsection{Selectivity}

Microalgae are known to produce a wide variety of value-added molecules that can be used for different applications. Therefore, for the development of efficient separation and purification technology, it is important for an adsorbent to be selective for specific molecules. To demonstrate the selectivity of PFP-MSN for $\alpha$-tocopherol, $25 \mathrm{mg}$ of PFP-MSN was mixed with $10 \mathrm{~mL}$ of a simulated solution closely resembling microalgae oil containing a mixture of squalene (0.8 mM), $\alpha$-tocopherol (1.6 mM) and palmitic acid (3.2 mM). After removal of PFPMSN from the solution, the remaining analytes were quantified using GC-MS. Figure 4 shows the percentage of each analyte adsorbed by PFP-MSN with highest adsorption of $\alpha$-tocopherol (67\%) compared to palmitic acid (16\%) and squalene (3\%). These observations highlight the significant selectivity of PFP-MSN for $\alpha$-tocopherol molecules. 


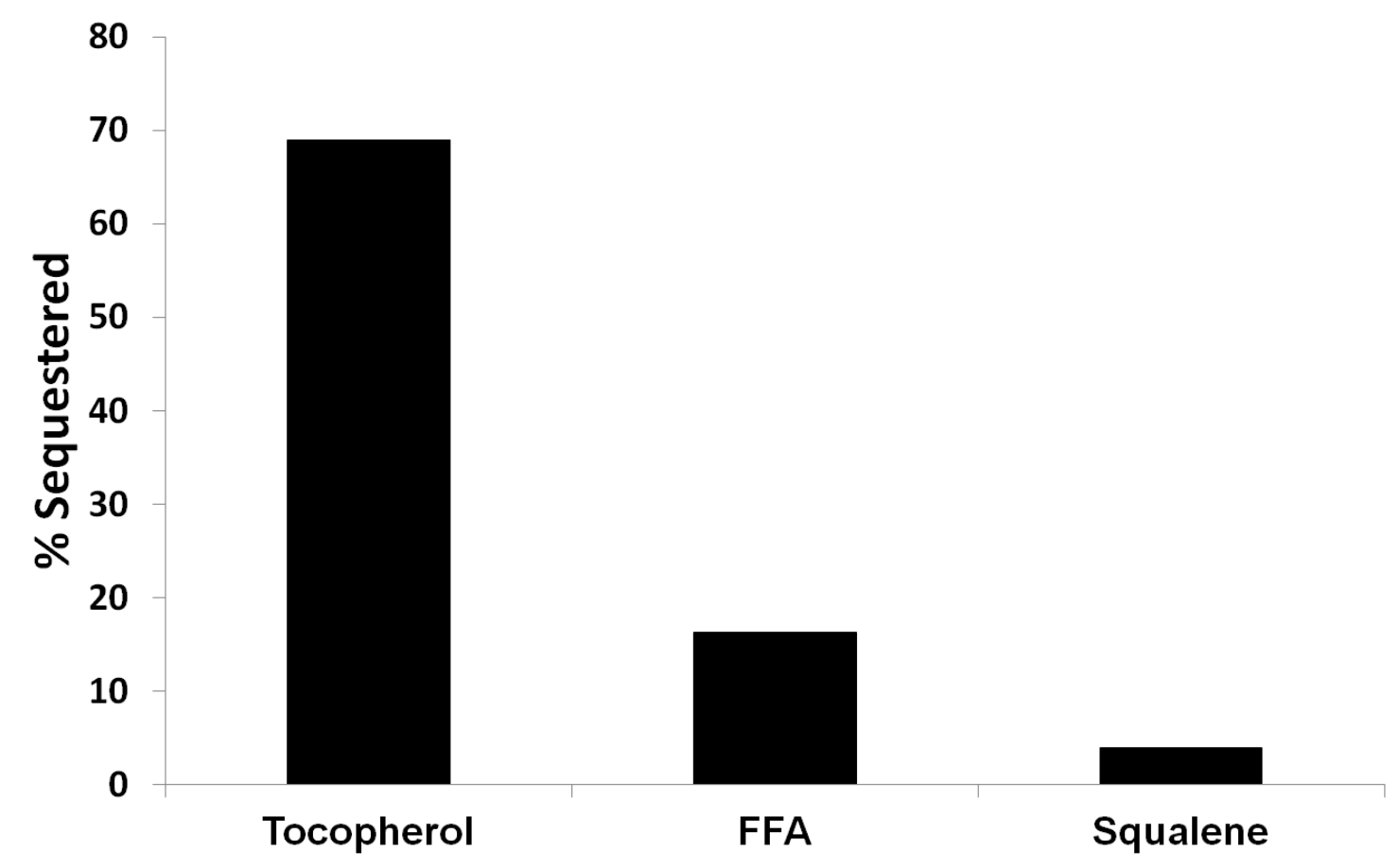

Figure 4. Percentage of $\alpha$-tocopherol adsorbed compared to FFA and squalene.

\section{Conclusion}

PFP-MSN was found to selectively sequester $\alpha$-tocopherol from a mixture of FFAs and squalene. The maximum adsorption of $\alpha$-tocopherol was determined to be $0.75 \mathrm{mmol} \mathrm{g}^{-1}$. SSNMR proved the $\pi-\pi$ ring stacking interaction between PFP groups and $\alpha$-tocopherol, supporting our hypothesis that the electron deficient aromatic ring of the pentafluorophenyl group will strongly bind the electron-rich phenyl group of $\alpha$-tocopherol. The maximum desorption of $\alpha$-tocopherol from the material was obtained by extraction with acetone due to the more favourable $\mathrm{O}^{\cdots} \pi$ interaction between the oxygen atom of acetone and the PFP groups. Further investigation on the stability and anti-oxidant activity of $\alpha$-tocopherol after adsorption in PFP-MSN will provide insight into the storage and delivery of these materials. 


\section{References}

1. H.-W. Yen, I. C. Hu, C.-Y. Chen, S.-H. Ho, D.-J. Lee and J.-S. Chang, Bioresource Technology.

2. I. S. Lee, N. Lee, J. Park, B. H. Kim, Y.-W. Yi, T. Kim, T. K. Kim, I. H. Lee, S. R. Paik and T. Hyeon, Journal of the American Chemical Society, 2006, 128, 10658-10659.

3. K. Ariga, A. Vinu, M. Miyahara, J. P. Hill and T. Mori, Journal of the American Chemical Society, 2007, 129, 11022-11023.

4. T. Itoh, K. Yano, Y. Inada and Y. Fukushima, Journal of the American Chemical Society, 2002, 124, 13437-13441.

5. M. Cano, K. Sbargoud, E. Allard and C. Larpent, Green Chemistry, 2012, 14, 1786-1795.

6. J. S. Valenstein, K. Kandel, F. Melcher, I. I. Slowing, V. S. Y. Lin and B. G. Trewyn, ACS Appl. Mater. Interfaces, 2012, 4, 1003-1009.

7. X. Wang and P. J. Quinn, Progress in lipid research, 1999, 38, 309-336.

8. F. Puoci, G. Cirillo, M. Curcio, F. Iemma, U. G. Spizzirri and N. Picci, Analytica Chimica Acta, 2007, 593, 164-170.

9. J. N. Hathcock, A. Azzi, J. Blumberg, T. Bray, A. Dickinson, B. Frei, I. Jialal, C. S. Johnston, F. J. Kelly, K. Kraemer, L. Packer, S. Parthasarathy, H. Sies and M. G. Traber, The American Journal of Clinical Nutrition, 2005, 81, 736-745. 
10. P. D. Reaven and J. L. Witztum, Arteriosclerosis, Thrombosis, and Vascular Biology, 1993, 13, 601-608.

11. M. Hartmann, A. Vinu and G. Chandrasekar, Chemistry of Materials, 2005, 17, 829-833.

12. M. LI, P. J. PHAM, C. U. PITTMAN Jr and T. LI, Analytical Sciences, 2008, 24, 12451250.

13. J. L. Brown, T. Chen, H. D. Embree and G. F. Payne, Industrial \& Engineering Chemistry Research, 2002, 41, 5058-5064.

14. S. Huh, J. W. Wiench, J.-C. Yoo, M. Pruski and V. S. Y. Lin, Chemistry of Materials, 2003, 15, 4247-4256.

15. T. Korenaga, H. Tanaka, T. Ema and T. Sakai, Journal of Fluorine Chemistry, 2003, 122, 201-205.

16. A. Jain, C. S. Purohit, S. Verma and R. Sankararamakrishnan, The Journal of Physical Chemistry B, 2007, 111, 8680-8683.

17. B. W. Gung, Y. Zou, Z. Xu, J. C. Amicangelo, D. G. Irwin, S. Ma and H.-C. Zhou, The Journal of Organic Chemistry, 2007, 73, 689-693.

18. K. Mao, T. Kobayashi, J. W. Wiench, H.-T. Chen, C.-H. Tsai, V. S. Y. Lin and M. Pruski, Journal of the American Chemical Society, 2010, 132, 12452-12457.

19. J. W. Wiench, V. S. Y. Lin and M. Pruski, Journal of Magnetic Resonance, 2008, 193, 233-242. 


\section{Supporting Information}

\section{Solid-state NMR measurements}

Solid-state NMR measurements were acquired with ${ }^{13} \mathrm{C},{ }^{1} \mathrm{H}$ and ${ }^{19} \mathrm{~F}$ to confirm the structure of PFP-MSN and to determine interactions between PFP and $\alpha$-tocopherol. These experiments were performed at 14.1 T on a Varian NMR System 600 spectrometer equipped with a 1.6-mm FastMAS ${ }^{\mathrm{TM}}$ probe operated at 599.6 MHz $\left({ }^{1} \mathrm{H}\right), 564.1 \mathrm{MHz}\left({ }^{19} \mathrm{~F}\right)$ and $150.8 \mathrm{MHz}$

$\left({ }^{13} \mathrm{C}\right) .{ }^{29} \mathrm{Si}$ solid-state NMR experiments were acquired to measure the loading of surface bound PFP. The ${ }^{29}$ Si DPMAS measurements were obtained at $9.4 \mathrm{~T}$ on Chemagnetics Infinity 400 spectrometer equipped with a 5-mm MAS probe operated at $400.0 \mathrm{MHz}\left({ }^{1} \mathrm{H}\right)$ and $79.4 \mathrm{MHz}$ $\left({ }^{29} \mathrm{Si}\right)$. Experimental parameters are given below using the following symbols: $v_{\mathrm{R}}$ denotes the MAS rate, $v_{\mathrm{RF}}(\mathrm{X})$ the magnitude of radiofrequency magnetic field $(\mathrm{RF})$ applied to $\mathrm{X}$ spins, $\tau_{\mathrm{CP}}$ the mixing time during cross polarization, $\tau_{\mathrm{RR}}$ the rotary resonance recoupling time, $\Delta t_{1}$ the increment of $t_{1}$ during $2 \mathrm{D}$ acquisition, $\tau_{\mathrm{RD}}$ the recycle delay, NS the number of scans, and AT the total acquisition time.

\section{Characterization of structure and investigation of interaction}

1D ${ }^{19} \mathrm{~F}$ DPMAS and ${ }^{13} \mathrm{C}$ CPMAS spectra (cross polarized from ${ }^{1} \mathrm{H}$ and ${ }^{19} \mathrm{~F}$ ) were acquired to confirm the structure of PFP-MSN and these shifts were consistent with earlier reported studies. ${ }^{18}$ Based upon the magnetization transfer in the $1 \mathrm{D}{ }^{13} \mathrm{C}\left\{{ }^{19} \mathrm{~F}\right\}$ spectra, indirectly detected $2 \mathrm{D}{ }^{19} \mathrm{~F}\left\{{ }^{13} \mathrm{C}\right\}$ spectrum were obtained (Figure S1). From this spectrum we can see the Fa exchanges with the carbons which resonate at $\sim 115 \mathrm{ppm}$. This interaction could be from Fa interacting with $\mathrm{C} 3, \mathrm{C} 4, \mathrm{C} 5$ and $\mathrm{C} 6$ in the $\alpha$-tocopherol, but it also could be an interaction of Fa 
with $\mathrm{C} 32$ on the PFP ring. Due to this uncertainty, we collected a $2 \mathrm{D}{ }^{1} \mathrm{H}\left\{{ }^{13} \mathrm{C}\right\}$ spectrum (Figure 3) to investigate the interaction further. These results are discussed in the main paper. The parameters used in the 2D spectra are listed below.

Figure 3: 2D indirectly detected ${ }^{1} \mathrm{H}\left\{{ }^{13} \mathrm{C}\right\}$ spectrum of PFP with $\alpha$-tocopherol: $v_{\mathrm{R}}=40$ $\mathrm{kHz}, v_{\mathrm{RF}}\left({ }^{13} \mathrm{C}\right)=95 \mathrm{kHz}, v_{\mathrm{RF}}\left({ }^{1} \mathrm{H}\right)$ during $\mathrm{CP}=55 \mathrm{kHz}, v_{\mathrm{RF}}\left({ }^{1} \mathrm{H}\right)$ during SPINAL-64 decoupling $=$ $10 \mathrm{kHz}, v_{\mathrm{RF}}\left({ }^{13} \mathrm{C}\right)$ during SPINAL-64 decoupling $=12 \mathrm{kHz}, \tau_{\mathrm{CP}}=4 \mathrm{~ms}, \tau_{\mathrm{RR}}=25 \mathrm{~ms}, \Delta t_{1}=25 \mu \mathrm{s}$, $\tau_{\mathrm{RD}}=\mathrm{s}, \mathrm{NS}=256$, and $\mathrm{AT}=18.5 \mathrm{hrs}$.

Figure S1:2D indirectly detected ${ }^{19} \mathrm{~F}\left\{{ }^{13} \mathrm{C}\right\}$ spectrum of PFP with $\alpha$-tocopherol: $v_{\mathrm{R}}=$ $40 \mathrm{kHz}, v_{\mathrm{RF}}\left({ }^{13} \mathrm{C}\right)=95 \mathrm{kHz}, v_{\mathrm{RF}}\left({ }^{1} \mathrm{H}\right)$ during $\mathrm{CP}=55 \mathrm{kHz}, \nu_{\mathrm{RF}}\left({ }^{1} \mathrm{H}\right)$ during SPINAL-64 decoupling = $12 \mathrm{kHz}, v_{\mathrm{RF}}\left({ }^{13} \mathrm{C}\right)$ during SPINAL-64 decoupling $=12 \mathrm{kHz}, \tau_{\mathrm{CP}}=3 \mathrm{~ms}, \tau_{\mathrm{RR}}=25 \mathrm{~ms}, \Delta t_{1}=25 \mu \mathrm{s}$, $\tau_{\mathrm{RD}}=\mathrm{s}, \mathrm{NS}=256$, and AT $=18 \mathrm{hrs}$.

\section{Quantification of loading of functional groups via ${ }^{29} \mathrm{Si}$ NMR.}

The ${ }^{29} \mathrm{Si}$ DPMAS spectrum of PFP-MSN is shown below in figure S2. Loading was determined based upon the ratio of $\mathrm{T}$ sites (covalent ${ }^{13} \mathrm{C}_{-}{ }^{29} \mathrm{Si}$ bonds) to $\mathrm{Q}$ sites, as previously described. ${ }^{19}$ The parameters used in this spectrum are as follows: ${ }^{29} \mathrm{Si}$ DPMAS: $v_{\mathrm{R}}=10 \mathrm{kHz}$, $\left.v_{\mathrm{RF}}{ }^{29} \mathrm{Si}\right)=55 \mathrm{kHz}, v_{\mathrm{RF}}\left({ }^{1} \mathrm{H}\right)$ decoupling $=45 \mathrm{kHz}, \tau_{\mathrm{RD}}=300 \mathrm{~s}, \mathrm{NS}=296$, and $\mathrm{AT}=25 \mathrm{~h}$. 


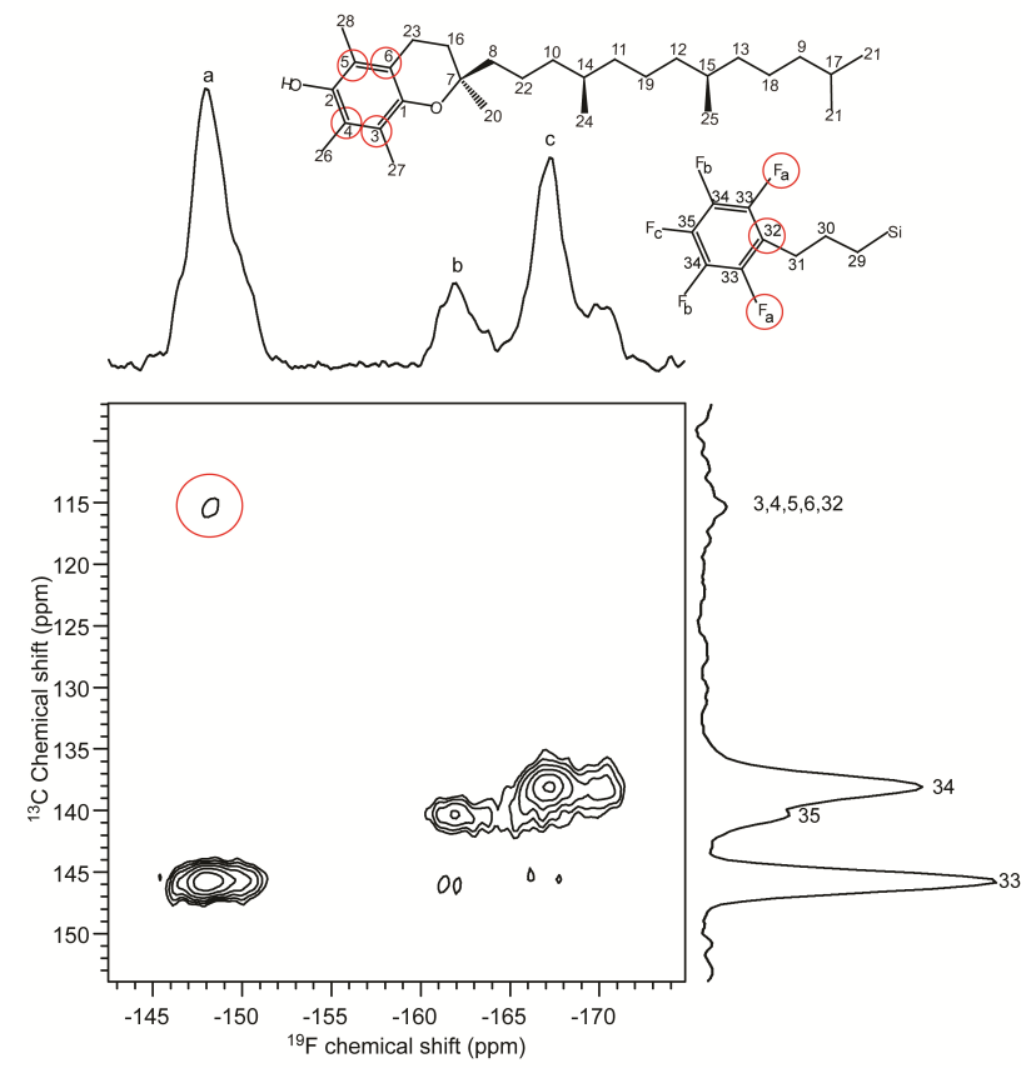

Figure S1. 2D indirectly detected ${ }^{19} \mathrm{~F}\left\{{ }^{13} \mathrm{C}\right\}$ spectrum of PFP-MSN with $\alpha$-tocopherol

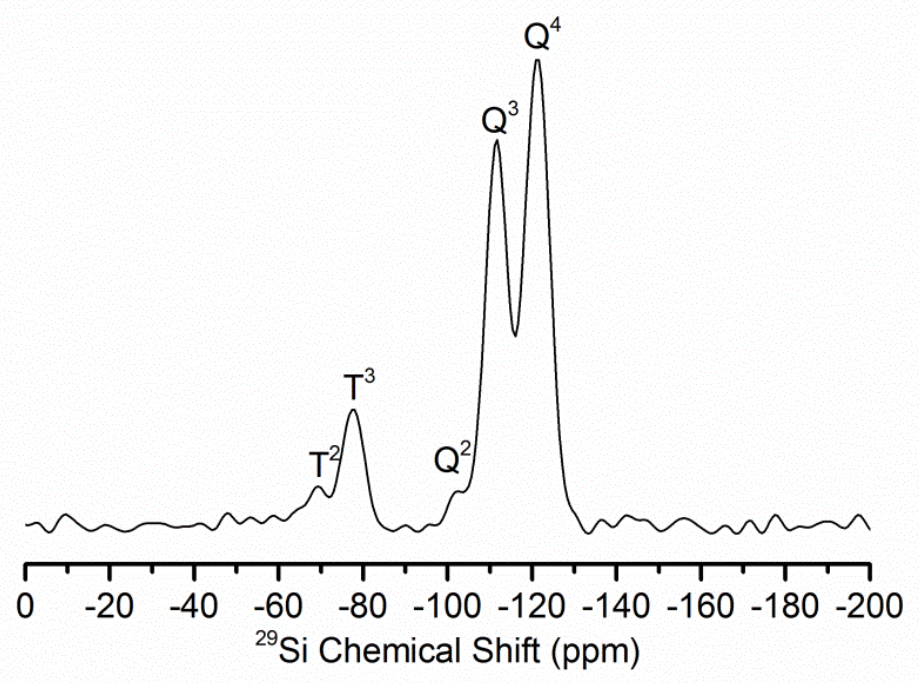


Figure S2. ${ }^{29} \mathrm{Si}$ DPMAS spectrum of PFP-MSN

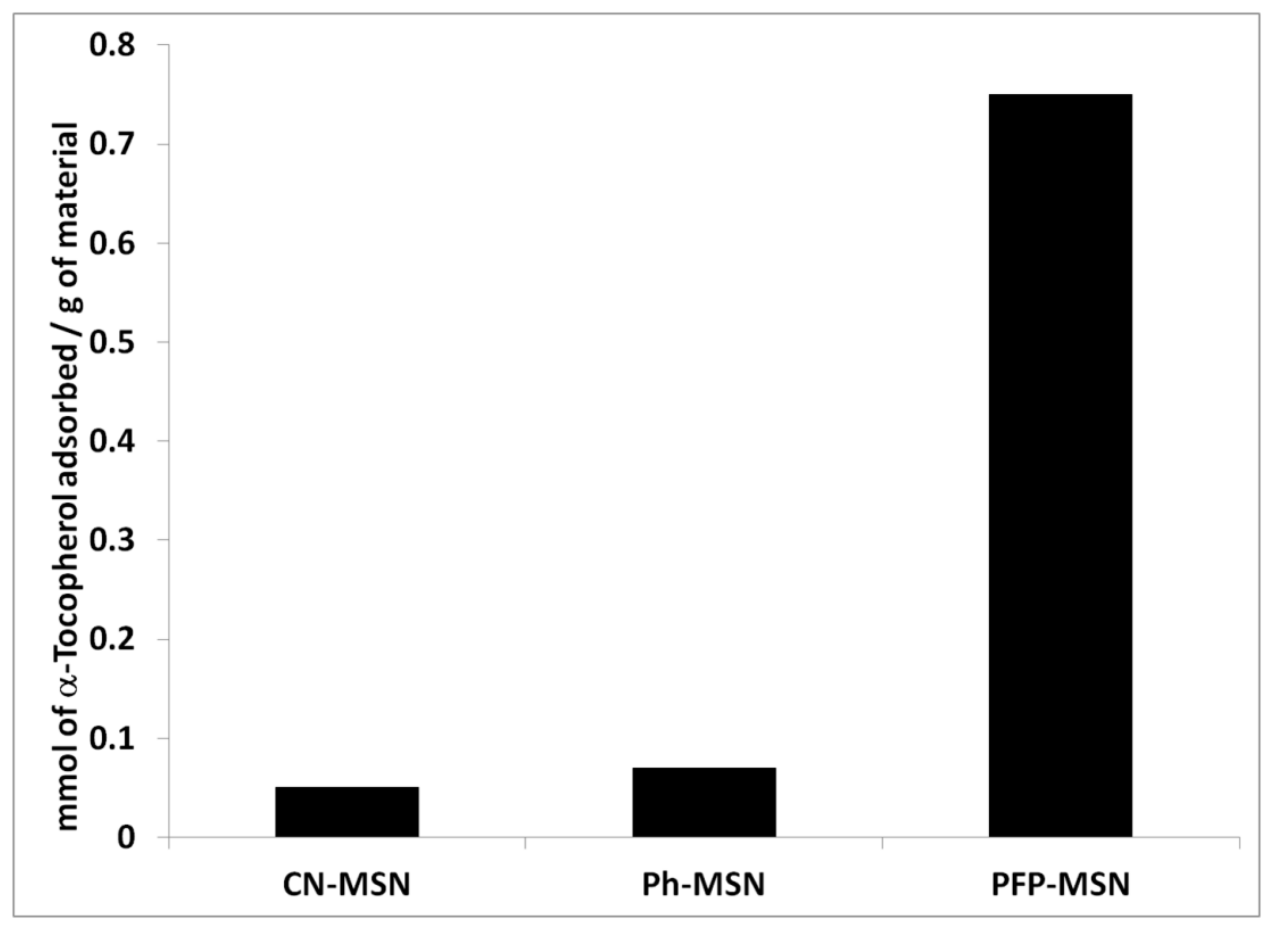

Figure S3. Comparison of different functional groups for adsorption. 


\section{CHAPTER 9. GENERAL CONCLUSIONS}

Mesoporous silica nanomaterials (MSN) have attracted great interest for last two decades due to their unique and advantageous structural properties, such as high surface area, pore volume, stable mesostructure, tunable pore size and controllable particle morphology. The robust silica framework provides sites for organic modifications, making MSNs ideal platforms for adsorbents and supported organocatalysts. In addition, the pores of MSNs provide cavities/ channels for incorporation of metal and metal oxide nanoparticle catalysts. Taking advantage of above mentioned unique properties of MSN, this dissertation has summarized my research progress on development of MSN based adsorbents and catalysts for biorefinery and biofuel production.

Chapter 2 highlighted the fact that the understanding achieved through mechanistic study can guide to the rational design of catalysts for improved activity. The formation of stable Schiff base inhibited the catalytic activity of primary amine functionalized MSN (AP-MSN) for the aldol condensation of p-nitrobenzaldehyde and acetone. This not only eliminated active catalytic sites but also blocked diffusion by decreasing the pore size. Two different pathways were demonstrated to reduce the inhibition effect: (i) increasing the pore size of the MSN support increased the activity and (ii) modifying the structure of the amine from primary (AP-MSN) to secondary (MAP-MSN) eliminated the formation of Schiff base and dramatically increased the activity. The cooperativity between silica support and amines proved to be significant for the improved activity of the heterogeneous catalysts compared to homogenous catalysts in solution.

Continuing this work, Chapter 3 rationalized the critical role of solvent in multicomponent heterogeneous catalytic process. AP-MSN showed lower activity in hexane but 
a higher activity in water whereas MAP-MSN showed higher activity in hexane but a lower activity in water. These large differences in behavior between closely related amine catalysts were due to the stability of inhibition products and shifts in reaction equilibria. Silanol groups participated in the reaction in water by acting as a buffer to allow the enamine pathway rather than general base catalysis and directly binding the carbonyl groups of the reactants.

In Chapter 4, the site-separation of two catalysts i.e. enzyme (alcohol oxidase) and primary amine on MSN was demonstrated. The enzyme was responsible for oxidation of ethanol to acetaldehyde and the amine catalyst served to promote self-aldol condensation of the acetaldehyde into longer chain molecules. The reaction catalyzed by this bifunctional catalyst displayed high selectivity for the product of trimerization, independent of the initial concentration of ethanol.

In an effort to develop mesoporous silica based nanotechnology for biorefinery applications, the synthesis of amine functionalized magnetic mesoporous silica nanomaterials $\left(\mathrm{AP}-\mathrm{Fe}_{3} \mathrm{O}_{4}-\mathrm{MSN}\right)$ are detailed in Chapter 5. A novel application of these functionalized magnetic nanomaterials was demonstrated for an integrated biorefinery process involving microalgae harvesting, lipids extraction and selective sequestration of free fatty acids (FFAs). The positive surface charge of magnetic nanomaterials was important for optimal microalgae harvesting. The lipids from the harvested microalgae were extracted with hydrophilic ionic liquids and sequentially, $\mathrm{AP}-\mathrm{Fe}_{3} \mathrm{O}_{4}-\mathrm{MSN}$ demonstrated selective separation of FFAs.

Continuing the effort on biorefinery, in Chapter 6, a hybrid adsorbent-catalytic nanostructure consisting of aminopropyl groups and nickel nanoparticles supported on mesoporous silica nanomaterials (AP-Ni-MSN) was employed to capture FFAs and convert them 
into saturated hydrocarbons. Synergistic interactions between the amine groups and nickel nanoparticles led to selective transformation of oleic acid to liquid hydrocarbons. Additionally, the product distribution of the reaction shifted from hydrocracking to hydrotreating with improved carbon economy. The application of this hybrid catalyst to crude microalgae oil demonstrated the selective sequestration of FFAs and subsequent conversion to diesel range alkanes.

In Chapter 7, a more economic and efficient mesoporous silica supported iron nanoparticle (Fe-MSN) was synthesized to convert microalgae oil to green diesel. A detailed mechanistic study was studied for hydrogenation of oleic acid. Fe-MSN efficiently hydrogenated oleic acid to aldehyde and alcohol intermediates. Depending on temperature, pressure and reaction time, the aldehydes produced heptadecane via decarbonylation route and alcohol gave octadecane via hydrodeoxygenation route. Compared to Ni-MSN catalyst, Fe-MSN catalyst showed minimal cracking and higher selectivity for diesel range alkanes. Study on the surface of catalyst revealed some iron oxide phases and suggested that the reaction proceeded by the combination of spillover mechanism and Mars-Van Krevelen mechanism.

Finally, Chapter 8 highlighted the significance of designing smart materials with basic understanding of bonding and interactions between different aromatic rings. Vitamin-E ( $\alpha-$ tocopherol), which consist of electron-rich aromatic ring, was selectively sequestered from microalgae oil with electron deficient aromatic ring of pentafluorophenyl functionalized mesoporous silica nanomaterial (PFP-MSN). Solid state NMR (SSNMR) proved the $\pi-\pi$ ring stacking interaction between PFP groups and $\alpha$-tocopherol. The desorption of $\alpha$-tocopherol from the material was obtained by replacing the $\pi-\pi$ ring stacking interaction with more favourable $\mathrm{O}^{\cdots}$ $\pi$ interaction between the oxygen atom of acetone and the PFP groups. 